DALMIR CAPETTA

SISTEMAS DE MEDIÇÃO PARA FATURAMENTO E O MERCADO DE ENERGIA ELÉTRICA: UMA VISÃO CRÍTICA DO REFERENCIAL REGULATÓRIO 


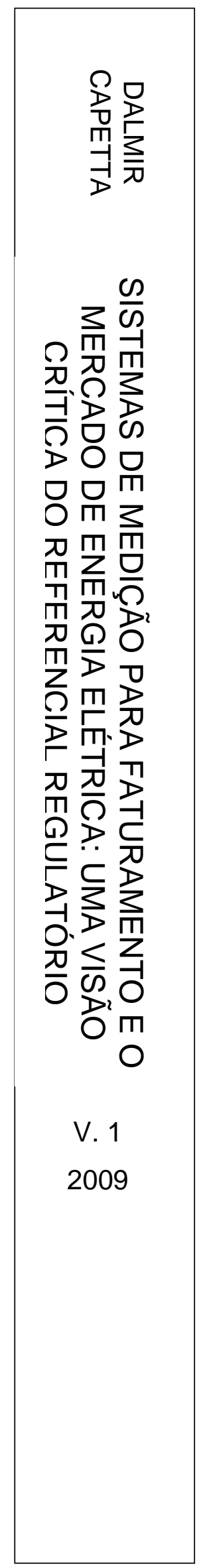


DALMIR CAPETTA

\title{
SISTEMAS DE MEDIÇÃO PARA FATURAMENTO E O MERCADO DE ENERGIA ELÉTRICA: UMA VISÃO CRÍTICA DO REFERENCIAL REGULATÓRIO
}

\author{
Dissertação apresentada à Escola \\ Politécnica da Universidade de São Paulo \\ para obtenção do título de Mestre em \\ Engenharia Elétrica.
}


DALMIR CAPETTA

SISTEMAS DE MEDIÇÃO PARA FATURAMENTO E O MERCADO DE ENERGIA ELÉTRICA: UMA VISÃO CRÍTICA DO REFERENCIAL REGULATÓRIO

Dissertação apresentada à Escola Politécnica da Universidade de São Paulo para obtenção do título de Mestre em Engenharia Elétrica.

Área de Concentração: Sistemas de Potência

Orientador: Prof. Dr. Luiz Cláudio R. Galvão 
Este exemplar foi revisado e alterado em relação à versão original, sob responsabilidade única do autor e com a anuência de seu orientador.

São Paulo, 05 de maio de 2009.

Assinatura do autor

Assinatura do orientador

\section{FICHA CATALOGRÁFICA}

\section{Capetta, Dalmir}

Sistemas de medição para faturamento e o mercado de energia elétrica - uma visão crítica do referencial regulatório / $D$. Capetta. -- ed.rev. -- São Paulo, 2009. $167 \mathrm{p}$.

Dissertação (Mestrado) - Escola Politécnica da Universidade de São Paulo. Departamento de Engenharia de Energia e Automação Elétricas.

1. Energia elétrica (Medição) 2. Faturamento I. Universidade de São Paulo. Escola Politécnica. Departamento de Engenharia de Energia e Automação Elétricas II. t. 


\section{DEDICATÓRIA}

Aos meus pais Elio e Dejanira e minha esposa Sandra Julia, pelos ensinamentos, dedicação e apoio incondicional em todos os momentos. 


\section{AGRADECIMENTOS}

À Deus, pela vida e oportunidade de melhorar a cada momento.

Ao meu orientador, Prof. Dr. Luiz Cláudio Ribeiro Galvão, pelo apoio durante a execução deste trabalho.

Aos participantes da banca do exame de qualificação, professor Doutor Fernando Amaral de Almeida Prado Junior e a Doutora Élbia Melo, pela sensatez, direcionamento e valiosas contribuições formuladas.

Aos integrantes da Coordenação de Engenharia e Operação da Medição da Câmara de Comercialização de Energia Elétrica - CCEE, pelo convívio, respeito e aprendizado.

Aos profissionais da área de medição que durante a minha carreira acreditaram em meu potencial e deram-me a oportunidade de iniciar o aprendizado do tema medição de energia elétrica. 


\section{RESUMO}

O Setor Elétrico Brasileiro tem sofrido nos últimos anos profundas transformações, principalmente nas questões voltadas à comercialização de energia. A criação do mercado, introduzindo o modelo competitivo, com a lei das concessões (Lei 8.987/95), a instituição do livre acesso, criação do produtor independente, consumidor livre e rede básica (Lei 9.074/95), criação da ANEEL (Lei 9.427/96), regulamentação do Mercado Atacadista de Energia (MAE, atual CCEE - Câmara de Comercialização de Energia Elétrica) e definição das regras de organização do Operador Nacional do Sistema (ONS), Lei 9.648/98, resultando na criação dos agentes de geração, transmissão, distribuição e comercialização.

O objetivo da criação do mercado foi desonerar o poder público dos investimentos em infra-estrutura, por meio da atração do capital privado, estimulando a livre concorrência, aumentando-se assim a competitividade.

Dentro deste novo arcabouço regulatório, considerando-se então o ambiente competitivo, surgem os aspectos referentes à medição de energia elétrica, cujas bases técnicas atuais vigentes estão fundamentadas nas recomendações oriundas de especialistas que integraram a Força Tarefa - Medição no âmbito do Grupo RESEB (Projeto de Reestruturação do Setor Elétrico Brasileiro) - requisitos técnicos estes que norteiam os processos de especificação, implantação e manutenção dos Sistemas de Medição para Faturamento do SIN (Sistema Interligado Nacional).

No presente trabalho apresenta-se uma avaliação crítica dos aspectos relativos à adequação/instalação dos Sistemas de Medição para Faturamento no que diz respeito à Regulação, Especificação Técnica e discussões atuais existentes entre os Agentes de Mercado. Para permitir solucionar eventuais entraves nos processos, são apresentadas contribuições, no sentido de indicar alternativas que visam consolidar as operações do mercado de energia no Brasil, que passam sem dúvida pela implantação dos Sistemas de Medição para Faturamento, bem como é abordado o tema Custos, que mediante simulações, procura-se identificar aos 
elegíveis futuros Consumidores Livres e Especiais a viabilidade de migrar para o Ambiente de Livre Contratação frente aos custos da medição.

Palavras-Chave: Medição de Energia Elétrica. Sistemas de Medição para Faturamento. Agentes de Mercado. Custos dos Sistemas de Medição para Faturamento. 


\section{ABSTRACT}

The Brazilian electric sector has undergone profound changes in recent years mainly focused on issues the marketing of energy. The establishment of the market entering the competitive model, with the concessions law (Law 8.987/95), the institution of free access, creation of the independent producer, consumer and core network free (Law 9.074/95), creation of ANEEL (Law 9427 / 96), regulation of the Wholesale Energy Market (MAE, today CCEE - Electric Power Commercialization Chamber) and defining the arrangements for the National System Operator (ONS), Law 9.648/98, resulting in the creation of agents of generation, transmission, distribution and commercialization.

The objective of establishing the market was able to relieve the public of investments in infrastructure, through the attraction of private capital, encouraging free competition by increasing the competitiveness.

Within this new regulatory framework, considering the competitive environment then there are aspects related to the measurement of electrical energy, whose bases are existing techniques based on current recommendations from experts who joined the Task Force - Measurement Group under the RE-SEB (Project for Restructuring of the Brazilian energy sector), these technical requirements that guide the process of specification, deployment and maintenance of Measurement Systems for Billing of SIN - National Interconnected System.

In this work presents a critical evaluation of aspects concerning the adequacy / installation of the Measurement Systems for Billing with regard to regulation, technical specification and current conflicts between the agents of the market. To allow any obstacles in resolving cases, contributions are made to indicate alternatives aimed at consolidating the operations of the energy market in Brazil that are without doubt the deployment of Measurement Systems for Billing and is dealt with the issue 
that cost through simulations seeks to identify eligible for future free consumers and the viability of Special to the Environment migrate Free Recruitment front the costs of measurement.

Keywords: Measurement of Electrical Energy. Measurement Systems for Billing. Agents of the Market. Costs of Measurement Systems for Billing. 


\section{LISTA DE ILUSTRAÇÕES}

Figura 1 - Medidor Eletromecânico utilizado em unidades tarifadas em Sistema Convencional

Figura 2 - Registrador Digital para Tarifação Diferenciada (RDTD) .........................32

Figura 3 - Visão Geral do SCDE - Sistema de Coleta de Dados de Energia. 62

Figura 4 - Tela do Sinercom (ou SCL) para entrada de dados via carga de arquivo no formato "txt". .63

Figura 5 - Exemplo de arquivo no formato "txt" .64

Figura 6 - Tela para inserção manual de dados de medição .64

Figura 7 - Coleta de Dados de Medição via Canais Dedicados pela CCEE. .66

Figura 8 - Coleta de Dados de Medição via Central de Aquisição de Dados do Agente Responsável pela CCEE (forma alternativa) 67

Figura 9 - Visão Atual do SCDE - Sistema de Coleta de Dados de Energia .69

Figura 10 - Cadeia Produtiva Mercado Colombiano .75

Figura 11 - Principais Características Sistema Elétrico - Colômbia. .76

Figura 12 - Configuração de Subestação Compartilhada entre Consumidores Livres

Figura 13 - Configuração de Subestação Compartilhada entre Consumidores Livres e Cativo .84

Figura 14 - Simulação 1: Distribuidora A Sudeste ............................................98

Figura 15 - Simulação 1: Distribuidora B Sul.................................................. 98

Figura 16 - Simulação 1: Distribuidora C Nordeste .............................................. 99

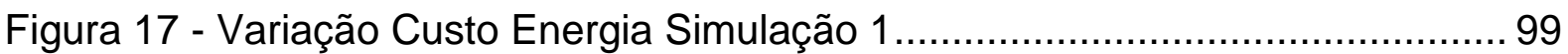

Figura 18 - Tempo Retorno Adequação SMF Simulação 1 ................................ 100

Figura 19 - Simulação 2: Distribuidora A Sudeste ........................................... 101

Figura 20 - Simulação 2: Distribuidora B Sul.............................................. 101

Figura 21 - Simulação 2: Distribuidora C Nordeste .......................................... 102

Figura 22 - Variação Custo Energia Simulação 2 ................................................. 102

Figura 23 - Tempo Retorno Adequação SMF Simulação 2 ................................. 103

Figura 24 - Simulação 3: Distribuidora A Sudeste.............................................. 104

Figura 25 - Simulação 3: Distribuidora B Sul................................................. 104

Figura 26 - Simulação 3: Distribuidora C Nordeste ......................................... 105 
Figura 27 - Variação Custo Energia Simulação 3 …………………………...... 105

Figura 28 - Tempo Retorno Adequação SMF Simulação 3 ................................... 106

Figura 29 - Simulação 4: Distribuidora A Sudeste .............................................. 107

Figura 30 - Simulação 4: Distribuidora B Sul................................................. 107

Figura 31 - Simulação 4: Distribuidora C Nordeste .......................................... 108

Figura 32 - Variação Custo Energia Simulação 4 .............................................. 108

Figura 33 - Tempo Retorno Adequação SMF Simulação 4 …………………..... 109

Figura 34 - Simulação 5: Distribuidora A Sudeste .............................................. 110

Figura 35 - Simulação 5: Distribuidora B Sul.................................................110

Figura 36 - Simulação 5: Distribuidora C Nordeste ............................................ 111

Figura 37 - Variação Custo Energia Simulação 5............................................. 111

Figura 38 - Tempo Retorno Adequação SMF Simulação 5 ................................. 112

Figura 39 - Simulação 6: Distribuidora A Sudeste ............................................. 113

Figura 40 - Simulação 6: Distribuidora B Sul.................................................. 113

Figura 41 - Simulação 6: Distribuidora C Nordeste ............................................ 114

Figura 42 - Variação Custo Energia Simulação 6............................................. 114

Figura 43 - Tempo Retorno Adequação SMF Simulação 6 .................................. 115

Figura 44 - Simulação 7: Distribuidora A Sudeste ............................................... 116

Figura 45 - Simulação 7: Distribuidora B SUL ................................................ 117

Figura 46 - Simulação 7: Distribuidora C Nordeste ............................................... 118

Figura 47 - Diagrama de Instalação utilizando o recurso de compensação de perdas

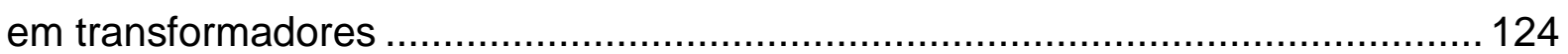

Figura 48 - Usinas conectadas na Rede Básica ou Rede de Distribuição ............. 125

Figura 49 - Total de Sistemas de Medição a serem instalados no Complexo Industrial 128

Figura 50 - Total de Sistemas de Medição a serem instalados após a autorização da medição por diferença 


\section{LISTA DE TABELAS}

Tabela 1 - Relação dos medidores disponibilizados no site da CCEE ....................48

Tabela 2 - Categorias e requisitos técnicos dos grandes consumidores..................72

Tabela 3 - Características de Equipamentos e Classe de Exatidão Argentina .........73

Tabela 4 - Características de Equipamentos e Classe de Exatidão Colômbia..........77

Tabela 5 - Tributos incidentes e respectivos percentuais ...................................91

Tabela 6 - Custo médio praticado no mercado para adequação do SMF ................94

Tabela 7 - Custo médio dos medidores....................................................95 


\section{LISTA DE ABREVIATURAS E SIGLAS}

ABB

ABRACE

ABRADEE

ABRAGE

ABRATEE

$\mathrm{ACL}$

ACR

ANEEL

ASMAE

AT

ATD

BT

CAMMESA

CCD

CCEE

CCON

CCT

CEPEL

$\mathrm{CGH}$

CND

COEX

COMAE

CPST

CREG

CUSD

CUST

Asea Brown Boveri

Associação Brasileira de Grandes Consumidores Industriais

Associação Brasileira de Distribuidores de Energia Elétrica

Associação Brasileira das Empresas Geradoras de Energia Elétrica

Associação das Grandes Empresas de Transmissão de Energia Elétrica

Ambiente de Contratação Livre

Ambiente de Contratação Regulada

Agência Nacional de Energia Elétrica

Administradora de Serviços do Mercado Atacadista de Energia Elétrica

Alta Tensão

Auto Transformadores de Defasamento

Baixa Tensão

Compañia Administradora del Mercado Mayorista Eléctrico

Sociedad Anónima

Contrato de Conexão ao Sistema de Distribuição

Câmara de Comercialização de Energia Elétrica

Comitê Coordenador de Operações do Norte/Nordeste

Contrato de Conexão ao Sistema de Transmissão

Centro de Pesquisas de Energia Elétrica

Centrais Geradoras Hidrelétricas

Operador Nacional do Sistema - Colômbia

Comitê Executivo

Conselho do Mercado Atacadista de Energia Elétrica

Contrato de Prestação de Serviços de Transmissão

Comisión de Regulación de Energía y Gas

Contrato de Uso do Sistema de Distribuição

Contrato de Uso do Sistema de Transmissão 
DIT Demais Instalações de Transmissão

DNAEE Departamento Nacional de Águas e Energia Elétrica

EDF Eletricité de France

ELETROBRÁS Centrais Elétricas Brasileiras S.A.

ELO ELO Sistemas Eletrônicos Ltda

ENRE Ente Nacional Regulador de la Electricidad

ESS Encargos de Serviços do Sistema

FAE Ferragens e Aparelhos Elétricos S/A

GCOI Grupo Coordenador para Operação Interligada

GCPS Grupo Coordenador do Planejamento do Sistema Elétrico

GUMA Gran Usuario Mayor

GUME Gran Usuario Menor

GUPA Gran Usuario Particular

IEC International Electrotechnical Commission

INMETRO Instituto Nacional de Metrologia, Normalização e Qualidade Industrial

LED

Light Emitting Diode (Diodo Emissor de Luz)

MAE

Mercado Atacadista de Energia Elétrica

MEMP

Medidor Eletrônico Memorizador Programável

MEM

Mercado Eléctrico Mayorista

MME

Ministério das Minas de Energia

MR

Marco Regulatório

MT

NAT

Média Tensão

OED

Network Address Translation

Organismo Encargado del Despacho

ONS

Operador Nacional do Sistema Elétrico

$\mathrm{PCH}$

Pequenas Centrais Hidrelétricas

PDC

Procedimentos de Comercialização

PM

Procedimentos de Mercado

PNUD

Programa das Nações Unidas para o Desenvolvimento

PRODIST

Procedimentos de Distribuição de Energia Elétrica no Sistema

Elétrico Nacional

PROINFA

Programa de Incentivo às Fontes Alternativas de Energia Elétrica 


$\begin{array}{ll}\text { PRÓLOGO } & \text { PRÓLOGO Produtos Eletrônicos } \\ \text { QEE } & \text { Qualidade de Energia Elétrica } \\ \text { RDMT } & \text { Registrador Digital para Média Tensão } \\ \text { RDTD } & \text { Registrador Digital para Tarifação Diferenciada } \\ \text { RE-SEB } & \text { Projeto de Reestruturação do Setor Elétrico Brasileiro } \\ \text { REP } & \text { Registrador Eletrônico Programável } \\ \text { REP-TD } & \text { Registrador Eletrônico Programável com Transdutor Digital } \\ \text { SCDE } & \text { Sistema de Coleta de Dados de Energia } \\ \text { SCL } & \text { Sistema de Contabilização e Liquidação } \\ \text { SCM } & \text { Subcomitê de Manutenção } \\ \text { SEI } & \text { Secretaria Especial de Informática } \\ \text { SF6 } & \text { Hexafluoreto de Enxofre } \\ \text { SIN } & \text { Sistema Interligado Nacional } \\ \text { SISCOMEX } & \text { Sistema Integrado de Comércio Exterior } \\ \text { SMF } & \text { Sistema de Medição para Faturamento } \\ \text { TC } & \text { Transformador de Corrente } \\ \text { TELEMÁTICA } & \text { TELEMÁTICA - Sistemas Inteligentes Ltda. } \\ \text { THS } & \text { Tarifa Horo-Sazonal } \\ \text { TI } & \text { Transformador para Instrumentos } \\ \text { TOTIMP } & \text { Totalizador de Pulsos } \\ \text { TP } & \text { Transformador de Potencial } \\ \text { TUSD } & \text { Tarifa Uso Sistema de Distribuição } \\ \text { UCM } & \text { Unidade Central de Coleta de Medição } \\ \text { VPN } & \text { Virtual Private Network } \\ \text { VR } & \text { Valor de Referência } \\ \text { VTCD } & \text { Variação de Tensão de Curta Duração } \\ & \end{array}$




\section{SUMÁRIO}

1. INTRODUÇÃO

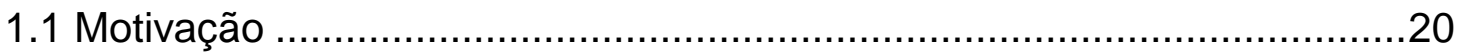

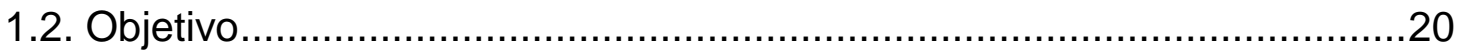

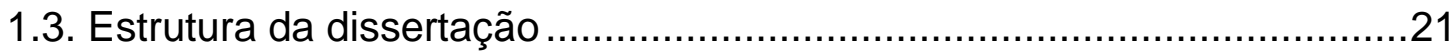

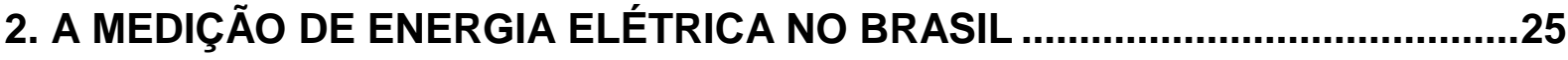

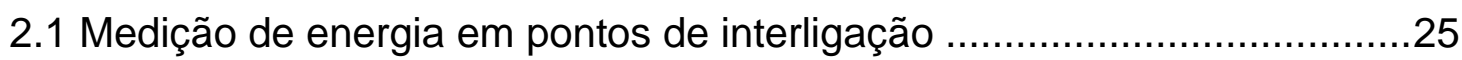

2.2 Medição de energia elétrica em sistemas primários de distribuição ........29

2.2.1. Sistema tarifário convencional .................................................30

2.2.2. Sistema Tarifário Horo-Sazonal (THS) .....................................30

2.2.3. Equipamentos utilizados para medição ....................................31

2.2.4. Medição de energia elétrica em sistemas secundários de distribuição.

3. APARATO REGULATÓRIO REFERENTE À IMPLANTAÇÃO DOS SISTEMAS

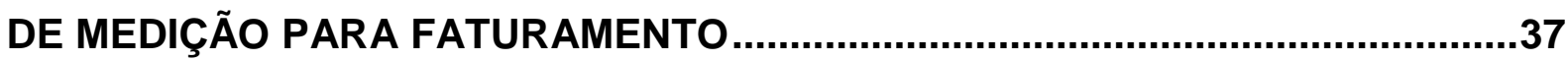

4. MÓDULO 12 DOS PROCEDIMENTOS DE REDE DO ONS ..............................43

5. PRODIST-PROCEDIMENTOS DE DISTRIBUIÇÃO DE ENERGIA ELÉTRICA...51

6. IMPLEMENTAÇÃO DO SCDE - SISTEMA DE COLETA DE DADOS DE ENERGIA

7. PANORAMA DE IMPLANTAÇÃO DE SISTEMAS DE MEDIÇÃO EM OUTROS MERCADOS .71

7.1 Análise do mercado Argentino ............................................................

7.2 Análise do mercado Colombiano ...........................................................74

8. DISCUSSÕES EXISTENTES NO MERCADO BRASILEIRO …..........................78

9. CUSTOS DE IMPLANTAÇÃO DOS SISTEMAS DE MEDIÇÃO PARA FATURAMENTO

9.1. Descrição dos serviços necessários para adequação dos sistemas de medição para faturamento

10. AVALIAÇÃO DA VIABILIDADE DE MIGRAR PARA O AMBIENTE DE LIVRE CONTRAÇÃO DE ENERGIA FRENTE AO CUSTO DE ADEQUAÇÃO DOS SISTEMAS DE MEDIÇÃO PARA FATURAMENTO …........................................96

11. FLEXIBILIZAÇÃO DOS REQUISITOS TÉCNICOS - PEDIDOS DE EXCEPCIONALIDADE 
11.1 Compartilhamento de enrolamento de transformadores para instrumentos (transformadores de corrente e transformadores de potencial) ........ 121

11.2 Utilização de medidores dotados de recursos de algoritmo de compensação de perdas ........................................................................ 122

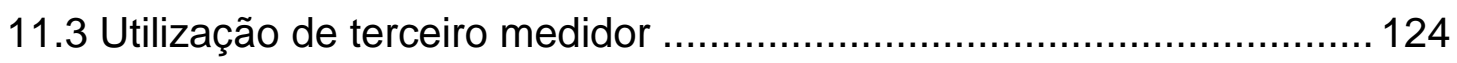

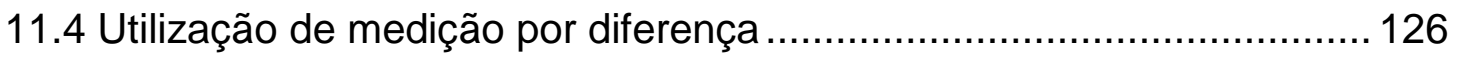

12. PENALIDADES DE MEDIÇÃO

12.1 Penalidade por infração na instalação e/ou adequação do SMF - sistema de medição para faturamento 132

12.2 Penalidade por infração na inspeção lógica 133

12.3 Penalidade por infração por ausência de coleta de dados de medição para contabilização 134

13. PROPOSIÇÕES 138

14. CONSIDERAÇÕES FINAIS 147 REFERÊNCIAS 154 GLOSSÁRIO 158 


\section{INTRODUÇÃO}

\subsection{Motivação}

A profunda transformação ocorrida no Setor Elétrico Brasileiro, com a adoção da abertura do mercado e mediante o crescimento da quantidade de Agentes que interagem entre si nas operações do mercado, trazem conseqüências que culminam com inúmeras discussões, principalmente nas questões referentes à implantação dos Sistemas de Medição para Faturamento, por partilharem responsabilidades, não concordarem com os custos envolvidos nas instalações/adequações, bem como discussões quanto às questões regulatórias e requisitos técnicos.

A oportunidade de participar em vários momentos de reuniões, discussões e grupos de trabalho voltados ao tema medição de energia elétrica, e a oportunidade que o curso de mestrado propicia, é importante se debruçar sobre o tema buscando proposições e respostas a muitos questionamentos formulados pelos Agentes do Mercado.

Acredita-se que as implantações dos Sistemas de Medição para Faturamento são fundamentais para consolidar as operações do mercado de energia no Brasil. A conseqüente motivação para contribuir neste processo para promover as ações que minimizem a existência de entraves, é o que o presente trabalho aborda em forma de avaliação e proposições.

\subsection{Objetivo}

No atual momento em que o atraso é considerável, com relação à implantação dos Sistemas de Medição para Faturamento, que por sua vez apresentam constantes discussões dos Agentes responsáveis no que diz respeito aos custos de 
implantação, que muitas vezes são identificados como inviáveis do ponto de vista financeiro e que são apontados principalmente pelos Consumidores Livres como fator inibidor para migrar para o ACL (Ambiente de Livre Contratação), as eventuais possibilidades de flexibilização nos atuais requisitos técnicos, o compartilhamento de responsabilidades, limitação de opções de equipamentos e sistemas, sendo que todas estas questões por si só merecem uma análise do tema de forma a sugerir soluções.

Em virtude deste cenário é importante encontrar alternativas, que passam sem dúvida pela estabilidade regulatória do tema, mas principalmente, a questão do compartilhamento de responsabilidades técnica e financeira dos Agentes de Medição e Consumidores Livres respectivamente, que é o que provoca as maiores discussões atualmente e que devem ser explorados no sentido de se buscar as soluções cabíveis.

A abordagem deste trabalho identifica soluções que permitam a continuidade das implantações dos Sistemas de Medição para Faturamento e que eventuais justificativas de custos onerosos não sejam fatores motivadores para inibir a continuidade da abertura do mercado que permite a expansão da opção de compra de energia no mercado livre para um maior número de consumidores.

A questão regulatória da medição de energia elétrica plenamente estabilizada e a erradicação de eventuais conflitos entre os Agentes são essenciais neste momento para garantir a estabilidade das operações de mercado.

\subsection{Estrutura da dissertação}

No Capítulo 2 é realizada uma síntese da questão da evolução da medição de energia elétrica no Brasil, nos pontos de interligação entre Empresas, consumidores de média e baixa tensão identificando as grandezas a serem medidas e equipamentos de medição utilizados. O intuito é identificar os principais pontos de evolução da medição que antecederam a abertura do mercado. 
No Capítulo 3 são mencionados os principais documentos regulatórios nos últimos dez anos que tratam das questões de responsabilidades, requisitos técnicos e prazos, que por sua vez, norteiam o tema medição e conseqüente implantação dos Sistemas de Medição para Faturamento, com destaque para as Resoluções nํ 247 e 248 que impactam significativamente os Consumidores Livres e Especiais.

No Capítulo 4 é apresentado o tema Procedimentos de Rede do Operador Nacional do Sistema (ONS), com destaque para o Módulo 12, onde estão disciplinadas as questões de responsabilidades, localização, Agentes e entidades envolvidas nos processos de implantação e manutenção dos Sistemas de Medição para Faturamento.

No Capítulo 5 é apresentado o PRODIST (Procedimentos de distribuição de energia elétrica), principalmente o Módulo 5 - Sistemas de Medição. Ao disciplinar a medição no mercado cativo, prepara a medição dos novos consumidores voltada a atender no futuro a possível migração da unidade para o mercado livre.

No Capítulo 6 realiza-se a apresentação do Sistema de Coleta de Dados de Energia (SCDE), sistema este implantado pela Câmara de Comercialização de Energia Elétrica (CCEE), cujos Agentes e ONS possuem acesso às suas funcionalidades. Este sistema mantém o cadastro de todos os Pontos de Medição do mercado e realiza a coleta e tratamento de dados de medição a serem utilizados na contabilização e liquidação do mercado.

No Capítulo 7 é apresentado os requisitos técnicos dos Sistemas de Medição para Faturamento dos mercados vizinhos localizados na América do Sul, Argentina e Colômbia, que podem servir de referência futura para possíveis flexibilizações nos requisitos técnicos constantes no Anexo I do Submódulo 12.2 dos Procedimentos de Rede do ONS.

No Capítulo 8 é realizada síntese dos principais temas, que são objetos de discussões entre os Agentes quando se trata do tema adequação dos Sistemas de Medição para Faturamento. É realizada para cada item uma sugestão de encaminhamento para solução da questão apontada. 
No Capítulo 9 são apresentados os custos médios de adequação dos Sistemas de Medição para Faturamento, buscando identificar as diferenças significativas por nível de tensão. É apresentada também a variação do custo de aquisição dos medidores em particular considerando fabricantes ou fornecedores diferentes, embora não necessariamente identificando-os.

No Capítulo 10 são realizadas simulações no intuito de identificar a viabilidade de migrar para o Ambiente de Livre Contratação (ACL) frente aos custos dos Sistemas de Medição para Faturamento apresentados no Capítulo 9. As simulações adotam como premissa o preço da energia elétrica no mercado livre em $\mathrm{R} \$ / \mathrm{MWh}$; custo da tarifa no mercado cativo e tarifas de uso de rede. São realizadas simulações para as mesmas condições em três áreas diferentes do país, ou seja, hipoteticamente caso a unidade esteja localizada em uma área de concessão de uma Distribuidora da região Sudeste, Sul e Nordeste, pois as tarifas do mercado cativo e de uso de rede são diferentes. Estas simulações podem servir de alerta para os empresários definirem eventualmente a localização das futuras implantações de suas instalações industriais, pois os custos finais são diferentes. O tempo de retorno do investimento nas adequações também é apresentado.

No Capítulo 11 são identificadas possíveis flexibilizações que eventualmente são aceitas quando do atendimento aos requisitos técnicos da especificação técnica que balizam as adequações dos Sistemas de Medição para Faturamento, pois deve ser analisado cada caso e as aprovações das flexibilizações são realizadas para cada instalação em particular.

No Capítulo 12 é apresentado o tema Penalidades de Medição, pois existem tipos de infrações diferentes, bem como são apresentados os critérios de apuração, valores e responsáveis.

No Capítulo 13 são realizadas proposições para viabilizar a continuidade das implantações necessárias baseadas nos temas apresentados no trabalho. 
No Capítulo 14 são apresentadas as conclusões e recomendações do trabalho, no intuito de colaborar na identificação de ações que permitam a continuidade do processo de implantação dos Sistemas de Medição para Faturamento. 


\section{MEDIÇÃO DE ENERGIA ELÉTRICA NO BRASIL}

\subsection{Medição de energia em pontos de interligação}

O Sistema Interligado Brasileiro, em 1974, contava com uma capacidade instalada de 13000 MW evoluindo para 53000 MW em 1994. Tais valores nesta época já justificavam medidas de controle, manutenção e planejamento para o Setor Elétrico Brasileiro.

O faturamento de energia elétrica nos Pontos de Interligação do Sistema, que por sua vez estavam alicerçados nos valores de energia e demanda, eram contabilizados e distribuídos entre as empresas que integravam o Sistema naquela oportunidade.

Os Sistemas de Medição para Faturamento nos Pontos de Interligação foram projetados à luz do documento Recomendação SCM - 018 (Recomendações para Uniformização dos Sistemas de Medição para Fins de Faturamento nos Pontos de Interligação), sendo que de maneira geral as empresas do Setor Elétrico utilizavam nos referidos sistemas, medidores eletromecânicos (tipo indução) classe 2, registradores de demanda, printometros, e totalizadores.

A manutenção dos Sistemas obedecia a periodicidade anual exigindo aferição, da qual podia resultar a necessidade de se efetuar a calibração dos medidores, substituição de peças mecânicas e/ou dos equipamentos registradores e totalizadores.

Os serviços eram realizados em campo, e conforme algumas estatísticas de Departamentos de Engenharia de Medição das empresas, em média $20 \%$ dos medidores utilizados nos Pontos de Interligação necessitavam ser calibrados. Os serviços consistiam em se retirar o medidor do circuito e atuar em seus ajustes, de forma a colocar seus erros dentro dos limites estabelecidos na SCM - 018. Com 
relação aos printometros, a confiabilidade de suas partes mecânicas já ultrapassava em muito os limites aceitáveis, como também a prática de aproveitamento de componentes de equipamentos 'canabalizados' que já tinham sido retirados de uso, comprometiam de forma temerária o desempenho desejado.

Não fosse suficiente a modernização como justificativa da necessidade de substituição dos equipamentos, e as perspectivas de mudanças estruturais futuras, com a possibilidade de desverticalização das empresas separando-as em atividades de geração, transmissão e distribuição, as Empresas buscam então em seus processos a excelência em seus serviços ao menor custo visando maximizarem seus lucros.

Com a necessidade de se efetuar melhorias e modernização nos Sistemas de Medição em função dos aspectos de exatidão, problemas operacionais e de controle, devido aos montantes elevados de energia e demanda nos Pontos de Intercâmbio; obsolescência tecnológica dos equipamentos de medição do sistema e oportunidades de modernização face à crescente evolução tecnológica, tornando assim irreversível a modernização dos Sistemas de Medição.

A medição de energia é de fundamental importância, pois os dados de medição são utilizados no faturamento, como também para outras finalidades tais como: planejamento, controle, mercado, operação e expansão.

Com relação à propriedade dos sistemas de medição para faturamento dos intercâmbios, cabe esclarecer que a empresa supridora era a proprietária e como conseqüência tinha a responsabilidade de efetuar sua operação, manutenção e modernização, cabendo à empresa suprida ser faturada com os dados de medição obtidos. Não se utilizava a medição de faturamento na geração, apenas medição operacional de controle, uma vez que as perdas elétricas no sistema de transmissão eram assumidas pelas empresas geradoras.

Como até ao ano de 1974 os Sistemas de Medição para Faturamento utilizado nas empresas não seguiam padronização, embora como anteriormente mencionado, utilizava-se geralmente medidores com classe de exatidão $2 \%$, e contavam com 
considerável número de fabricantes: Westinghouse, General Electric, Landis \& Gyr e Aprel (ABB).

A coleta dos dados de medição era realizada localmente, mediante leitura dos medidores pelos operadores de subestações ou de leituristas que se deslocavam até os locais onde estavam instalados os medidores, e considerando que todo o faturamento realizado em processo manual incorria em consideráveis erros e retrabalhos com conseqüentes impactos no faturamento final.

Com a Portaria o 046 do Departamento Nacional de Águas e Energia Elétrica (DNAEE) publicada em 1985, se estabelece então a tarifação diferenciada, sendo que impressoras de demanda a relógios foram substituídas por registradores microprocessados, de fabricação nacional, chamados Registrador Digital para Tarifação Diferenciada (RDTD).

Este é um marco importante porque dá inicio à entrada do sistema de medição para faturamento na era digitalizada. Se comparada à etapa anterior, esta faz uso de fitas cassetes, ao invés de boletins, para a contabilização. É mais um avanço no sentido de se dotar maior confiabilidade ao faturamento.

Os RDTD foram desenvolvidos com objetivo de atender a nova estrutura tarifária preconizada em estudo conjunto DNAEE-Eletrobrás - Estudo da Estrutura Tarifária Brasileira - e que viria a ser implantada no país. A Portaria oㅡ 046 de 10/01/82 do Ministério das Minas de Energia (MME) definiu as primeiras diretrizes sobre 0 assunto, e levou o Departamento Nacional de Águas e Energia Elétrica (DNAEE) a criar um grupo de trabalho constituído por especialistas em medição e eletrônica pertencentes às empresas concessionárias, Secretaria Especial de Informática (SEI), Centro de Pesquisas de Energia Elétrica (CEPEL), Eletricité de France (EDF) e Eletrobrás.

Tal grupo foi coordenado pelo DNAEE e contou também com a participação de profissionais da indústria eletrônica brasileira. Após as fases de especificação, projeto e padronização, três empresas foram pré-qualificadas pela SEI: ELO Sistemas Eletrônicos Ltda, PRÓLOGO - Produtos Eletrônicos e TELEMÁTICA - 
Sistemas Inteligentes Ltda, e apresentaram seus protótipos, os quais foram submetidos a testes de laboratório e campo, e aprovados para o processo de produção industrial. O objetivo principal do uso destes equipamentos era permitir a implantação das tarifas diferenciadas em:
a) AT - Alta Tensão: fornecimentos em tensão igual ou superior a $69 \mathrm{kV}$;
b) MT - Média Tensão: fornecimentos em tensão entre 2,3 kV e 69 kV, incluindo os da BT de maior porte;
c) BT - Baixa Tensão: fornecimentos em tensão inferior a 2,3 kV;
d) Suprimentos nas interligações;
e) Campanhas de medidas.

O desenvolvimento de tais equipamentos considerava desde a sua especificação técnica até a fase inicial de industrialização, incluindo os ensaios e o estabelecimento dos periféricos.

Os trabalhos desenvolvidos visavam também dar apoio às atividades de:
a) Análise de carga e campanhas de medidas;
b) Construção de tarifas de alta tensão;
c) Construção de tarifas de média tensão;
d) Construção de tarifas de baixa tensão;
e) Construção de tarifas de suprimento.

Uma importante modernização que o RDTD trouxe para a medição do suprimento de energia foi a integralização da demanda dos pontos de suprimento numa mesma base de tempo, ao utilizá-lo acoplado aos totalizadores de pulsos (TOTIMP), permitindo o faturamento de demandas coincidentes integralizadas em 01 hora, ao invés do somatório de demandas integralizadas em 15 minutos.

Embora a utilização dos Registradores Digitais significasse avanço tecnológico, a partir dos anos 90 começa a ocupar espaço os medidores estáticos de fabricantes como a Landis \& Gyr e Schlumberger. 
Como filosofia a ser adotada para a modernização dos Sistemas, podia se optar pela filosofia européia ou pela americana, embora com vantagens distintas.

A grande vantagem da filosofia européia, em utilizar remotas com memória para transmitir as informações dos medidores de energia até as centrais de coleta das empresas, está em aproveitar todo o parque instalado de medidores de energia, quer sejam eletromecânicos, estáticos ou microprocessados, desde que tivessem a capacidade de emitir pulsos proporcionais a energia elétrica medida e a americana por empregar medidores de energia microprocessados, cujas características além de permitir mais facilmente o processamento de outras grandezas, tais como corrente e tensão, e ainda de poderem ser associados a sistemas supervisórios das empresas.

Praticamente todos os fabricantes de renome estavam substituindo suas linhas de medidores mecânicos para eletrônicos, sendo os primeiros sinais da consolidação da medição eletrônica.

\subsection{Medição de energia elétrica em sistemas primários de distribuição}

Conforme definido na Resolução ANEEL no 456, de 29 de novembro de 2000, a tensão primária de distribuição, é a tensão disponibilizada no sistema elétrico da concessionária com valores padronizados iguais ou superiores a 2,3 kV. Define também que para atendimento em tensão primária de distribuição inferior a 69 kV só é possível quando a carga instalada na unidade consumidora for superior a $75 \mathrm{~kW}$, e a demanda contratada ou estimada pelo interessado, para o fornecimento, for igual ou inferior a $2.500 \mathrm{~kW}$. Para atendimento em tensão primária de distribuição igual ou superior a $69 \mathrm{kV}$ só é possível quando a demanda contratada ou estimada pelo interessado, para o fornecimento, for superior a $2.500 \mathrm{~kW}$.

Realizada esta contextualização, é possível identificar que tipo de Sistemas de Medição para Faturamento as concessionárias ainda utilizam, com a atualização tecnológica apenas dos medidores, sendo que gradativamente e a partir de meados 
dos anos 90 se começou a intensificar a utilização de medidores eletrônicos neste tipo de sistema. Cabe ressaltar que a medição dos consumidores cativos é realizada em conformidade com a estrutura tarifária a qual a unidade está classificada.

\subsubsection{Sistema Tarifário convencional}

Para definição do sistema de medição para os consumidores atendidos em tensão primária de distribuição é necessário identificar a estrutura tarifária a qual se enquadra.

O Sistema Tarifário Convencional apura o consumo de energia elétrica faturado em kWh e a demanda de energia em kW, que é obtida pelo maior dos seguintes valores:

- Maior potência demandada, verificada por medição, durante o período de faturamento;

- $85 \%$ da maior demanda verificada em qualquer dos últimos 11 meses anteriores;

- Demanda contratada, quando houver;

\subsubsection{Sistema Tarifário Horo-Sazonal (THS)}

A Estrutura tarifária horo-sazonal é caracterizada pela aplicação de tarifas diferenciadas de consumo de energia elétrica e de demanda de potência de acordo com as horas de utilização do dia e dos períodos do ano, conforme descrição a seguir:

Tarifa Azul: modalidade estruturada para aplicação de tarifas diferenciadas de consumo de energia elétrica de acordo com as horas de utilização do dia e os períodos do ano, bem como de tarifas diferenciadas de demanda de potência de acordo com as horas de utilização do dia. 
Aplica-se às unidades consumidoras que atendam as condições de serem atendidas em tensão de fornecimento igual ou superior a $69 \mathrm{kV}$; quando atendidas em tensão inferior a $69 \mathrm{kV}$ com demanda superior a $500 \mathrm{~kW}$ ou em caráter excepcional abaixo de 500kW;

> Tarifa Verde: modalidade estruturada para aplicação de tarifas diferenciadas de consumo de energia elétrica de acordo com as horas de utilização do dia e os períodos do ano, bem como de uma única tarifa de demanda de potência. Aplica-se sempre por opção às unidades consumidoras atendidas em tensão de fornecimento inferior a $69 \mathrm{kV}$;

> Horário de ponta $(\mathrm{P})$ : período definido pela concessionária e composto por 3 (três) horas diárias consecutivas, exceção feita aos sábados, domingos e feriados nacionais, considerando as características do sistema elétrico.

Horário fora de ponta $(F)$ : período composto pelo conjunto das horas diárias consecutivas e complementares àquelas definidas no horário de ponta.

Período úmido (U): período de 5 (cinco) meses consecutivos, compreendendo os fornecimentos abrangidos pelas leituras de dezembro de um ano a abril do ano seguinte.

Período seco (S): período de 7 (sete) meses consecutivos, compreendendo os fornecimentos abrangidos pelas leituras de maio a novembro.

\subsubsection{Equipamentos utilizados para medição}

Os equipamentos utilizados para medição de energia em tensão primária de distribuição foram concebidos de acordo com o tipo de energia que se desejava medir. Sendo assim os equipamentos utilizados em unidades consumidoras 
atendidas em tensão primária de distribuição eram dispostos em painéis, chamados de painéis de medição que eram constituídos da seguinte forma:

- Composição do painel de medição para sistema tarifário convencional: medidor eletromecânico (kWh, kW e kVArh) e defasador;
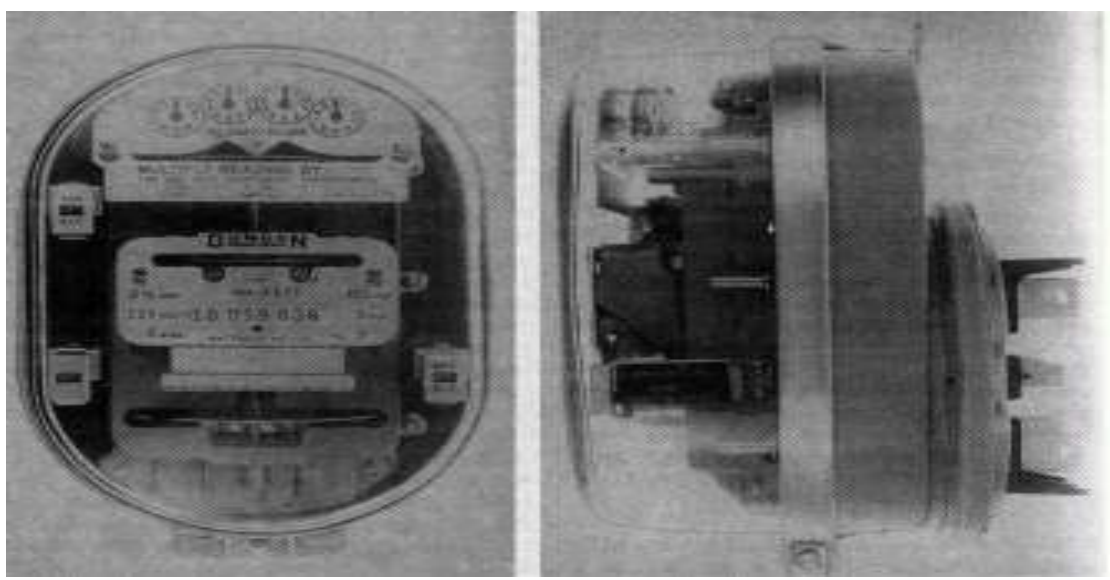

Figura 1 - Medidor Eletromecânico utilizado em unidades tarifadas em Sistema Convencional Fonte: Actaris (2008, p. 2).

- Composição do painel de medição para sistema tarifário horo-sazonal (THS): medidor eletromecânico ( $\mathrm{kWh}, \mathrm{KQh}$ e $\mathrm{V}^{2} \mathrm{~h}$ ), iniciador de pulsos e registrador digital (RDTD, RDMT e REP);

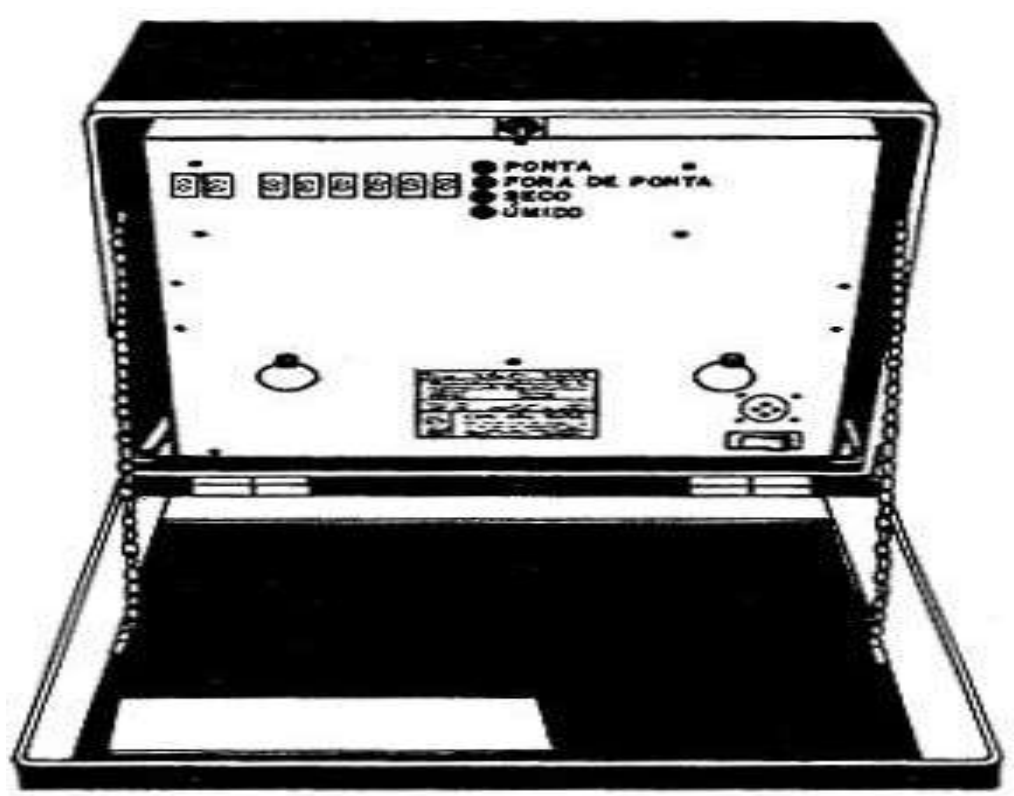

Figura 2 - Registrador Digital para Tarifação Diferenciada (RDTD)

Fonte: Baroni Neto e Moretti (2007, p. 143). 
Com relação aos registradores digitais, pode-se relatar que ao longo do tempo foram incorporadas inovações tecnológicas nos Registradores Digitais, visando adaptar este tipo de equipamento às novas exigências do mercado, sendo:

- RDMT- Registrador Digital para Média Tensão (menor custo, sem memória massa);

- REP- Registrador Eletrônico Programável (saída serial cliente, maior memória massa);

- REP-TD - Transdutor Digital elimina necessidade de medidores com emissor de pulsos;

- MEMP - Medidor Eletrônico Memorizador Programável.

Como principais fabricantes destacam-se: ELO (Sistemas Eletrônicos Ltda), PRÓLOGO (Produtos Eletrônicos) e TELEMÁTICA (Sistemas Inteligentes Ltda).

Em 1985 os dados medidos passam a ser registrados nos RDTD e coletados à distância e posteriormente gravados em fitas cassete. Estes instrumentos registradores evoluíram ao estágio de medidores eletrônicos digitais, e continuam até hoje sendo utilizados pelas empresas brasileiras, principalmente no faturamento de consumidores.

Referente aos medidores eletromecânicos destaca-se como principais fabricantes: FAE, Nansen, General Electric, Schulumberger, APREL (atual ABB) e Westinghouse.

Os medidores eletromecânicos não possuem memória de massa e registram apenas uma grandeza (energia ativa). Para a medição da energia reativa se utilizava os Auto Transformadores de Defasamento (ATD). Esses transformadores eram acoplados aos medidores e tinham a função de defasar a tensão em $90^{\circ}$, de modo que se obtivesse o valor de energia reativa, utilizando-se os valores de tensão defasados e o valor de corrente. Ou seja, quando se desejava medir energia ativa e reativa, era necessária a utilização de dois medidores eletromecânicos, um para 
medição de energia ativa e outro, com um ATD acoplado à entrada de tensão, para medição de energia reativa.

O medidor de consumo de energia elétrica eletromecânico de indução magnética, chamado popularmente de 'relógio', é composto por quatro partes principais: corpo (carcaça), elemento móvel (disco), registrador e elemento frenador.

No corpo estão presentes as bobinas de potencial e de corrente. Ao serem energizadas, criam campos eletromagnéticos que por indução fazem o disco girar. O disco é fixo em mancais mecânicos ou de suspensão magnética. No mecânico, há uma esfera de safira no eixo inferior dentro de uma cápsula para minimizar o atrito.

A energia medida é obtida por meio de leituras realizadas nos mostradores dos registradores mecânicos que indicam 0 valor da energia de forma cumulativa, constituindo-se em 2 tipos: o de ponteiro e o ciclométrico (tambores numerados).

Seu sistema de relojoaria é único para cada tipo de medidor devido às engrenagens utilizadas em sua montagem, o que implica a multiplicação da leitura por uma constante proporcional à relação de engrenagens. O disco do medidor gira com maior ou menor velocidade na proporção direta da corrente que circula pela bobina de corrente, acionando o registrador por meio dessas engrenagens.

O elemento frenador é o responsável pelo "equilíbrio" geral da calibração do medidor. Há indicação + e -, que significa maior e menor fluxo magnético, induzindo ao erro e possibilitando ações de pessoas com intenções ilícitas. (BARONI NETO E MORETTI, 2007, p.21-22)

Tipos de medidores:

> Monofásico - Composto por uma bobina de corrente, uma bobina de tensão e um disco;

> Bifásico - Composto por duas bobinas de corrente, duas bobinas de tensão e um ou dois discos;

$>$ Trifásico - Composto por três bobinas de corrente, três bobinas de tensão e um ou três discos. (BARONI NETO E MORETTI, 2007, p.21-22).

Como principais vantagens dos medidores eletrônicos em relação aos medidores eletromecânicos destacam-se: melhor classe de exatidão, multifuncionalidade, medição de energias ativa e reativa capacitiva e indutiva, nos 2 sentidos de fluxo de energia (4 quadrantes), medição e armazenamento de outras grandezas como tensão, corrente, monitoramento de qualidade de energia, programação e armazenamento de alarmes associados ao sistema de potência e aos medidores, 
acesso remoto e simultâneo de mais de um usuário aos dados, baixo consumo, simplicidade de instalação, operação e manutenção, velocidade de transporte de dados, flexibilidade operacional e tamanho reduzido.

\subsubsection{Medição de energia elétrica em sistemas secundários de distribuição}

Conforme definido na Resolução ANEEL n 456, de 29 de novembro de 2000, definise tensão secundária de distribuição como a tensão disponibilizada no sistema elétrico da concessionária com valores padronizados inferiores a 2,3 kV.

Existem basicamente dois tipos de fornecimento de energia elétrica em sistema secundário de distribuição ou BT - Baixa Tensão, a saber:

- Sistema ligado em estrela no primário e delta no secundário $(\mathrm{Y} \Delta)$, através de transformadores monofásicos, com ou sem neutro;

- Sistema ligado em delta no primário e estrela no secundário $(\Delta \mathrm{Y})$, através de transformadores trifásicos, com ou sem neutro;

Em algumas concessionárias de distribuição, o fornecimento de energia é efetuado em uma das seguintes tensões secundárias de baixa tensão:

- 127/220V, sistema trifásico, estrela com neutro multi-aterrado, freqüência $60 \mathrm{~Hz}$;

- 127/254V, sistema monofásico com neutro multi-aterrado, freqüência $60 \mathrm{~Hz}$, em substituição gradativa a 120/240V, de acordo com a padronização de tensões secundárias estabelecidas pela Portaria 004, de 10 de janeiro de 1989, do DNAEE.

- Em casos específicos como áreas atendidas em sistemas subterrâneos, a tensão nominal é 127/220 e 120/208V; 
Para cada tipo de fornecimento, existem tipos específicos de medidores adequados para a realização da medição de energia elétrica, dos quais são:

> Monofásico - Composto por uma bobina de corrente, uma bobina de tensão e um disco.

> Bifásico - Composto por duas bobinas de corrente, duas bobinas de tensão e um ou dois discos.

$>$ Trifásico - Composto por três bobinas de corrente, três bobinas de tensão e um ou três discos. (BARONI NETO E MORETTI, 2007, p. 22).

O estado da arte da medição de energia elétrica no Brasil se apresenta de forma necessária e irreversível para utilização de forma geral da medição eletrônica, pois além dos aspectos metrológicos, é muito importante se agregar serviços adicionais com a utilização de medidores eletrônicos que possuem recursos importantes que permitem a realização de corte e religa a distância, medição de diversas grandezas, possibilidade de implementação de novas tarifas e preparação das unidades consumidoras, no quesito medição, para migração futura ao mercado livre.

Neste momento em que as empresas de Distribuição de energia buscam incessantemente a redução das perdas técnicas e comerciais em suas áreas de concessão, os sistemas de medição podem contribuir significativamente neste processo.

A substituição gradativa do parque instalado de medidores eletromecânicos para medidores eletrônicos pode sem dúvida ser um sinal importante para os fabricantes de medidores, pois com a ampliação do mercado os custos finais para aquisição destes equipamentos podem ser mais atrativos do ponto de vista econômico, como também a evolução tecnológica não deve ser estagnada, buscando assim melhorias no quesito funcionalidades e aprimoramento da metrologia. 


\section{APARATO REGULATÓRIO REFERENTE Á IMPLANTAÇÃO DOS SISTEMAS DE MEDIÇÃO PARA FATURAMENTO}

A ANEEL nos últimos anos promoveu alterações na busca do aprimoramento regulatório, portanto cabe a indicação dos principais momentos em que neste arcabouço tratou das questões referentes às responsabilidades pelo investimento para instalação/adequação dos Sistemas de Medição para Faturamento nos Pontos de Medição do Sistema Interligado Nacional.

A Resolução ANEEL 264 de 1998, de 13 de agosto de 1998, estabelecia as condições para contratação de energia elétrica por consumidores livres, sendo que em seu Art. 8ํำ define que os equipamentos de medição seriam de propriedade do concessionário ou permissionário proprietário do sistema elétrico ao qual a unidade do consumidor livre estivesse conectada, podendo ser instalado equipamento adicional a critério do comercializador ou consumidor. Nota-se aqui uma nova etapa neste processo, pois permitia a instalação de equipamento adicional por parte dos outros Agentes envolvidos, sendo este um sinal claro da abertura do mercado competitivo.

Posteriormente, o disposto na Resolução ANEEL no 281, de 01 de outubro de 1999, em seu Art. $18 \S 3^{\circ}$ estabelecia que a responsabilidade técnica e financeira pela instalação do Sistema de Medição para Faturamento era da detentora do fio onde a unidade consumidora estava conectada. $O$ investimento seria ressarcido via encargo de conexão.

A Resolução ANEEL n‥ 344, de 25 de Junho de 2002, definiu as datas limites para a entrada em operação comercial do Sistema de Medição para Faturamento, fixando em 31/07/2003 a operacionalização da primeira etapa da medição (medição no lado de baixa da transformação, considerando as conexões que constam da Resolução ANEEL nํ. 166, de 31 de Maio de 2000), e a segunda etapa para 31/12/2004 (medição no lado de alta da transformação conforme Resolução ANEEL nº. 433, de 
10 de Novembro de 2000). Em ambas as situações foram definidas as fronteiras da Rede Básica;

A Resolução Normativa ANEEL nํ. 067, de 08 de Junho de 2004, alterou os critérios de adequação do sistema de medição, tal que os Consumidores Livres fossem responsáveis financeiramente pelo seu SMF (sistema de medição para faturamento). Também estabeleceu novos prazos para instalação dos Sistemas de Medição de Faturamento para as concessionárias de distribuição, e a obrigação para o 'MAE' (atualmente CCEE) disciplinar em Procedimentos de Mercado (atual Procedimentos de Comercialização), as condições para a aplicação de penalidade pela não observância das datas definidas.

Em complemento, no Art. 8ํe estabeleceu que as concessionárias ou permissionárias deviam instalar em sua área de concessão Sistema de Medição nos barramentos com tensão inferior a $230 \mathrm{kV}$, ligado aos transformadores de potência integrantes da Rede Básica. No $\S 1^{\circ}$ estabeleceu que as concessionárias ou permissionárias de distribuição que compartilhem as DIT's (Demais Instalações de Transmissão Compartilhadas) também devem instalar Sistema de Medição para Faturamento em cada ponto de conexão com as referidas instalações.

A mesma Resolução 067/04 em seu $\S 4^{\circ}$ estabeleceu que para os pontos de medição existentes na data de publicação da Resolução (08/06/2004), além da Especificação Técnica citada da Resolução ANEEL n‥ 344, de 25 de Junho de 2004, as concessionárias ou permissionárias de distribuição devem observar:

- Data limite de 31/12/2004 para entrada em operação dos medidores;

- Data limite de 30/06/2005 para entrada em operação dos transformadores de instrumentos, com a classe de precisão requerida;

O § 5ํ da Resolução 067/04 estabeleceu que o MAE - Mercado Atacadista de Energia Elétrica (atualmente CCEE) deverá disciplinar, nos Procedimentos de Mercado (atuais Procedimentos de Comercialização), as condições para aplicar "penalidades à concessionária ou permissionária de distribuição que não observar 
as datas limites estabelecidas no $\S 4^{\circ} \stackrel{\circ}{ }$, independente da ação fiscalizadora da ANEEL". (ANEEL, 2008, resolução 067/04, p. 3).

A referida Resolução 067/04 não faz menção aos Pontos de Medição de Geração, embora no Módulo 12 dos Procedimentos de Rede do ONS, existe o item referente à Localização dos Pontos de Medição do qual cita que deve ser instalado SMF:

- Nas Unidades Geradoras onde existe contabilização de serviços ancilares;

- Nas Unidades Geradoras de Usinas despachadas centralizadamente pelo ONS, para medição de geração bruta nas Unidades Geradoras ou por Grupo de Unidades Geradoras e para a medição de Geração Líquida.

Embora os prazos para implantação dos Sistemas de Medição para Faturamento dos Pontos de Medição de geração estavam definidos na Resolução ANEEL n‥ 344, de 25 de junho de 2002.

O Despacho ANEEL №. 73, de 13 de Janeiro de 2006, permitiu a migração de "consumidores cativos para a condição de livres, mantendo temporariamente o seu sistema de medição existente, até que ato complementar emitido pela ANEEL definisse prazo para sua adequação". (ANEEL, 2006, Despacho n.ำ 73, p.1). Complementarmente, a CCEE preparou o Procedimento Provisório para Adequação do Sistema de Medição de Faturamento ao SCDE (válido até 31.03.2007 - Oficio SEM ANEEL n‥ 124/2006), cujos anexos - Termos de Compromisso / Termos de Adequação - firmavam, respectivamente, o comprometimento em realizar a adequação do SMF conforme cronograma com data definida ou a adequação definitiva conforme prazos a serem definidos pela ANEEL.

A Resolução Autorizativa ANEEL no. 787, de 23 de Janeiro de 2007, autorizou também a utilização em caráter provisório da Revisão 1 do Módulo 12 dos Procedimentos de Rede do ONS, ressaltando que a Revisão 1 contempla a inclusão da Especificação Técnica do Sistema de Medição para Faturamento, que apresenta como novidade a permissão de uso de medidores classe 0,5 (2 quadrantes) para Pontos de consumidores livres atendidos em tensão inferior a 44 kV. 
Este é o primeiro sinal de flexibilização permitido nos requisitos técnicos até então exigidos, ou seja, flexibiliza-se a utilização de um novo tipo de medidor com características técnicas diferentes dos até então utilizados no mercado.

Outro marco importante foi o momento em que a ANEEL publicou a Resolução Normativa ANEEL №. 248, de 23 de Janeiro de 2007, que estabelece que para implementação do SMF dos consumidores livres e especiais, existentes e com Sistema de Medição para Faturamento não adequados aos requisitos técnicos previstos no Anexo I, do Submódulo 12.2 dos Procedimentos de Rede do ONS, que assinaram os Contratos de Uso e de Conexão em data anterior à aprovação da Resolução ANEEL ํo. 208, de 7 de junho de 2001 ou em data posterior à aprovação da Resolução ANEEL $n^{\circ}$ 67, de 08 de Junho de 2004, deverão observar o prazo de 30 de outubro de 2007 para adequação do SMF conforme requisitos técnicos integrantes na Revisão 1 do Módulo 12 dos Procedimentos de Rede do ONS.

Para os consumidores que assinaram seus Contratos de Uso e de Conexão entre as datas da Resolução №. 208/01 e da Resolução n 67/04, a adequação deverá ser realizada e custeada pela concessionária ou permissionária a qual se conecta até o prazo de 30.10.2007. Os novos consumidores que exercerem a opção pelo Ambiente de Contratação Livre após a publicação da Resolução Normativa №. 248/2007 também deverão respeitar o prazo de 30.10.2007 para adequarem ao seu SMF, "e após essa data, a adequação deverá ser prévia à entrada em operação comercial”. (ANEEL, 2007, Resolução n. ${ }^{\circ}$ 248, p. 2).

A Resolução $\mathrm{n}$ ‥ 248/07, também contempla a forma de ressarcimento das distribuidoras, e dispõe que a:

Concessionária de transmissão acessada poderá efetuar a compra dos equipamentos de medição para faturamento e cobrar 0 valor da concessionária ou permissionária de distribuição, via encargo de conexão, hipótese em que a propriedade do equipamento será da concessionária que foi acessada. (ANEEL, 2007, Resolução n.․․ 248, p. 1).

A Resolução № 247, de 21 de dezembro de 2006, estabelece as condições para a comercialização de energia elétrica, "oriunda de empreendimentos de geração, que 
utilizem fontes primárias incentivadas, com unidade ou conjunto de unidades consumidoras cuja carga seja maior ou igual a 500 KW". (ANEEL, 2006, Resolução

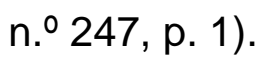

Este ato regulatório foi emitido em virtude da necessidade de disciplinar a comercialização de energia elétrica com "unidade ou conjunto de unidades consumidoras que possuam carga igual ou superior a $500 \mathrm{~kW}$ ”, nos termos do $\S$ 50 do art. 26 da Lei no 9.427, de 26 de dezembro 1996, como também mediante os subsídios oriundos das contribuições recebidas na Audiência Pública no 033/2005, realizada no dia 11 de janeiro de 2006. (ANEEL, 2006, Resolução n.ำ 247, p. 1).

O Consumidor Especial é o:

Consumidor responsável por unidade consumidora ou conjunto de unidades consumidoras do Grupo 'A', integrante(s) do mesmo Submercado no SIN, reunidas por comunhão de interesses de fato ou de direito, cuja carga seja maior ou igual a $500 \mathrm{KW}$, [podendo então por agrupamento migrarem para 0 ACL]. (ANEEL, 2006, Resolução n.ำ 247, p. 2).

Especificamente a questão da medição é objeto do Art.10, onde está identificado que o "Consumidor Especial deverá implementar em sua unidade consumidora, ou em todas as unidades consumidoras que constituem a comunhão de fato e de direito, o Sistema de Medição para Faturamento" (SMF) de acordo com a regulamentação específica. Portanto devem atender os requisitos técnicos previstos no Submódulo 12.2 dos Procedimentos de Rede do ONS. (ANEEL, 2006, Resolução

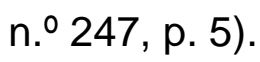

Outra questão importante é que este ato regulatório permite a unificação da "medição para o conjunto de unidades consumidoras, reunidas por comunhão de interesses de fato ou de direito, que estejam localizadas em áreas contíguas". (ANEEL, 2006, Resolução n.ำ 247, p. 5).

Destaca-se a aprovação dos Procedimentos de Comercialização: PdC ME.04 Mapeamento de Pontos de Medição no SCDE; PdC ME.05 - Manutenção do Cadastro de Medição do SCDE; PdC ME.06 - Coletar Dados de Medição do SCDE; e PdC ME.07 - Apuração de Não Conformidades e Penalidades de Medição, 
através da emissão do Despacho SEM-ANEEL n 934, de 07 de março de 2008, sendo na oportunidade aprovada a aplicação de penalidades de medição aos Agentes que não cumprirem suas obrigações com relação aos aspectos de adequação/implantação dos Sistemas de Medição para faturamento.

Em função da Audiência Pública no 10/2005, realizada no dia 29 de setembro de 2005 e da Consulta Pública no 10/2007, realizada no período de 03 a 17 de outubro de 2007, foram coletados subsídios para aperfeiçoar o ato regulamentar da ANEEL, Resolução Normativa no 67, de 08 de junho de 2004. Face exposto, foi emitida a Resolução Normativa no 302, de 26 de fevereiro de 2008 (publicada em 06 de março de 2008), alterando assim a Resolução Normativa no 67, que estabelece critérios para a composição da Rede Básica do Sistema Interligado Nacional.

Destaque para a alteração do Art. 8o, sendo:

Art. $8^{\circ}$, $\S 5^{\circ} \mathrm{A}$ Câmara de Comercialização de Energia Elétrica - CCEE deverá disciplinar, nos Procedimentos de Mercado, as condições para aplicação de penalidade à concessionária ou permissionária de distribuição que não observar as datas limite estabelecidas no parágrafo anterior, independente da ação fiscalizadora da ANEEL. (ANEEL, 2008, Resolução n.ํ 302, p. 3).

Esta abordagem é importante sob o ponto de vista de identificar a evolução histórica recente sobre o tema e a preocupação constante do órgão regulador na busca de disciplinar o tema, visando minimizar lacunas que eventualmente poderiam se traduzir em entraves para a implantação dos Sistemas de Medição para Faturamento. O histórico é importante, pois permite o entendimento atual do estágio regulatório e possíveis necessidades de aprimoramento.

As Resoluções no 247 e 248, sem dúvida, são as que trazem maiores impactos para a implantação dos Sistemas de Medição para Faturamento em Consumidores Livres e Especiais. A abordagem dos custos e viabilidade para migrar para o Ambiente de Livre Contratação (ACL) são realizadas nos Capítulos 9 e 10.

Face exposto é evidente a evolução ocorrida nos últimos anos no que diz respeito aos aspectos regulatórios referente ao tema medição de energia elétrica. 


\section{MÓDULO 12 DOS PROCEDIMENTOS DE REDE DO ONS}

Os Procedimentos de Rede são:

Documentos de caráter normativo elaborados pelo ONS, com participação dos agentes, e aprovados pela ANEEL, que definem os procedimentos e os requisitos necessários à realização das atividades de planejamento da operação eletroenergética, administração da transmissão, programação e operação em tempo real no âmbito do SIN - Sistema Interligado Nacional. (ONS, 2008, www.ons.org.br, em 'procedimentos de rede').

Os Procedimentos de Rede do ONS, possuem alguns objetivos específicos que são:

- Legitimar, garantir e demonstrar a Transparência, Integridade, Equanimidade, Reprodutibilidade e Excelência da Operação do Sistema Interligado Nacional;

- Estabelecer, com base legal e contratual, as responsabilidades do ONS e dos Agentes de Operação, no que se refere às atividades, insumos, produtos e prazos dos processos de operação do sistema elétrico;

- Especificar os requisitos técnicos contratuais exigidos nos Contratos de Prestação de Serviços de Transmissão - CPST, dos Contratos de Conexão ao Sistema de Transmissão - CCT e dos Contratos de Uso do Sistema de Transmissão - CUST. (ONS, 2008, www.ons.org.br, em 'procedimentos de rede').

Os Procedimentos de Rede do ONS são:

- Módulo 1: Introdução Geral ao ONS e aos Procedimentos de Rede;

- Modulo 2: Requisitos Mínimos para Instalações e Gerenciamento de Indicadores de Desempenho da Rede Básica e de seus Componentes;

- Módulo 3: Acesso aos Sistemas de Transmissão;

- Módulo 4: Ampliações e Reforços na Rede Básica;

- Módulo 5: Consolidação de Previsão de Carga;

- Módulo 6: Planejamento da Operação Elétrica;

- Módulo 7: Planejamento da Operação Energética;

- Módulo 8: Programação Diária da Operação Eletroenergética;

- Módulo 9: Recursos Hídricos e Meteorologia;

- Módulo 10: Manual de Procedimentos da Operação;

- Módulo 11: Proteção e Controle; 
- Módulo 12: Medição para Faturamento;

- Módulo 13: Telecomunicações;

- Módulo 14: Administração dos Serviços Ancilares

- Módulo 15: Administração de Serviços e Encargos de Transmissão;

- Módulo 16: Acompanhamento de Manutenção;

- Módulo 17: Requisitos de Informações entre o ONS e os Agentes;

- Módulo 18: Sistemas e Modelos Computacionais;

- Módulo 19: Identificação, Tratamento e Penalidades para as Não Conformidades;

- Módulo 20: Glossário e Termos Técnicos;

- Módulo 21: Estudos para Reforço da Segurança Operacional Elétrica, Controle Sistêmico;

- Módulo 22: Análise de Ocorrências e Perturbações;

- Módulo 23: Critérios para Estudos;

- Módulo 26: Modalidade de Operação de Usinas.

Para o presente trabalho é importante 0 detalhamento de alguns aspectos específicos do Módulo 12 dos Procedimentos de Rede do ONS, pois é justamente este Módulo que disciplina as questões referentes à Medição para Faturamento.

O referido Módulo é composto por 6 Submódulos, sendo:

- Submódulo 12.1: Medição para faturamento: Visão Geral;

- Submódulo 12.2: Instalação do sistema de medição para faturamento;

- Submódulo 12.3: Manutenção do sistema de medição para faturamento:

- Submódulo 12.4: Leitura de medição para faturamento;

- Submódulo 12.5: Certificação de padrões de trabalho;

- Submódulo 12.6: Configurações de medição para faturamento.

A necessidade de todos os Agentes observarem o disposto neste Módulo, quando da adequação / instalação dos Sistemas de Medição para Faturamento, deve-se ao fato de que todas as atividades relativas à medição para faturamento estabelecidas neste módulo são necessárias para manter o Sistema de Medição para Faturamento (SMF) nos padrões especificados no documento Especificação Técnica 
das Medições para Faturamento e para garantir, não só o controle dos processos de contabilização de energia no âmbito da Câmara de Comercialização de Energia Elétrica (CCEE) realizados no Sistema de Contabilização e Liquidação (SCL), como também a apuração das demandas pelo Operador Nacional do Sistema Elétrico (ONS).

Sendo o SMF constituído pelos medidores principal e de retaguarda, pelos "Transformadores para Instrumentos (TI) - transformadores de potencial e de corrente -, pelos canais de comunicação entre os agentes e a CCEE, e pelos sistemas de coleta de dados de medição para faturamento", define-se no Submódulo 12.2 dos Procedimentos de Rede todas as etapas para implantação dos Sistemas, tais como: responsabilidades dos Agentes, CCEE e ONS; elaboração do projeto; aprovação do projeto; montagem dos equipamentos; comissionamento do Sistema de Medição e interligação ao SCDE - Sistema de Coleta de Dados de Energia da CCEE. (ONS, 2008, p. 3).

Com relação ao Anexo I - Especificação Técnica das Medições para Faturamento, é importante destacar que todos os Agentes que necessitem adequar/implantar seus Sistemas de Medição para Faturamento devem realizá-los em conformidade com os requisitos técnicos previstos neste Anexo. Todos os requisitos técnicos específicos sobre medidores de energia elétrica estão detalhados, sendo:

- Características elétricas;

- Classe de exatidão (pertinentes à classe 0,2 prescritos na norma NBR 14519 ou à classe 0,2S da norma IEC-60687 e suas revisões, para todos os sentidos de fluxo de energia);

- Certificação;

- Grandezas a medir (energia ativa, energia reativa, demanda, de forma bidirecional, com pelo menos 4 registros independentes, sendo 2 para cada sentido de fluxo - 4 quadrantes);

- Memória de massa (memória interna para preservação dos registros por um período mínimo de 32 dias);

- Relógio/calendário interno;

- Preservação dos registros; 
- Leitura dos registros;

- Autodiagnose;

- Código de identificação (14 dígitos fornecidos ao Agente pela CCEE);

- QEE - Qualidade de energia elétrica.

A flexibilização da utilização de medidores classe 0,5 (ou melhor) para consumidores livres atendidos em tensão abaixo de $44 \mathrm{KV}$ é muito importante, sendo que muitas empresas de distribuição de energia elétrica que possuíam uma quantidade considerável de consumidores livres em sua área de concessão pleiteavam a flexibilização dos requisitos técnicos dos medidores a serem utilizados para permitir que os consumidores pudessem migrar do ACR - Ambiente de Contratação Regulada (Consumidor Cativo) para o $\mathrm{ACL}$ - Ambiente de Livre Contratação (Consumidor Livre). Dentro deste contexto, foi aprovada a utilização deste tipo de medidor, quando da emissão pela ANEEL da Resolução Autorizativa № 787, de 23 de janeiro de 2007, que autorizou a utilização, em caráter provisório, da Revisão 1 do Módulo 12 dos Procedimentos de Rede do ONS.

Nesta oportunidade a flexibilização atendeu consumidores livres dos Subgrupos tarifários A4 (tensão de fornecimento de $2,3 \mathrm{kV}$ a $25 \mathrm{kV}$ ) e A3a (tensão de fornecimento de $30 \mathrm{kV}$ a $44 \mathrm{kV}$ ). Mesmo após esta flexibilização, algumas empresas de distribuição que possuíam sistemas de distribuição subterrânea em sua área de concessão, solicitaram ao ONS ampliar a flexibilização para consumidores livres do Subgrupo tarifário AS (tensão de fornecimento inferior a 2,3 kV, atendidas a partir de sistema subterrâneo de distribuição e faturadas neste Grupo em caráter opcional).

Entende-se que esta ampliação solicitada pelas empresas de distribuição de energia, é totalmente pertinente e com certeza deveria ser atendida. Em algumas oportunidades, as entidades CCEE e ONS avaliaram a solicitação e tinham o consenso de que deveria ser contemplada no Anexo I do Submódulo 12.2 dos Procedimentos de Rede do ONS. Sendo assim, o ONS teria que aguardar nova oportunidade de revisão do texto do Módulo 12 para realizar tal alteração. Em atendimento ao Ofício da SRT/ANEEL 001-2008, de 07 de janeiro de 2008, que solicitava a alteração de itens específicos, realizou-se então a implementação da ampliação da flexibilização passando assim o item 1.2.1.12 ter a seguinte redação: 


\subsubsection{Consumidores Livres com tensão abaixo de 44kV}

A classe de exatidão dos medidores para esses tipos de consumidores deve atender a todos os requisitos metrológicos pertinentes a classe 0,5 , ou melhor, prescritos na norma NBR 14519.

Os medidores devem permitir a medição e o registro de pelo menos as seguintes grandezas elétricas: energia ativa, energia reativa, demanda de forma unidirecional com pelo menos 2 registros independentes para o sentido de fluxo (dois quadrantes) ou de forma bidirecional, com pelo menos 4 registros independentes, 2 para cada sentido de fluxo (quatro quadrantes), além das correntes e tensões fase-neutro para medidores de 3 elementos a 4 fios ou fase-fase para medidores de 2 elementos a 3 fios.

Os consumidores livres que possuírem gerações embutidas em suas plantas devem utilizar medidores que armazenem pelo menos 4 registros independentes, 2 para cada sentido de fluxo (4 quadrantes). (ANEEL, 2006, Nota técnica $\mathrm{n}$. $=105$, p.3-8).

A flexibilização não poderá ser contemplada para consumidores livres que possuam geração interna em suas plantas.

Para auxiliar os Agentes a optarem por um determinado tipo de medidor, a CCEE disponibiliza em seu site a relação de medidores que são utilizados, e que segundo informações prestadas pelos fabricantes à CCEE, atendem todos os requisitos técnicos mencionados anteriormente. Para tal, os fabricantes encaminharam para a CCEE "TABELAS DE CONFORMIDADE" atestando assim o atendimento a cada requisito técnico. A CCEE não tem por atribuição homologar medidores, pois esta atribuição é do Instituto Nacional de Metrologia, Normalização e Qualidade Industrial (INMETRO), sendo que a disponibilização em seu site é apenas para contribuir com os Agentes quando da opção por determinado tipo de equipamento que atenda às exigências de mercado e do Agente conectado que tem como atribuição pré aprovar o projeto dos sistemas de medição.

A tabela 1 indica a relação dos medidores disponibilizada na seção Comercialização de energia/ Medição do site da CCEE, sendo importante observar que os medidores que atendem aos requisitos técnicos previstos no Anexo I (Especificação Técnica do SMF) do Sub-módulo 12.2 dos Procedimentos de Rede do ONS, estão relacionados conforme informação obtida junto aos fabricantes. 
Tabela 1 - Relação dos medidores disponibilizados no site da CCEE

\begin{tabular}{|c|c|c|}
\hline Fabricante & Medidor / Modelo & Firmware \\
\hline Actaris & SL 7000 & 3.XX, 4.XX, 5.XX $\left(^{\star}\right)$ \\
\hline Electro Industries & Nexus / 1270 & Aguardando informação do fabricante \\
\hline Elo & ELO / 2180 & não aplicável $\left(^{\star \star}\right)$ \\
\hline Itron & Q1000 & 2.XXy, 3.XXy, 4.XXy, 5.XXy (*) \\
\hline \multirow[t]{2}{*}{ Power } & ION / 7500 & não aplicável $\left({ }^{* *}\right)$ \\
\hline & ION / 7550 & não aplicável $\left({ }^{* *}\right)$ \\
\hline \multirow[t]{6}{*}{ Measurement } & ION / 7600 & não aplicável $\left({ }^{\star \star}\right)$ \\
\hline & ION / 7650 & não aplicável $\left({ }^{* *}\right)$ \\
\hline & ION / 8300 & não aplicável $\left({ }^{* *}\right)$ \\
\hline & ION / 8400 & não aplicável $\left({ }^{* \star}\right)$ \\
\hline & ION / 8500 & não aplicável $\left({ }^{* \star}\right)$ \\
\hline & ION / 8600 & não aplicável $\left({ }^{* *}\right)$ \\
\hline Landis \& Gyr & Saga $1000 / 1681$ & 7101 a 7110,8110 e 8111 \\
\hline ZIV & 5CTE / E5A & Aguardando informação do fabricante \\
\hline
\end{tabular}

Nota:

$\left(^{*}\right) \mathrm{X}=$ Caractere Numérico $/ \mathrm{y}=$ Caractere Alfa $(\mathrm{A}$ a Z)

$\left({ }^{* *}\right)$ A versão do firmware dos medidores ION da Power e 2180 da ELO não interfere na leitura dos mesmos pela CCEE.

Fonte: site da CCEE (www.ccee.org.br, 2008).

Conforme consta no próprio site da CCEE, todo o desenvolvimento e eventuais manutenções futuras no driver de protocolo/biblioteca do medidor será de responsabilidade do fabricante do mesmo.

Com o detalhamento dos medidores, outro aspecto importante é sobre os requisitos técnicos de outros equipamentos, que são integrantes do Sistema de Medição para Faturamento. Segue explanação sobre TI - Transformador para Instrumentos.

Os secundários dos Tl's devem ser exclusivos para medição de faturamento e "devem ter classe de exatidão 0,3 (ou melhor) para todas as cargas, e para todas as relações, consideradas as condições de projeto, e para a freqüência nominal do sistema" (ONS, 2008, submódulo 12.2, p. 18).

Especificamente para a medição de serviço auxiliar se aceita a classe de exatidão 0,6 e: 
Para consumidores livres com tensão abaixo de $44 \mathrm{kV}$, os secundários exclusivos para medição de faturamento dos Tl's devem ter classe de exatidão 0,6 (ou melhor) para todas as cargas, e para todas as relações, consideradas as condições de projeto, e para a freqüência nominal do sistema. (ONS, 2008, submódulo 12.2, p. 18).

Existe flexibilização para consumidores livres com tensão abaixo de 44 kV.

Os Tl's devem possuir enrolamento secundário exclusivo para a medição de faturamento. $O$ eventual compartilhamento só poderá ser aceito mediante o pedido de excepcionalidade a ser encaminhado pelo solicitante para análise e deliberação da CCEE e ONS, conforme disposto no Capítulo 11. FLEXIBILIZAÇÃO DOS REQUISITOS TÉCNICOS - PEDIDOS DE EXCEPCIONALIDADE deste trabalho.

Consta no Anexo 1 do Submódulo dos Procedimentos de Rede do ONS, itens como:

- Cabeação secundária;

- Informações básicas relativas ao projeto;

- Comunicação de dados;

- Recursos de programação;

- Medição de retaguarda;

- Localização dos pontos de medição;

- Arquitetura básica do Sistema de Medição para Faturamento (Comunicação de Dados).

Sobre o Submódulo 12.2 dos Procedimentos de Rede do ONS, é importante informar sobre a necessidade de se realizar o comissionamento dos Sistemas de Medição para Faturamento, pois é a única forma de se atestar o atendimento aos requisitos técnicos, bem como do correto funcionamento do sistema, situações estas tão importantes para garantir a correta contabilização de energia no âmbito da CCEE e a apuração das demandas pelo Operador Nacional do Sistema Elétrico ONS.

Os itens a serem verificados quando do comissionamento do Sistema de Medição para Faturamento são (os requisitos estão dispostos no Anexo 2 do Submódulo 12.2 dos Procedimentos de Rede do ONS): 
- Verificação do aterramento dos equipamentos;

- Verificação das condições do isolamento da cabeação secundária dos TI's e dos medidores;

- Verificação da polaridade dos Tl's;

- Verificação da interligação secundária dos Tl's aos painéis ou aos cubículos de medidores;

- Verificação da fiação interna dos painéis ou cubículos de medidores;

- Verificação de todas as constantes e parâmetros envolvidos no SMF;

- Programação do(s) código(s) de identificação do(s) medidor (es) fornecido(s) pela Câmara de Comercialização de Energia Elétrica - CCEE;

- Verificação da programação dos medidores;

- Verificação dos valores das correntes, das tensões e da seqüência de fases;

- Realização de estudo vetorial das tensões e correntes, com o circuito energizado, e do Desenho do diagrama fasorial encontrado;

- Verificação da calibração dos medidores através de ensaio monofásico ou trifásico;

- Medição da carga imposta aos Tl's;

- Execução de leitura inicial dos medidores;

- Colocação de lacres pelos agentes envolvidos em todos os pontos previstos;

- Elaboração de relatório com todos os resultados do comissionamento.

Cabe ressaltar que está em curso a Audiência Pública ํo. 049/2008, que visa obter subsídios para aprimoramento de ato regulamentar sobre os Procedimentos de Rede do ONS. Com ênfase no Módulo 12, que disciplina as questões inerentes a medição, inclusive a Especificação Técnica SMF, observa-se que foram encaminhadas aproximadamente 500 (quinhentas) contribuições para aprimorar este Módulo, embora ao analisar as contribuições formuladas pelos Agentes, não se encontra solicitações de alterações significativas, fato este que preocupa pois este momento é fundamental para se externar as proposições que comumente são colocadas pelos Agentes para a CCEE e o ONS. A ANEEL ainda está em fase de análise das contribuições referentes a esta Audiência Pública. 


\title{
5. PROCEDIMENTOS DE DISTRIBUIÇÃO DE ENERGIA ELÉTRICA
}

O PRODIST (Procedimentos de distribuição de energia elétrica) é um conjunto de:

\begin{abstract}
Documentos regulatórios na forma de regulamentações, normatizações e padronizações que têm como objetivo possibilitar a conexão elétrica aos sistemas de distribuição por usuários, garantindo que os indicadores de desempenho ou de qualidade de serviço sejam atingidos de forma clara e transparente, preservando, dentre outros aspectos, a segurança, a eficiência e a confiabilidade dos sistemas elétricos. (ANEEL, 2008, www.aneel.gov.br, em 'informações técnicas').
\end{abstract}

O conjunto de documentos regulatórios estão organizados em assuntos da seguinte forma:

- Módulo 1 - Introdução;

- Módulo 2 - Planejamento da Expansão do Sistema de Distribuição;

- Módulo 3 - Acesso aos Sistemas de Distribuição;

- Módulo 4 - Procedimentos Operativos do Sistema de Distribuição;

- Módulo 5 - Sistemas de Medição;

- Módulo 6 - Informações Requeridas e Obrigações;

- Módulo 7 - Perdas Técnicas Regulatórias;

- Módulo 8 - Qualidade da Energia Elétrica;

Como objetivo, tem o de:

\begin{abstract}
Disciplinar todos os aspectos técnicos relativos ao planejamento de expansão e à operação das redes de distribuição, bem como à conexão de usuários e também aos requisitos técnicos da interface com a Rede Básica, complementando de forma harmônica os Procedimentos de Rede dos Sistemas de Transmissão. (ANEEL, 2008, www.aneel.gov.br, em 'informações técnicas').
\end{abstract}

Para continuidade da análise, remete-se ao RE-SEB o início das discussões, pois a regulamentação das distribuidoras é bastante simplificada e não existem documentos consolidados para procedimentos relativos a planejamento e operação das distribuidoras, a exemplo dos documentos existentes no âmbito do GCPS e GCOI, portanto a partir de então sentiram-se a necessidade de elaborarem o PRODIST em duas etapas, sendo: 
- Na primeira etapa foi elaborada uma versão preliminar partindo-se do anexo $\mathrm{H}$ do documento final elaborado pela Coopers \& Lybrand, da documentação existente na ABRADEE (Associação Brasileira de Distribuidores de Energia Elétrica) e de outros documentos pertinentes. Os documentos desta etapa foram elaborados pelo CEPEL com supervisão da ANEEL;

- Na segunda etapa foi contratado, por licitação pelo PNUD (Programa das Nações Unidas para o Desenvolvimento), tendo como beneficiária a ANEEL, o consórcio PROCEDI5, composto pelas empresas Promon e Con Energia, FUPAI e Advocacia Waltenberg. O documento foi amplamente discutido, interna e externamente, desde as premissas até as versões iniciais, recebendo 1500 contribuições dos mais diversos segmentos do setor elétrico.

O Consórcio PROCEDI5 efetuou apresentações, referente ao Módulo 5 - Sistemas de Medição, oportunidade esta onde já se defendia a separação dos requisitos técnicos dos Sistemas de Medição para Faturamento em dois tópicos: Sistema de Medição para Faturamento para atendimento ao mercado cativo; e os aspectos relacionados medição de cargas do sistema de distribuição, estudos de previsão de demanda, qualidade de energia (QEE) e curvas de carga. Por outro lado, para atendimento ao mercado livre e mercado de forma geral os aspectos de medição estão disciplinados no Submódulo 12.2 dos Procedimentos de Rede do ONS.

O processo de coleta de subsídios para a elaboração do presente documento, foi balizado pela publicação no Diário Oficial da União - Seção 3 o Aviso de Audiência Pública no 14 / 2008, cujas contribuições poderiam ser encaminhadas para a ANEEL no período 20/02/2008 a 18/04/2008. Como os consumidores, agentes do setor elétrico poderiam realizar suas contribuições, tais subsídios permitiam se realizar o aprimoramento do ato regulamentar referente ao PRODIST.

Como aspectos principais do documento objeto da Audiência Pública ํo 14 / 2008, e neste caso relata-se apenas o Módulo 5 - Sistemas de Medição, onde se destaca as seguintes seções: 
- Seção 5.0 - Introdução;

- Seção 5.1 - Aplicabilidade - identifica os Agentes aos quais o Módulo 5 se aplica, sua abrangência e as responsabilidades;

- Seção 5.2 - Especificação dos Sistemas de Medição - esta seção é muito importante, pois uniformiza os critérios para as especificações dos sistemas de medição de energia elétrica utilizados nas conexões de acessantes aos sistemas de distribuição destinados ao faturamento da energia elétrica, ao planejamento da expansão dos sistema e à qualidade da energia elétrica;

- Seção 5.3 - Implantação, Inspeção e Manutenção dos Sistemas de Mediçãoesta seção define as responsabilidades e procedimentos para os agentes envolvidos nas atividades de implantação, inspeção e manutenção dos sistemas de medição nas unidades consumidoras ou instalações da distribuidora;

- Seção 5.4 - Leitura, Registro, Compartilhamento e Disponibilização das Informações de Medição - esta seção estabelece os procedimentos básicos para leitura, registro, compartilhamento e disponibilização das informações de medição de grandezas elétricas dos agentes conectados, acessados ou acessantes, ao sistema de distribuição. (ANEEL, 2008, www.aneel.gov.br, em 'informações técnicas').

Alguns pontos merecem destaque, pois os consumidores cativos que optarem por migrar ao ACL são responsáveis pelos custos de adequação / implantação dos Sistemas de Medição para Faturamento, ficando a concessionária responsável técnica pelas implantações. Uma das constantes controvérsias ocorridas quando da migração dos consumidores para o ACL é justamente a questão sobre ressarcir ou não a concessionária pelo sistema de medição instalado quando este estiver adequado aos requisitos técnicos previstos no Submódulo 12.2 dos Procedimentos de Rede do ONS. Neste quesito, o PRODIST define que o futuro consumidor livre deve ressarcir a concessionária pelo custo do Sistema de Medição.

Outro aspecto a ser destacado, é a situação da necessidade de:

Substituição de equipamentos com a vida útil esgotada, substituição decorrente de avarias e a substituição por motivos que comprometam a segurança de instalações ou de pessoas devem ser arcadas e realizadas pela distribuidora acessada, excluindo-se o sistema de comunicação de dados. (ANEEL, 2008, www.aneel.gov.br, em 'Módulo 5').

Destaca-se a importância das tratativas destes temas no âmbito do PRODIST, pois a partir da publicação do documento, para novas instalações, a distribuidora deve adotar Sistemas de Medição com os mesmos requisitos técnicos mínimos e mesmas 
instalações associadas, tanto para os consumidores livres quanto para os consumidores cativos.

Quando da instalação de novos sistemas de medição para consumidores cativos, a concessionária adotando o mesmo padrão de consumidores livres, tem-se significativo ganho, pois quando ocorrer a eventual migração do consumidor para o ACL se realiza o ressarcimento do custo de implantação do Sistema de Medição para a concessionária, ficando o consumidor livre responsável por dotar o ponto de medição de sistema de comunicação às suas expensas.

Cabe crítica ao disposto no documento no item 3.7 da Seção 3, sendo que este item trata da possível aplicação de percentuais de perdas para determinados níveis de tensão, quando não existir viabilidade técnica ou quando por opção dos agentes. Segue abaixo a íntegra do texto do item 3.7 da Seção 3:

3.7 Para os casos de conexões em tensão primária de distribuição, os sistemas de medição podem ser instalados no lado de baixa tensão dos transformadores de potência, se existir viabilidade técnica e for opção dos agentes, atendendo o seguinte:

a) o método de compensação de perdas de transformação pode ser um algoritmo processado pelo medidor eletrônico, desde que seja aprovado por regulamentação metrológica, ou na sua inexistência por laboratório reconhecido pelo INMETRO;

b) se não forem instalados os medidores com capacidade de medição das perdas de transformação, poderá ser utilizado um método alternativo de compensação de perdas, que é acrescentar aos valores medidos de demanda e consumo de energia elétrica ativas e reativas excedentes os seguintes percentuais:

I - 1\% (um por cento) nos fornecimentos em tensão superior a $44 \mathrm{kV}$;

II - $2,5 \%$ (dois e meio por cento) nos fornecimentos em tensão igual ou inferior a $44 \mathrm{kV}$.

c) para os sistemas de medição cujos pontos são contabilizados na CCEE, este método de medição deverá obedecer de forma complementar aos requisitos estabelecidos nos Procedimentos de Rede e nas Regras e Procedimentos de Comercialização; (ANEEL, 2008, www.aneel.gov.br, em 'Módulo 5', p. 8).

Como ressalva, deve-se estar mais explícito que a utilização da aplicação dos referidos percentuais. Só poderá ser aceito em consumidores cativos, não se aplicando aos consumidores livres ou até mesmo como sugestão a definitiva 
supressão da opção de uso da aplicação dos referidos percentuais em consumidores cativos, pois neste caso o entendimento é de que para instalações novas o Sistema de Medição deve ser instalado no Ponto de Conexão tornando assim desnecessário a aplicação de eventuais percentuais para aplicação das referidas perdas de transformação.

Para todos os pontos que são contabilizados na CCEE deve estar claro que esta situação é uma excepcionalidade, que é tratada neste trabalho no Capítulo 11. FLEXIBILIZAÇÃO DOS REQUISITOS TÉCNICOS - PEDIDOS DE EXCEPCIONALIDADE - Utilização de medidores dotados de recursos de algoritmo de compensação de perdas.

A questão de utilização do algoritmo de compensação de perdas está disciplinada no documento da CCEE, Procedimento de Comercialização ME.04 - Mapeamento de Pontos de Medição no SCDE.

Caso seja aceita esta situação para os pontos de medição que são contabilizados no mercado, ter-se-ia constantes "ajustes" nos dados de medição a serem contabilizados na CCEE, pois após serem coletados automaticamente seria necessário se efetuar os ajustes se aplicando os percentuais de $1 \%$ ou $2,5 \%$, conforme o caso.

Outra crítica é a de manter no PRODIST o atual disposto no item 5.4 da Seção 5.4, que trata das informações que devem ser configuradas nos medidores, para os agentes de distribuição membros da CCEE, sendo:

5.4 Para os agentes de distribuição membros da CCEE, os medidores de energia devem estar instalados e configurados em condições de fornecer as seguintes informações:
a) parâmetros do medidor;
i. número de série do medidor de energia;
ii. código de identificação da CCEE (código alfanumérico de, no mínimo, 14 posições);
iii. constante de integração ou intervalo de integração (tempo entre dois registros de medição, em segundos);
iv. relação do TP;
v. relação do TC.
b) dados de energia, para agentes acessantes; 
i. energia ativa, de 5 em 5 minutos;

ii. energia reativa indutiva/capacitiva, de 5 em 5 minutos;

iii. energia ativa, de 5 em 5 minutos, com compensação de perda, fornecendo, os valores de energia compensados e os valores sem compensação;

iv. energia reativa indutiva/capacitiva, de 5 em 5 minutos, com compensação de perda, fornecendo os valores de energia compensados e os valores sem compensação;

v. os medidores que trabalham com compensação de perdas deverão fornecer os valores de energia compensados e os valores sem compensação.

c) dados de engenharia;

i. tensão RMS fase neutro, por fase ou fase-fase;

ii. corrente por fase.

d) alarmes.

i. log de eventos do medidor de energia, contendo causa e efeito (código e descrição dependendo do modelo do medidor). (ANEEL, 2008, www.aneel.gov.br, em 'Módulo 5', p. 29).

Este item torna-se desnecessário, pois no Anexo I do Submódulo 12.2 dos Procedimentos de Rede do ONS mais precisamente no item 1.2.1 Medidores de Energia existe a seguinte definição:

\subsubsection{Grandezas a Medir}

Devem permitir a medição e o registro de pelo menos as seguintes grandezas elétricas: energia ativa, energia reativa, demanda, de forma bidirecional, com pelo menos 4 registros independentes, 2 para cada sentido de fluxo (quatro quadrantes). Podem possuir,adicionalmente, uma saída específica para as medições instantâneas (potências ativa e reativa, fator de potência, corrente, tensão, freqüência, etc.). (ONS, 2008, Submódulo 12.2, p. 15).

Para os consumidores livres com tensão abaixo de $44 \mathrm{kV}$ vale o seguinte:

[...] Os medidores devem permitir a medição e o registro de pelo menos as seguintes grandezas elétricas: energia ativa, energia reativa, demanda de forma unidirecional com pelo menos 2registros independentes para o sentido de fluxo (dois quadrantes) ou de forma bidirecional, com pelo menos 4 registros independentes, 2 para cada sentido de fluxo (quatro quadrantes), além das correntes e tensões fase-neutro para medidores de 3 elementos a 4 fios ou fase-fase para medidores de 2 elementos a 3 fios.

Os consumidores livres que possuírem gerações embutidas em suas plantas devem utilizar medidores que armazenem pelo menos 4 registros independentes, 2 para cada sentido de fluxo (4 quadrantes). (ONS, 2008, Submódulo 12.2, p.17).

Todas as grandezas elétricas necessárias para atendimento ao mercado estão mencionadas no Submódulo 12.2 dos Procedimentos de Rede, estando assim 
preservada a situação de que na necessidade de se realizar qualquer alteração nas grandezas a serem medidas torna-se necessária a alteração em apenas um dos documentos, bem como para os agentes que devem observar em apenas um documento as questões referentes à parametrização dos medidores para atendimento ao mercado.

O PRODIST está definindo a medição para o mercado cativo da distribuidora, que deve prever a instalação de equipamentos de medição cujas características técnicas sejam idênticas ao do mercado livre, exceto a comunicação de dados, pois as unidades consumidoras que futuramente possam migrar para o Ambiente de Livre Contratação possam estar com os Sistemas de Medição para Faturamento adequado aos requisitos técnicos previstos no Anexo I do Submódulo 12.2 dos Procedimentos de Rede do ONS.

A questão é de fundamental importância, pois a adoção de um padrão único de medição pode evitar as questões atualmente enfrentadas pelos Agentes com relação aos custos de adequação, projeto de medição, substituição de equipamentos, obras civis em subestações e dúvidas quanto às responsabilidades em cada uma das etapas deste processo.

O ganho será considerável, pois poder-se-ia ter nova abertura de mercado para um maior número de possíveis clientes livres, sem ter-se a questão da medição como possível entrave para continuidade dos processos de migração e conseqüente ampliação e consolidação do mercado de energia no Brasil.

A defesa por um padrão único é o que tem-se a perseguir, pois as questões técnicas adicionais podem ser obtidas no Módulo 12 dos Procedimentos de Rede do ONS, ficando o Módulo 5 do PRODIST definindo apenas a questão da medição para o mercado cativo, embora a manutenção de um padrão único de medição é de fundamental importância para minimizar discussões futuras entre os Agentes. Cabe destacar que o conjunto de documentos do PRODIST foram aprovados pela ANEEL em 16/12/2008 mediante publicação da Resolução Normativa ANEEL №. 345. 


\section{IMPLEMENTAÇÃO DO SCDE (SISTEMA DE COLETA DE DADOS DE ENERGIA)}

O mercado necessita, para manter os processos de contabilização e liquidação realizados pela CCEE, dos dados de medição oriundos de vários pontos de medição localizados em todo o território nacional. Portanto, não basta apenas os Agentes instalarem os seus Sistemas de Medição para Faturamento, torna-se necessário também realizar a coleta dos dados de medição diariamente.

A CCEE desenvolveu e implantou o SCDE - Sistema de Coleta de Dados de Energia, que realiza a coleta dos dados de medição e mantém em sua base de dados as informações cadastrais de cada ponto de medição. A coleta automática contribui para agilizar a aquisição dos dados e confere maior confiabilidade dos dados de todos os Agentes.

O ONS - Operador Nacional do Sistema Elétrico Nacional é usuário do Sistema, pois utiliza os dados coletados para os seus processos e verifica os Pontos de Medição mapeados pela CCEE como parte do processo de aprovação dos Projetos de Medição encaminhados pelos Agentes.

Para entendimento da concepção deste Sistema, deve ser referenciada a Resolução ANEEL $n^{\circ}$. 290, de 3 de Agosto de 2000, que na oportunidade definiu que para possibilitar o pleno funcionamento do mercado, seria necessário que o Operador Nacional do Sistema Elétrico - ONS, e na oportunidade a Administradora de Serviços do Mercado Atacadista de Energia - ASMAE (sucedida pelo MAE e posteriormente pela CCEE), celebrassem um Acordo Operacional estabelecendo uma base harmoniosa para regular as atividades e procedimentos comuns entre estas duas entidades.

O referido acordo foi celebrado em 01 setembro de 2000, sendo que neste acordo estavam previstos os direitos e deveres de cada uma das entidades, formas de 
comunicação, de intercâmbio das informações, sistemáticas para a validação das metodologias e dos modelos computacionais, bem como as responsabilidades de cada parte na implantação do sistema de medição e o processo de compatibilização dos Procedimentos de Rede com os Procedimentos de Mercado.

Atribuiu-se ao ONS a responsabilidade de coordenar a implantação do sistema físico de medição para faturamento, enquanto que à ASMAE coube a implantação da Central de Coleta de Dados de Medição.

Celebrou-se então um Protocolo de Entendimentos, que visava a Gestão da Implantação do Sistema de Medição para Faturamento. Em novembro de 2001, foi constituída uma comissão, com representação de Conselheiros do MAE e do ONS, além de representantes da ABRAGE, ABRADEE, ABRACE e, posteriormente da ABRATEE, com o objetivo de analisar as 'Especificações Técnicas dos Sistemas de Medição de Faturamento', bem como propor um plano de implantação do Sistema de Medição de Faturamento (SMF).

Como resultado dos trabalhos realizados por esta Comissão, elaborou-se um Plano de Implantação da Medição, sendo constituídos dois documentos, a saber:

- Especificação Técnica do Sistema de Medição de Faturamento de Energia; e

- Cronograma de Implantação do Sistema de Medição de Faturamento de Energia.

Os referidos documentos foram aprovados pelo Conselho de Administração do ONS e também na oportunidade pelo COMAE (Conselho do Mercado Atacadista de Energia Elétrica), cuja aprovação foi realizada através da Deliberação № 049/2001, de 06 de dezembro de 2001.

Os documentos foram encaminhados à ANEEL, sendo posteriormente emitida a Resolução ํㅡ 344/2002, de 25 de junho de 2002, que por sua vez, fixava as datas limite para entrada em operação comercial do Sistema de Medição de Faturamento de Energia Elétrica, bem como, estabelecia também a responsabilidade pela respectiva implementação. Na mesma Resolução consta também que o Conselho 
de Administração do Mercado Atacadista de Energia Elétrica e o Conselho de Administração do Operador Nacional do Sistema Elétrico (ONS) aprovaram os documentos acima mencionados.

Finalmente o Conselho de Administração do MAE decidiu pela implantação do Sistema de Coleta de Dados de Medição de Energia - SCDE, cuja decisão estipularia que a referida implantação se daria em duas etapas:

- Escolha e contratação de uma consultoria para participar da Gestão do Projeto; e

- Finalização das Especificações Técnicas para permitir a licitação para a definição do fornecedor do sistema;

Então a necessidade de implantar o referido Sistema, o SCDE, pois de que adiantaria se implantar os Sistemas de Medição em campo e não fosse possível se realizar a coleta dos dados de medição de forma automática refletindo assim em um processo mais ágil e seguro, pois os dados de medição coletados serão utilizados na contabilização do mercado, definindo assim a comparação entre os contratos celebrados e registrados entre os Agentes na CCEE, com os respectivos montantes de energia medidos em cada um dos Pontos de Medição.

Durante o ano de 2002, o MAE - Mercado Atacadista de Energia Elétrica, efetuou a preparação do edital de contratação para permitir a contratação de empresa de fornecimento de software e hardware, como também implementar o SCDE em conformidade com a Especificação Técnica vigente.

O Sistema deveria ser implementado em acordo com a sua finalidade principal que é a medição de faturamento, pois como já mencionado, a medição em cada Ponto de Medição é utilizada no processo de determinação de compra e/ou venda de cada Agente para todo o mercado. Então os dados a serem coletados seriam:

- Coleta dos dados de Medição de Energia: leitura dos dados de energia ativa e energia reativa de forma bidirecional (4 quadrantes); 
- Coleta dos dados de Medição de Qualidade de Energia Elétrica: leitura dos valores de "valor de tensão eficaz em regime permanente e os valores de tensão resultantes de eventos do tipo variação de tensão de curta duração (VTCD)". Estes dados são de uso exclusivo do ONS - Operador Nacional do Sistema Elétrico. (ONS, 2008, Submódulo 12.2, p.7).

- Coleta dos dados de Medição para realização de Inspeção Lógica: Este processo consiste na existência de acesso direto aos medidores para verificação dos registros armazenados na memória de massa dos medidores.

Dentre deste contexto, o Sistema começou a ser implantado dentro de uma situação bem peculiar, pois deveria permitir a interligação com um número considerável de Agentes que por sua vez já possuíam sua opção com relação a suas próprias soluções de coleta.

Embora o mais significativo é que deveria ter a capacidade de se comunicar com vários tipos de medidores instalados em todo o território nacional, respeitando também a diversidade de protocolos e formas de comunicação.

$\mathrm{Na}$ concepção inicial, definiu-se que o Sistema seria composto pelos seguintes Módulos:

- Coleta;

- Cadastro;

- Tratamento de Dados (Consistência e Consolidação);

- Cálculo e Mapeamento (Equações);

- Auditoria (Inspeção Lógica);

- Relatórios;

- Integração com o ONS;

- Mapeamento dos Pontos de Medição (incluído posteriormente); 


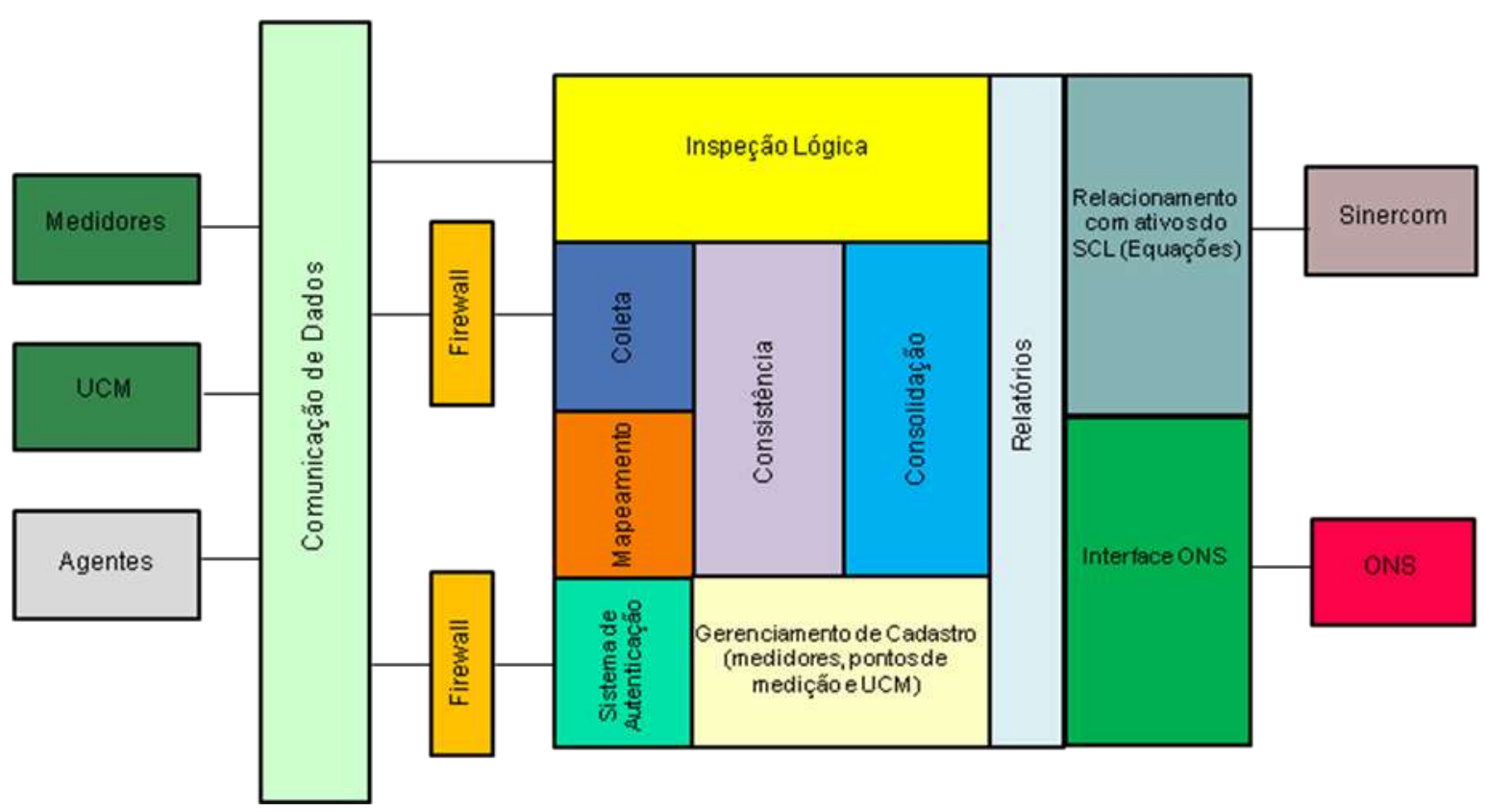

Figura 3 - Visão Geral do SCDE (Sistema de Coleta de Dados de Energia)

A figura 3 representa a integração de todos os Módulos de forma que seja possível se coletar os dados de medição, manter o cadastro de todos os Pontos de Medição e respectivos atributos (algo em torno de 178 itens), realizar as verificações através das consistências previstas e integração com outros Sistemas (SCL - Sistema de Contabilização e Liquidação), como também com o ONS.

Para permitir a integração com os diversos sistemas de coleta de dados diferentes, de propriedade dos Agentes dotados de vários meios de comunicação e diversos tipos de medidores, existem algumas interferências externas que merecem citação, pois não basta a implementação do lado da CCEE, mas tem-se a necessidade de contar com as providências de Agentes externos, tais como:

- Fabricantes de Medidores;

- Agentes de Mercado;

- ONS;

- Fornecedores de Soluções de Medição;

- Provedoras de Serviços de Telecomunicações;

- Prestadores de Serviços de Implantação de Sistemas. 
Em continuidade ao histórico de implantação, a partir de 31 de julho de 2003, iniciaram-se as primeiras coletas automáticas dos dados de medição, sendo que na oportunidade iniciou-se a população da base de dados do Sistema.

A partir do início do recebimento dos dados, começou-se estudo interno na época no âmbito do MAE (atualmente CCEE) para efetivamente se utilizar os dados de medição para serem contabilizados no SCL. Desenvolveu-se então uma interface para transferir automaticamente os dados para o SCL, iniciando-se assim 0 processo de substituição gradativa do processo de inserção dos dados de medição no SCL, uma vez que, os dados de medição sempre foram inseridos no SCL, manualmente pelos agentes através de tela do SCL (Figura 4) ou via carga de arquivos com o formato "txt" (Figura 5) ou via tela do sistema (Figura 6).
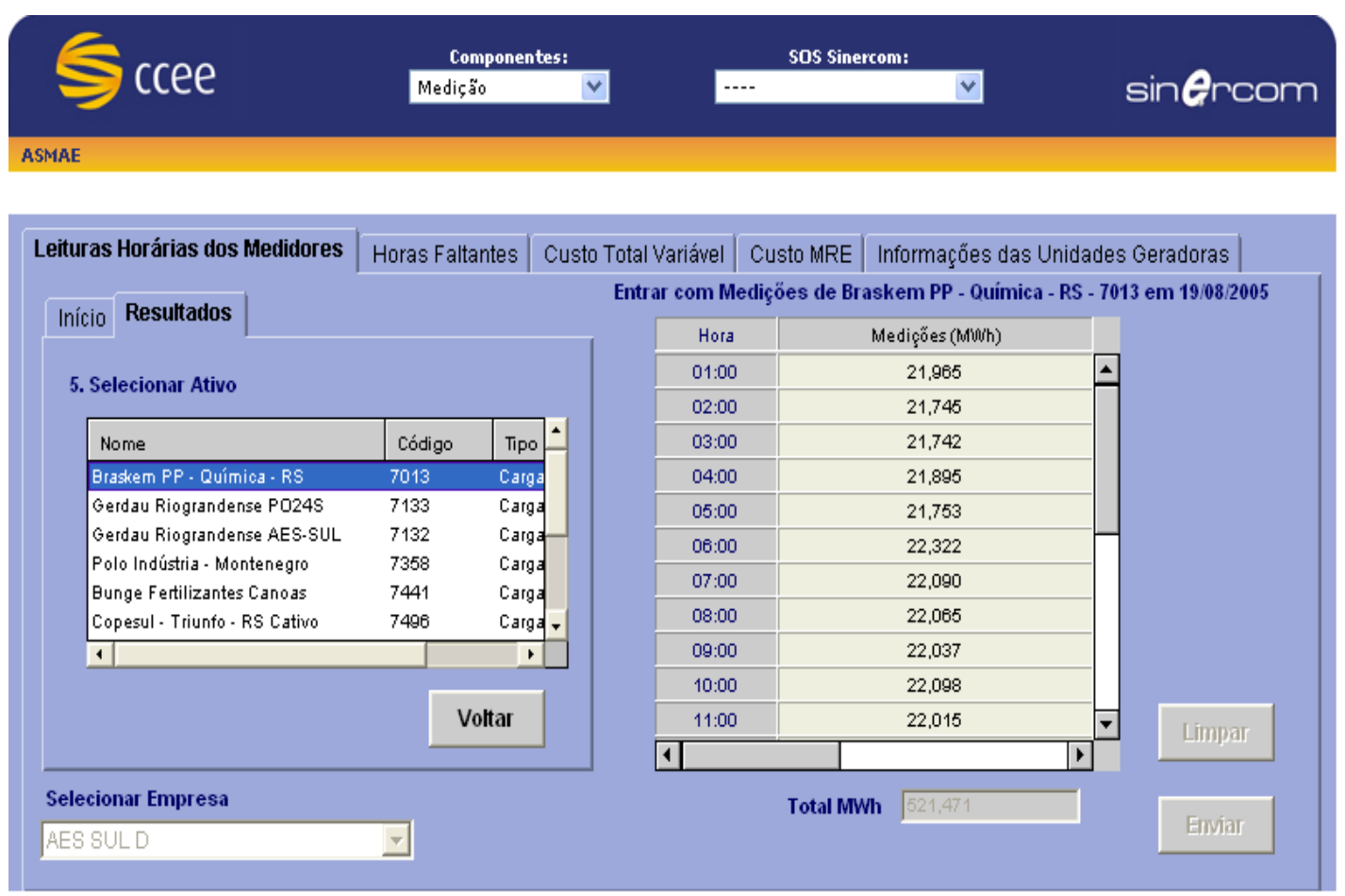

Figura 4 - Tela do Sinercom (ou SCL) para entrada de dados via carga de arquivo no formato "txt"

Fonte: Baroni Neto e Moretti (2007, p. 29). 


\begin{tabular}{|c|c|}
\hline FORMATO & DESCRICAOO \\
\hline Mediçódo & 1a Linhia - Mediçăo \\
\hline Diario & $2^{a}$ Linhla - Diarío \\
\hline & Ja Linila - tres asterisoss \\
\hline 42,$4247 ;$, conex $60 ; 01 / 06 / 2002$ & Áa Linha - núfnero do Agente (ate 4 \\
\hline $1,0,123$ & dlgitos); núfero do Alvo (ate 9 \\
\hline $2,0,456$ & (dlgitos); se es unidade geradora, carga \\
\hline $3,1,769$ & ou contexlo; data das leituras (nó \\
\hline $4,4,111$ & fomato DD/MM/AMAA - año Din 4 \\
\hline $5,3,222$ & digitos) \\
\hline $6,8,868$ & 5a Linha ent diante - hóra (de 1 a 24), \\
\hline 7,0 & valor medido (eni MWh, cont ate 3 \\
\hline & (casas decimals) \\
\hline 9,0 (etc) & \\
\hline
\end{tabular}

Figura 5 - Exemplo de arquivo no formato "txt"

Fonte: Baroni Neto e Moretti (2007, p. 29).

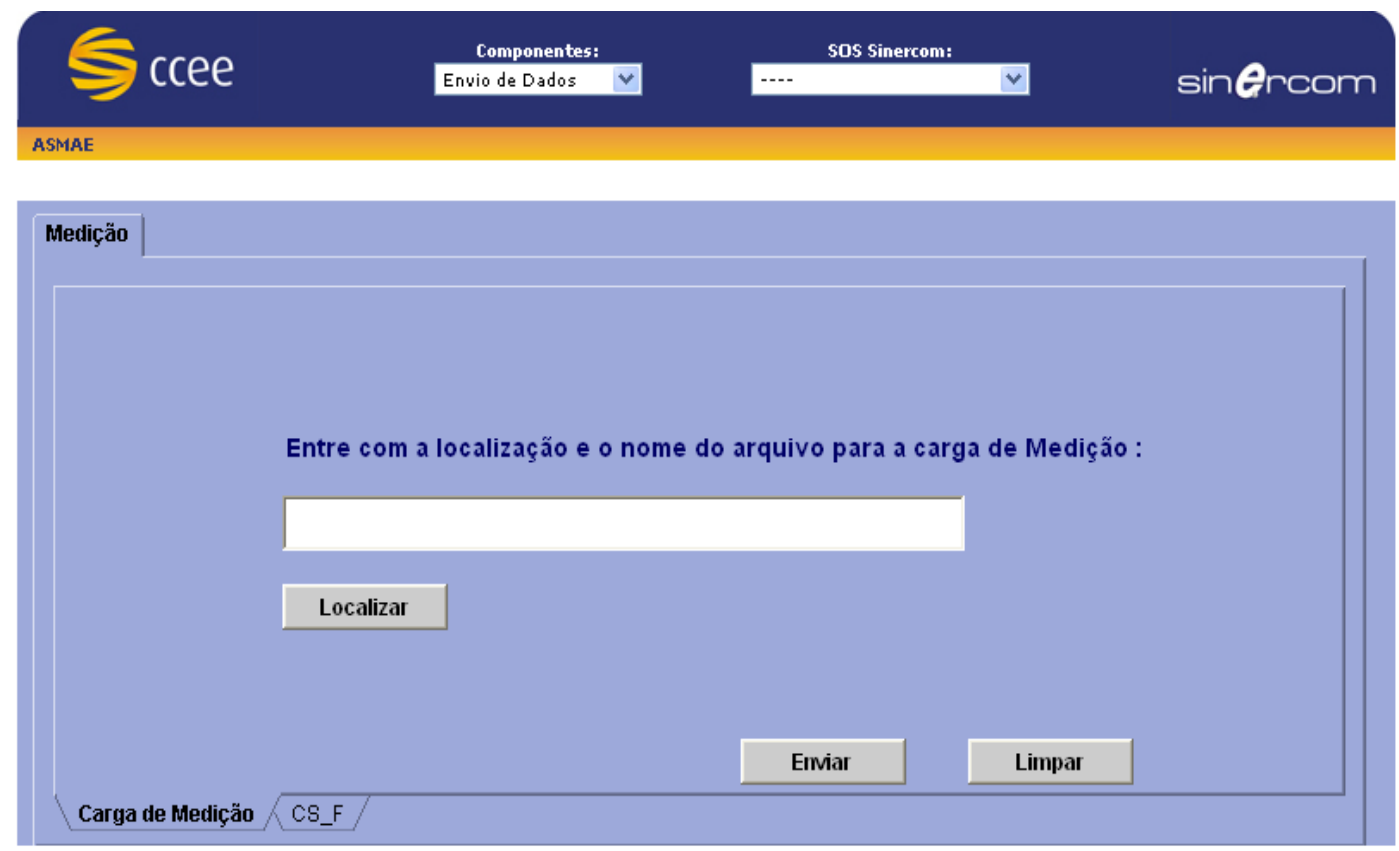

Figura 6 - Tela para inserção manual de dados de medição

Fonte: Baroni Neto e Moretti (2007, p. 30).

Para a substituição do processo iniciou-se, em janeiro de 2004, a utilização na contabilização da CCEE de parte dos dados coletados automaticamente pelos medidores de apenas um Agente de Mercado como teste piloto, sendo que a partir do mês subseqüente foram incluídos novos Agentes de forma gradativa. 
Atualmente o SCDE possui cadastrado na sua base de dados aproximadamente 9000 (nove mil) medidores (conforme modelos identificados na Tabela 2). Em um curto espaço de tempo a tendência é de se atingir algo em torno de 10000 (dez mil) medidores, fato este que se torna preocupação constante para que o SCDE possa permitir a expansão da quantidade de medidores a serem coletados sem prejuízo no desempenho das coletas de dados, como também dos usuários do Sistema.

Aproximadamente $90 \%$ dos medidores possuem coleta de dados via coleta passiva (UCM) e o restante as coletas são realizadas pelo processo de coleta direta aos medidores.

Em ambos os processos é necessário se realizar Inspeção Lógica dos dados de medição, que é o processo de coleta de dados de memória de massa, memória de programação e demais registros diretamente dos medidores, com o objetivo de comparar os dados obtidos com os cadastrados na base de dados do SCDE, tais como dados de energia, número de série do medidor e período de integração.

Esta comparação é necessária principalmente para os dados coletados via coleta passiva (UCM - Unidade Central de Coleta de Medição do Agente), pois os arquivos tipo 'XML' de coleta podem ser alterados pelo agente. Caso ocorra divergência, o dado a ser utilizado na contabilização será o obtido diretamente do medidor. No monitoramento dos processos, caso ocorram divergências, o agente é notificado para realizar as correções necessárias.

Para entender o processo de coleta de dados, abaixo estão ilustradas as arquiteturas básicas para permitir a coleta dos dados de medição via Canais dedicados e via Central de Aquisição dos dados do Agente, embora em ambos os casos devam permitir a coleta de Inspeção Lógica. 

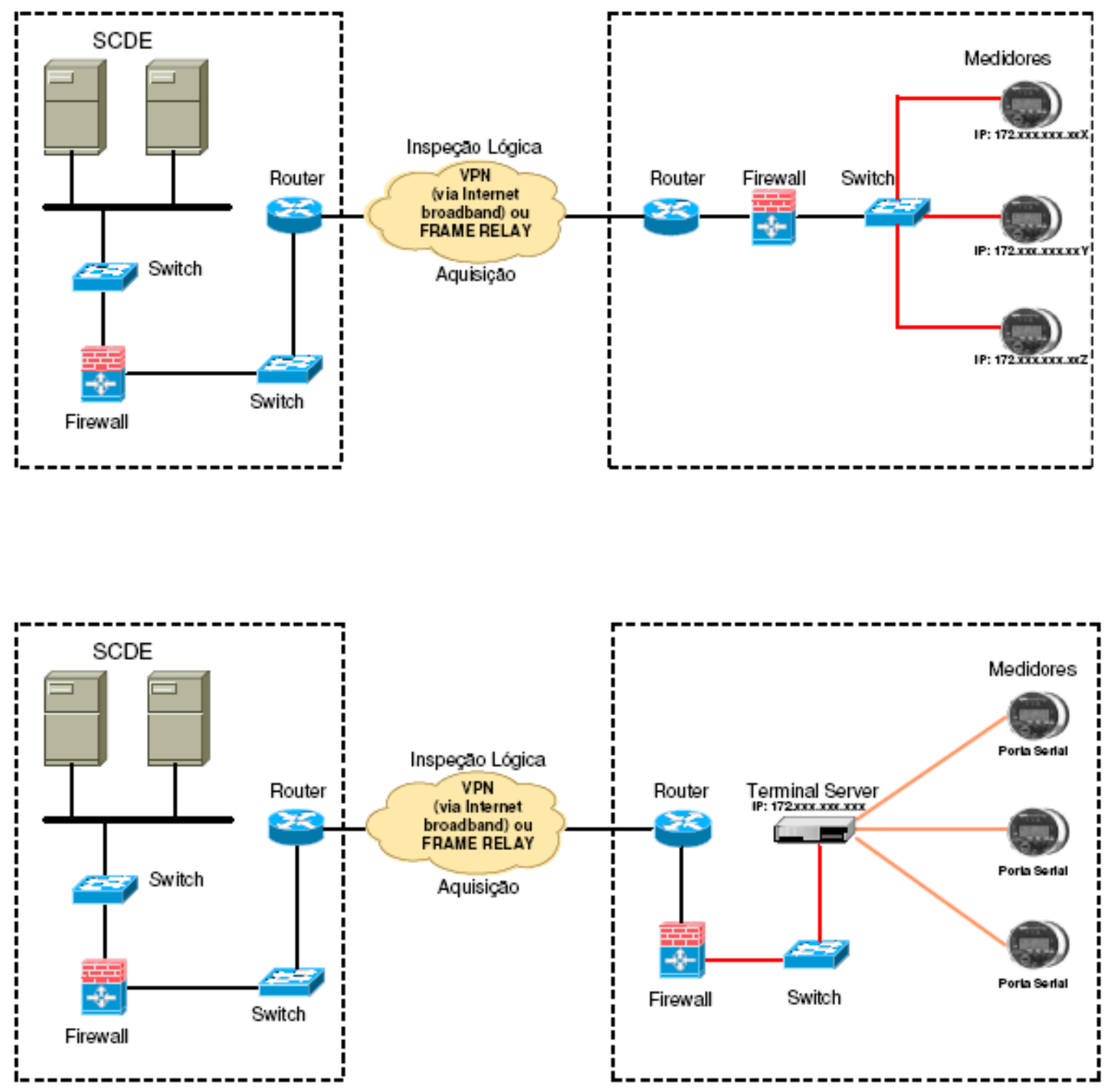

Figura 7 - Coleta de Dados de Medição via Canais Dedicados, pela CCEE

Fonte: ONS (2008, p. 27).

Para a figura acima, torna-se importante realizar alguns esclarecimentos, sendo:

- Meio de comunicação: Canal VPN (canal de Internet Broadband dedicada e com IP fixo) ou Frame Relay, configurado entre a rede da CCEE e a rede do Agente. $O$ range de IP's de acesso aos medidores será especificado pela CCEE. Caso os medidores já possuam endereçamento da rede do agente (ex. 10.0.0.0) será necessário criar um NAT (Network Address Translation) para permitir a associação dos IP's dos medidores aos endereços do range fornecido pela CCEE;

- Medidores de energia: Acesso através da porta Ethernet de cada medidor. O medidor deverá permitir mais de um acesso simultâneo através da porta Ethernet a fim de que se atenda a especificação de porta exclusiva de uso da CCEE; 
- Aquisição: O SCDE (Sistema de Coleta de Dados de Energia) gerenciará as requisições de coleta;

- Inspeção Lógica: O SCDE gerenciará as requisições de coleta. (CCEE, 2008, www.ccee.org.br, em 'seção Medição/SCDE/Formas de Comunicação').
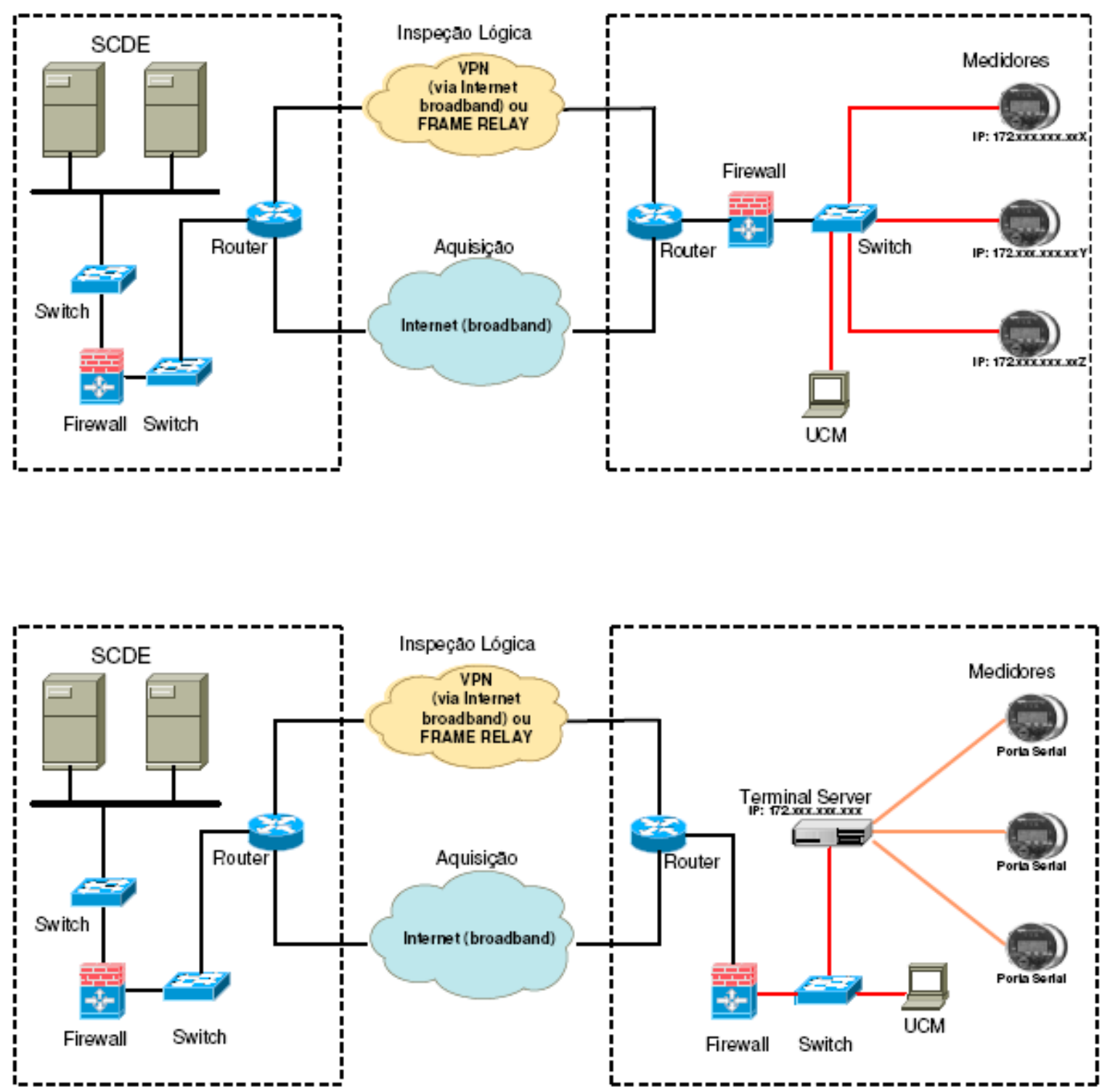

Figura 8 - Coleta de Dados de Medição via Central de Aquisição de Dados do Agente Responsável, pela CCEE (forma alternativa)

Fonte: ONS (2008, Submódulo 12.2, p. 28).

Para a figura 8, torna-se importante realizar alguns esclarecimentos, sendo:

- Meio de comunicação: Canal Internet (broadband) para envio dos XML's pela UCM e Inspeção Lógica através de Linha Discada. Cada medidor deverá estar ligado a um número de telefone distinto. $O$ acesso do agente aos 
medidores para aquisição dos dados na UCM poderá ser feito da maneira que $\mathrm{o}$ agente decidir;

- Medidores de energia: Os medidores deverão permitir mais de um acesso simultâneo através de suas portas de comunicação a fim de que se atenda a especificação de porta exclusiva de uso da CCEE;

- Aquisição: A UCM envia os dados de medição coletados em arquivos XML através do Client SCDE (conectado á Internet);

- Inspeção Lógica: O SCDE efetua inspeção sobre os Medidores de cada localidade através de Linha Discada (a porta serial dos Medidores para Inspeção Lógica deverá ser distinta da porta utilizada pelo Agente para a Aquisição de dados);

- Conversor RS-232/485(caso necessário) = Conversor de interface (converte uma interface RS-232 em interface RS-485). (CCEE, 2008, www.ccee.org.br, em 'seção Medição/SCDE/Formas de Comunicação').

Para os Agentes que pretendem implantar seus Sistemas de Medição para Faturamento, precisam verificar o que não se adequa às suas necessidades em virtude de que deve atender não só a CCEE, mas também suas próprias necessidades internas, de forma que possa integrar a solução aos demais processos ou Sistemas que eventualmente já tenham implantado. O disposto aqui deve ser complementado em pesquisa pelo Agente aos requisitos técnicos previsto no Anexo I do Submódulo 12.2 dos Procedimentos de Rede do ONS.

O SCDE passa atualmente pelo processo de melhorias e implementação de novas funcionalidades, visando permitir o acompanhamento da evolução das necessidades de realização da coleta dos dados de medição, como também prover aos usuários maior flexibilidade operacional em suas operações diárias.

Como evolução, estão sendo implementadas as funcionalidades: Ajuste de Dados, Notificações, Apuração das Penalidades de Medição, Reestruturação do Módulo de Cadastro e Gerenciamento da Coleta.

A figura 9 representa os Módulos do SCDE, considerando os novos Módulos. 


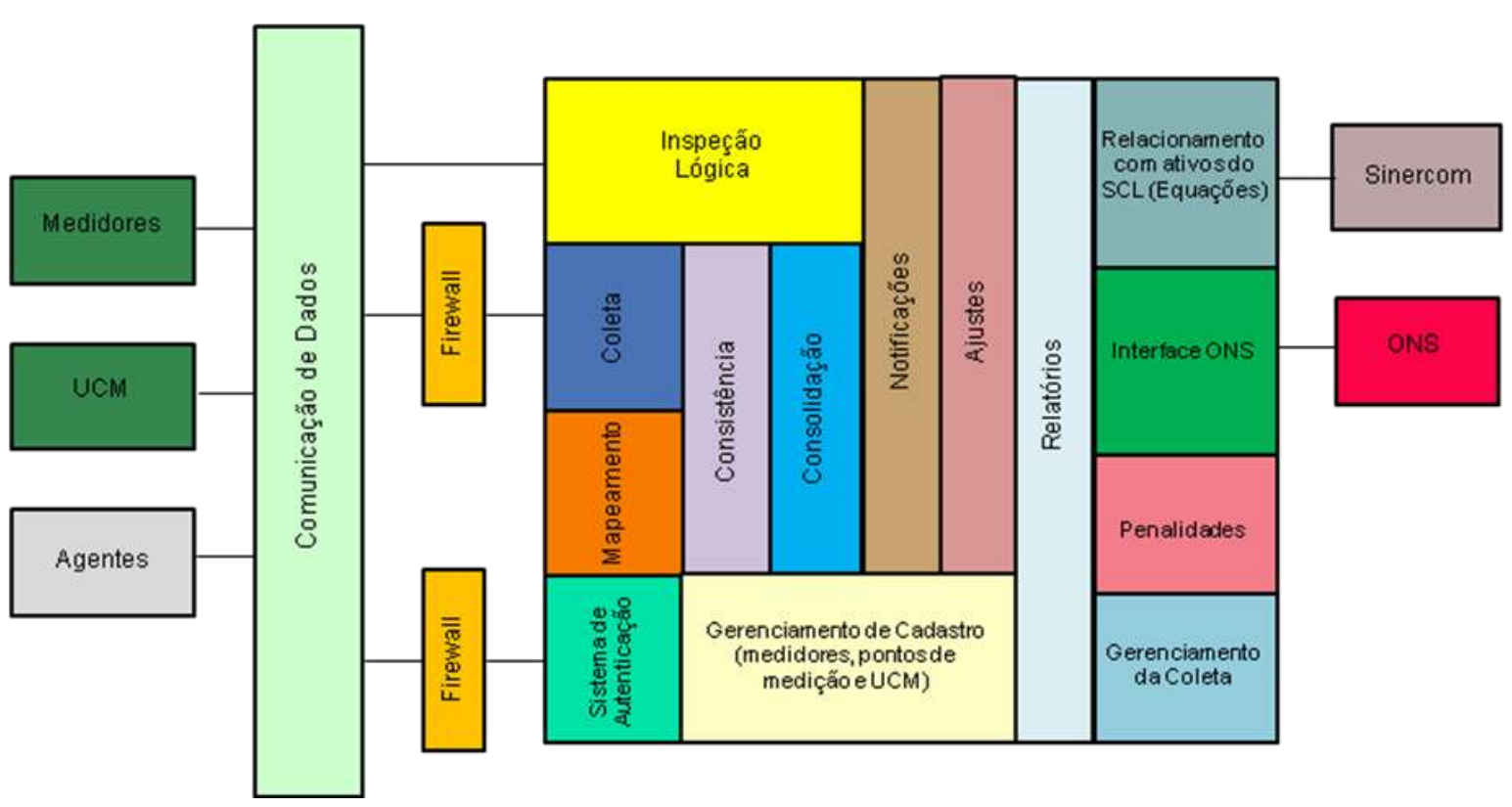

Figura 9 - Visão Atual do SCDE (Sistema de Coleta de Dados de Energia)

Segue descritivo dos Módulos adicionais a serem implementados:

a) Ajuste de Dados: O processo de ajuste de dados de medição, é um processo pelo qual o Agente de Medição responsável por determinados Pontos de Medição, poderá solicitar alterações nos dados de medidas finais de energia coletados, a partir das seguintes formas de solicitação: Ajuste Manual; e File Up-Load (Arquivo XML);

Além disso, o módulo de ajuste também possuirá um cadastro para períodos de abertura de solicitações e um cadastro para justificativas de aprovação/reprovação por parte do Analista de Medição da CCEE.

b) Notificações: Este módulo visa atender o definido no Módulo 12 dos Procedimentos de Rede do ONS, onde o Agente responsável pela manutenção do SMF deve encaminhar para a CCEE os Boletins de Ocorrência em Medição, visando informar sobre eventuais intervenções preventivas ou corretivas. Os usuários deste módulo serão:

- Analista de Medição da CCEE - responsável por analisar as notificações e solicitar a Inspeção Física; 
- Agente de Medição - responsável por solicitar/cadastrar notificações. Um Agente de Medição só poderá solicitar uma notificação para um Ponto de Medição Físico caso ele seja o Agente de Medição responsável pelo ponto na vigência válida para a data de solicitação;

- ONS - responsável por cadastrar as Solicitações de Inspeção Física.

c) Reestruturação do Cadastro: Avaliação dos atributos existentes no cadastro dos Pontos de Medição, visando atualização das informações necessárias aos processos internos da CCEE, ONS e Agentes.

d) Apuração das Penalidades de medição: Integração do processo de coleta ao de apuração das penalidades de medição, visando apurar possíveis irregularidades referente a dados faltantes de medição e impossibilidade de acesso aos medidores (Inspeção Lógica).

e) Gerenciamento de Coleta: Incremento do processo de gerenciamento de coleta de dados visando melhoria nos processos existentes, como também obtenção de novos produtos oriundos do processo.

f) Relatórios: Atualização dos relatórios existentes e especificação/ desenvolvimento de novos relatórios em função da implantação de novos Módulos no Sistema.

O Sistema deve permitir se agregar novas funcionalidades visando atender as necessidades do mercado no que se refere à medição de energia elétrica, permitindo a ampliação contínua ao acesso para os novos Agentes de Medição, embora a performance necessária para operar dentro de condições normais frente às ampliações futuras do mercado deva ser permanentemente garantida. 


\section{PANORAMA DE IMPLANTAÇÃO DE SISTEMAS DE MEDIÇÃO EM OUTROS MERCADOS}

O intuito da análise de mercados como o da Argentina e Colômbia é de identificar diferenças significativas nos requisitos técnicos dos Sistemas de Medição para Faturamento. Constata-se que para os pontos, cujo nível de tensão existe maior preocupação com as questões de precisão, o fluxo de energia elétrica são mais significativos.

\subsection{Análise do mercado Argentino}

A Argentina sofreu uma profunda alteração com a publicação da Lei n. $² 4.065$, também conhecida como Marco Regulatório (MR) do setor elétrico. Com a sua entrada em vigor, o Estado passou de uma posição de administrador e planificador para uma posição de supervisor e regulador da atividade. O sistema elétrico até então verticalmente integrado, sofreu também, uma profunda alteração que passou pela desverticalização e privatização do setor.

O MR cria e estabelece as funções de organismos inexistentes até a privatização e concessão do setor, como é o caso da Compañía Administradora del Mercado Mayorista Eléctrico Sociedad Anónima (CAMMESA) e da Ente Nacional Regulador de la Electricidad (ENRE).

A função técnica de despacho atribuída à CAMMESA é realizada através do Organismo Encargado Del Despacho (OED).

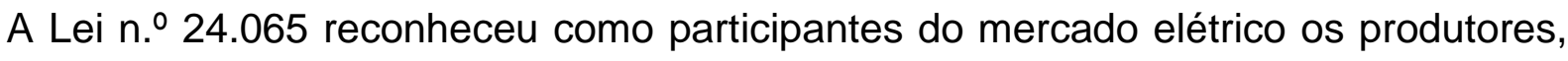
os transportadores, os distribuidores e os grandes consumidores e, com a completa separação do exercício das atividades do setor elétrico, a produção foi declarada de 'interesse geral' permitindo-se, assim, a livre concorrência nesse setor de atividade. 
Pelo contrário, o transporte e a distribuição foram declarados 'serviços públicos', continuando-se a exercer estas atividades em regime de monopólio natural, através de um contrato de concessão.

A Lei $n$. 24.065 definiu como grandes consumidores aqueles que contratam uma potência superior a $5 \mathrm{MW}$. Contudo, o conceito de grande consumidor sofreu ao longo dos anos e após várias resoluções inúmeras alterações, sendo a definição atual de grande consumidor a publicada na Resolução $n .{ }^{\circ}$ 423/98. A Resolução $n .{ }^{\circ}$ 423/98 distribui os grandes consumidores por categorias, dependentes da potência contratada, da energia anual consumida e do nível de tensão. Na Tabela 2 efetua-se uma descrição das categorias para os grandes consumidores, bem como os requisitos técnicos que os mesmos devem satisfazer.

Tabela 2 - Categorias e requisitos técnicos dos grandes consumidores

\begin{tabular}{cccc}
\hline Categoria & $\begin{array}{c}\text { Potência } \\
\text { Mínima }\end{array}$ & $\begin{array}{c}\text { Energia } \\
\text { Mínima }\end{array}$ & $\begin{array}{c}\text { Nível de } \\
\text { Tensão }\end{array}$ \\
\hline Gran Usuario Mayor (GUMA) & $1 \mathrm{MW}$ & $4830 \mathrm{MWh}$ & Alta, Média e Baixa Tensão $(<1 \mathrm{kV})$ \\
Gran Usuario Menor (GUME) & $0.1 \mathrm{MW}-2 \mathrm{MW}$ & Alta, Média e Baixa Tensão $(<1 \mathrm{kV})$ \\
Gran Usuario Particular (GUPA) & $50 \mathrm{~kW}-0.1 \mathrm{MW}$ & Alta, Média e Baixa Tensão $(<1 \mathrm{kV})$ \\
\hline
\end{tabular}

Fonte: Adaptado de Butera (2000, p.10).

A Secretaría de Energía de La Nacion emitiu a Resolución ํำ164/92, que por sua vez dentre outras determinações, incluía a instalação de um Sistema de Medição nas fronteiras elétricas de todo o mercado argentino composto de Geradores, Transmissores, Distribuidores e Grandes Consumidores (demanda maior que 1 $M W)$. Outra determinação era a fixação de prazo de instalação que era de 10 meses, como também definia a forma de repartir os gastos entre os Agentes participantes do Mercado Eléctrico Mayorista (MEM).

Com referência aos aspetos técnicos, pode-se citar que os equipamentos devem atender: 
- Os medidores de energia devem ser trifásicos, de 3 elementos (devem conter emissores de pulsos proporcionais a energia medida);

- Registradores de demanda média de 15 minutos, com memória de massa que permita armazenar o registro dos dados por um período mínimo de 35 (trinta e cinco) dias;

- Os medidores poderiam ser multi-função;

- Os Registradores deveriam possuir modem com a finalidade de que diariamente ocorresse a coleta dos dados medidos;

- Devem possuir senha de acesso para impedir a comunicação aos medidores por pessoas não autorizadas;

A tabela 3 mostra as características dos equipamentos e classe de exatidão:

Tabela 3 - Características de Equipamentos e Classe de Exatidão Argentina

\begin{tabular}{l|c|c|c|c}
\hline \multicolumn{5}{c}{ Mercado Argentino - Características de Equipamentos e Classe de Exatidão } \\
\hline Instalação & TC & TP & Medidor Principal & Medidor Retaguarda \\
Interconexões $\geq 132 \mathrm{KV}$ & 0,2 & 0,2 & 0,2 & 0,2 \\
Grupos $\geq 20 \mathrm{MW}$ & 0,2 & 0,2 & 0,2 & 0,2 \\
Interconexão entre Transmissoras & 0,5 & 0,5 & 0,5 & Não obrigatório \\
Interconexões $\leq 132 \mathrm{KV}$ & 0,5 & 0,5 & 0,5 & Não obrigatório \\
Grupos < 20 MW & 0,5 & 0,5 & 0,5 & Não obrigatório \\
Serviços internos & 0,5 & 0,5 & 0,5 & Não obrigatório \\
\hline
\end{tabular}

Fonte: Saenz (1996, p.1).

Com relação aos Transformadores de Instrumentos pode-se destacar que os mesmos devem ter seus circuitos carregados entre 25 e 100\% da potência nominal para que se possa garantir a classe de exatidão, como também a queda de tensão não deve exceder de $0,1 \%$ da tensão nominal.

Outra informação importante, é que o Centro Principal de Coleta situa-se na CAMMESA na província de Santa Fé.

No quesito comunicação de dados, se prioriza a utilização dos sistemas particulares em relação às públicas, pois tais empresas são responsáveis pela comunicação entre os medidores e os Centros de Coleta de Dados. 
O Mercado Eléctrico Mayorista (MEM) possui equipamentos com classe de exatidão 0,2 e 0,5\%, e conforme suas informações operam diariamente com índice de coleta em torno de $97 \%$. Após 5 (cinco) dias do término do mês em referência, são disponibilizadas as faturas aos Agentes de Mercado.

Um dos tipos de medidores utilizados, é o modelo Q1000 do fabricante ITRON que por sua vez também é utilizado pelos Agentes no mercado brasileiro.

A classe dos equipamentos utilizados é similar ao utilizado no Brasil, embora se observe divergência quanto à classe dos Transformadores para Instrumentos utilizados.

\subsection{Análise do mercado Colombiano}

A Colômbia é um dos países em que tem ocorrido um processo de reestruturação da indústria de energia elétrica. $O$ novo esquema de mercado entrou em funcionamento no dia 20 de julho de 1995, com a entrada da Bolsa de Energia. A partir de então, mudou-se de um despacho centralizado, determinado pela otimização do uso dos recursos energéticos, para um despacho econômico de geração, utilizando preços de oferta e declaração de disponibilidade, fornecida diariamente pelos agentes geradores.

Realizou-se a abertura para permitir a participação do investimento privado, e seguindo um esquema similar a dos países pioneiros nesse desenvolvimento, em especial o Reino Unido.

Essa reestruturação se realizou com as leis 142 (Lei de Serviços Públicos) e 143 (Lei Elétrica) de 1994, que definiram o marco regulatório para estabelecer as condições que permitissem que seu desenvolvimento fosse determinado pela competição. Essas leis criaram o Mercado Atacadista de Energia Elétrica. A regulamentação desse mercado foi desenvolvida pela Comisión de Regulación de Energía y Gas - CREG. 
$\mathrm{Na}$ figura 10 estão dispostas as principais atividades da cadeia produtiva do Mercado Elétrico Colombiano.

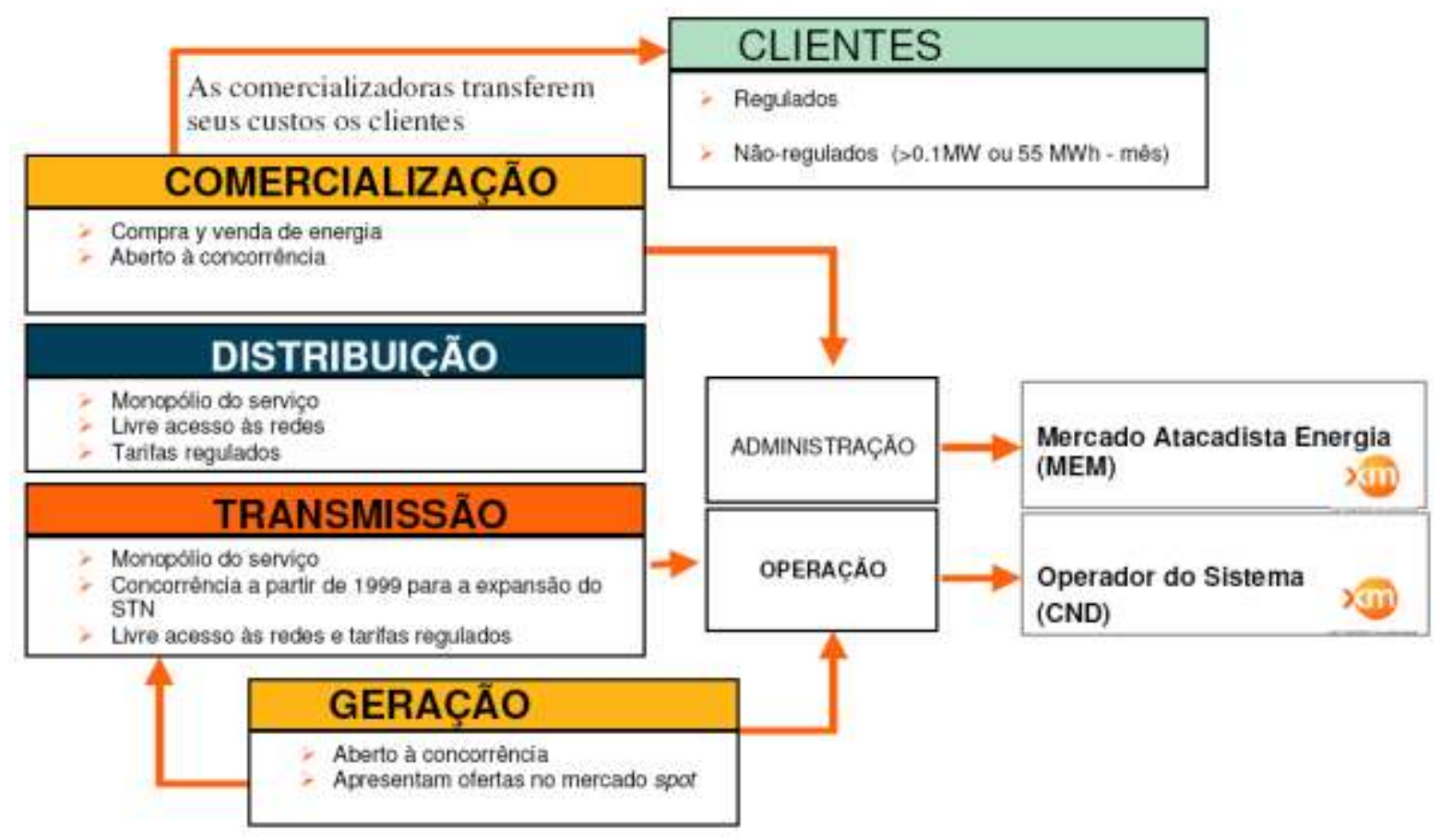

Figura 10 - Cadeia Produtiva Mercado Colombiano Fonte: Ruiz e Mesa (2006, p. 4).

A energia é comercializada em dois mercados competitivos: a) mercado de curto prazo, em que a energia é comercializada em base horária para o dia seguinte; e b) mercado de longo prazo, em que a energia também é comercializada em base horária, mas para períodos mais longos através de contratos financeiros bilaterais. Na Bolsa de Energia, somente preços de oferta de geradores ( $\$ / \mathrm{MW}$ ) e disponibilidade declarada $(\mathrm{MW})$ neste mercado para cada uma das fontes de geração. Preços e disponibilidade são submetidos ao Operador Nacional do Sistema (CND) para cada hora do dia de operação. A demanda não é flexível, isto é, não existe licitação nem para os consumidores nem para as comercializadoras, e é definida através de uma previsão de demanda que é acordada entre o CND e os operadores da rede. (RUIZ e MESA, 2006, p. 4).

Usando a oferta de preços, disponibilidade declarada, restrições de transmissão (representadas pelos limites de intercâmbios ou modelo de transmissão DC), restrições locais e regionais (representadas pela confiabilidade de geração "must run") reserva de AGC, características das unidades geradoras e previsão da demanda, o CND determina a relação de despacho ótimo para cada unidade térmica e hidráulica para as próximas $24 \mathrm{~h}$ do dia seguinte. (RUIZ e MESA, 2006, p. 4).

Existem também as interligações internacionais entre Colômbia e Equador que estão interligados desde março de 2003. Segundo Ruiz e Mesa (2006, p. 4): 
A interligação desses dois diferentes sistemas elétricos tem trazido vantagens para ambos os países. A principal vantagem são os custos operacionais evitados. Para um determinado momento, a energia pode ser transferida de um sistema para outro através da interligação pelo país que tem o menor custo de energia. Outra vantagem é o aumento da disponibilidade de energia como resultado da otimização da utilização das fontes dos dois países ao mesmo tempo. (RUIZ e MESA, 2006, p. 4).

Atualmente, existem duas interligações que conectam os sistemas elétricos da Colômbia e Equador. O primeiro em 220 kV tem uma capacidade de 250 MW e o segundo em $138 \mathrm{kV}$, com uma capacidade de $35 \mathrm{MW}$. Em janeiro de 2007, entrará em operação um novo circuito em 220 kV, com uma capacidade de 250 MW. (RUIZ e MESA, 2006, p. 4).

O Sistema Elétrico Colombiano é consistido de uma rede interconectada simples que atende aproximadamente $99 \%$ da demanda. A demanda restante, um pouco mais de $1 \%$ do total, é suprido por geração local. (RUIZ e MESA, 2006, p. 2).

Em 2005, o pico de carga foi $8.639 \mathrm{MW}$. A demanda de energia registrada foi de 48,829 GWh, com um aumento de $4,14 \%$ em relação a 2004 . O consumo é distribuído em diferentes setores: $43,0 \%$ residencial, $34 \%$ industrial e $23 \%$ nos seguintes setores: comercial, órgãos do governo, iluminação pública e outros consumos. A capacidade instalada total é 13.365,7 MW composta por $64 \%$ de usinas hidrelétricas e $36 \%$ de usinas térmicas. (RUIZ e MESA, 2006, p. 3).

Na Figura 11, pode-se observar as principais características do Sistema Elétrico e a distribuição geográfica da capacidade instalada e demanda na Colômbia.
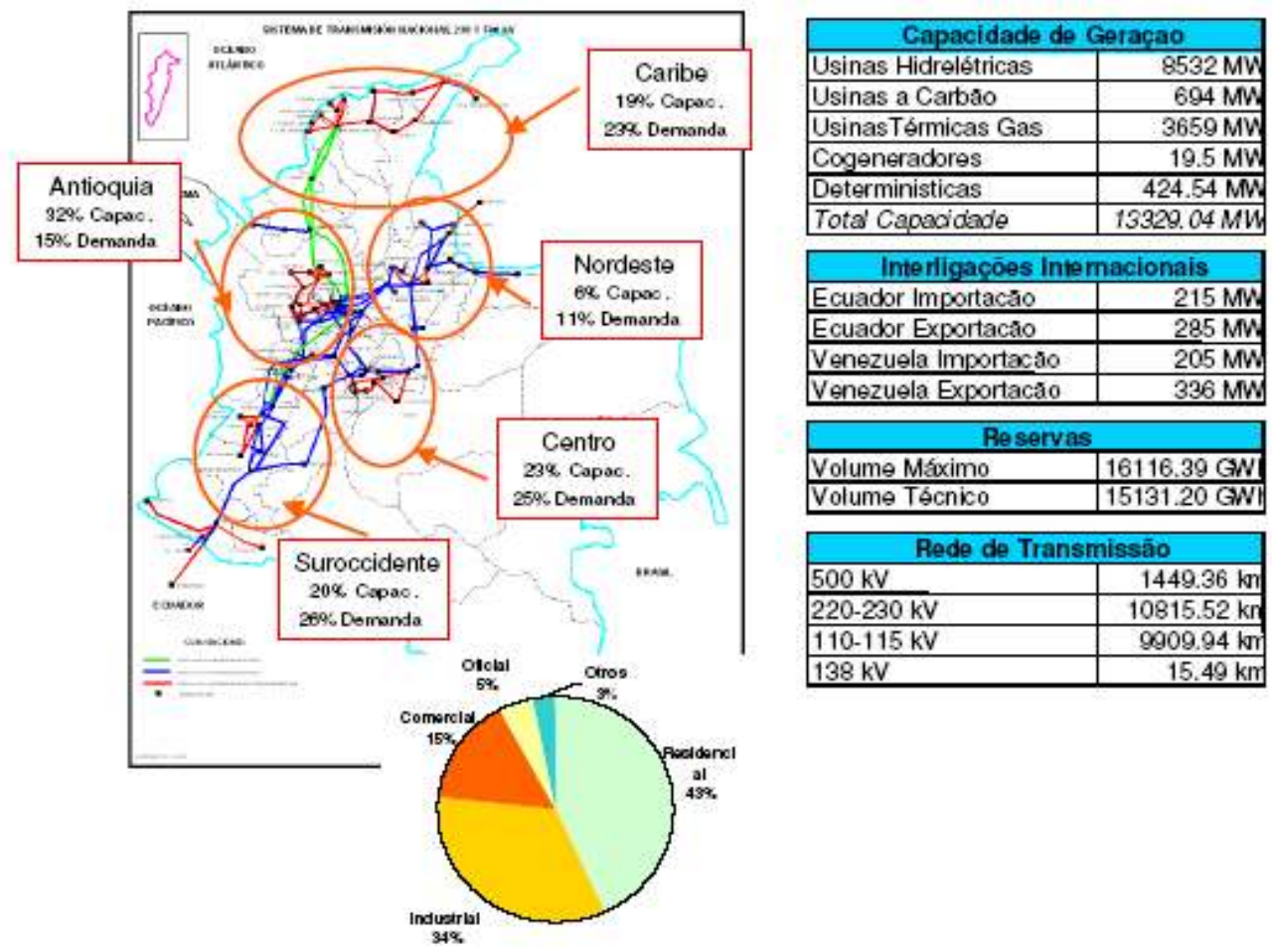

\begin{tabular}{|l|r|}
\hline \multicolumn{2}{|c|}{ Rede de Transmissāo } \\
\hline $500 \mathrm{kV}$ & $1449.36 \mathrm{~km}$ \\
\hline $220-230 \mathrm{kV}$ & $10815.52 \mathrm{kr}$ \\
\hline $110-115 \mathrm{kV}$ & $9909.94 \mathrm{~km}$ \\
\hline $138 \mathrm{kV}$ & $15.49 \mathrm{~km}$ \\
\hline
\end{tabular}

Figura 11 - Principais Características Sistema Elétrico - Colômbia Fonte: Ruiz e Mesa (2006, p. 3). 
A tabela 4 indica os requisitos técnicos dos equipamentos que são similares ao mercado brasileiro, embora exista flexibilização nas classes de exatidão $(0,5 \%)$ para níveis de tensão inferiores a 110 kV e transferências médias horárias menores que 20 MWh, fato este que não ocorre no mercado brasileiro. Esta flexibilização é importante se notar, pois poderá servir de base quando eventualmente ocorrer estudos no sentido de ocorrer algum tipo de flexibilização nos requisitos técnicos da Especificação Técnica SMF.

Tabela 4 - Características de Equipamentos e Classe de Exatidão Colômbia

\begin{tabular}{llccc}
\hline \multicolumn{1}{c}{ INSTALAÇÃO } & TP & TC & MEDIDOR \\
\hline $\begin{array}{l}\text { Fronteiras com tensão maiores ou iguais a } 110 \mathrm{kV} \text { ou } \\
\text { transferências médias horárias maiores ou iguais a } 20 \mathrm{MWh} \text {. }\end{array}$ & 0,2 & 0,2 \\
$\begin{array}{l}\text { Fronteiras com tensão menores que } 110 \mathrm{kV} \text { e transferências } \\
\text { médias horárias menores que } 20 \mathrm{MWh} .\end{array}$ & 0,5 & 0,5 & 0,5 \\
Serviços Auxiliares. & 0,5 & 0,5 & 0,5 \\
\hline
\end{tabular}

Fonte: Asociación Colombiana de Comercializadores de Energía

Os equipamentos possuem classes similares (mercados brasileiro e colombiano), embora até pelas características distintas dos Sistemas Elétricos principalmente pelo porte e dimensões do sistema, é que depara-se com inúmeras questões que atualmente tem-se de superar para instalação e/ou adequação dos Sistemas de Medição para Faturamento no mercado brasileiro.

As flexibilizações observadas nos mercados Argentino e Colombiano podem ser fator importante quando do estabelecimento de estudos para balizar possíveis flexibilizações na Especificação Técnica que atualmente estabelece os requisitos técnicos a serem atendidos no âmbito do mercado Brasileiro, quando das adequações dos Sistemas de Medição para Faturamento. 


\section{DISCUSSÕES EXISTENTES NO MERCADO BRASILEIRO}

Atualmente existem algumas discussões no âmbito do Setor Elétrico Brasileiro, sobre a implantação dos Sistemas de Medição para Faturamento. Pois, embora exista todo o aparato regulatório apresentado no Capítulo 3, freqüentemente surgem sugestões e discussões sobre a necessidade de se aprimorar os atos existentes ou até mesmo a criação de novos.

Neste contexto, surgem questões que podem tornar incertas a seqüência dos processos de implantação dos Sistemas de Medição para Faturamento, uma vez que temas como os relacionados a seguir são muitas vezes objeto de questionamentos oficiais junto a CCEE, ONS e ANEEL, e que normalmente visam solicitar permissão para proceder de forma diferenciada do que atualmente a legislação e especificação técnica estabelecem:

- O Distribuidor (Agente de Medição) pode exigir do Cliente Livre a doação dos equipamentos de medição conforme padrão técnico próprio;

- Não concordância por parte dos Clientes Livres, no que se refere aos custos apresentados pelos distribuidores;

- Divergências significativas nos custos para aquisição de equipamentos de medição por Agentes diferentes;

- Administrar custos de leitura e envio dos dados para a CCEE, uma vez que não existem custos referenciais;

- O Distribuidor (Agente de Medição) pode exigir do Cliente Livre a doação dos equipamentos de medição, após o processo de adequação/instalação, pois o distribuidor é o Agente responsável pela manutenção do sistema;

- Atender aos Clientes Livres no que concerne à implantação dos sistemas com empresas de sua livre escolha visando o estabelecimento de concorrência, visando à redução dos custos de adequação/implantação dos Sistemas de Medição para Faturamento; 
- Responsabilidade pelos custos de manutenção dos Sistemas de Medição instalados em Clientes Livres após a implantação;

- Para o caso de instalações compartilhadas por mais de um Agente (todos Clientes Livres), torna-se necessário a definição do responsável financeiro pela adequação dos Sistemas de Medição para Faturamento do Ponto de Conexão com a Distribuidora;

- Para o caso de instalações compartilhadas por mais de um Agente (Clientes Livres e Clientes Cativos), torna-se necessária a definição do responsável financeiro pela adequação dos Sistemas de Medição para Faturamento do Ponto de Conexão com a Distribuidora e no Ponto de Conexão do Cliente Cativo;

- Implantação de Sistemas de Medição para Faturamento em empreendimentos do PROINFA (Programa de Incentivo às Fontes Alternativas de Energia Elétrica);

- Implantação de Sistemas de Medição para Faturamento em unidades de Auto-produtores;

- Solicitação de Agentes para implantação de Sistemas de Medição para Faturamento em local não regulamentar;

- Implantação de Sistemas de Medição para Faturamento em fronteiras de Submercados e de Intercâmbio Internacional;

- Implantação de Sistemas de Medição para Faturamento dos Agentes Distribuidores que não possuem participação obrigatória na CCEE;

- Possibilidade de flexibilizar os requisitos técnicos para Pontos de Medição que apuram pequenos valores de energia, ou até mesmo a desobrigação de implantação de Sistemas de Comunicação aos medidores, principalmente em locais onde ocorra a dificuldade de implantação de infra-estrutura de comunicação de dados;

- Aceitação de apuração de medição por diferença em instalações em que se torna necessário a instalação de uma quantidade considerável de Sistemas de Medição para Faturamento, o que ocasiona enorme custo a ser suportado pelos Agentes responsáveis; 
Em termos de análise e proposições surgem os seguintes encaminhamentos para a adoção de ações que possibilitem a continuidade dos processos de implantação dos Sistemas de Medição para Faturamento:

a) Com relação à exigência das Distribuidoras em que os Consumidores Livres adotem o mesmo tipo de medidor, conforme padrão técnico próprio, existem duas questões importantes, sendo a primeira a questão de eventualmente permitir ao Consumidor Livre, responsável pelo custeio da adequação e/ou implantação do Sistema de Medição para Faturamento, a conseguir a redução do custo final desta implementação tendo a liberdade de fazer a opção pelo tipo de equipamento que melhor atenda seus critérios de escolha. Por outro lado, existe a questão de que, como a Distribuidora é o Agente de Medição responsável pela coleta dos dados e envio para a CCEE, bem como se responsabiliza por eventuais ajustes de medição, estas empresas necessitam de software específico dos medidores e sem dúvida a adoção de uma única plataforma para todos os medidores (de um único fabricante) pode facilitar as operações diárias das equipes de medição.

Para encaminhamento da solução, pode-se permitir ao Consumidor Livre que opte eventualmente pelo tipo de medidor que melhor o atenda, embora ocorra a necessidade, muitas vezes, de investir valores adicionais para compra do software específico do medidor escolhido e repassá-lo ao Distribuidor, que por sua vez não poderia rejeitar a utilização de outro tipo de equipamento.

Entretanto, o custo final não seja atrativo ao Consumidor Livre, mas de qualquer forma existiria a liberdade de escolha de equipamentos diferentes do padrão da Distribuidora. Deve estar previsto no Contrato de Conexão ao Sistema de Distribuição - CCD estas questões, inclusive a eventual possibilidade do Consumidor Livre remanejar os equipamentos de sua propriedade para serem utilizados em outras unidades consumidoras do mesmo grupo empresarial.

Além da questão da instalação e envio dos dados de medição necessários à CCEE, o Agente Conectado (Distribuidora) necessita também apurar os valores contratados de uso de rede e valores de energia reativa para cobrança de eventual baixo fator de potência, ou seja, abaixo de 0,92. Sendo assim o Agente responsável deverá ter 
todos os recursos técnicos necessários para administrar os dados de medição de sua responsabilidade.

A situação acima mencionada se aplica também quando o Agente conectado for uma empresa de Transmissão.

b) No que diz respeito aos custos repassados aos Consumidores Livres, deve se estabelecer valores de referência visando balizar o valor a ser pago no momento das adequações dos Sistemas de Medição para Faturamento, bem como definir que após a implantação, os custos de manutenção devem ser absorvidos pelos Agentes de Medição, neste caso, os Distribuidores, não cabendo portanto o desembolso de valores adicionais para a aquisição de equipamentos sobressalentes para suportar as manutenções corretivas. Cabe lembrar que apenas o sistema de comunicação poderia ser de responsabilidade dos Consumidores Livres, podendo toda esta questão operacional estar disposta nos Contratos de Uso e Conexão (CCD / CUSD) celebrado entre os Agentes envolvidos.

No âmbito do mercado é normalmente praticado alguns valores, que eventualmente poderiam ser adotados para se estabelecer os custos de referência para adequação dos Sistemas de Medição.

Poderia ser estipulado um valor máximo de referência para estes custos, sendo que como sugestão poderia se criar valores de referência por nível de tensão, da seguinte forma:

- Nível de tensão de 2,3 e $25 \mathrm{KV}$;

- Nível de tensão de 30 a 44 KV;

- Nível de tensão de $69 \mathrm{KV}$;

- Nível de tensão de 88 a 138 KV;

- Nível de tensão igual ou superior a 230 KV;

Os custos devem ser atualizados pelo órgão regulador em função de planilhas de cálculo a serem apresentadas pelos Agentes responsáveis pelas implantações dos Sistemas de Medição para Faturamento, visando o estabelecimento dos valores de 
referência, como também deve ser definido o índice econômico e periodicidade para se reajustar os valores adotados.

Estes custos devem cobrir as implantações considerando os seguintes componentes:

- Projeto de Medição;

- Realização de obras civis nas instalações (caso necessário);

- Aquisição de Medidores;

- Aquisição de Transformadores de Potencial;

- Aquisição de Transformadores de Corrente;

- Aquisição de Painéis de Medição;

- Instalação dos equipamentos e fiação;,

- Parametrização dos medidores;

- Canais de comunicação de dados;

- Comissionamento das instalações;

- Elaboração do relatório final de comissionamento das instalações.

A adoção de valores de referência pode sem dúvida coibir a cobrança de valores considerados eventualmente abusivos e desta forma poderia minimizar os conflitos atuais existentes entre os Agentes envolvidos (principalmente Distribuidores e Clientes Livres).

Uma análise sobre os custos é realizada no Capítulo 9.

c) Outro aspecto a ser definido é o de responsabilidade por custear a adequação quando existem diversos compartilhantes em uma mesma instalação. A figura 12 ilustra esta situação. 


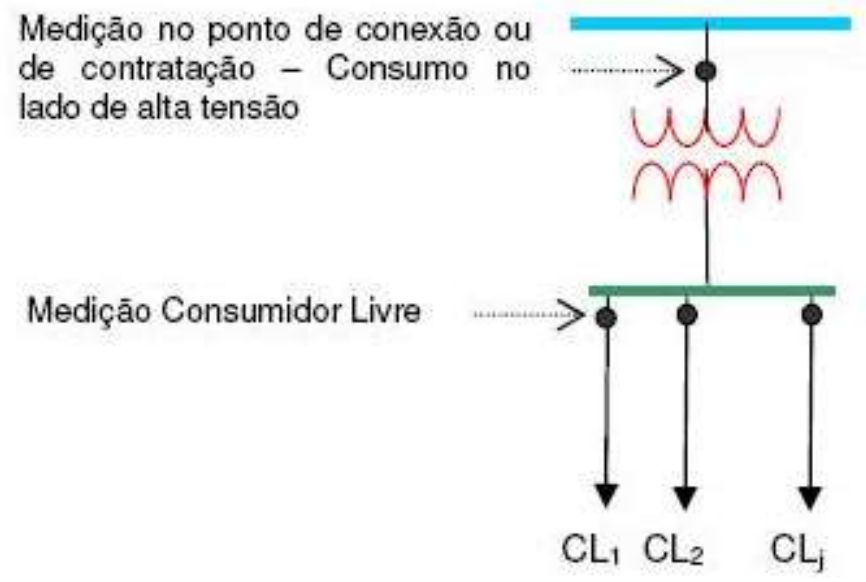

Figura 12 - Configuração de Subestação Compartilhada entre Consumidores Livres Fonte: ONS (2008, p. 6).

Para se apurar corretamente a contabilização dos Consumidores Livres compartilhantes, deve-se apurar os valores de energia para contabilização referidos ao ponto de conexão ou contratação.

"Dessa forma, a medição a ser considerada para faturamento é referida ao ponto de conexão ou contratação e as perdas comuns serão rateadas entre os aproveitamentos, na proporção de seus consumos", conforme apresentado na figura 12. (ONS, 2008, Submódulo 12.6, p. 7).

Para atendimento ao acima exposto, é necessária a instalação de Sistemas de medição conforme a especificação técnica do SMF nos seguintes pontos:

$>$ Na conexão com a rede básica ou concessionária de distribuição local, e $>$ Nos consumidores livres.

Neste caso, normalmente a discussão gira em torno de quem é o responsável por custear a implantação do Sistema de Medição no Ponto de Conexão, sendo que normalmente o entendimento é de que o Agente conectado (Distribuidor ou Transmissor) é o responsável.

Para dirimir tais dúvidas deve-se prever em documento regulatório a responsabilidade por custear a adequação do Ponto de Medição. Inicialmente devese observar qual o Consumidor Livre que migrou inicialmente e respectiva data para 
o ACL, para então em conformidade com o disposto na Resolução 248, de 23 de janeiro de 2007, se definir se a responsabilidade é do Consumidor Livre ou do Agente conectado.

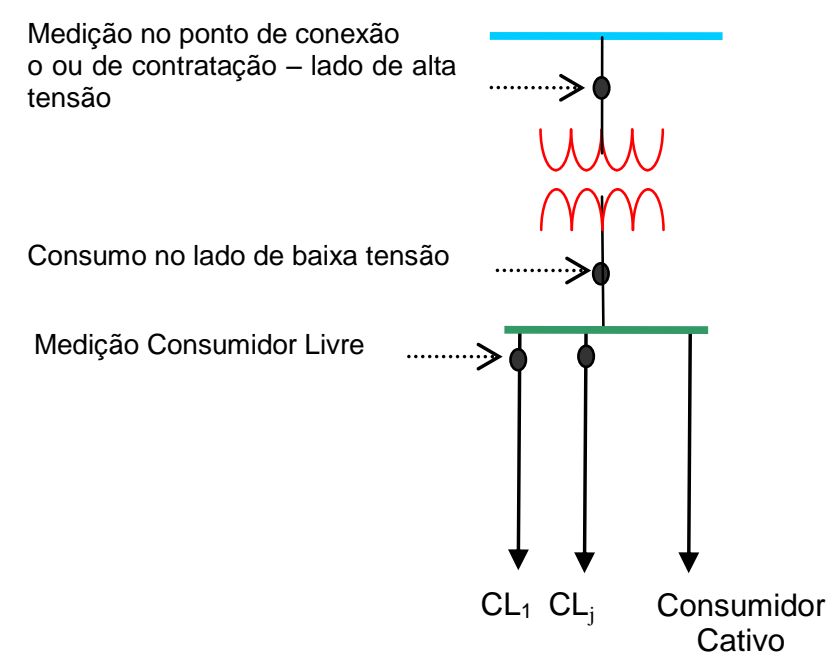

Figura 13 - Configuração de Subestação Compartilhada entre Consumidores Livres e Cativo Fonte: ONS (2008, p. 8).

$\mathrm{Na}$ situação onde exista o compartilhamento de instalações entre Consumidores Livres e Cativos, há também a necessidade da explicitação dos montantes de energia consumidos pelos consumidores separadamente, referidos ao Ponto de Conexão ou contratação.

Portanto, as perdas comuns serão rateadas entre os aproveitamentos, na proporção de seus consumos.

Para esta situação, será necessária a instalação de Sistemas de Medição, no Ponto de Conexão ou de contratação e em cada consumidor livre.

Para possibilitar o rateio de perdas de transformação, torna-se necessário também a instalação de Sistema de Medição no Consumidor Cativo. O mesmo critério pode ser aplicado, ou seja, inicialmente deve-se observar qual o Cliente Livre que primeiro migrou e respectiva data para o $A C L$, para então em conformidade com o disposto na Resolução 248, de 23 de janeiro de 2007, se definir se a responsabilidade é do Cliente Livre ou do Agente conectado a responsabilidade por custear a adequação do Sistema de medição para Faturamento da unidade do Consumidor Cativo. 
d) Para os empreendimentos do PROINFA, está definido na Resolução Normativa ANEEL nำ 062, de 05 de maio de 2004 a necessidade de instalação de Sistema de Medição em todas as Unidades Geradoras participantes do referido Programa. Para os empreendimentos que não são despachados centralizadamente pelo ONS, e geram energia integralmente para o PROINFA, como é o caso de Pequenas Centrais Hidrelétricas - $\mathrm{PCH}$ e Usinas Eólicas, poderia ser definida a medição apenas no Ponto de Conexão com o Agente conectado.

$\mathrm{Na}$ situação de existência de contratos de venda de energia com terceiros além do PROINFA, como também atender o consumo interno da Usina, então seria necessária a instalação de Sistema de Medição em todas as Unidades Geradoras participantes do Programa além do Ponto de Conexão com o Agente conectado.

A constante atualização do Módulo 12 dos Procedimentos de Rede é primordial, visando contemplar estas situações, para que os Agentes que participam do referido Programa possam balizar seus investimentos em Sistemas de Medição mediante o previsto no referido Módulo.

e) A questão referente à implantação de Sistemas de Medição para Faturamento em unidades de Auto-produtores, deve ser analisada a partir do disposto nos documentos Convenção de Comercialização e Módulo 12 dos Procedimentos de Rede do ONS.

A Convenção de Comercialização instituída pela Resolução Normativa ANEEL no 109, de 26 de outubro de 2004, que estabelece as condições de comercialização de energia elétrica e as bases de funcionamento da Câmara de Comercialização de Energia Elétrica - CCEE, sendo que por sua vez a referida Convenção aborda, dentre outros temas, os direitos e obrigações dos Agentes; as diretrizes para elaboração das Regras e Procedimentos de Comercialização; as condições de comercialização de energia elétrica nos Ambientes de Contratação Regulada e Livre e o Processo de Contabilização e Liquidação Financeira das operações realizadas no mercado de curto prazo. 
Neste documento consta no item 'Do processo de contabilização no âmbito da CCEE', no Art. 43 em seu $\S 1^{\circ}$ que:

Os Encargos dos Serviços do Sistema - ESS incidem sobre todo o volume da energia elétrica consumida pelos Agentes da Categoria de Distribuição, pela parcela de energia consumo próprio dos Auto-produtores e pelos Agentes da Categoria de Comercialização, exceto os agentes importadores, em cada período de apuração, e serão rateados de acordo com o estabelecido nas Regras de Comercialização. (ANEEL, 2004, Resolução n.ำ 109, p. 23).

Como também no Anexo I Submódulo 12.2 dos Procedimentos de Rede do ONS em seu item 6, Localização dos Pontos de Medição, está definido que deve ser instalado Sistema de Medição para Faturamento em:

- Na Conexão com Autoprodutor; e

- No Autoprodutor, para a medição de geração bruta.

Deve ser segregado os montantes de geração e consumo neste tipo de empreendimento, embora como situação real os empreendedores defendem que apenas se torna necessário se instalar o Sistema de Medição para Faturamento no Ponto de Conexão com o Agente conectado, apurando-se assim na Contabilização da CCEE apenas o montante de geração excedente do empreendimento.

Esta situação está regulamentada, embora não haja concordância na maioria dos casos em se instalar os Sistemas de Medição conforme a regulamentação exige.

Deve ser solicitada a segregação dos montantes de energia prevendo-se assim a correta Contabilização dos dados, ou seja, se obter exatamente os montantes de energia relacionadas ao consumo e geração do empreendimento. Cabe portanto, deixar bem claro esta situação, aos empreendedores, da necessidade de se instalar os Sistemas de Medição nos Pontos de Medição mapeados pela CCEE.

f) Outro tema importante é a freqüente solicitação dos Agentes em se instalar Sistemas de Medição em local não regulamentar, ou seja, em locais que contradizem o disposto no item 6.1 do Anexo I do Submódulo 12.2 dos Procedimentos de Rede do ONS. Segue o disposto no referido Submódulo: 
6.1 Para atender a contabilização da Câmara de Comercialização de Energia Elétrica - CCEE, dos Encargos de Uso do Sistema de Transmissão e dos Serviços Ancilares, para verificar as capacidades declaradas de geração e o cumprimento das instruções de despacho, as medições de faturamento devem ser instaladas nos seguintes pontos:

- na conexão com a rede básica;

- na conexão com as Demais Instalações de Transmissão Compartilhadas DITC;

- na conexão de consumidor livre;

- nas unidades geradoras onde existe contabilização de serviços ancilares;

- na conexão entre sistemas de agentes que fazem parte da CCEE;

- na interligação internacional (importação e exportação de energia) nos sistemas interligados;

- na interligação entre submercados;

- nas unidades geradoras das usinas despachadas centralizadamente pelo ONS, para medição de geração bruta;

- nas unidades geradoras ou por grupo de unidades geradoras, para a medição de geração líquida;

- na conexão de autoprodutor;

- no autoprodutor, para a medição de geração bruta;

- serviço auxiliar de usinas e subestações. (ONS, 2008, Submódulo 12.2).

Neste aspecto de localização do Ponto de Medição não há nenhuma dúvida, a definição é clara, embora em algumas situações, os Agentes solicitam ao ONS e CCEE para instalar os Sistemas de Medição em local que diferem do acima exposto, sendo a título de exemplo solicitado os seguintes casos:

- Instalação do Sistema de Medição na Subestação do Consumidor Livre cujo ponto regulamentar é o Ponto de Conexão com a Distribuidora, sendo neste caso solicitado se ajustar os dados de medição compensando as perdas na Linha de Conexão entre a Distribuidora e o Cliente Livre. Esta situação muitas vezes está disposta nos Contratos de Uso e Conexão celebrados entre os Agentes envolvidos;

- Instalação do Sistema de Medição na Subestação de Geração Líquida de Usinas, cujo ponto regulamentar é o Ponto de Conexão com a Distribuidora, sendo neste caso solicitado se ajustar os dados de medição compensando as perdas na Linha de Conexão entre a Distribuidora e o Ponto de Geração Líquida, geralmente localizados na Subestação da Usina;

- Nestes casos anteriores os Agentes solicitam também que o ONS e a CCEE aprovem um Pedido de Excepcionalidade para utilização de algoritmo de 
compensação de linhas. Recurso este que alguns medidores de energia elétrica possuem como recurso de parametrização. Este tipo de exceção não é aceito pela CCEE e ONS sendo o Agente instruído a instalar o Sistema de Medição para Faturamento em local regulamentar.

Para estas situações mencionadas, tais práticas não são aceitáveis e caso sejam implantados os Sistemas de Medição em discordância com o definido pela CCEE e ONS, tais casos devem ser objeto de análise específica da ANEEL.

g) Com relação à Implantação de Sistemas de Medição para Faturamento em fronteiras de Submercados e em Pontos de Intercâmbio Internacional, não resta dúvida de que é necessária a instalação. Pois, de forma análoga a outros mercados a medição e respectivo monitoramento dos montantes de energia que fluem internamente entre regiões ou até mesmo entre países é de fundamental importância para permitir: a correta contabilização e verificação dos contratos celebrados entre Agentes de Importação e Exportação de energia; controle de despacho por parte do Operador Nacional quer seja do Brasil ou de outros países, bem como, das questões relativas a garantir a operação dos Sistemas mediante a programação de manutenção e licitação de novas Linhas de Transmissão visando a garantia da confiabilidade do Sistema como um todo.

Conforme previsto no item 6.1 do Anexo I do Submódulo 12.2 dos Procedimentos de Rede do ONS, mencionado no item ' $f$ ', está identificada a necessidade de se instalar Sistema de Medição nestes Pontos.

Em complemento, é importante mencionar a emissão, por parte da ANEEL, da Resolução Normativa no 225, de 18 de julho de 2006, que estabelece as condições para a anuência, no âmbito do SISCOMEX - Sistema Integrado de Comércio Exterior, às operações de importação e de exportação de energia elétrica realizadas no Sistema Interligado Nacional e no Sistema Isolado.

No Art. $2^{\circ}$ que trata dos deveres do Agente de Importação e Exportação de energia elétrica, e mais precisamente no item III, consta a questão do dever em adequar a 
medição às exigências definidas pela ANEEL e aos requisitos previstos no Módulo 12 dos Procedimentos de Rede do ONS.

Não há dúvida sobre a necessidade de se instalar Sistema de Medição para Faturamento nestes Pontos. Fato este que não deve ser questionado pelos Agentes responsáveis pelas implantações, embora em alguns casos não exista a concordância ou até mesmo o pleno entendimento quanto aos deveres dos Agentes de Importação e Exportação de energia elétrica.

h) Com relação à Implantação de Sistemas de Medição para Faturamento dos Agentes Distribuidores que não possuem participação obrigatória na CCEE, este tema é de caráter Regulatório, e devem ser instalados Sistemas de Medição para Faturamento nos Pontos de suprimento de energia a estas empresas. Pois, conforme disposto na Resolução n 344, de 25 de junho de 2002, onde define a entrada em operação comercial do Sistema de Medição para Faturamento de energia elétrica às especificações técnicas e ao cronograma, aprovado na época pelo então Conselho de Administração do Mercado Atacadista de Energia Elétrica MAE e pelo Conselho de Administração do Operador Nacional do Sistema Elétrico ONS.

Esta análise tem 0 intuito de contribuir para identificar nas diversas situações expostas, e se existe a definição Regulatória ou de como deve ser resolvida ou até mesmo encaminhada a solução para os assuntos abordados, pois ao longo de várias tratativas entre os Agentes e entidades do Setor Elétrico, principalmente a CCEE e o ONS, surgem divergências de entendimentos e até a não concordância da questão de implantação dos Sistemas de Medição para Faturamento. O aprimoramento regulatório é fundamental para a solução das situações abordadas, pois disciplinadas as questões de responsabilidades nestes documentos, seria necessário aos Agentes envolvidos celebrarem os contratos de uso e de conexão de rede para estabelecer os quesitos que envolvem a medição de energia elétrica.

i) As questões sobre possíveis flexibilizações são tratadas no Capítulo 10, pois é importante detalhar as flexibilizações já permitidas pela CCEE e ONS, embora as análises são realizadas particularmente para cada caso. 


\section{CUSTOS DE IMPLANTAÇÃO DOS SISTEMAS DE MEDIÇÃO PARA FATURAMENTO}

Todas as questões levantadas permeiam uma situação particular, que é o custo de implantação do Sistema de Medição para Faturamento, pois nos demais pontos de medição, com exceção dos pontos de medição de consumidores livres, as empresas de distribuição, geração e transmissão instalam os seus Sistemas e os custeiam integralmente, já que necessitam medir, registrar e disponibilizar os seus dados de medição para permitir a contabilização do mercado que é realizado no âmbito da CCEE, como também obter dados para operar a rede de sua responsabilidade, efetuar o planejamento da expansão do seu sistema e dados para supervisão e controle.

Os componentes necessários que integram os Sistemas de Medição para Faturamento, devem estar em conformidade com os requisitos técnicos previstos no Anexo I do Submódulo 12 dos Procedimentos de Rede do ONS.

Os equipamentos que compõem os Sistemas são:

- Medidor (Principal e Retaguarda), exceto para Pontos de Geração Bruta onde é necessária apenas a instalação de um único medidor;

- Transformadores de Potencial;

- Transformadores de Corrente;

- Painéis e ligações;

- Canais de Comunicação

Para permitir uma análise dos custos totais para adequação dos Sistemas de Medição para Faturamento é necessário o detalhamento dos itens que compõem esta adequação, que não se restringe apenas aos equipamentos, sendo necessário considerarem os serviços a serem executados. 
Segue descrição dos serviços a serem executados, desde a fase de projeto até a conclusão da adequação que servem de base para quantificar o custo das adequações, sendo evidente que o custo é diferenciado pelo nível de tensão em que a instalação está conectada.

O grande diferencial de custo está associado ao nível de tensão da instalação uma vez que o custo dos Transformadores para Instrumentos (Transformadores de Corrente e Potencial) é muito significativo no custo final, proporcionalmente ao nível de tensão no qual a instalação está conectada.

\subsection{Descrição dos serviços necessários para adequação dos sistemas de medição para faturamento}

Para definição dos custos totais das adequações é importante detalhar as atividades de forma geral e não apenas o custo de aquisição, pois comumente e de forma superficial se associa o custo final com apenas o dispêndio com a aquisição dos equipamentos.

Deve ser preferencialmente dividido os custos em: Gerenciamento; Projeto; Mão-deObra; Equipamentos/ Materiais e Tributos.

Os tributos a serem aplicados e respectivos percentuais estão indicados na Tabela 5.

Tabela 5 - Tributos e respectivos percentuais

\begin{tabular}{|c|c|}
\hline TRIBUTO & VALOR PERCENTUAL (\%) \\
\hline ISS & Conforme Município \\
\hline PIS & 0,65 \\
\hline COFINS & 3,00 \\
\hline IR & 4,80 \\
\hline CSLL & 2,88 \\
\hline INSS (MÃO DE OBRA) & 11,0 \\
\hline
\end{tabular}

Fonte: o autor por meio de pesquisa no mercado (2008). 
Adiante é apresentado o roteiro técnico a ser seguido para execução dos serviços, inclusive quando se tratar de execução de adequações de Sistemas de Medição para Faturamento de Consumidores Livres.

a) Visitas Técnicas e Levantamento de campo:

Esta atividade é necessária para avaliar as particularidades da instalação e para permitir a avaliação do planejamento dos serviços. Para pontos de consumidores livres esta atividade só deve ser realizada após a aceitação dos serviços a serem executados pelo contratado.

b) Projeto Sistema de Medição para Faturamento:

Em geral o projeto executivo é composto de esquema funcional da medição, diagrama trifilar e/ou unifilar da instalação, sendo que é necessário também elaborar o relatório da instalação no qual deve constar informações sobre: memorial descritivo, diagramas, anotação de responsabilidade técnica, relatórios de ensaios e esquemas funcionais da medição.

Para pontos de medição de consumidores livres, esta documentação só poderá ser realizada pelo executante mediante a prestação de informações do proprietário da instalação.

O Projeto de Medição deve ser previamente aprovado pelo Agente Conectado e posteriormente deve ser encaminhado para aprovação do ONS. Este procedimento está disciplinado no Módulo 12 dos Procedimentos de Rede do ONS.

\section{c) Execução dos Serviços:}

Caso a instalação seja existente, geralmente é necessário se realizar o desligamento do fornecimento de energia para a realização dos serviços, conforme o caso, sendo que os serviços devem ser realizados prevendo a instalação dos Transformadores de Corrente e Transformadores de Potencial, cablagem, painéis, 
ensaios e instalações dos medidores e kit de comunicação conforme a opção do Agente.

d) Ensaios Elétricos:

Os ensaios elétricos a serem realizados devem prever a execução dos seguintes serviços.

- Ensaios Elétricos TP's:

$\checkmark$ Resistência de isolação;

$\checkmark$ Resistência de enrolamento;

$\checkmark$ Relação de transformação;

$\checkmark$ Polaridade;

$\checkmark$ Fator de Potência.

- Ensaios Elétricos TC's:

$\checkmark$ Resistência de isolação;

$\checkmark$ Resistência de enrolamento;

$\checkmark$ Relação de transformação;

$\checkmark$ Polaridade;

$\checkmark$ Fator de Potência;

$\checkmark$ Excitação (saturação).

e) Instalação dos Medidores:

Esta atividade deve contemplar a fixação dos medidores principal e retaguarda no painel como também as ligações necessárias, e posteriormente, devem ser parametrizados os medidores conforme características técnicas da instalação.

f) Conectividade do Sistema de Comunicação:

Deve ser realizado o "Start-Up" da medição considerando a conectividade dos medidores aos usuários, bem como verificar o acesso aos medidores pela CCEE. A 
forma de comunicação deve estar em conformidade com o previsto no Anexo I do Módulo 12 dos Procedimentos de Rede do ONS.

g) Comissionamento do Sistema de Medição para Faturamento:

Quando da implantação definitiva, deve ser elaborado o Relatório de Comissionamento, que é o documento que atesta o perfeito funcionamento dos componentes do sistema, como também que todos atendem aos requisitos previstos no Anexo I do Módulo 12 dos Procedimentos de Rede do ONS.

Após a conclusão do Relatório, deve ser encaminhado para aprovação do ONS.

h) Mão de Obra:

Os profissionais devem ser capacitados para a execução dos serviços. Devem estar munidos de todos os equipamentos de proteção individual e coletiva.

A Tabela 6 indica os custos referenciais obtidos a partir de pesquisas realizadas e conhecimento dos custos praticados no mercado.

Os custos são proporcionais aos níveis de tensão aos quais as instalações estão conectadas, sendo referenciais também nas adequações dos Sistemas de Medição de Consumidores Livres.

Tabela 6 - Custo médio praticado no mercado para adequação do SMF

\begin{tabular}{cccccc}
\hline Nível de Tensão & $15 \mathrm{kV}$ & $34,5 \mathrm{kV}$ & $69 \mathrm{kV}$ & $138 \mathrm{kV}$ & Acima 230 kV \\
Custo (R\$) & $50.000,00$ & $70.000,00$ & $90.000,00$ & $250.000,00$ & $320.000,00$ \\
\hline
\end{tabular}

Fonte: o autor por meio de pesquisa no mercado (2008).

Com relação especificamente aos medidores, existe também preços diferenciados praticados no mercado pelos fabricantes, embora ressalta-se que estes medidores possuem eventualmente recursos adicionais a serem utilizados pelos Agentes responsáveis além da exigência de atender os requisitos técnicos previstos no Anexo I dos Procedimentos de Rede do ONS. 
A tabela 7 indica os custos praticados no mercado pelos fabricantes ou fornecedores para aquisição dos medidores. Sendo que o intuito não é de apontar a diferença entre os custos praticados entre os diferentes fabricantes e sim identificar aos Agentes que existem custos diferenciados e devem ser ponderados no momento da compra, levando em conta o equipamento que melhor atenda as suas necessidades.

Tabela 7 - Custo médio dos medidores

\begin{tabular}{ccccc}
\hline FABRICANTE & A & B & C & D \\
Custo (R\$) & $3.400,00$ & $4.800,00$ & $10.200,00$ & $11.500,00$ \\
\hline Fonte: O autor - Pesquisa no mercado junto aos fabricantes / fornecedores (2008).
\end{tabular}

Existe variação significativa, mas alguns Agentes podem usufruir de redução de custos em função da quantidade de medidores a serem adquiridos, ou até mesmo por optarem pela compra de uma solução integrada completa de um determinado fabricante ou fornecedor que melhor atenda as suas necessidades.

Para os Pontos de Medição de Consumidores Livres e Especiais, além de suscitarem discussões, os custos envolvidos são apontados como fator impeditivo para a continuidade da expansão do mercado de energia.

Para permitir melhor avaliação do tema, no Capítulo 10 são realizadas simulações identificando, conforme premissas assumidas, o respectivo ganho na migração para o Ambiente de Livre Contratação - ACL em contraposição com o investimento inicial para adequação dos Sistemas de Medição para Faturamento, identificando o tempo de retorno do investimento, como também a conseqüente avaliação da viabilidade ou não de migração frente aos custos das adequações dos Sistemas de Medição para Faturamento. 


\section{AVALIAÇÃO DA VIABILIDADE DE MIGRAR PARA O AMBIENTE DE LIVRE CONTRAÇÃO DE ENERGIA FRENTE AO CUSTO DE ADEQUAÇÃO DOS SISTEMAS DE MEDIÇÃO PARA FATURAMENTO}

Atualmente os Consumidores com demanda superior a $500 \mathrm{~kW}$ (consumidores especiais) podem ser 'livres' desde que adquiram energia de fonte Incentivada.

Considerando que obrigatoriamente os Consumidores livres e especiais devem ser agentes da CCEE e que $30 \%$ da energia do Sistema Interligado Brasileiro é comercializada no mercado livre, e a expressiva representatividade dos Consumidores Livres que é da ordem de 65\% deste mercado, e de forma genérica se dividem principalmente nos segmentos de metalurgia, químicos, minerais e celulose, que são os mais representativos.

As simulações realizadas visam identificar a viabilidade dos Consumidores Livres e Especiais migrarem para o Ambiente de Livre Contratação - ACL, frente aos custos de adequação dos Sistemas de Medição para Faturamento (apresentados no Capítulo 9). As simulações adotam como premissa o preço da energia no mercado livre em $\mathrm{R} \$ \mathrm{MWh}$ obtido mediante pesquisa da curva de preço praticada no mercado; preço da tarifa no mercado cativo e tarifas de uso de rede. São realizadas simulações para as mesmas condições em três áreas diferentes do país, ou seja, hipoteticamente caso a unidade industrial esteja localizada em uma área de concessão de uma Distribuidora da região Sudeste, Sul e Nordeste, pois as tarifas do mercado cativo e de uso de rede são diferentes. Estas simulações podem servir de alerta para os empresários definirem eventualmente a localização das futuras implantações de suas instalações industriais, já que os custos finais são diferentes e podem impactar as despesas finais com o insumo energia elétrica.

Para contextualizar a importância deste segmento de mercado, atualmente o total de Pontos de Medição de Consumidores Livres e Especiais é da ordem de 1500. E obrigatoriamente devem ser dotados de Sistemas de Medição para Faturamento, de acordo com os requisitos técnicos previstos no Módulo 12 dos Procedimentos de Rede do ONS. A avaliação dos custos necessários para continuidade das migrações 
em contraposição com os benefícios auferidos são os que suscitam maiores discussões.

As simulações abaixo fornecem indicativos aos futuros consumidores livres para poderem avaliar a questão da viabilidade em migrar para o ACL, embora com a introdução de um fator adicional que é a simulação do custo de aquisição de energia e o respectivo tempo para se obter retorno do investimento relativo ao custo do Sistema de Medição para Faturamento.

Para tornar a avaliação mais consistente, as simulações levam em conta se a referida unidade está localizada na área de concessão da Distribuidora $A$ (ELETROPAULO), B (RGE) ou C (COELBA), regiões Sudeste, Sul e Nordeste respectivamente, pois os valores, principalmente de uso de rede e tarifa do mercado cativo, variam de acordo com a Distribuidora na qual a instalação está conectada.

As tarifas do mercado cativo utilizadas nas simulações foram homologadas pela ANEEL, mediante publicação das Resoluções 675/2008 de 01/07/2008 (ELETROPAULO); 636/2008 de 17/04/2008 (RGE) e 638/2008 de 17/04/2008 (COELBA).

Cabe lembrar que o custo de adequação do Sistema de Medição para Faturamento utilizado para as simulações de 1 a 4 é de $R \$ 50.000,00$.

\section{- Simulação 1}

Empresa Tarifa Horo-Sazonal Verde (A4)

Demanda Contratada $=500 \mathrm{KW}$

Aquisição Fonte Alternativa = Desconto 50\% TUSD (Tarifa Uso Sistema de Distribuição)

Custo Previsto para adequação do $S M F=R \$ 50.000,00$

Fator de Carga $=0,75$

Preço Médio R \$156,75/MWh em relação a 4 anos de contrato

Empresa Distribuidora $A=$ Região Sudeste

Empresa Distribuidora $B$ = Região Sul

Empresa Distribuidora $\mathrm{C}=$ Região Nordeste 


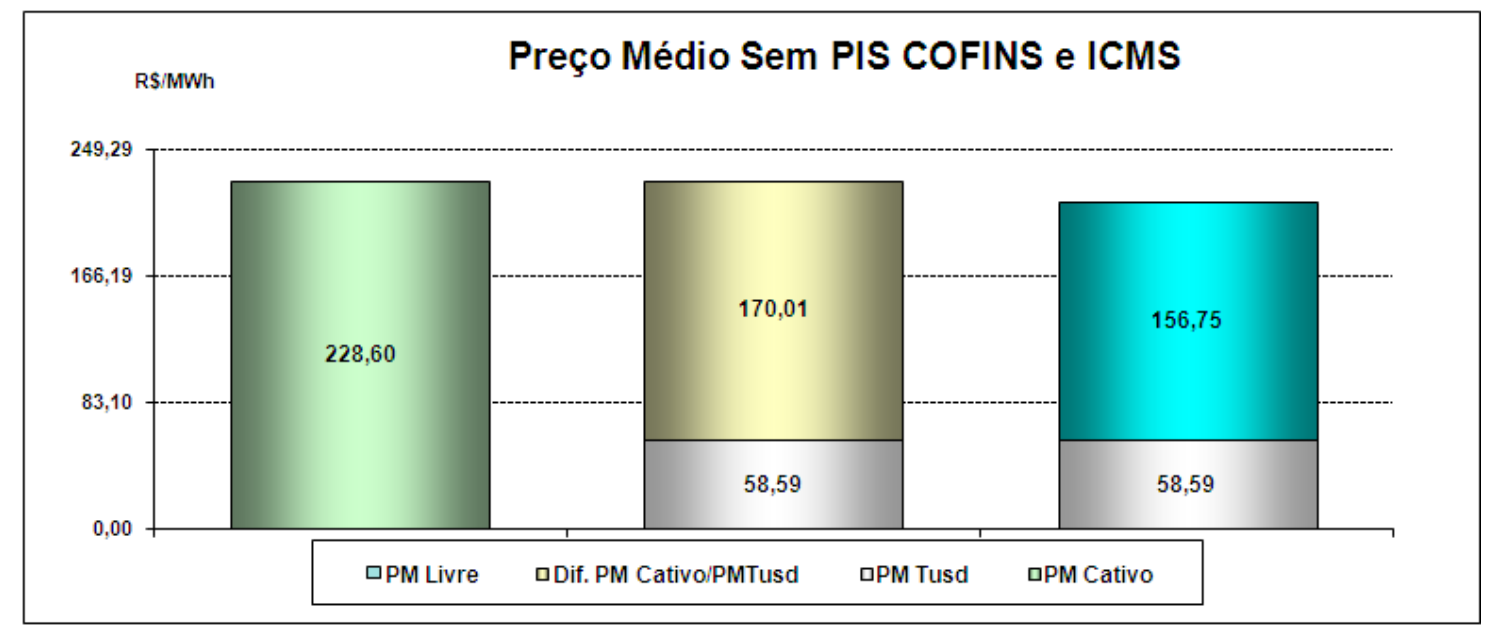

\begin{tabular}{|c|c|} 
Preço Médio da Energia Livre - R\$/MWh & 156,75 \\
\hline Preço Médio Energia Livre + Preço Médio TUSD - R\$/MWh & 215,34 \\
\hline Diferença PM Cativo com PM Livre + PM Tusd - R\$/MWh & 13,26 \\
\hline \% da Diferença Sobre Preço Médio Cativo & $5,80 \%$ \\
\hline Economia de Energia com Relação Consumo/Mês R\$/MWh & 3631,21125 \\
\hline Lucro com relação ao meses de Contrato R\$ & 174298,14 \\
\hline Qt. Meses para Pagar Adequação SMF & 14 \\
\hline
\end{tabular}

Figura 14 - Simulação 1: Distribuidora A Sudeste

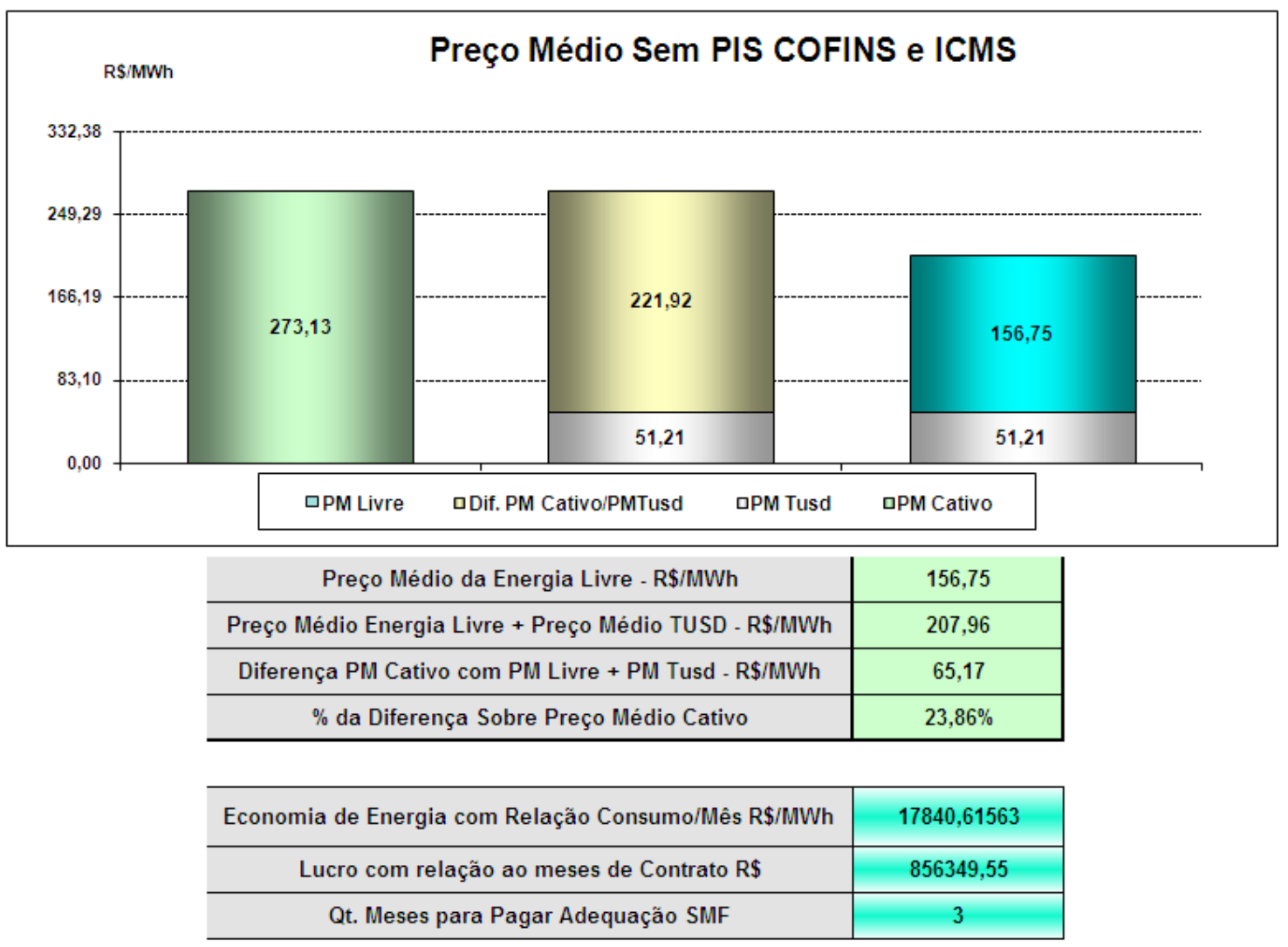

Figura 15 - Simulação 1: Distribuidora B Sul 


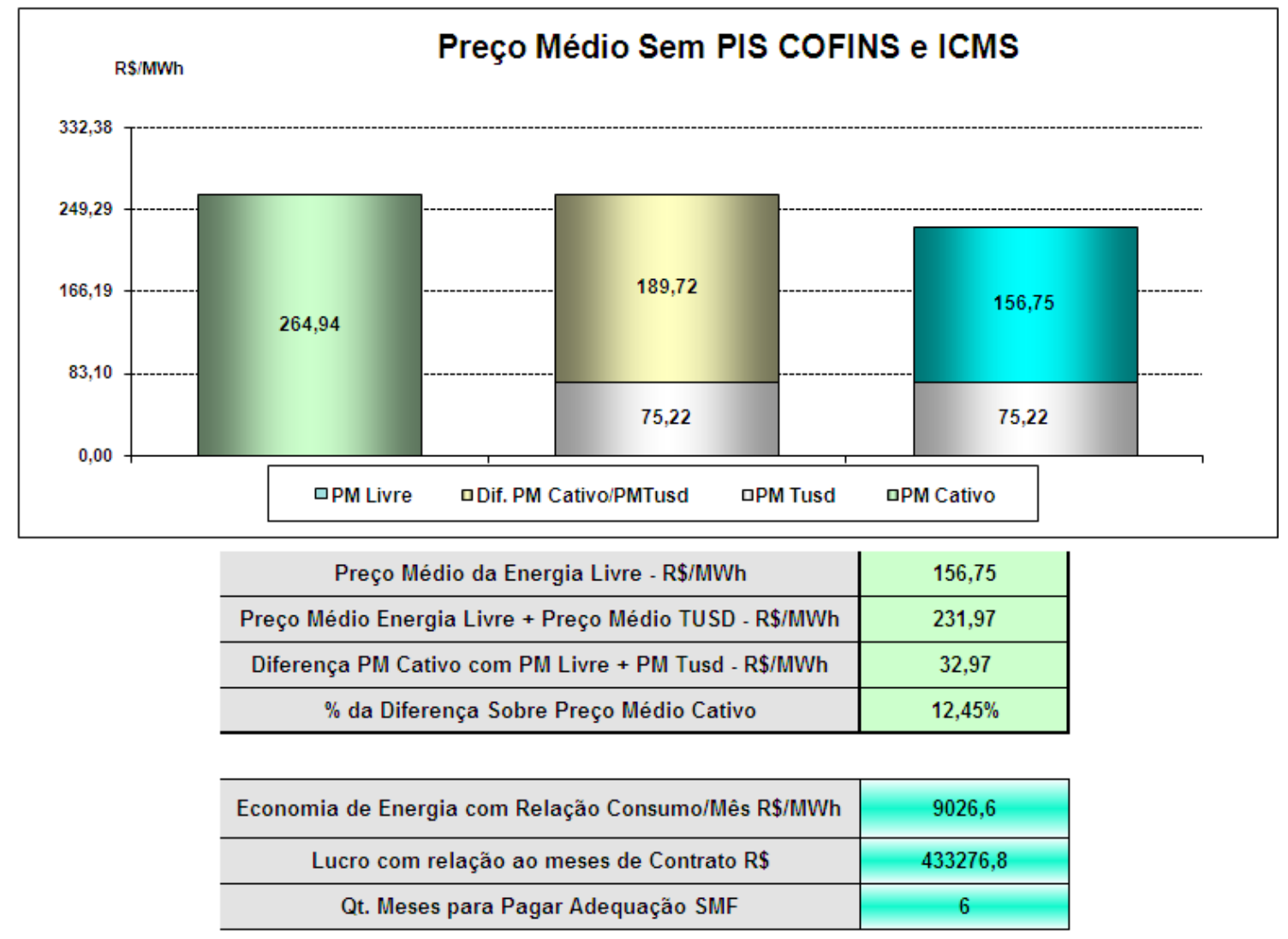

Figura 16 - Simulação 1: Distribuidora C Nordeste

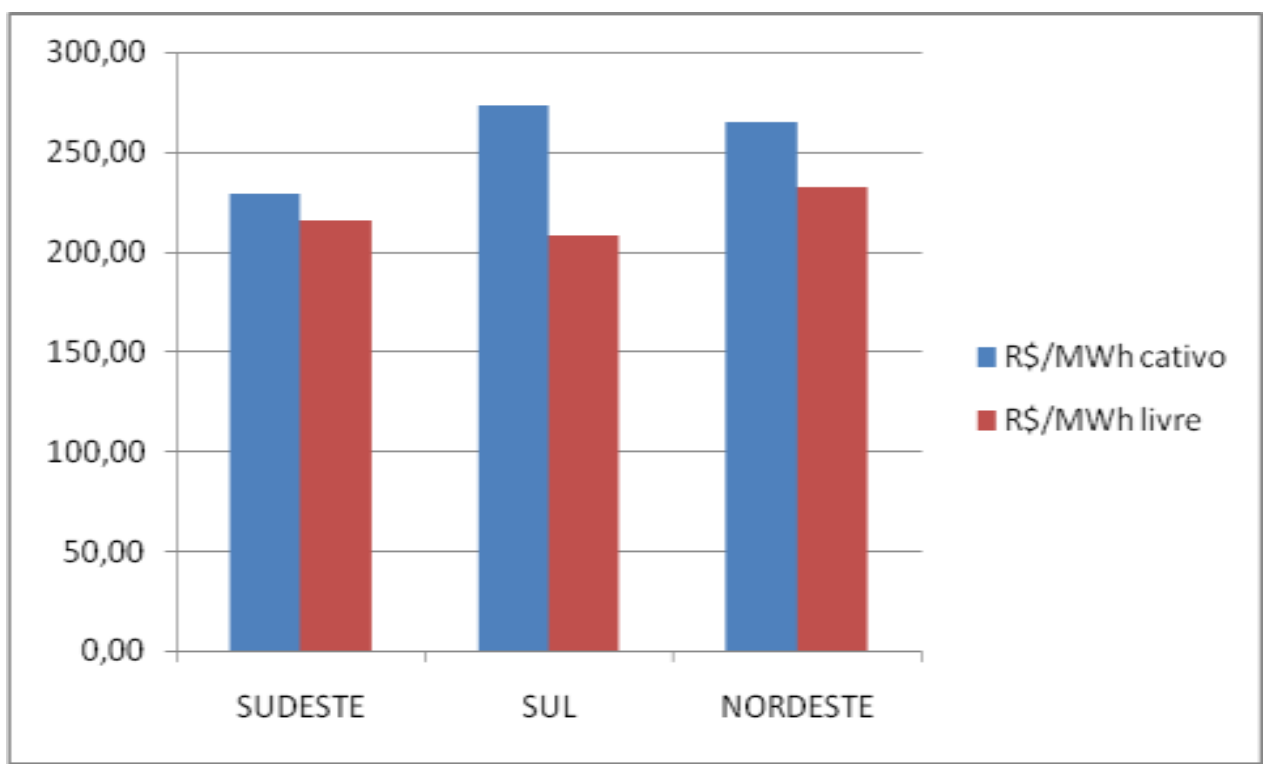

Figura 17 - Variação Custo Energia Simulação 1 


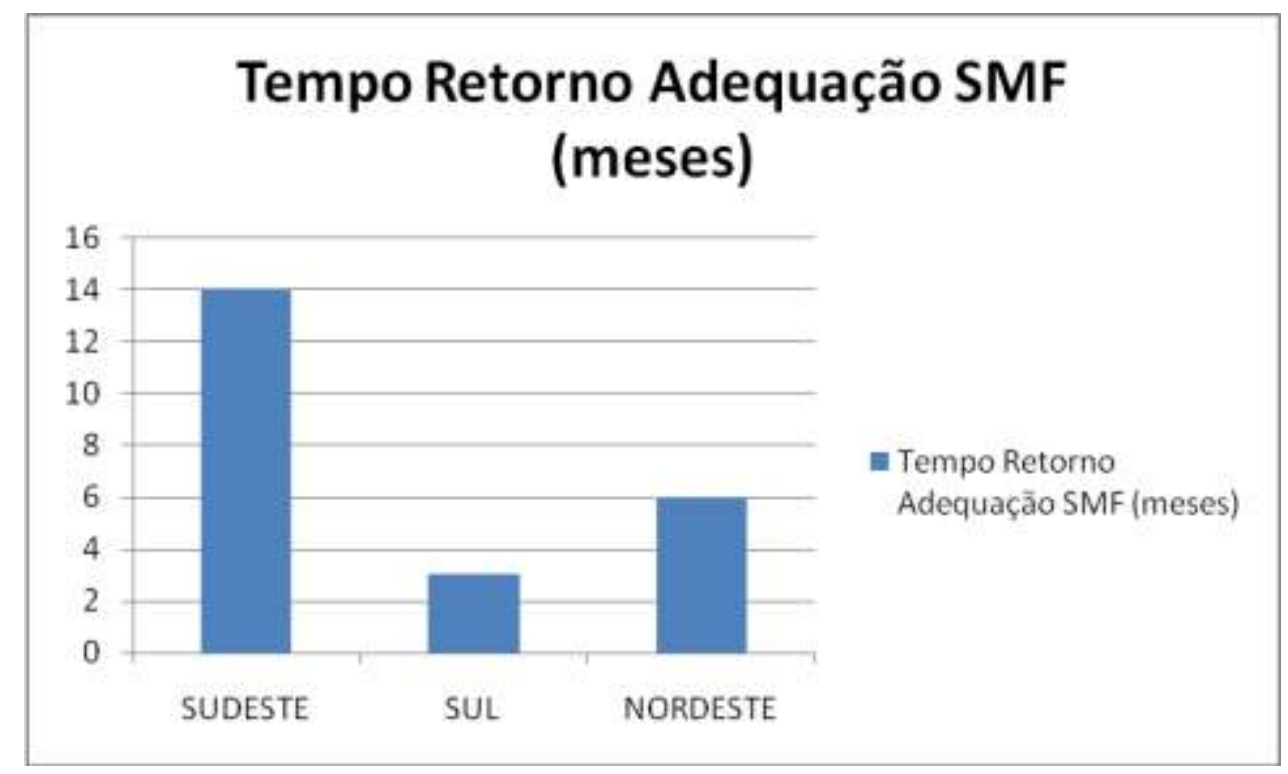

Figura 18 - Tempo Retorno Adequação SMF Simulação 1

Esta simulação indica, que independentemente da localização, uma unidade que esteja nestas condições no mercado cativo torna-se atrativo, do ponto de vista econômico, migrar para o Ambiente de Livre Contratação - ACL pois o custo de energia final no mercado livre é atrativo em comparação com o praticado no mercado cativo, bem como o custo de adequação se paga em no máximo 14 meses.

\section{- Simulação 2}

Empresa Tarifa Horo-Sazonal Verde (A4)

Demanda Contratada $=500 \mathrm{KW}$

Aquisição Fonte Alternativa $=$ Desconto 100\% TUSD (Tarifa Uso Sistema de Distribuição)

Custo Previsto para adequação do $S M F=R \$ 50.000,00$

Fator de Carga $=0,75$

Preço Médio $\mathrm{R} \$ 156,75 / \mathrm{MWh}$

Empresa Distribuidora $\mathrm{A}=$ Região Sudeste

Empresa Distribuidora $B=$ Região Sul

Empresa Distribuidora $\mathrm{C}=$ Região Nordeste 


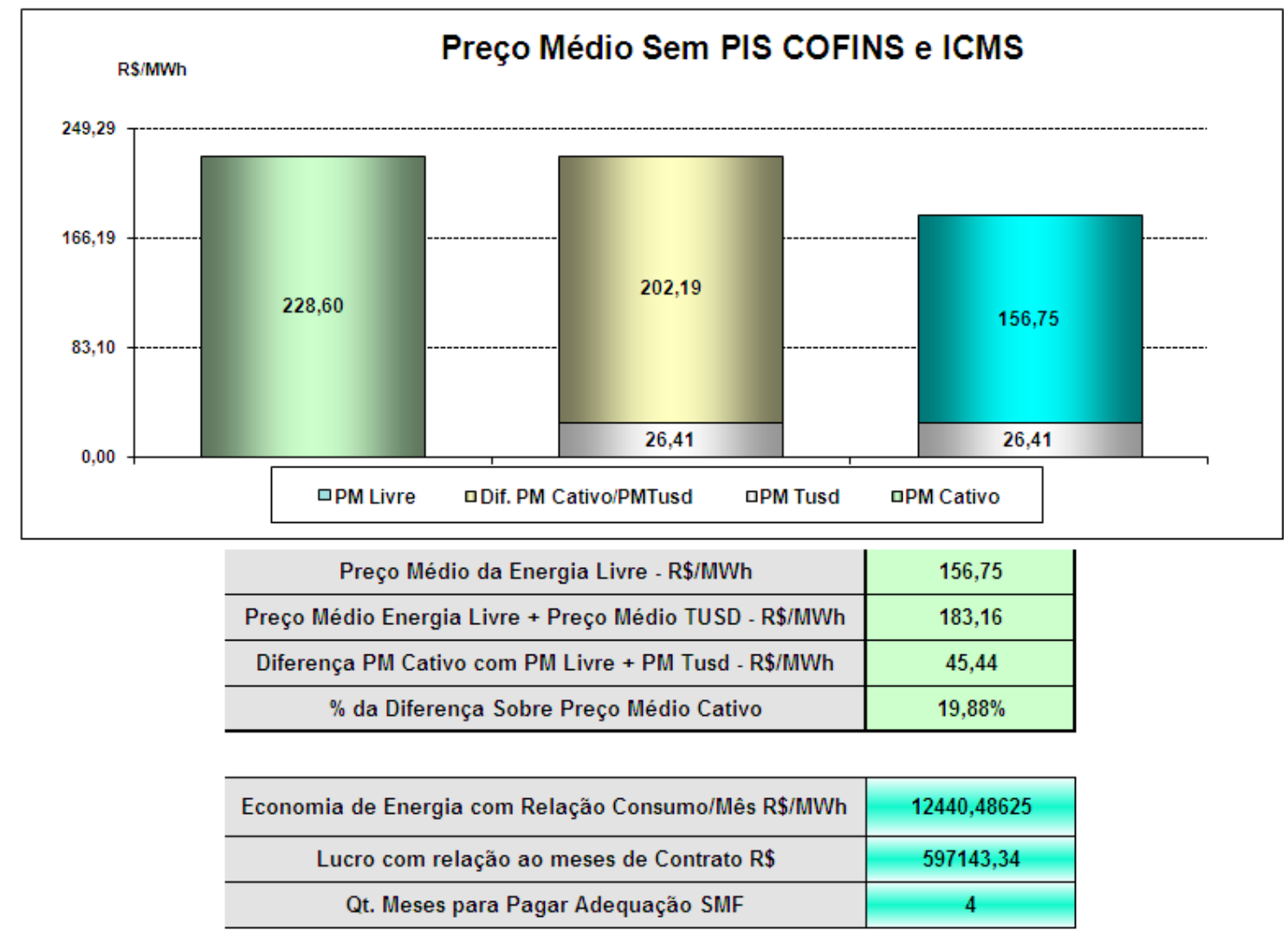

Figura 19 - Simulação 2: Distribuidora A Sudeste

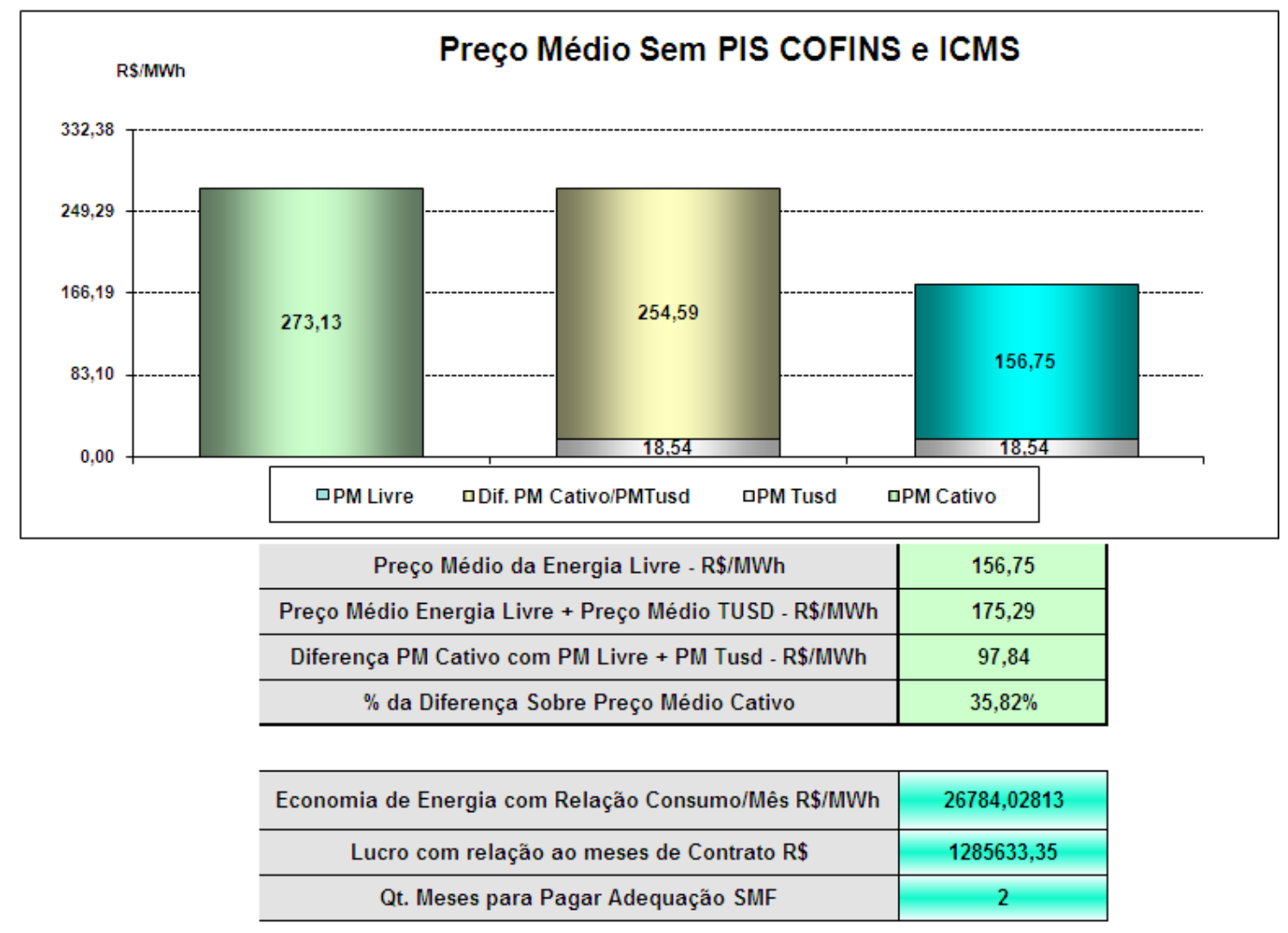

Figura 20 - Simulação 2: Distribuidora B Sul 


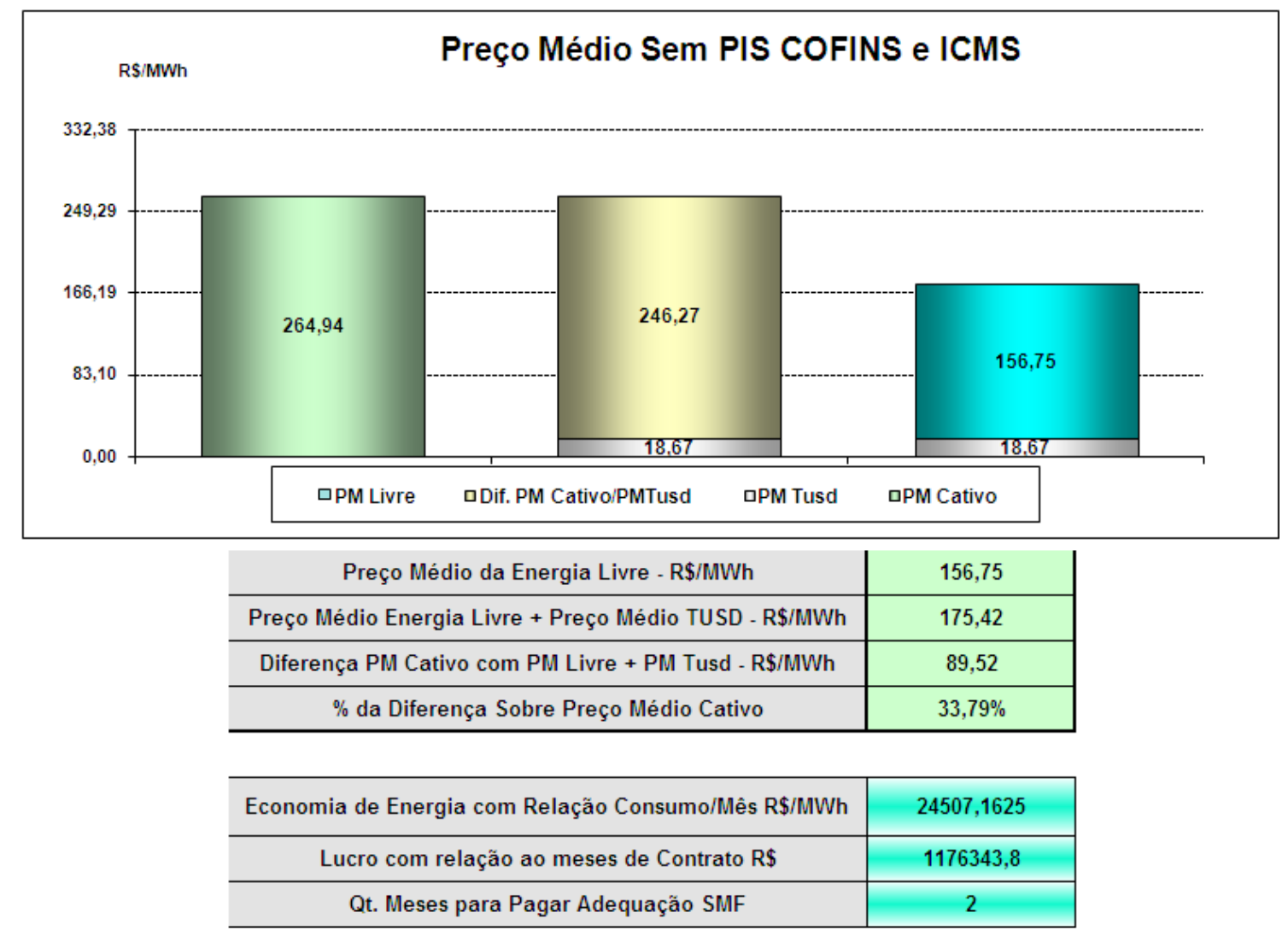

Figura 21 - Simulação 2: Distribuidora C Nordeste

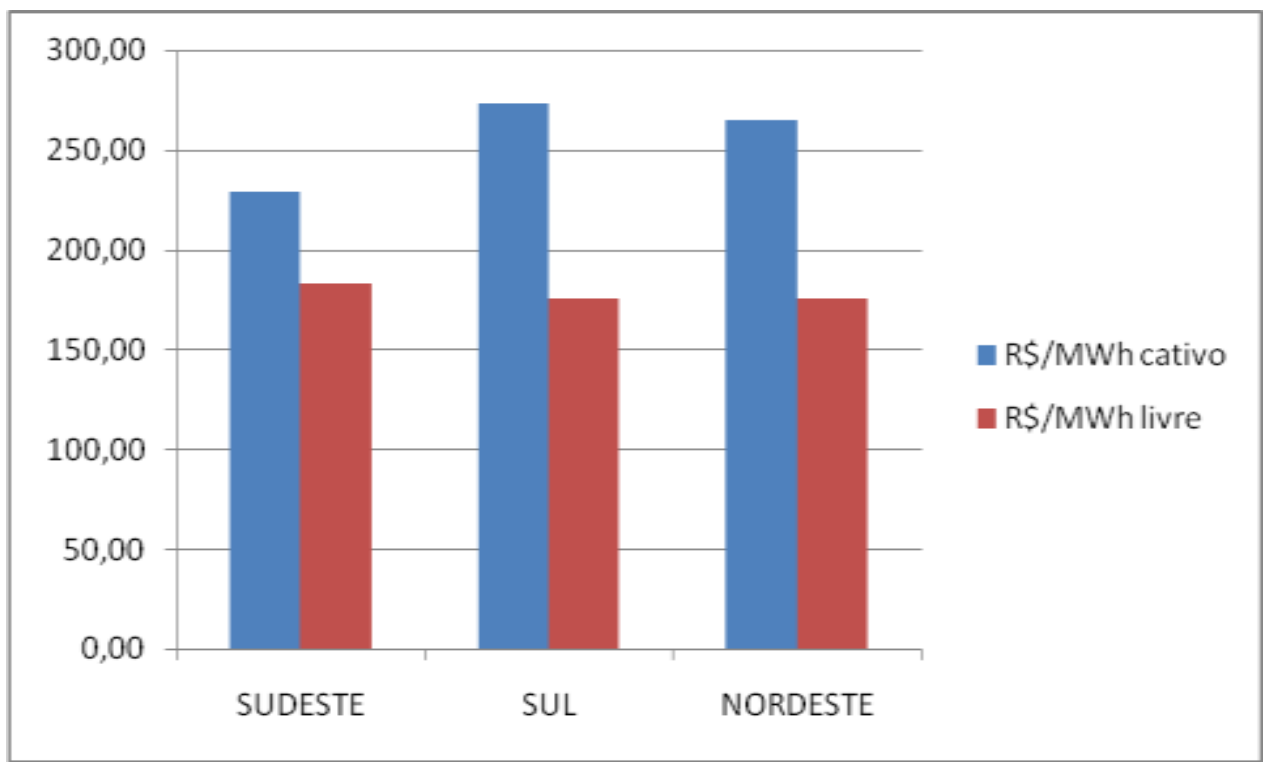

Figura 22 -Variação Custo Energia Simulação 2 


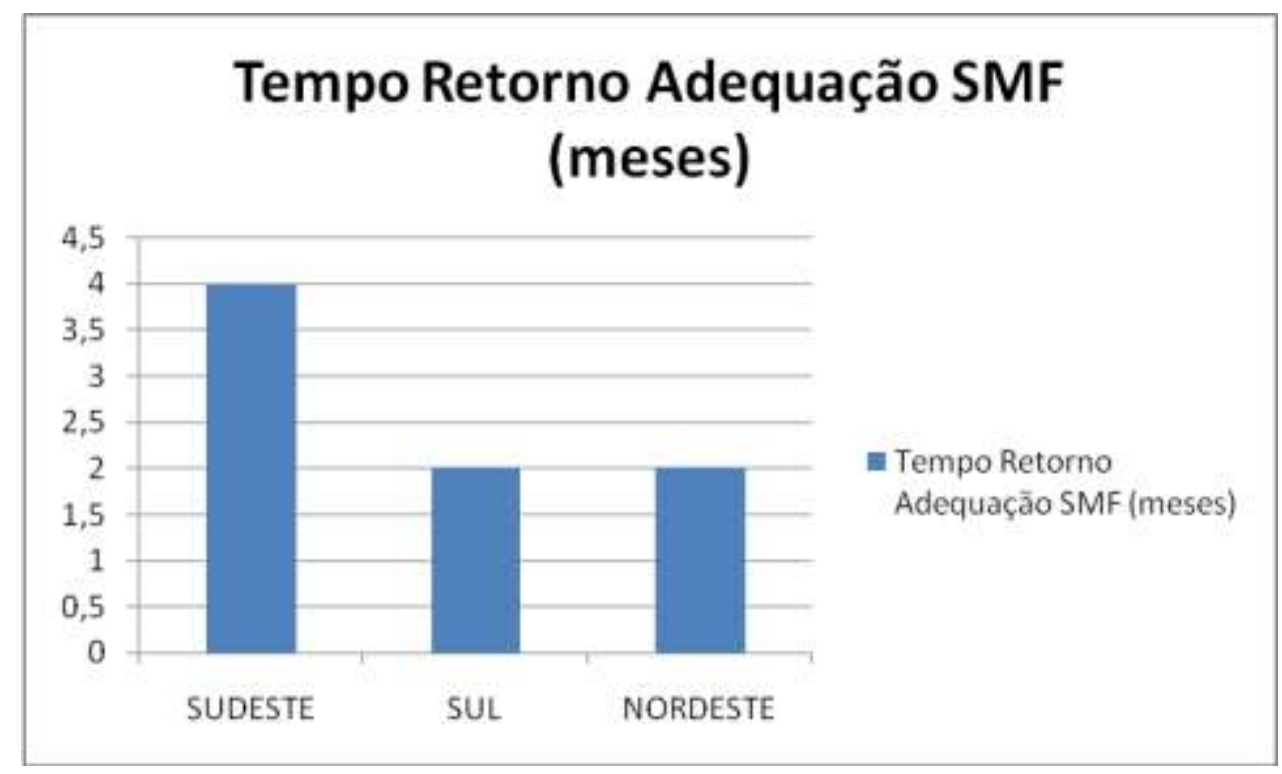

Figura 23 - Tempo Retorno Adequação SMF Simulação 2

Esta simulação indica que, independentemente da localização, uma unidade que esteja nestas condições no mercado cativo torna-se atrativo, do ponto de vista econômico, migrar para o Ambiente de Livre Contratação - ACL pois o custo de energia final no mercado livre é atrativo em comparação com o praticado no mercado cativo, bem como o custo de adequação se paga em no máximo 4 meses, sendo que cabe ressaltar que esta unidade possui desconto no uso de rede da ordem de $100 \%$.

\section{- Simulação 3}

Empresa Tarifa Horo-Sazonal Verde (A4)

Demanda Contratada $=1000 \mathrm{KW}$

Aquisição Fonte Alternativa $=$ Desconto $50 \%$ TUSD (Tarifa Uso Sistema de Distribuição)

Custo Previsto para adequação do SMF $=R \$ 50.000,00$

Fator de Carga $=0,75$

Preço Médio R \$156,75/MWh

Empresa Distribuidora $\mathrm{A}=$ Região Sudeste

Empresa Distribuidora $B=$ Região Sul

Empresa Distribuidora $\mathrm{C}=$ Região Nordeste 


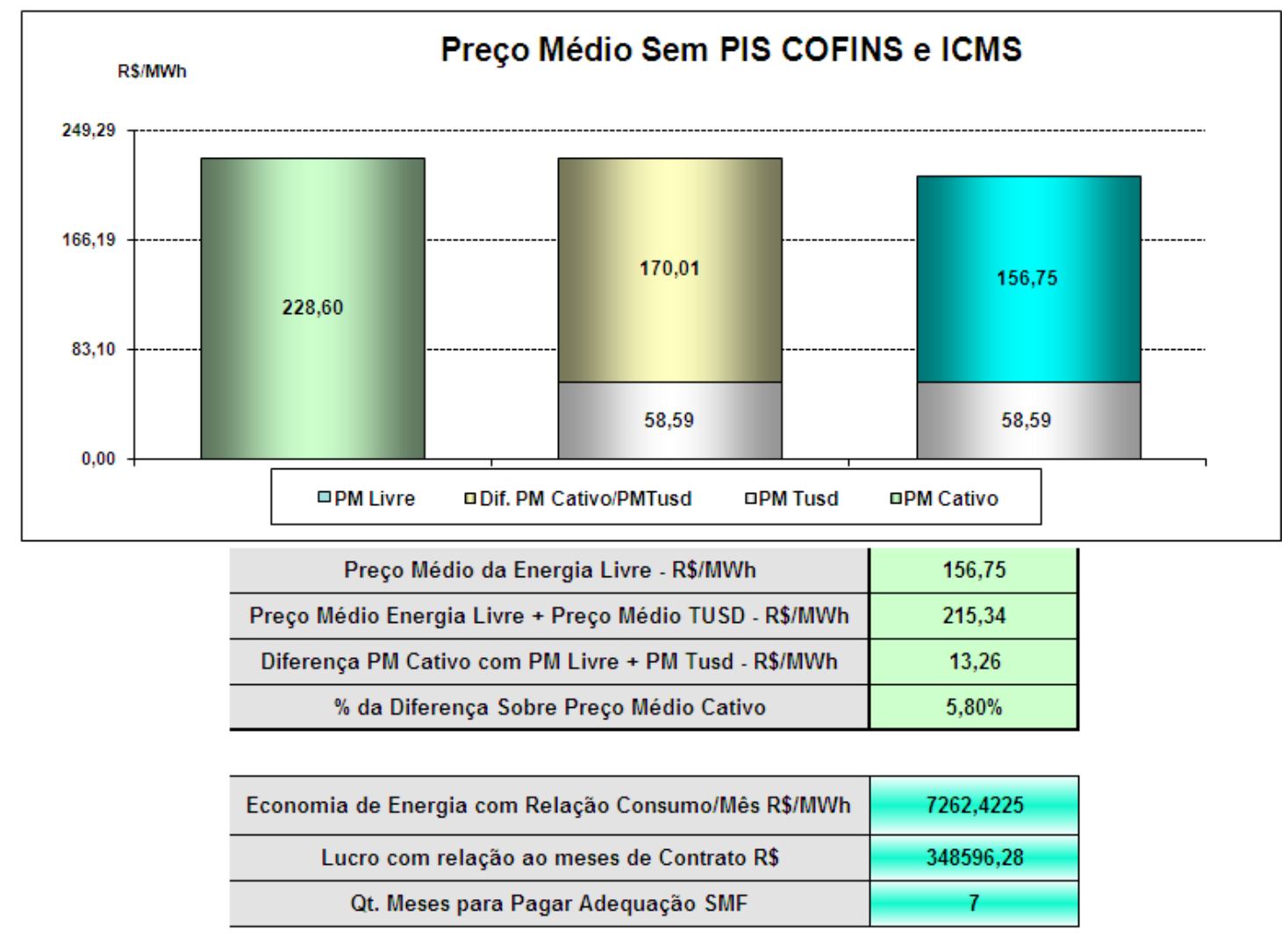

Figura 24 - Simulação 3: Distribuidora A Sudeste

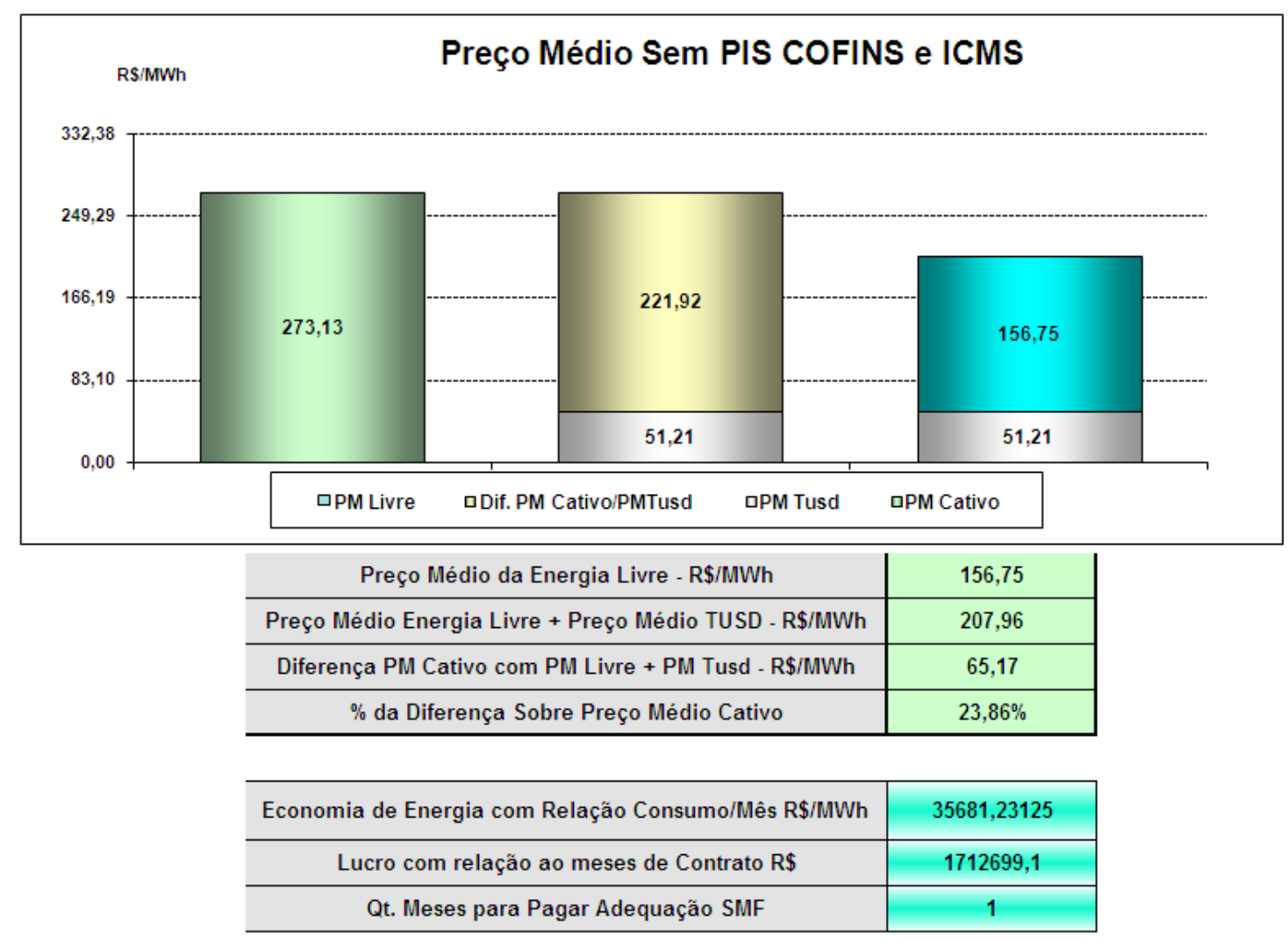

Figura 25 - Simulação 3: Distribuidora B SUL 


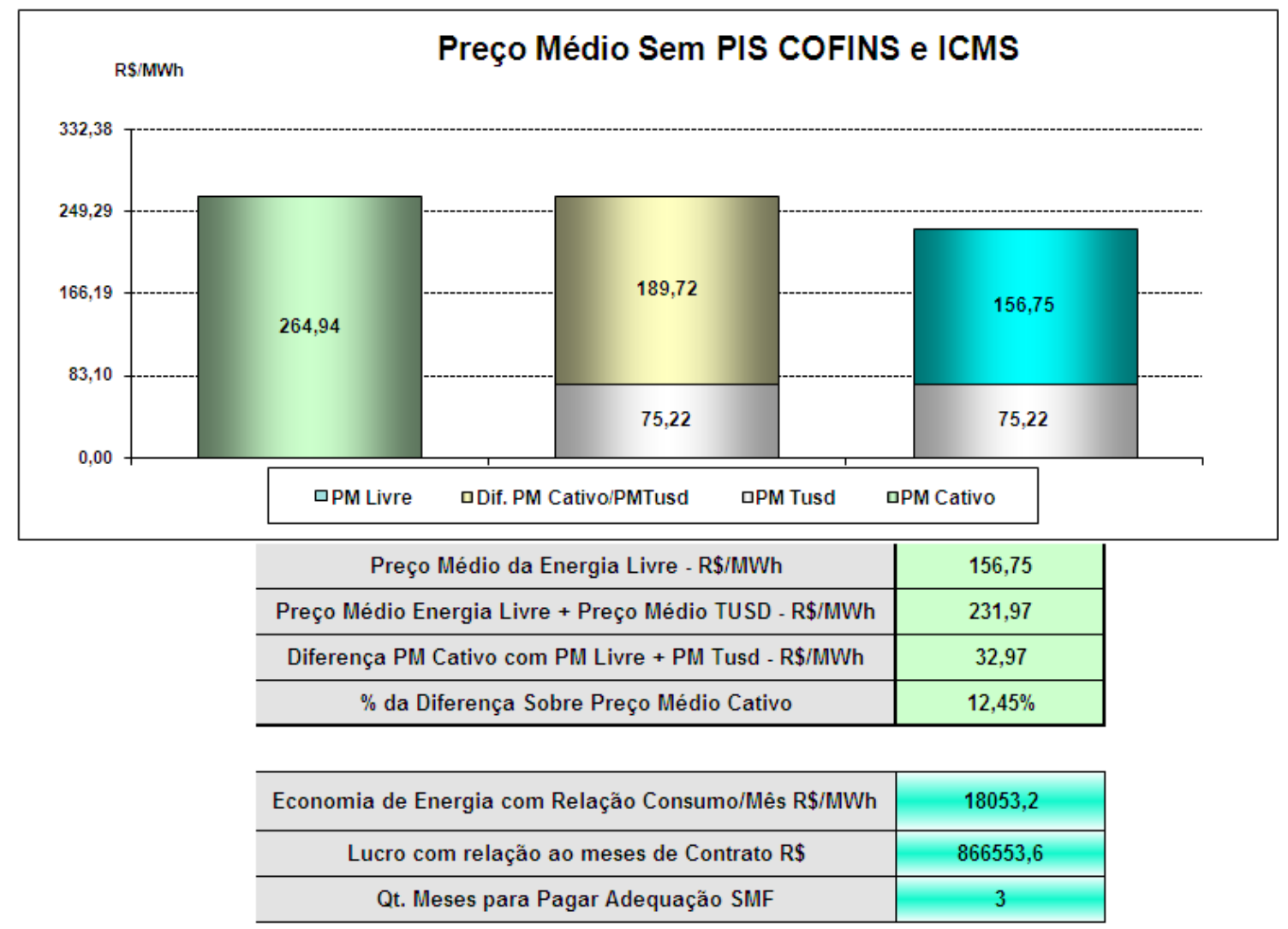

Figura 26 - Simulação 3: Distribuidora C Nordeste

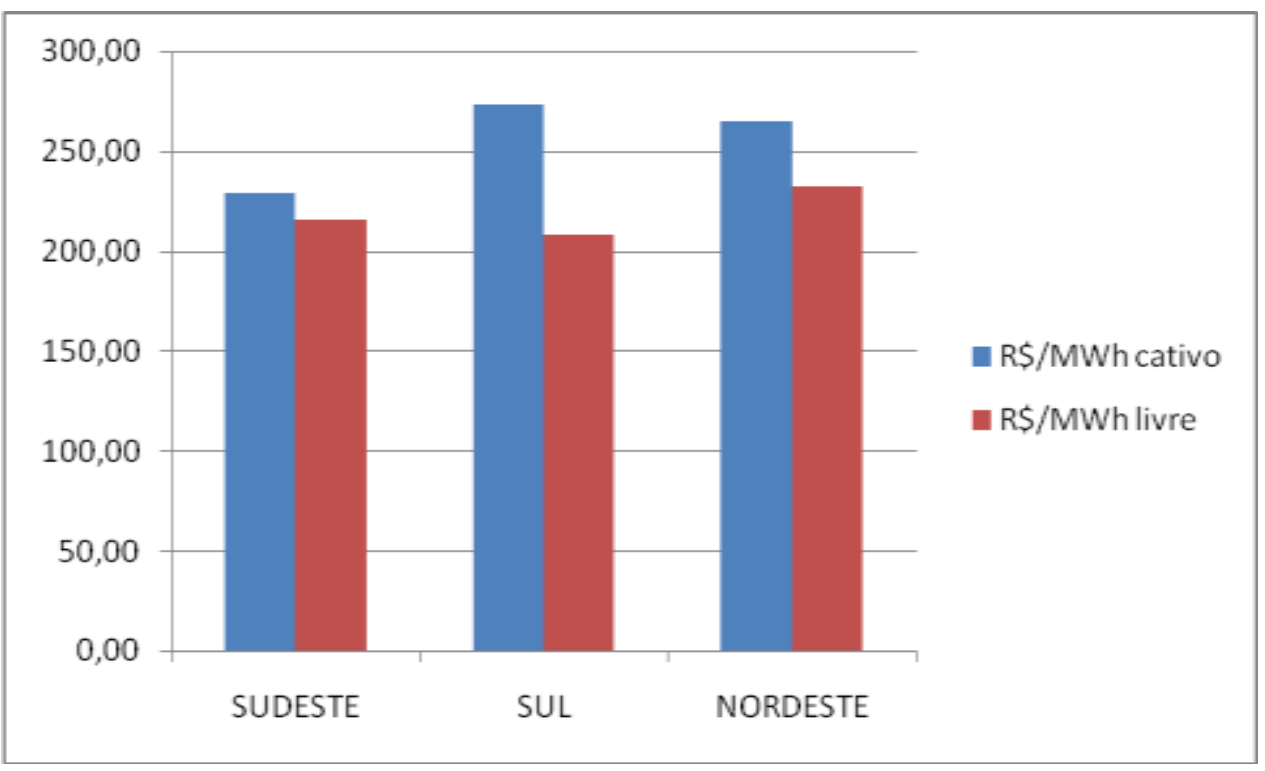

Figura 27 - Variação Custo Energia Simulação 3 


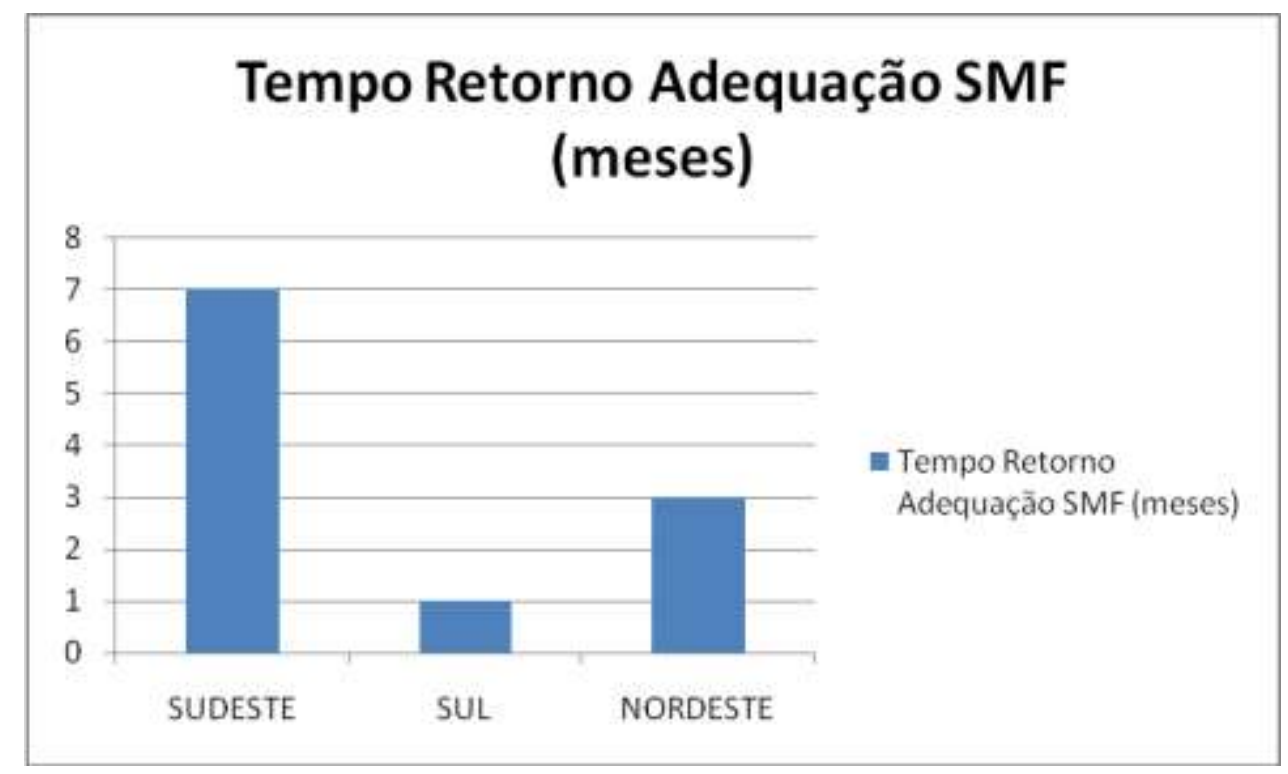

Figura 28 - Tempo Retorno Adequação SMF Simulação 3

Esta simulação indica que, independentemente da localização, uma unidade que esteja nestas condições no mercado cativo torna-se atrativo, do ponto de vista econômico, migrar para o Ambiente de Livre Contratação - ACL pois o custo de energia final no mercado livre é atrativo em comparação com o praticado no mercado cativo, bem como o custo de adequação se paga em no máximo 7 meses, sendo que cabe ressaltar que esta unidade possui demanda da ordem de $1000 \mathrm{KW}$, ou seja, mesmo com uma unidade maior ainda é atrativa a migração.

\section{- Simulação 4}

Empresa Tarifa Horo-Sazonal Verde (A4)

Demanda Contratada $=2000 \mathrm{KW}$

Aquisição Fonte Alternativa $=$ Desconto $50 \%$ TUSD (Tarifa Uso Sistema de Distribuição)

Custo Previsto para adequação do SMF $=R \$ 50.000,00$

Fator de Carga $=0,75$

Preço Médio R \$156,75/MWh

Empresa Distribuidora $\mathrm{A}=$ Região Sudeste

Empresa Distribuidora $B=$ Região Sul

Empresa Distribuidora $\mathrm{C}=$ Região Nordeste 


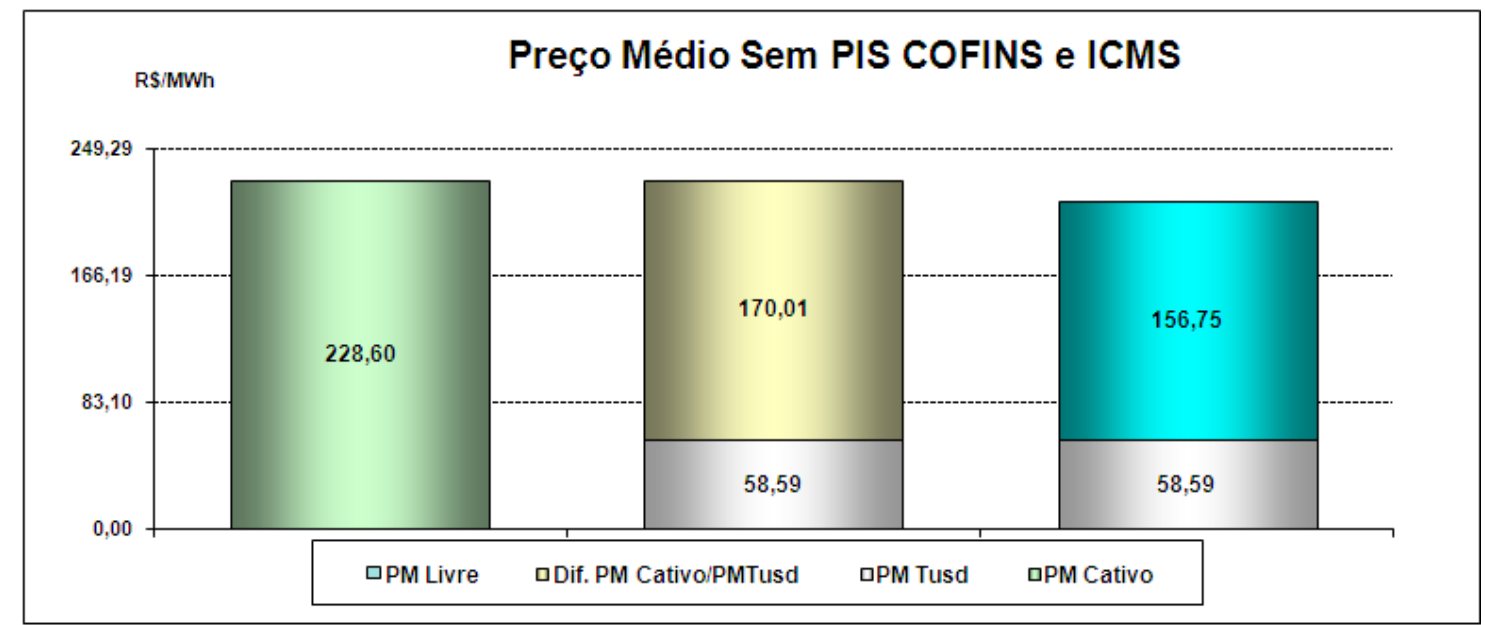

\begin{tabular}{c|c|}
\hline Preço Médio da Energia Livre - R\$/MWh & 156,75 \\
\hline Preço Médio Energia Livre + Preço Médio TUSD - R\$/MWh & 215,34 \\
\hline Diferença PM Cativo com PM Livre + PM Tusd - R\$/MWh & 13,26 \\
\hline$\%$ da Diferença Sobre Preço Médio Cativo & $5,80 \%$ \\
\hline
\end{tabular}

\begin{tabular}{|c|c|}
\hline Economia de Energia com Relação Consumo/Mês R\$/MWh & 14524,845 \\
\hline Lucro com relação ao meses de Contrato R\$ & 697192,56 \\
\hline Qt. Meses para Pagar Adequação SMF & 3 \\
\hline
\end{tabular}

Figura 29 - Simulação 4: Distribuidora A Sudeste

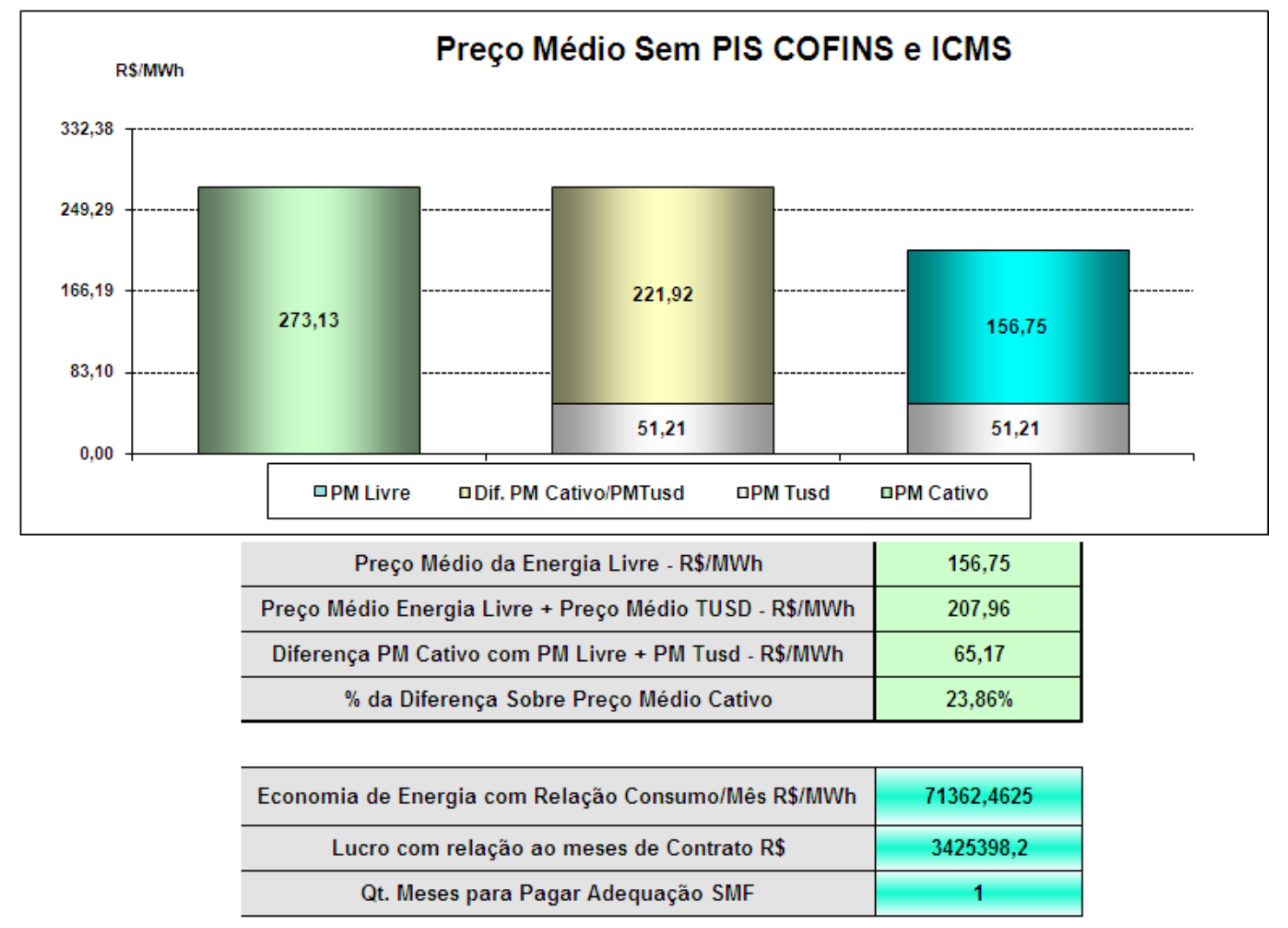

Figura 30 - Simulação 4: Distribuidora B SUL 


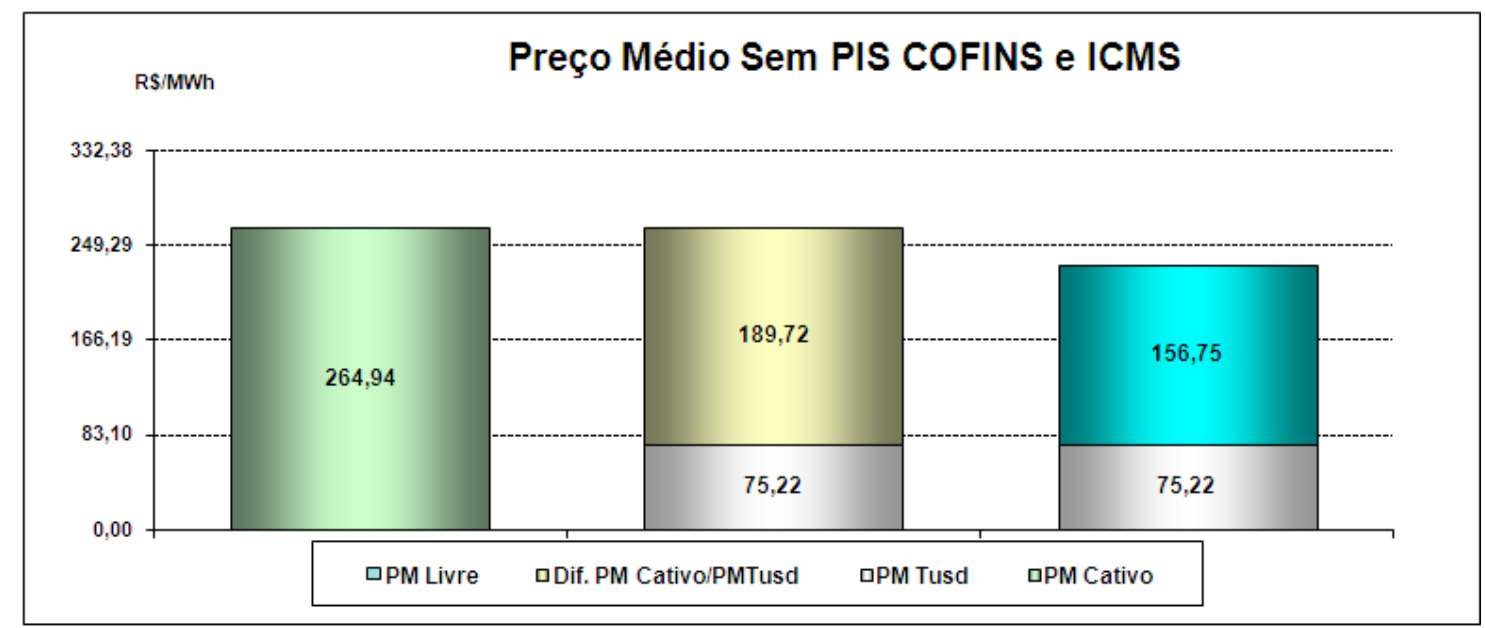

\begin{tabular}{c|c|} 
Preço Médio da Energia Livre - R\$/MWh & 156,75 \\
\hline Preço Médio Energia Livre + Preço Médio TUSD - R\$/MWh & 231,97 \\
\hline Diferença PM Cativo com PM Livre + PM Tusd - R\$/MWh & 32,97 \\
\hline \% da Diferença Sobre Preço Médio Cativo & $12,45 \%$ \\
\hline
\end{tabular}

\begin{tabular}{c|c|}
\hline Economia de Energia com Relação Consumo/Mês R\$/MWh & 36106,4 \\
\hline Lucro com relação ao meses de Contrato R\$ & 1733107,2 \\
\hline Qt. Meses para Pagar Adequação SMF & 1 \\
\hline
\end{tabular}

Figura 31 - Simulação 4: Distribuidora C Nordeste

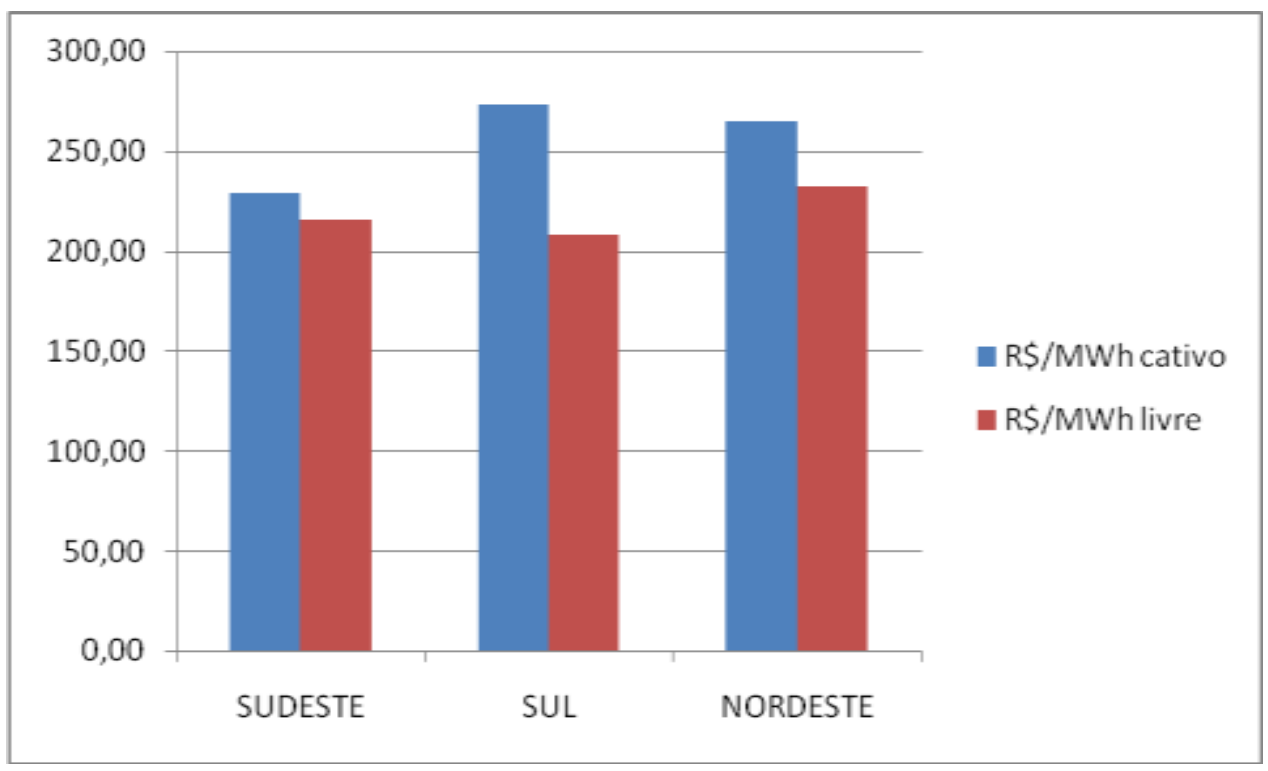

Figura 32 - Variação Custo Energia Simulação 4 


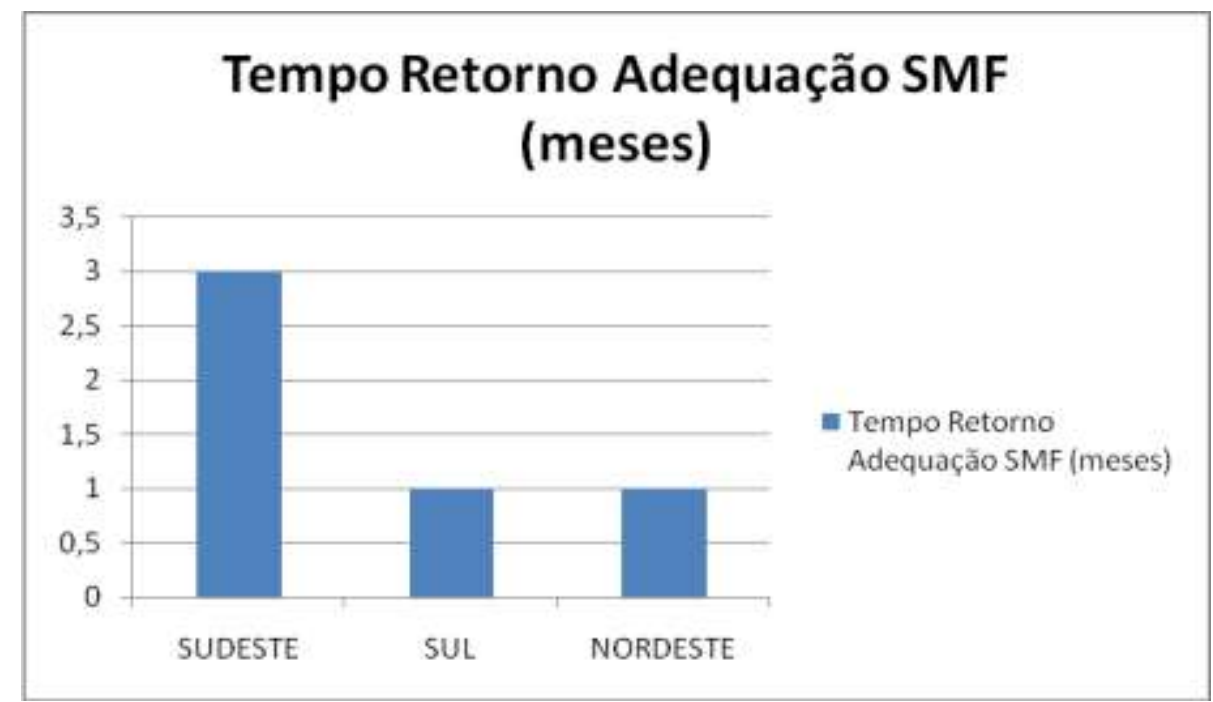

Figura 33 - Tempo Retorno Adequação SMF Simulação 4

Esta simulação indica que, independentemente da localização, uma unidade que esteja nestas condições no mercado cativo torna-se atrativo, do ponto de vista econômico, migrar para o Ambiente de Livre Contratação - ACL, pois o custo de energia final no mercado livre é atrativo em comparação com o praticado no mercado cativo, bem como o custo de adequação se paga em no máximo 3meses, sendo que cabe ressaltar que esta unidade possui demanda da ordem de $2000 \mathrm{KW}$, ou seja, mesmo com uma unidade maior ainda continua a atratividade para migração.

Cabe lembrar que o custo utilizado para as simulações 5 e 6 é de $R \$ 70.000,00$.

\section{- Simulação 5}

Empresa Tarifa Horo-Sazonal Verde (A3a)

Demanda Contratada $=1000 \mathrm{KW}$

Aquisição Fonte Alternativa = Desconto 50\% TUSD (Tarifa Uso Sistema de Distribuição)

Custo Previsto para adequação do $S M F=R \$ 70.000,00$

Fator de Carga $=0,75$

Preço Médio $\mathrm{R} \$ 156,75 / \mathrm{MWh}$

Empresa Distribuidora $A=$ Região Sudeste

Empresa Distribuidora B = Região Sul

Empresa Distribuidora C = Região Nordeste 


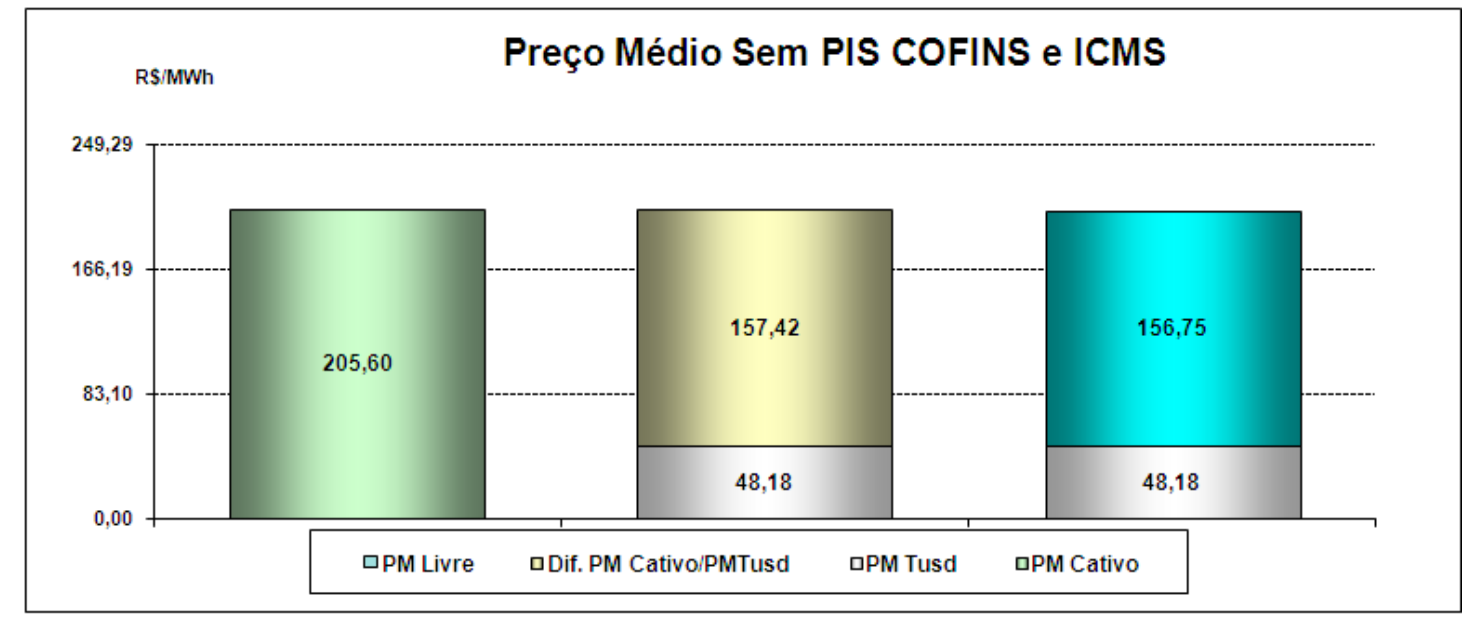

\begin{tabular}{c|c|} 
Preço Médio da Energia Livre - R\$/MWh & 156,75 \\
\hline Preço Médio Energia Livre + Preço Médio TUSD - R\$/MWh & 204,93 \\
\hline Diferença PM Cativo com PM Livre + PM Tusd - R\$/MWh & 0,67 \\
\hline \% da Diferença Sobre Preço Médio Cativo & $0,33 \%$ \\
\hline
\end{tabular}

\begin{tabular}{|c|c|}
\hline Economia de Energia com Relação Consumo/Mês R\$/MWh & 366,6375 \\
\hline Lucro com relação ao meses de Contrato R\$ & 17598,6 \\
\hline Qt. Meses para Pagar Adequação SMF & 191 \\
\hline
\end{tabular}

Figura 34 - Simulação 5: Distribuidora A Sudeste

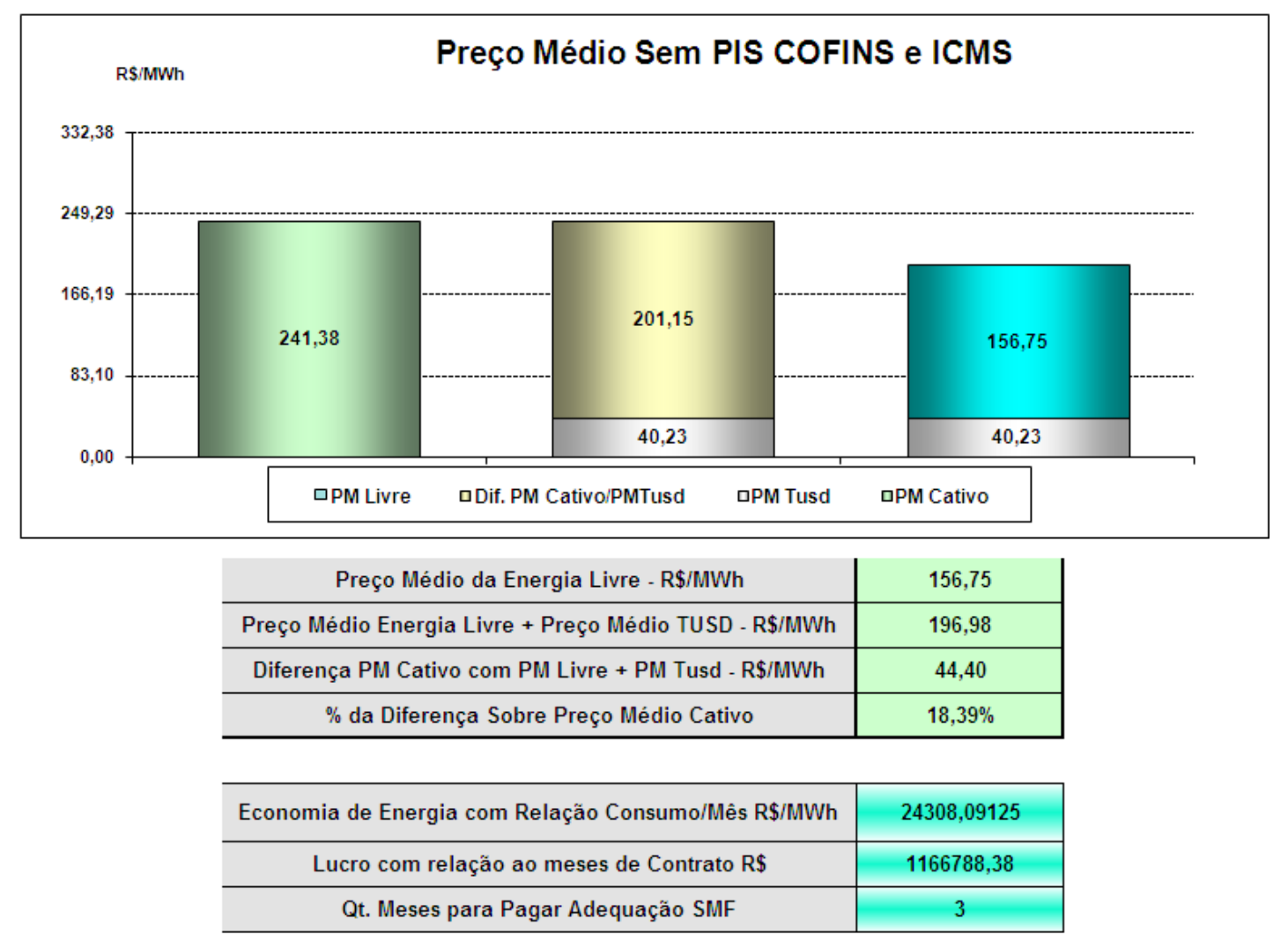

Figura 35 - Simulação 5: Distribuidora B SUL 


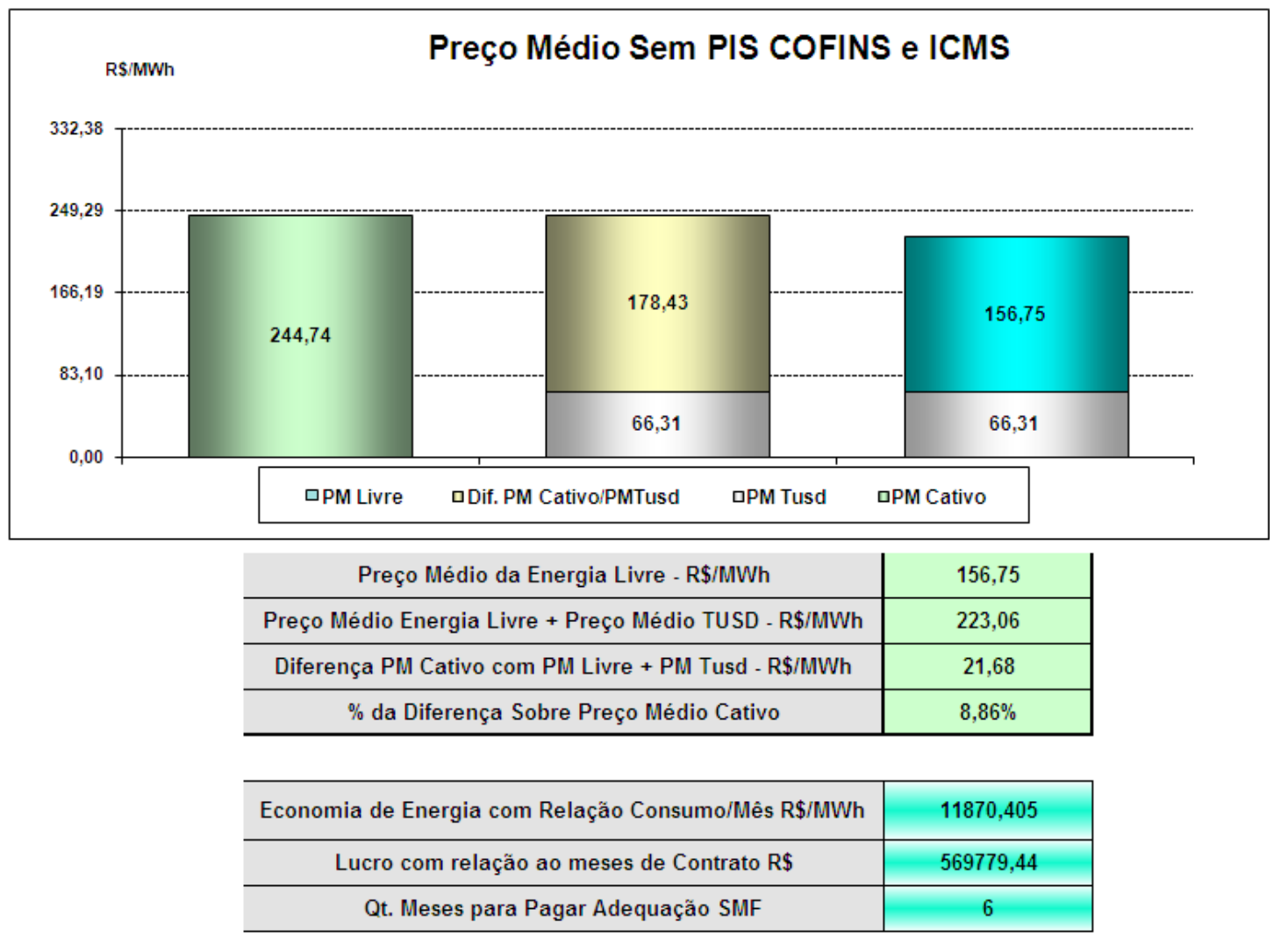

Figura 36 - Simulação 5: Distribuidora C Nordeste

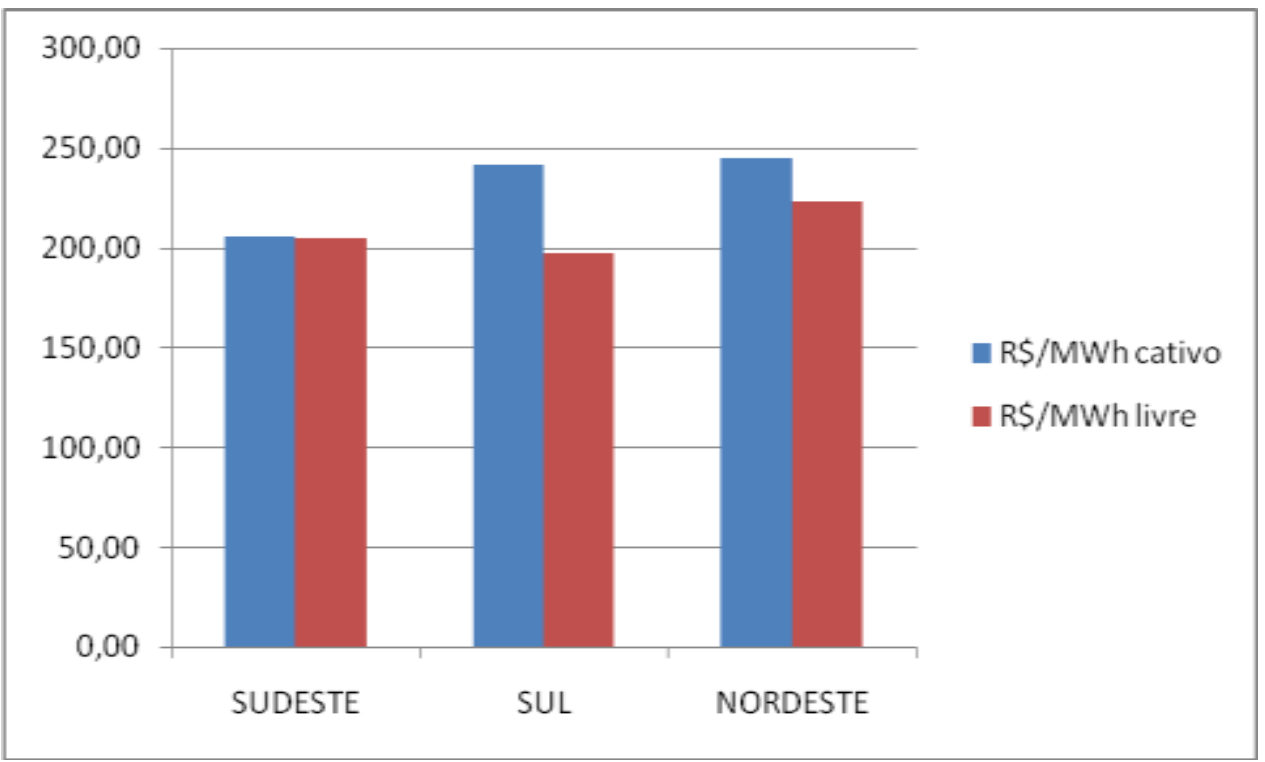

Figura 37 - Variação Custo Energia Simulação 5 


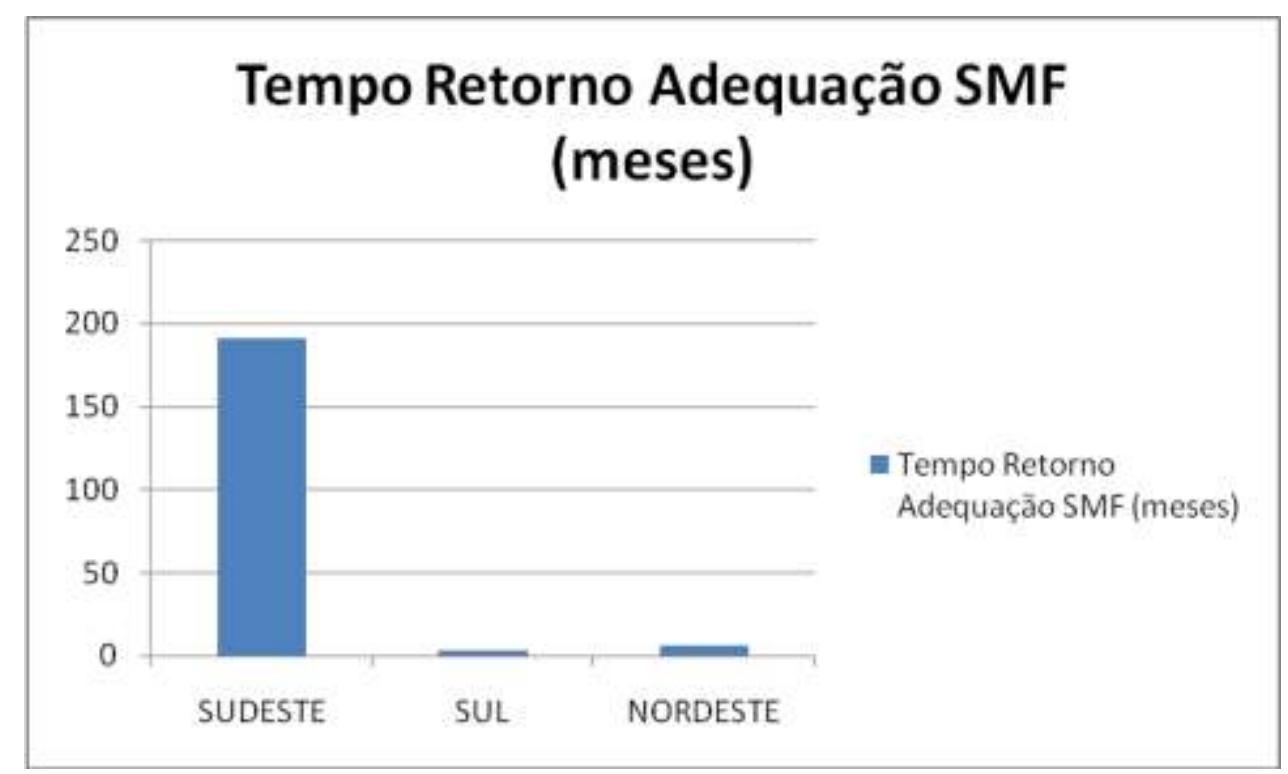

Figura 38 - Tempo Retorno Adequação SMF Simulação 5

Esta simulação indica que ao considerar que a tarifa do cativo começa a se tornar atrativa em relação ao mercado livre, os ganhos começam a ser reduzidos em algumas situações, pois as tarifas são muito diferentes e principalmente, na unidade conectada à Distribuidora da região Sudeste, o tempo de retorno do investimento é muito longo, o que faz pensar que o custo da energia no mercado livre não é atrativo para o Consumidor potencialmente livre, pois as simulações levam em conta o valor fixo da adequação do Sistema de Medição para Faturamento em todas as situações.

\section{- Simulação 6}

Empresa Tarifa Horo-Sazonal Verde (A3a)

Demanda Contratada $=2000 \mathrm{KW}$

Aquisição Fonte Alternativa $=$ Desconto $50 \%$ TUSD (Tarifa Uso Sistema de Distribuição)

Custo Previsto para adequação do SMF $=\mathrm{R} \$ 70.000,00$

Fator de Carga $=0,75$

Preço Médio R \$156,75/MWh

Empresa Distribuidora $A$ = Região Sudeste

Empresa Distribuidora $B=$ Região Sul

Empresa Distribuidora $\mathrm{C}=$ Região Nordeste 


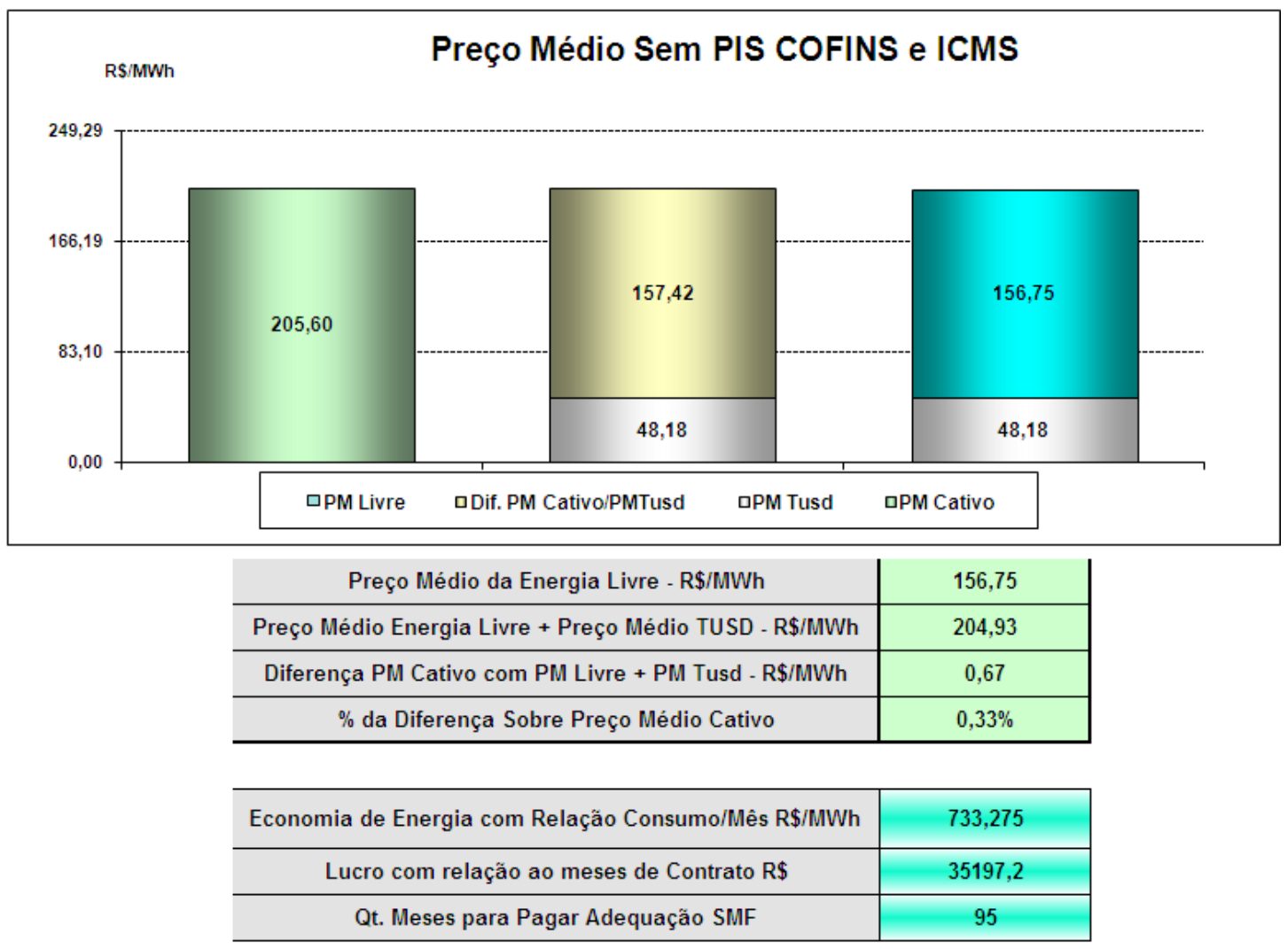

Figura 39 - Simulação 6: Distribuidora A Sudeste

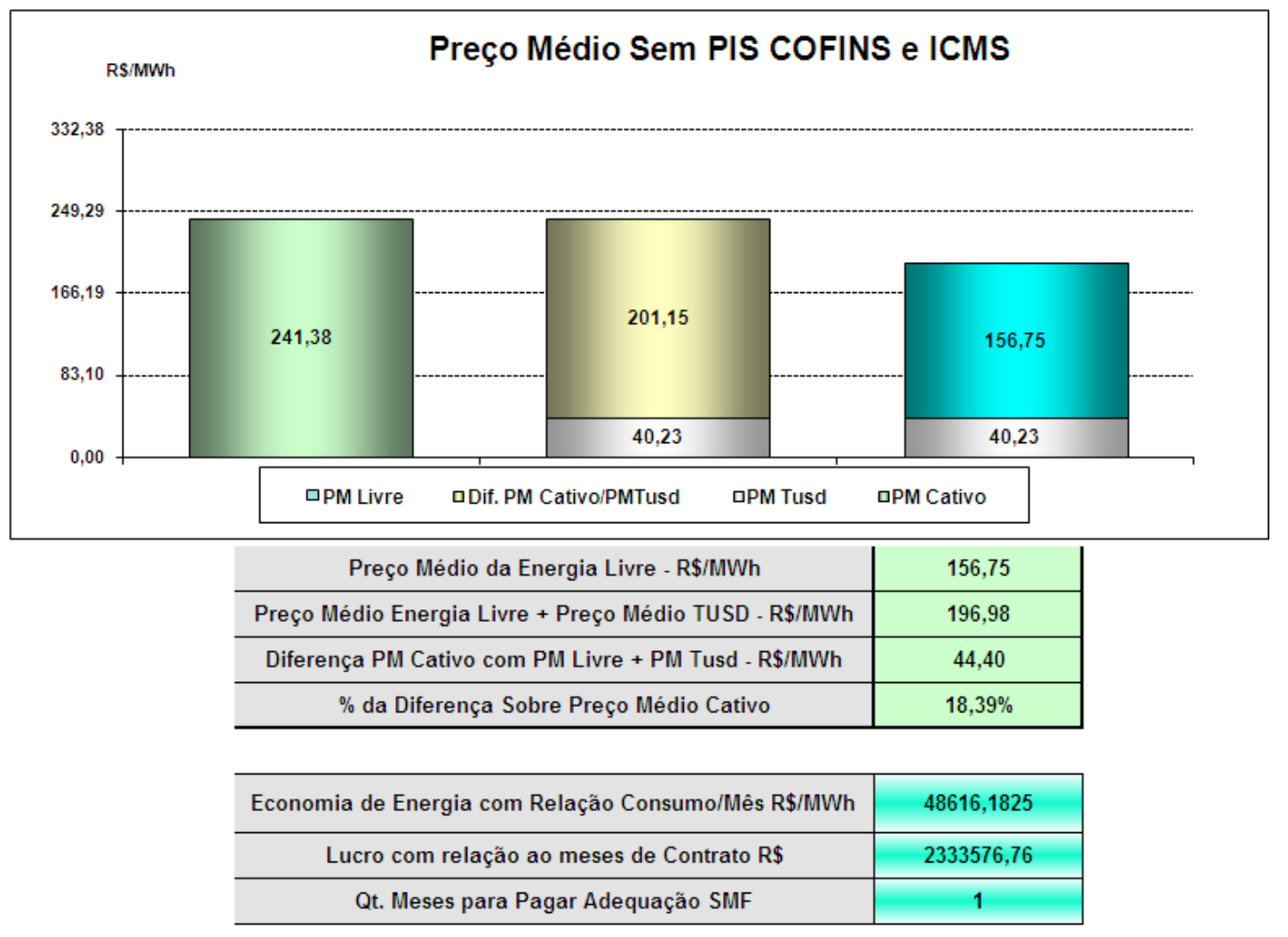

Figura 40 - Simulação 6: Distribuidora B SUL 


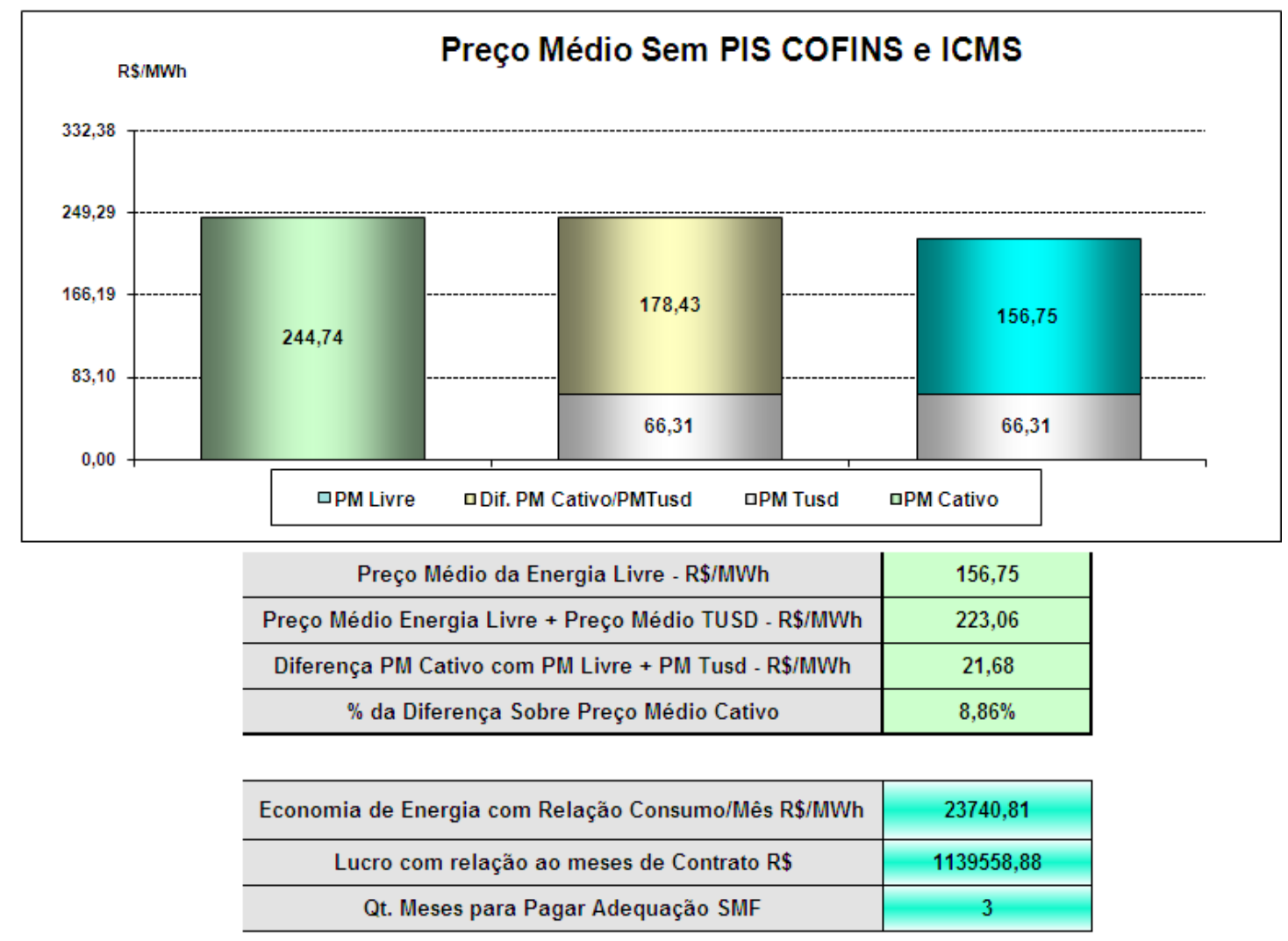

Figura 41 - Simulação 6: Distribuidora C Nordeste

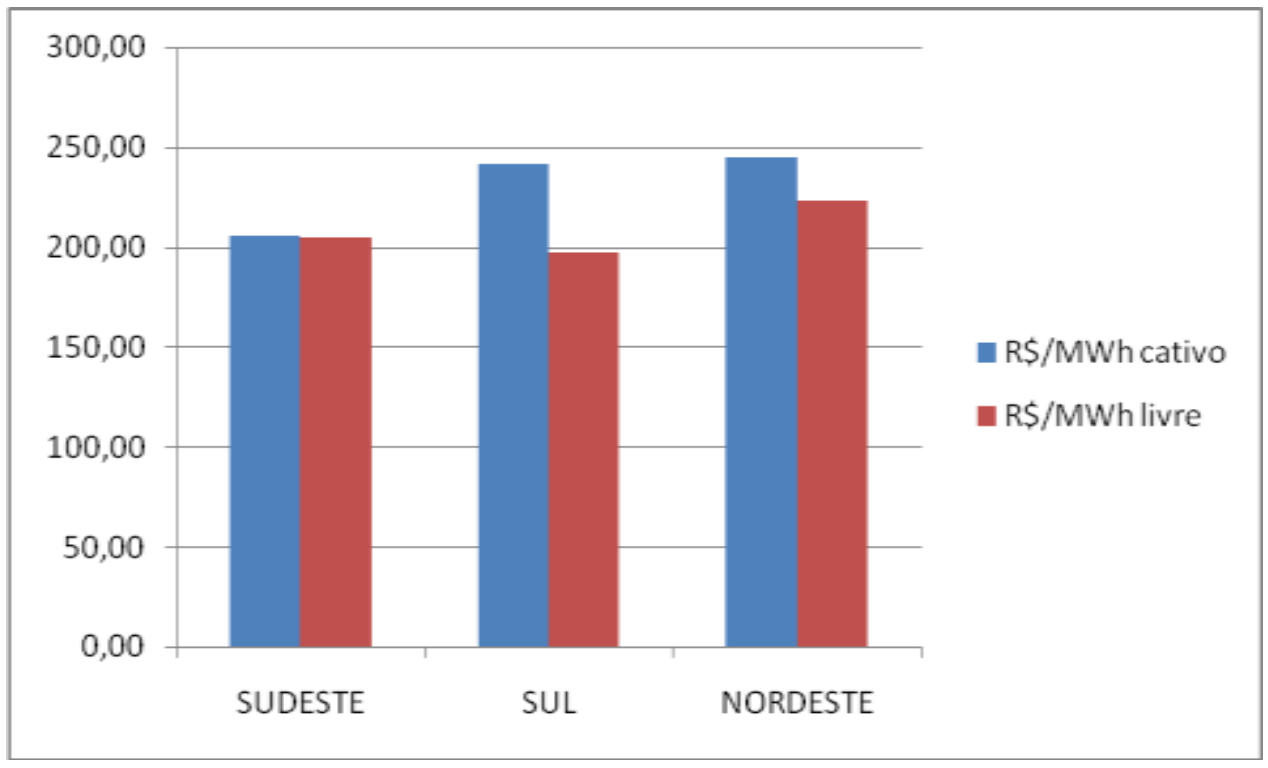

Figura 42 - Variação Custo Energia Simulação 6 


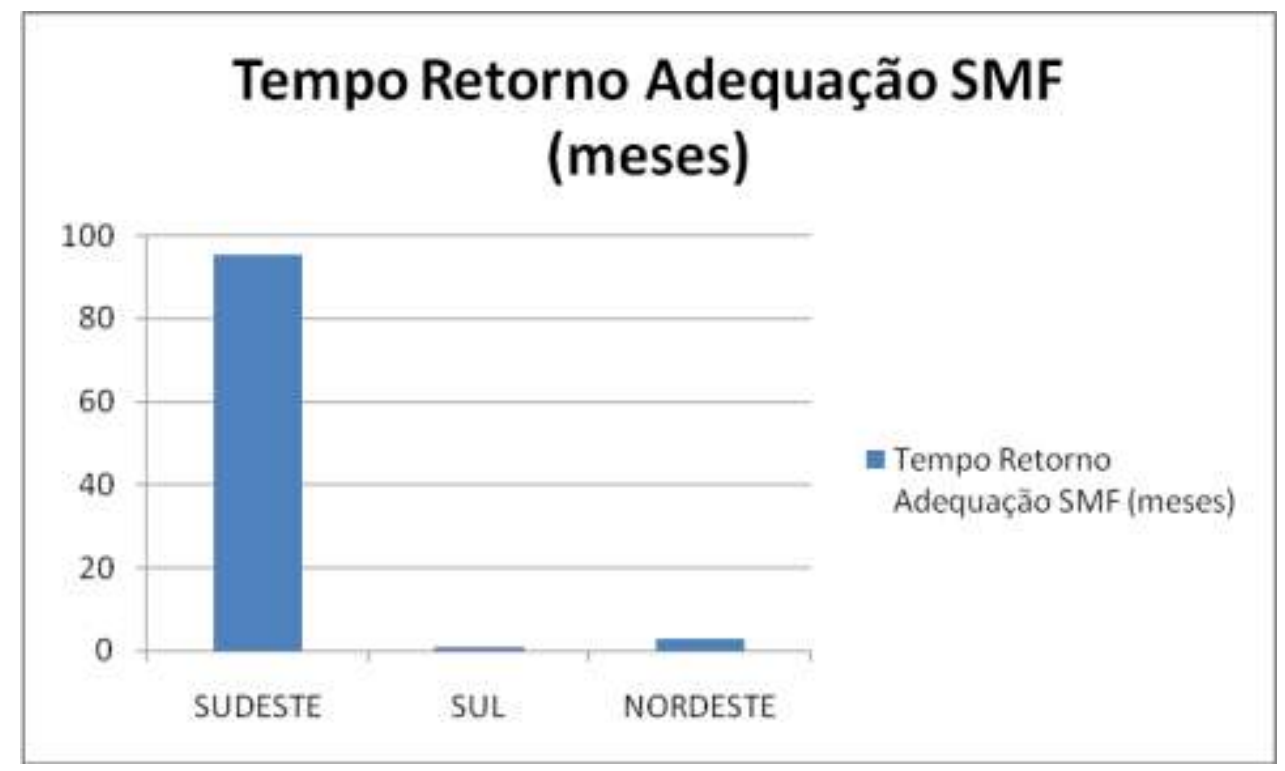

Figura 43 - Tempo Retorno Adequação SMF Simulação 6

Esta simulação indica que mesmo para uma unidade de maior demanda e, portanto maior consumo de energia elétrica, a tarifa do cativo começa a se tornar atrativa em relação ao mercado livre, os ganhos começam a ser reduzidos em algumas situações, pois as tarifas são muito diferentes e principalmente, na unidade conectada à Distribuidora da região Sudeste, o tempo de retorno do investimento é muito longo, o que faz pensar que o custo da energia no mercado livre não é atrativa para o Consumidor potencialmente livre, pois as simulações levam em conta o valor fixo da adequação do Sistema de Medição para Faturamento em todas as situações.

A simulação 7 considera 0 custo de adequação do Sistema de Medição para Faturamento da ordem de $\mathrm{R} \$ 250.000,00$ e um contrato de energia no Ambiente de Livre Contratação de 4 anos.

\section{- Simulação 7}

Empresa Tarifa Horo-Sazonal Azul (A2)

Demanda Contratada $=3.000 \mathrm{KW}$

Aquisição Fonte Alternativa $=$ Desconto 00\% TUSD

Custo Previsto para adequação do SMF $=R \$ 250.000,00$

Fator de Carga $=0,75$ 
Preço Médio $\mathrm{R} \$ 126,25 / \mathrm{MWh}$

Empresa Distribuidora $A$ = Região Sudeste

Empresa Distribuidora $B=$ Região Sul

Empresa Distribuidora $\mathrm{C}=$ Região Nordeste

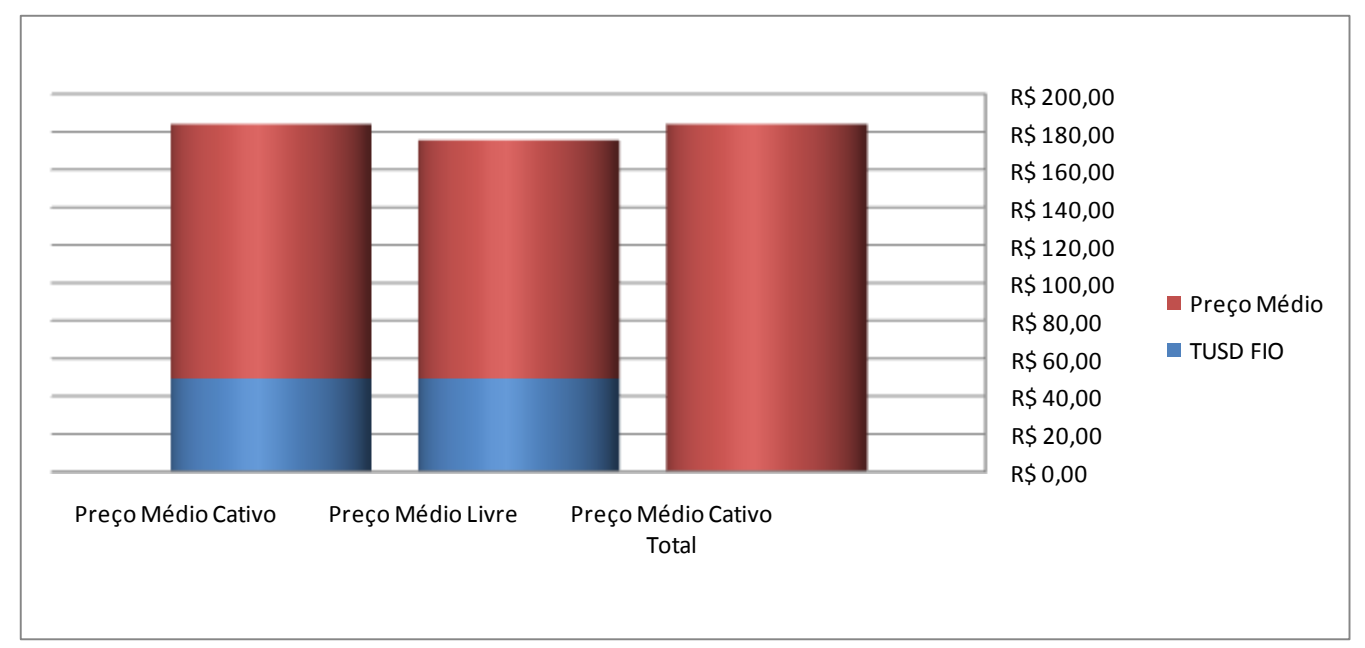

\begin{tabular}{|c|c|c|c|}
\hline & Preço Médlo Cativo & Preço Médio Llvre & Preço Médlo Cativo Total \\
\hline TU5D FIO & FS 49,32 & R5 49,32 & \\
\hline Preço Médlo & RS 134,68 & $\operatorname{RS} 126,25$ & RS 184,00 \\
\hline
\end{tabular}

Economia de Energia com Relação ConsumoMlès R\$MAWh

R\$ $13.850,74$

Lucro com relação ao meses de Contrato Rs

$\%$ sobre o Preço Cativo

R3 $664,835,58$

Valor da Adequação de Iledição

$5 \%$

Qt. lleses para Pagar Adequação S.IF

Rs 250.000

18

Figura 44 - Simulação 7: Distribuidora A Sudeste 


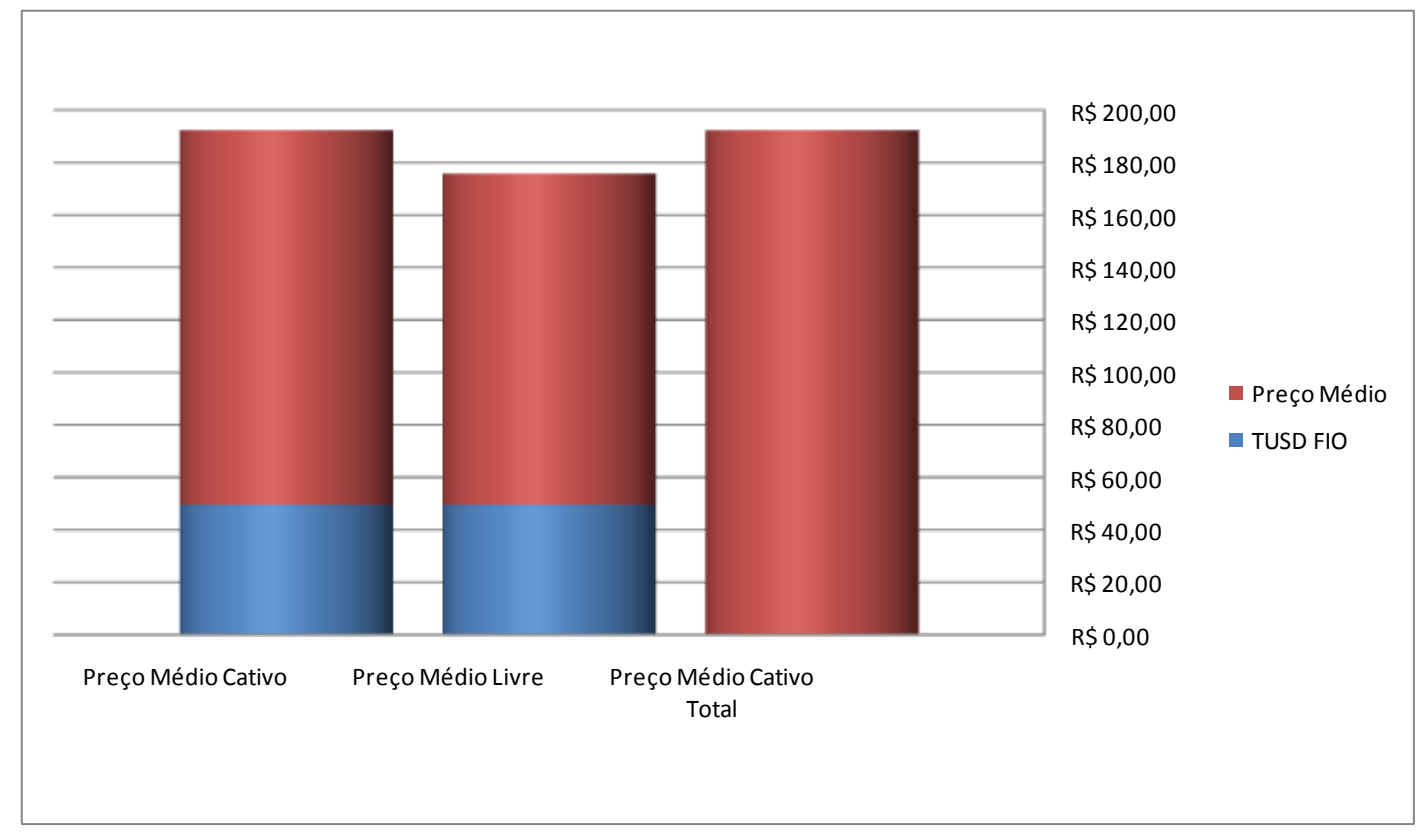

\begin{tabular}{|c|ccc|}
\hline & Preço Médlo Cativo & Preço Médlo Llvre & Preço Médlo Cativo Total \\
TUSD FIO & RS 49,49 & RS 49,49 & \\
Preço Médlo & RS 142,94 & RS 126,25 & RS 192,43 \\
\hline
\end{tabular}

\begin{tabular}{|c|c|}
\hline Economia de Energia com Relação Cons umo/llès RSMa Wh & RS $27,411,43$ \\
\hline Lucro com relação ao meses de Contrato RS & RS $1.315 .748,70$ \\
\hline Valor da A de quação de Mle dição & RS 250.000 \\
\hline \% sobre o Preço Cativo & $9 \%$ \\
\hline Qt. II eses para Paga r A dequação SIIIF & 9 \\
\hline
\end{tabular}

Figura 45 - Simulação 7: Distribuidora B SUL 


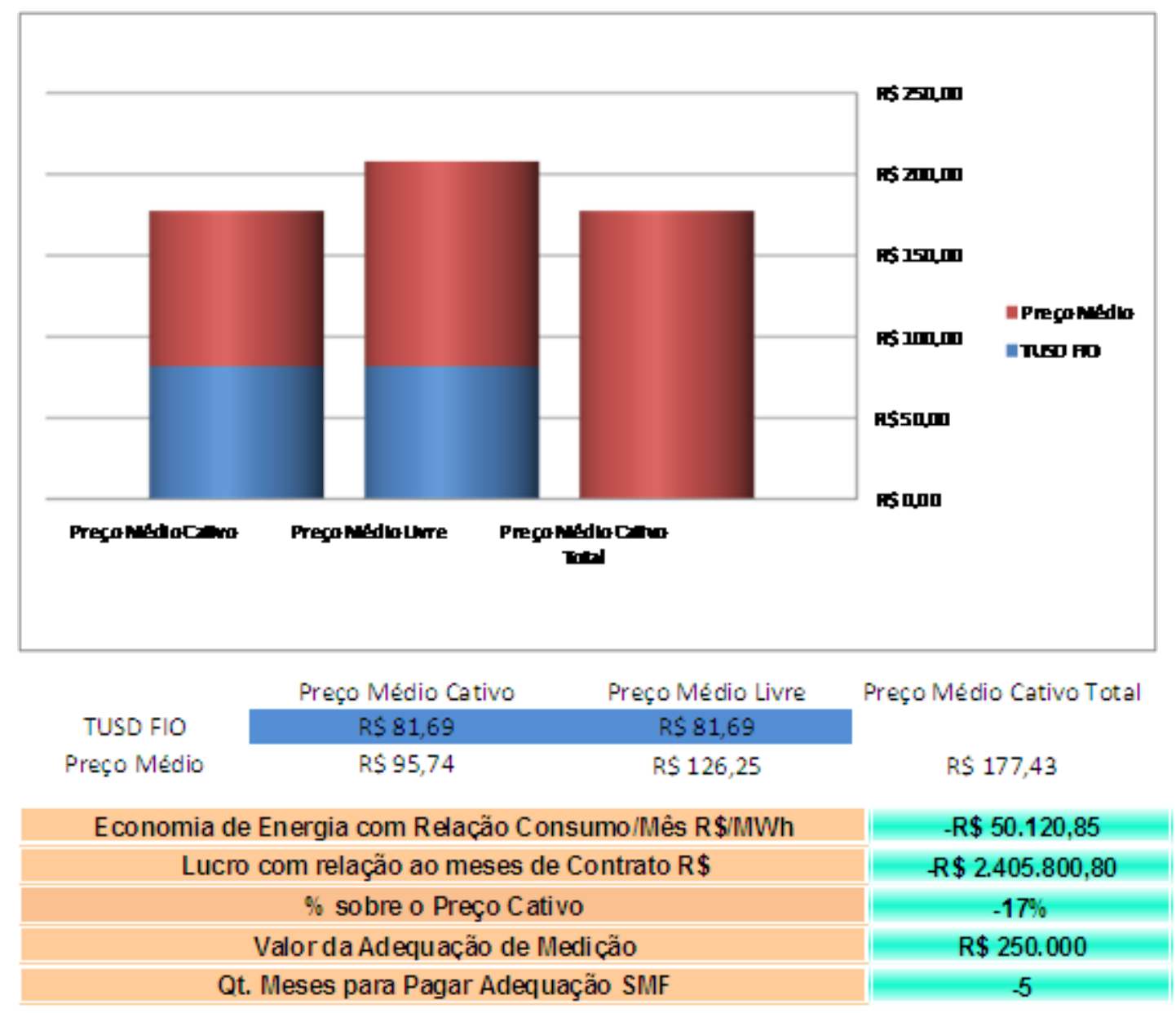

Figura 46 - Simulação 7: Distribuidora C Nordeste

As simulações foram realizadas utilizando-se as tarifas de energia elétrica do mercado cativo, as tarifas de uso de rede e o preço de aquisição da energia elétrica no mercado livre, cujo preço médio utilizado de $R \$ 156,75$, foi obtido a partir de pesquisa no mercado mediante a curva praticada pelas comercializadoras, levandose em consideração os contratos para os anos de 2008, 2009 e 2010. Os resultados finais indicam a economia mensal com o dispêndio para aquisição de energia elétrica, ou seja, qual a redução em $R \$$ que o consumidor livre aufere por ter migrado para o mercado livre em comparação com os custos do mercado cativo.

Com a eventual economia obtida nos quatro anos de contrato, pode-se então calcular o "pay-back" referente ao custo de adequação do SMF, ou seja, em quanto tempo o investimento inicial com a adequação do SMF retorna ao consumidor livre, sendo este fator muito importante quando da decisão de migrar ou não para o 
mercado livre, embora a análise definitiva deve ser efetuada de forma a considerar todos custos, não sendo possível embasar uma decisão de forma simplista por parte dos responsáveis.

Para o consumidor que está no mercado cativo e que possui as características desta simulação, dependendo da região onde se localiza a instalação, torna-se desestimulado a migrar para o Ambiente de Livre Contratação - ACL, em virtude dos custos finais de energia e encargos não serem atrativos principalmente na região Nordeste onde a tarifa de energia no mercado cativo é bem atrativa.

Nas demais regiões Sudeste e Sul, embora o tempo de retorno do investimento na adequação do Sistema de Medição para Faturamento seja pequeno, o valor mensal de diferença do custo de energia não é interessante sendo da ordem de 5 e $9 \%$ de economia mensal em relação ao mercado cativo.

Como avaliação das simulações, conclui-se que para os consumidores atualmente tarifados no mercado cativo (A4 e A3a) que usufruem de desconto no uso de rede e considerando o porte da instalação, torna-se atrativo migrar para o ambiente livre que além do retorno do investimento da adequação do Sistema de Medição para Faturamento o percentual de redução da aquisição da energia também é considerável.

As unidades supridas atualmente em tarifa (A2) começa a não ser viável migrar para o Ambiente de Livre Contratação - ACL frente aos custos de adequação e ganhos auferidos com a aquisição de energia, sendo, portanto necessário se realizar um avaliação mais criteriosa para tomada de decisão.

Outro ponto importante observado é que a avaliação final deve considerar os custos relativos à medição, o de aquisição de energia no mercado livre e as tarifas de uso de rede, que são diferenciadas em cada área de concessão. Após esta análise é que efetivamente é possível se tomar a decisão e não apenas se basear em um único dispêndio, o de medição, que invariavelmente é apontado como fator inibidor para a migração. 


\section{FLEXIBILIZAÇÃO DOS REQUISITOS TÉCNICOS - PEDIDOS DE EXCEPCIONALIDADE}

Com referência ao atendimento de todos os requisitos técnicos previstos no Anexo I do Submódulo 12.2 dos Procedimentos de Rede do ONS, quando da instalação e/ou adequação dos Sistemas de Medição para Faturamento, ao longo do tempo surgiram inúmeras situações que merecem destaque.

Surgiram as seguintes solicitações de excepcionalidade:

- Compartilhamento de enrolamento de Transformadores para Instrumentos (Transformadores de Corrente e Transformadores de Potencial);

- Utilização de medidores dotados de recursos de algoritmo de compensação de perdas;

- Utilização do terceiro medidor, além dos medidores principal e retaguarda previstos para serem instalados em uma determinada instalação;

- Utilização de Medição por Diferença, ou seja, se apurar o montante de energia de um determinado Ponto(s) de Medição de Geração, Distribuição ou Cliente Livre a partir de cálculos de dados de medição existentes.

A CCEE e ONS possuem a prerrogativa de definição da localização dos Pontos de Medição e aprovação de projetos respectivamente, sendo que passaram a receber inúmeras solicitações que se enquadravam dentro de umas das situações relacionadas acima.

Uma constatação importante é que alguns Agentes de Mercado, sistematicamente, solicitam flexibilização dos requisitos constantes na Especificação Técnica para implantação dos Sistemas de Medição para Faturamento, a CCEE e ONS iniciaram a avaliação das solicitações e deliberaram pela aceitação das solicitações, caracterizando assim flexibilização para implantação dos Sistemas de Medição para Faturamento. 


\subsection{Compartilhamento de enrolamento de transformadores para instrumentos (transformadores de corrente e transformadores de potencial)}

Com relação a este tema, o disposto no item 1.2.2.2 - Transformadores para Instrumentos do Anexo I do Submódulo 12.2 dos Procedimentos de Rede do ONS, estabelece que:

Os secundários exclusivos para medição de faturamento dos $\mathrm{TI}$ devem ter classe de exatidão 0,3 ou melhor, para todas as cargas, e para todas as relações, consideradas as condições de projeto, e para a freqüência nominal do sistema. (ONS, 2008, Submódulo 12.2, p. 18).

Os secundários dos Tranformadores para Instrumentos devem ser exclusivos para medição de faturamento não devendo ser compartilhados para outras utilizações como por exemplo: proteção, medição de controle e alimentação de outros equipamentos.

As solicitações de excepcionalidade se devem ao fato de que normalmente não existe espaço físico para se instalar novos Transformadores de Instrumentos para a realização de medição, de montantes de energia, nos Pontos de Medição localizados em Subestações de Rede Básica, quando da derivação de alimentação para empresas de Distribuição de energia elétrica.

Nesta situação, já existe equipamentos instalados, embora sejam de propriedade da empresa de Transmissão, que neste caso é a proprietária da instalação, sendo que o pedido é que seja aceito o compartilhamento do enrolamento dos Transformadores de Instrumentos, evitando-se assim a necessidade de realização de obras de adequação das instalações visando a liberação de espaço para a instalação de novos equipamentos.

As solicitações são encaminhadas para a CCEE e ONS através de correspondência formal acompanhada de Relatório Técnico que comprove a inexistência de espaço físico para a instalação de novos Tranformadores para Instrumentos. 
Após a análise e deliberação para o compartilhamento, os Agentes responsáveis e interessados pelo compartilhamento devem, através de acordo operacional, definir as regras básicas de intervenção nos equipamentos visando minimizar os impactos que possam ser ocasionados quando das interveções ocasionadas por realização de manutenções corretivas ou preventivas nos equipamentos.

A CCEE e ONS mantêm em seus registros o controle dos Pontos de Medição que possuem autorização em caráter excepcional para operarem desta forma.

\title{
11.2 Utilização de medidores dotados de recursos de algoritmo de compensação de perdas
}

Este recurso trata-se de uma excepcionalidade e que apenas alguns medidores possuem caracterísiticas técnicas que atendem as exigências do Submódulo 12.2 dos Procedimentos de Rede do ONS e foram analisados e aprovados pelo laboratório do CEPEL - Centro de Pesquisas de Energia Elétrica.

A definição estabelece que:

\begin{abstract}
Algoritmo de Compensação de Perdas de Transformadores é um recurso existente em determinados modelos de medidores que permite, através de uma parametrização específica no medidor, a reflexão da energia medida do lado secundário do transformador para o lado primário ou vice-versa, considerando adequadamente as perdas de transformação. (CCEE, 2008, www.ccee.org.br, em 'medição').
\end{abstract}

A utilização deste recurso está condicionada ao envio de pedido de excepcionalidade ao ONS/CCEE que procederão a análise. E somente são avaliados os pedidos para utilização em instalações existentes, não se aplicando a instalação novas, pois para estes casos deverá ser prevista a instalação do Sistema de Medição para Faturamento em local regulamentar definido pela CCEE. 
Com a crescente abertura do mercado e conseqüente aumento da quantidade de principalmente consumidores livres, cujas unidades se encontravam em condomínios ou complexos industriais. Dentro deste contexto, caso haja impedimentos técnicos para se efetuar a medição no local definido pela CCEE, ela poderá ser efetuada, mediante prévia autorização, no lado de baixa tensão dos transformadores ( ou no de alta tensão), refletindo-se as medidas para o lado de alta tensão ( ou baixa tensão ).

Os medidores a serem instalados deverão fazer parte da lista dos submetidos a testes, e aprovados pelo CEPEL, quanto ao recurso de compensação de perdas, e constantes no site da CCEE. Além disto, os medidores deverão armazenar tanto os valores compensados de energia como os não compensados, e permitir a coleta de ambos os valores pela CCEE.

Para que o ONS e a CCEE analisem o pedido de excepcionalidade, na solicitação do Agente responsável deve constar dados e informações que suportem a análise, tais como:

- Dados do fabricante e do modelo do medidor;

- Diagramas unifilares de cada instalação, com as indicações do ponto de medição e dos Transformadores de Corrente e Tranformadores de Potencial de medição a serem utilizados, e suas relações existentes / utilizadas, como também a classe de exatidão;

- Informações relativas aos transformadores de potência, relações, tipo de transformação usada (trifásica, banco monofásico ou autotransformador), número de enrolamentos ( 2 ou 3 enrolamentos ), a carga no enrolamento terciário (caso houver), existência de LTC e faixa de variação de taps;

- Relatório de ensaios do transformador de potência, onde conste as perdas em carga e vazio. 
A máxima variação de TAP permitida, de acordo com relatórios técnicos do CEPEL emitido para cada modelo de medidor, é de $+12,5 \%$ ( aditivo ) e $-12,5 \%$ ( subtrativo ). Para variações superiores, o Agente solicitante deverá encaminhar juntamente com a solicitação, um relatório técnico que comprove que o erro seja inferior à classe de exatidão do medidor.

O Agente de Medição não poderá solicitar a utilização do recurso do Algoritmo de Compensação de Perdas caso o transformador possua enrolamento terciário.

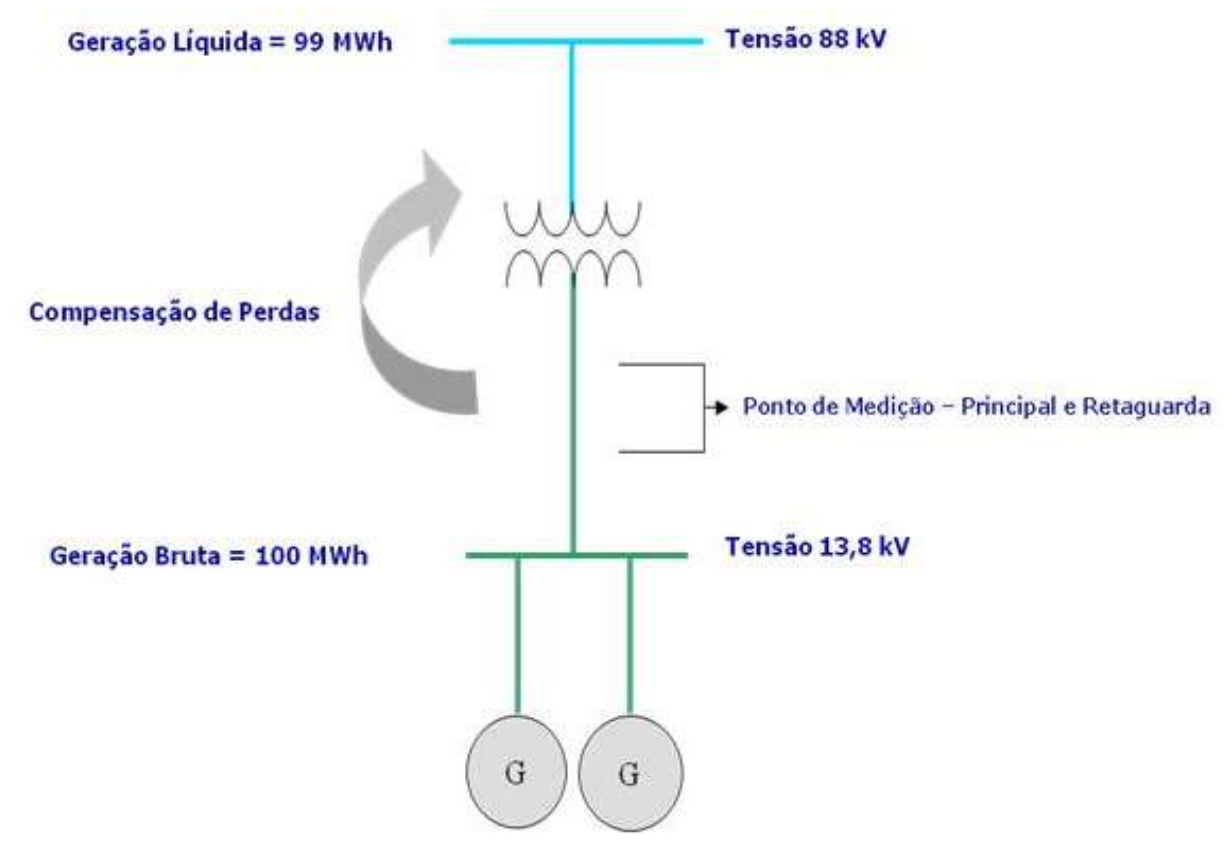

Figura 47 - Diagrama de Instalação utilizando o recurso de compensação de perdas em transformadores

\subsection{Utilização de terceiro medidor}

Com a finalidade de elucidar o que se trata esta excepcionalidade, torna-se importante destacar o que consta no item 5 do Anexo I do Submódulo 12.2 dos Porcedimentos de Rede do ONS, com relação a necessidade de instalação de medidores: 
enrolamentos secundários dos transformadores para instrumentos). Deve atender as características técnicas aqui especificadas, sobretudo, aquelas relativas à comunicação.

5.2 Esta medição deve ser instalada e comissionada conforme os critérios que foram estabelecidos para a medição principal.

5.3 A medição de retaguarda não é obrigatória nos pontos destinados a medição de geração. (ONS, 2008, Submódulo 12.2, p. 21).

Os Sistemas de Medição para Faturamento devem ser instalados prevendo-se que cada Ponto de Medição deve ser dotado de dois medidores denominados principal e retaguarda, com exceção de Pontos de Medição de geração bruta.

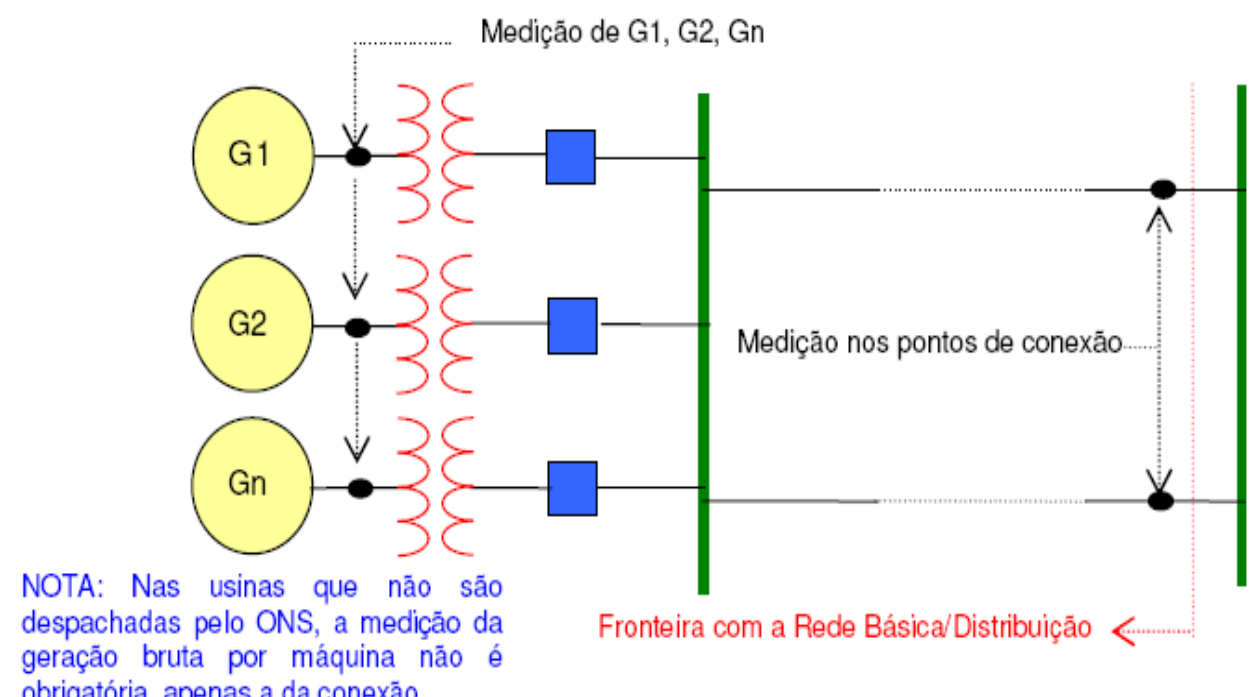

Figura 48 - Usinas conectadas na Rede Básica ou Rede de Distribuição Fonte: ONS (2008, Submódulo 12.2, p. 24).

$\mathrm{Na}$ figura 48 está caracterizada a situação onde uma determinada Usina está conectada na Rede Básica ou Rede de Distribuição, onde o responsável pela implantação do Sistema de medição para Faturamento e também pelo envio dos dados de medição para a CCEE é o dono do empreendimento, ou seja, o Agente Gerador. Nesta situação ocorre a necessidade de se celebrar os Contratos de Uso e Conexão de Rede, no caso de Rede de Transmissão (CCT/CUST) e no caso de Rede de Distribuição (CCD/CUSD). A empresa de Transmissão ou de Distribuição na qual a Usina está conectada, é responsável por permitir que a energia gerada seja distribuida através da sua rede, mediante o pagamento de um "pedágio" (tarifa de uso de rede de transmissão ou distribuição), que são homologadas pela ANEEL. 
Devido a necessidade de se apurar tais montantes, as empresas de Transmissão ou Distribuição, neste caso denominados de Agentes conectados, necessitam dos dados de medição para esta finalidade. Normalmente ocorre acordo entre os envolvidos para acesso aos dados via comunicação exclusiva, mas existem situações onde os Agentes conectados solicitam para a CCEE e ONS a autorização de instalação do terceiro medidor de sua propriedade visando a identificação de tais valores, se responsabilizando também pela instalação e manutenção dos equipamentos.

Este pedido deve ter autorização prévia do Agente proprietário da instalação, neste caso o proprietário da Usina.

Este tipo de solicitação é esporádica e a eventual autorização para instalação é precedida de uma análise por parte da CCEE e ONS. Quando da eventual autorização, o Agente solicitante é notificado de que os dados medidos e armazenados neste medidor não podem em hipótese alguma ser utilizados para a realização de enventuais questionamentos quanto aos dados obtidos na medição oficial, bem como não pode ser utilizado como base para a realização de ajustes de dados e eventuais pedidos de recontabilização realizados no âmbito da CCEE.

\subsection{Utilização de medição por diferença}

Trata-se da apuração de montantes de energia por diferença entre pontos de medição dotados de SMF, ou seja, apura-se o montante de energia de um determinado Ponto(s) de Medição de Geração, Distribuição ou Cliente Livre a partir de cálculos de dados de medição existentes.

Para esclarecer, cita-se o Anexo I do Submódulo 12.2 dos Procedimentos de Rede do ONS, onde está definido em seu item 6.1 os locais onde devem ser instalados os Sistemas de Medição para Faturamento, sendo: 
6.1 Para atender a contabilização da Câmara de Comercialização de Energia Elétrica, dos Encargos de Uso do Sistema de Transmissão e dos Serviços Ancilares, para verificar as capacidades declaradas de geração e o cumprimento das instruções de despacho, as medições de faturamento devem ser instaladas nos seguintes pontos:

- na conexão com a rede básica;

- na conexão com as Demais Instalações de Transmissão Compartilhadas DITC;

- na conexão de consumidor livre;

- nas unidades geradoras onde existe contabilização de serviços ancilares;

- na conexão entre sistemas de agentes que fazem parte da CCEE;

- na interligação internacional (importação e exportação de energia) nos sistemas interligados;

- na interligação entre submercados;

-nas unidades geradoras das usinas despachadas centralizadamente pelo ONS, para medição de geração bruta;

- nas unidades geradoras ou por grupo de unidades geradoras, para a medição de geração líquida;

- na conexão de autoprodutor;

- no autoprodutor, para a medição de geração bruta;

- serviço auxiliar de usinas e subestações. (ONS, 2008, Submódulo 12.2).

A localização de instalação dos Sistemas de Medição para Faturamento devem ser respeitados por todos os Agentes. Ocorre que sistematicamente os Agentes alegam para a CCEE e ONS sobre as dificuldades em se atender os aspectos constantes no Submódulo 12.2 dos Procedimentos de Rede do ONS, principalmente nas seguintes situações:

- Em Subestações Blindadas (SF6) o acesso é difícil para realizar substituições de Transformadores de Instrumentos (Transformadores de Potencial e Transformadores de Corrente);

- Necessidade de seccionar barramentos;

- Realização de obras para construção de novos cubículos de medição;

- Obras para instalação/adequação de alimentadores;

- Indisponibilidade de espaço físico para realizar as adequações necessárias;

- Dificuldade em separar a alimentação das unidades devido a existência de processos integrados (Ex: Complexos Industriais);

- Inviabilidade técnica e econômica;

A figura 49 ilustra uma situação onde torna-se possível verificar a necessidade de instalação de nove Sistemas de Medição para Faturamento para se apurar os 
montantes de energia consumidos pelos Agentes denominados neste caso de 'PO' e 'DC'.

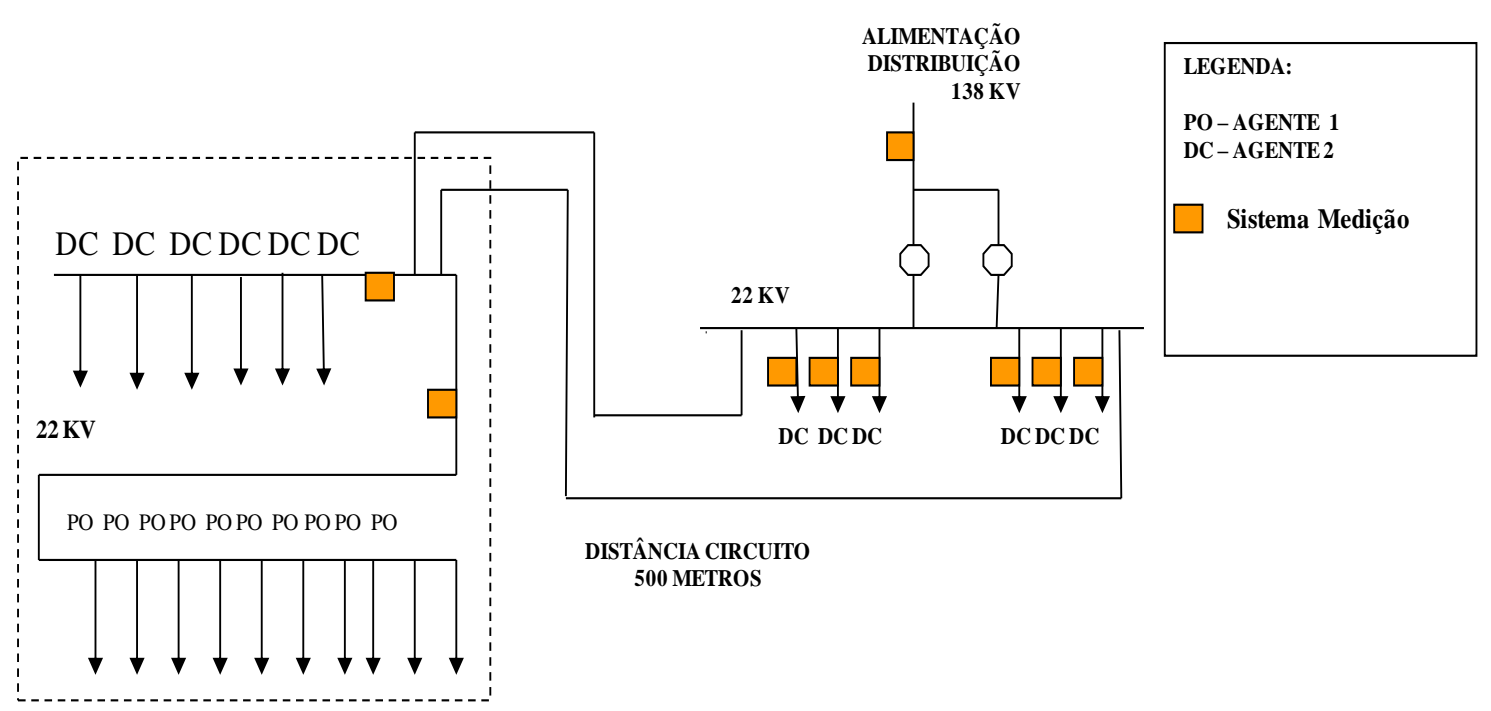

Figura 49 - Total de Sistemas de Medição a serem instalados no Complexo Industrial

Para exemplificar a questão de medição por diferença a figura 50 indica a redução da quantidade de Sistemas de Medição para Faturamento a serem instalados.

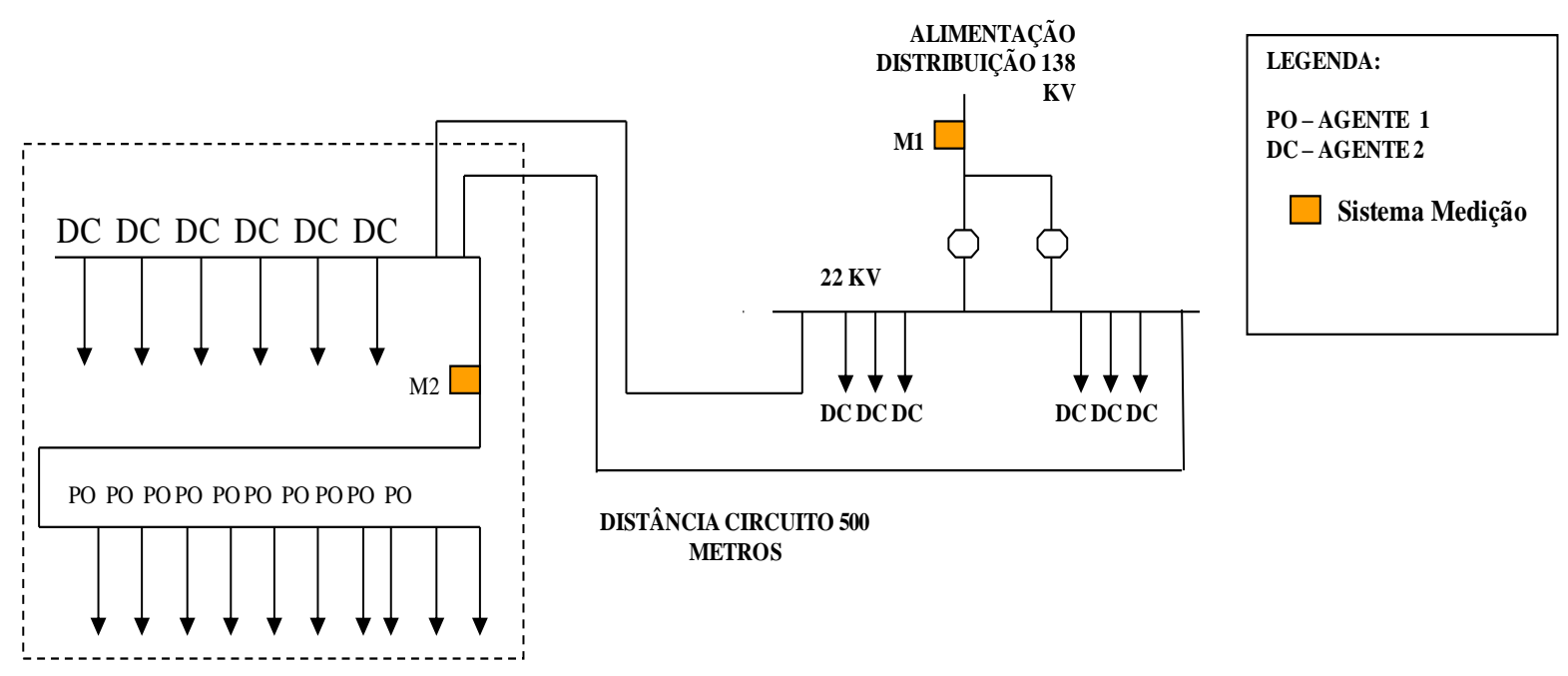

Figura 50 - Total de Sistemas de Medição a serem instalados após a autorização da medição por diferença 
Nesta situação a apuração dos montantes dos Agentes denominados 'PO' e 'DC' seria:

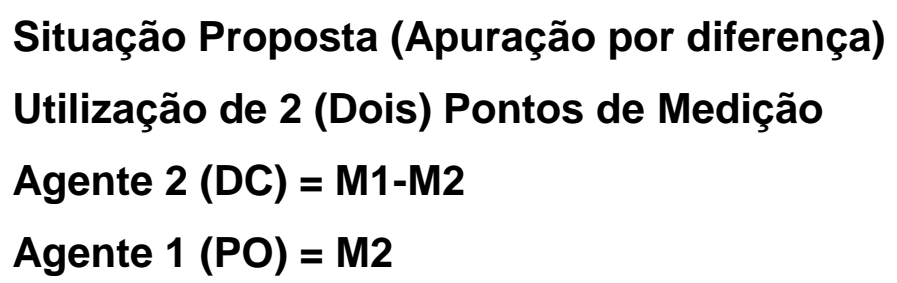

Após a análise de algumas situações particulares surgem as proposições de flexibilização, pois em determinadas situações, para possibilitar a apuração dos montantes de energia consumidos por consumidores livres em uma determinada instalação compartilhada, identifica-se a necessidade de instalação de mais de quarenta Sistemas de Medição para Faturamento o que sem dúvida pode vir a ser um fator de desestimulo para alavancar o mercado de contração livre de energia.

Não basta apenas nestas situações se definir pela medição por diferença pura e simplesmente, mas deve-se aqui, enumerar alguns cuidados quando da análise das solicitações, sendo que cada um dos casos merece análise particular devido às particularidades de cada um dos casos analisados.

Os aspectos a serem observados são:

- Se não existe restrição do ONS quanto à apuração por diferença, para verificação dos montantes de uso e conexão à Rede de Transmissão (CUST / CCT);

- Se não existe restrição do Distribuidor (para os envolvidos nos casos analisados) quanto à apuração por diferença dos montantes de uso e conexão à Rede de Distribuição (CUSD / CCD);

- A possibilidade de contabilizar adequadamente os montantes de energia individualmente para os Agentes envolvidos no âmbito da CCEE;

- Inviabilidade técnica para instalação dos Sistemas de medição para Faturamento; 
- Concordância dos Agentes envolvidos em assinar um acordo operacional que disciplina tais questões que por sua vez tem a CCEE e ONS como interveniente;

- Diminui investimentos dos Agentes na instalação/adequação dos Sistemas de Medição;

- Viabiliza a solução de casos complexos;

As atuais flexibilizações permitidas são analisadas conjuntamente pela CCEE e ONS, entretanto por se tratarem de excepcionalidades merecem análise criteriosa e não se deve se proliferar a quantidade de exceções permitidas, pois podem ocasionar problemas futuros com relação a possíveis divergências entre os Agentes envolvidos, como também impactar nos dados de medição obtidos para a instalação envolvida.

A CCEE e o ONS possuem o controle dos pontos de medição nos quais foram aprovados os pedidos de excepcionalidade, bem como avaliam permanentemente eventuais alterações ocorridas nas instalações que exigem eventualmente revisão nas exceções concedidas.

O mercado deve estar atento para este tema devido aos impactos que podem ocorrer com relação aos aspectos de negociação entre os Agentes, como também impactos na contabilização dos dados de medição no âmbito da CCEE, sendo que na ocorrência de situações rotineiras em que se traduzem em pedidos de exceção, torna-se necessário a avaliação dos aspectos técnicos exigidos o que pode levar a eventual reavaliação da Especificação Técnica do SMF atualmente vigente. 


\section{PENALIDADES DE MEDIÇÃO}

A Resolução Normativa ANNEL no 67, de 8 de junho de 2004, estabelece critérios para a composição da Rede Básica do Sistema Interligado Nacional. Determinava na oportunidade que o MAE - Mercado Atacadista de Energia Elétrica (sucedido pela CCEE - Câmara de Comercialização de Energia Elétrica) deveria disciplinar, nos PM - Procedimentos de Mercado (atual PDC - Procedimentos de Comercialização), as condições para aplicação de penalidades à concessionária ou permissionária de distribuição que não observar os limites estabelecidos, ou seja:

- Data limite de 31 de dezembro de 2004 para entrada em operação dos medidores; e

- Data limite de 30 de junho de 2005 para entrada em operação dos transformadores de instrumentos, com a classe de precisão requerida;

Esta situação é independente de eventual ação fiscalizadora da ANEEL.

No ano de 2007, a ANEEL instaurou a Consulta Pública 007/2007, cujo objetivo era obter subsídios e informações para elaboração de ato regulamentar a ser expedido pelo órgão regulador, para aprovação dos Procedimentos de Comercialização: PdC ME.04 - Mapeamento de Pontos de Medição no SCDE; PdC ME.05 - Manutenção do Cadastro de Medição do SCDE; PdC ME.06 - Coletar Dados de Medição do SCDE; e PdC ME.07 - Penalidades de Medição.

$\mathrm{Na}$ referida consulta pública ficou definido o período de 15/08/07 a 31/08/07 para envio das contribuições, mediante 0 intercâmbio de documentos. Ao término do período identificou-se um total de 48 (quarenta e oito) contribuições.

A ANEEL por sua vez, elaborou a Nota Técnica no 288/2007 SEM/SRT/SRD/ANEEL sobre o tema, que deu suporte a instauração da referida Consulta Pública. 
O Procedimento de Comercialização ME.07 - Penalidades de Medição disciplina três situações para aplicação de penalidade:

- Penalidade por Infração na Instalação e/ou Adequação do SMF - Sistema de Medição para Faturamento;

- Penalidade por Infração na Inspeção Lógica;

- Penalidade por Infração devido a Ausência de Coleta de Dados de Medição para Contabilização;

Seguem os principais aspectos das premissas referentes a cada um dos tipos de penalidades a serem apuradas.

\subsection{Penalidade por infração na instalação e/ou adequação do SMF (sistema de medição para faturamento)}

Premissas:

$\checkmark$ Penalidade aplicada para cada ponto de medição não instalado/adequado conforme requisitos técnicos previstos no Submódulo 12.2 dos Procedimentos de Rede do ONS;

$\checkmark$ O valor para aplicação da penalidade é definido pelo nível de tensão do ponto de medição, sendo que o montante a ser aplicado é de $\mathrm{R} \$ 5.000,00$ (cinco mil reais), multiplicado pelo Fator de Penalidade (FPE), sendo:

- $F P E=1$ para o nível de tensão de 2,3 kV a 25 kV;

- $\mathrm{FPE}=2$ para o nível de tensão de 30 kV a 44 kV;

- $\mathrm{FPE}=4$ para o nível de tensão de $69 \mathrm{kV}$;

- FPE=8 para o nível de tensão de 88 kV a 138 kV; e

- $\mathrm{FPE}=16$ para o nível de tensão de igual à superior a $230 \mathrm{KV}$. 
$\checkmark$ Para os pontos de medição de Consumidores Livres deverá ser prevista a notificação e cobrança das penalidades para os dois agentes envolvidos (Agente de Medição responsável e Cliente Livre);

$\checkmark$ Para os demais pontos de medição deverá ser prevista a notificação e aplicação das penalidades para o Agente de Medição;

$\checkmark$ Nova apuração a cada 120 dias a partir da data do efetivo pagamento da penalidade (reincidência).

\subsection{Penalidade por infração na inspeção lógica}

Premissas:

$\checkmark$ "Impossibilidade de realização de Inspeção Lógica pela CCEE, por motivo de responsabilidade do Agente de Medição, quando houver pelo menos 3 (três) tentativas fracassadas consecutivas", com intervalo mínimo de 1 (um dia) entre elas, sendo o Agente, na primeira tentativa fracassada, comunicado formalmente de sua condição irregular; (ANEEL, 2007, PdC, p. 1).

$\checkmark$ Apuração mensal;

$\checkmark$ A inspeção lógica a ser realizada nos medidores Principal e Retaguarda, quando aplicável;

$\checkmark$ Penalidade aplicada para cada ponto de medição, sendo que o montante a ser aplicado é de $R \$ 1.500,00$ (Um mil e quinhentos reais), multiplicado pelo Fator de Penalidade (FPE), sendo:

- FPE=1 para o nível de tensão de 2,3 kV a $25 \mathrm{kV}$;

- FPE=2 para o nível de tensão de $30 \mathrm{kV}$ a $44 \mathrm{kV}$;

- FPE=4 para o nível de tensão de 69 kV;

- FPE=8 para o nível de tensão de $88 \mathrm{kV}$ a $138 \mathrm{kV}$; e

- $F P E=16$ para o nível de tensão de igual a superior a $230 \mathrm{KV}$. 
$\checkmark$ Para todos os pontos de medição deverá ser prevista a notificação e cobrança das penalidades para o Agente de Medição;

\subsection{Penalidade por infração por ausência de coleta de dados de medição para contabilização}

As informações das horas faltantes dos pontos de medição serão apuradas nas situações em que ocorram um total superior a 120 horas ininterruptas faltantes ou 240 horas alternadas sem coletas (consideradas no mesmo mês de apuração), parametrizáveis no Sistema de Coleta de Dados de Energia, não justificadas para o mês de apuração em referência.

Premissas:

$\checkmark$ Ausência de dados de coleta em apuração de períodos com horas ininterruptas ou alternadas, de acordo com os critérios definidos no PdC ME.07;

$\checkmark$ Apuração mensal;

$\checkmark$ Penalidade aplicada para cada ponto de medição, sendo que o montante a "ser aplicado é o valor monetário do Valor de Referência (VR) pela quantidade de horas faltantes na Contabilização e pelo Fator de Penalidade (FPE)". (ANEEL, 2007, Nota Técnica n. ${ }^{\circ} 288$, p. 43). Sendo portanto:

- $\mathrm{FPE}=1$ para o nível de tensão de 2,3 kV a $25 \mathrm{kV}$;

- FPE=2 para o nível de tensão de $30 \mathrm{kV}$ a $44 \mathrm{kV}$;

- $F P E=4$ para o nível de tensão de 69 kV;

- FPE=8 para o nível de tensão de 88 kV a 138 kV; e

- FPE=16 para o nível de tensão de igual a superior a $230 \mathrm{KV}$. 
$\checkmark$ Para todos os pontos de medição deverá ser prevista a notificação e cobrança das penalidades para o Agente de Medição;

Este sinal é muito significativo para o estabelecimento de regras a serem cumpridas para o correto funcionamento do mercado, pois os Agentes proprietários dos Sistemas de Medição devem adequar os seus Sistemas de Medição, já que os dados a serem utilizados na contabilização/liquidação do mercado devem ser objeto de inspeções periódicas dos registros armazenados nos medidores instalados em campo, o que se traduz em maior confiabilidade dos dados utilizados no processo mencionado.

É importante ressaltar que após o processo de Consulta Pública instaurado pela ANEEL que culminou com o recebimento de contribuições de vários Agentes, de forma geral todos ficaram na expectativa da aprovação dos referidos Procedimentos de Comercialização, principalmente o Procedimento de Comercialização ME.07 Penalidades de Medição uma vez que o prazo de adequação dos Pontos de Medição de Clientes Livres, que já operavam no ACL era de 30/10/2007, conforme previsto na Resolução Normativa nº 248, de 23 de janeiro de 2007.

Após 30 de outubro de 2007, a quantidade de Pontos de Medição, sem adequação aos requisitos técnicos previstos no Anexo I do Submódulo 12.2 dos Procedimentos de Rede do ONS que já operavam na CCEE, aumentou gradativamente, justamente o contrário que se esperava quando do término previsto na regulamentação. Este número chegou a aproximadamente $50 \%$ do total de Pontos de Medição de Clientes Livres mapeados pela CCEE, pois muitos Agentes haviam concluído sua adesão ao mercado em data anterior a publicação da Resolução Normativa ANEEL nº. 248.

Posteriormente a data de 30 de outubro de 2007, a ANEEL em algumas oportunidades solicitou a CCEE o envio das informações da quantidade de Pontos de Medição que não possuíam o Sistema de Medição adequado, sendo constatado assim que efetivamente os Agentes não haviam implementado as adequações necessárias de sua responsabilidade.

As não conformidades mais usuais são: 
- Pontos de Medição não adequados/instalados;

- Pontos de Medição sem medidores de retaguarda (quando aplicável);

- Pontos de Medição sem acesso aos medidores para realização de Inspeção Lógica;

- Pendências junto ao ONS (Aprovação de Projeto de Medição e Relatório de Comissionamento);

Em 07 de março de 2008, através do Despacho no 934, a Superintendência de Estudos do Mercado da ANEEL aprovou os Procedimentos de Comercialização: ME.04 - Mapeamento de Pontos de Medição no SCDE; ME.05 - Manutenção do Cadastro de Medição do SCDE; ME.06 - Coletar Dados de Medição do SCDE; e ME.07 - Penalidades de Medição. Determinando assim que a CCEE realizasse a divulgação dos Procedimentos em até dez dias da data da referida publicação.

Portanto, se estabelece efetivamente um marco no Setor Elétrico Nacional no que diz respeito à medição de energia elétrica, pois embora as referidas penalidades já estivessem previstas de serem aplicadas em regulamentação, neste momento efetivamente dispõe-se de um documento que atribui à CCEE a aplicação de penalidades aos Agentes que operam no mercado e não cumprirem com suas obrigações com relação ao item medição, aplicando diretamente na contabilização do mercado os respectivos valores a serem pagos pelos Agentes.

No momento da aprovação do Procedimento de Penalidades de Medição, alguns Agentes estavam com os seus Sistemas de Medição completamente implantados em conformidade com o Módulo 12 dos Procedimentos de Rede do ONS, embora alguns não possuíam absolutamente nenhum Sistema implantado. Nota-se aqui que o processo realmente tinha discrepâncias muito significativas, pois os vários Sistemas implantados se confrontavam de outro lado com inúmeros sem implantação.

Cabe uma reflexão neste ponto, pois como é que um mercado pode operar em sua plenitude com um nível de inadimplência (apenas por não adequação/instalação) dos Sistemas de Medição, por parte dos Agentes que compõem esse mercado, que 
atingiu o patamar de 30\%. Este sinal de penalidade foi instituído por decorrência do nível de inadimplência ser considerável e que sistematicamente causavam inúmeros impactos nos processos de operação, contabilização e liquidação do mercado.

O objetivo de qualquer tipo de penalidade é sempre de caráter corretivo e não punitivo, ou seja, neste caso o mais importante não é efetivamente receber valores pagos a título de penalidade e de maneira alguma inviabilizar a operação no mercado de qualquer Agente, mas sim imputar penalidade aos Agentes que não cumprirem com suas obrigações, como de forma análoga a outros tipos de penalidades já aplicadas no âmbito da CCEE.

Ressalta-se que a definição por parte da ANEEL de aplicação de penalidades por nível de tensão, aplicando-se assim valores maiores para pontos de medição, cuja quantidade de energia transacionada é maior, é de fundamental importância, pois principalmente garante a aplicação de valores menores aos Consumidores Livres e Especiais, sendo que o sinal de penalidade não deve ser em hipótese alguma um fator de desestímulo para a continuidade da abertura de mercado, mesmo porque, não se pode mais migrar para o ACL, não estando com o Sistema de Medição para Faturamento adequado aos requisitos técnicos previstos no Submódulo 12.2 dos Procedimentos de Rede do ONS.

As penalidades apuradas e cobradas na Contabilização da CCEE são independentes das fiscalizações da ANEEL, o que pode sem dúvida ocorrer para o mesmo ponto de medição a aplicação de penalidades pela CCEE e a aplicação de multa por parte da ANEEL.

Com referência a efetiva cobrança das Penalidades de Medição, destaca-se que foi aprovado o novo Procedimento de Comercialização AM.14 - Gestão do Pagamento de Penalidades, cujo documento foi aprovado pelo Despacho SEM/ANEEL $n^{\circ}$ 2167, de 10 de junho de 2008, sendo que esta versão do documento já contempla as alterações descritas na Nota Técnica SEM/ANEEL n 156, de 23 de abril de 2008. Com a aprovação do referido Procedimento de Comercialização não há qualquer impedimento de ordem regulatória para se realizar a apuração e efetiva cobrança das Penalidades de Medição a serem contabilizadas e liquidadas pela CCEE. 


\section{PROPOSIÇÕES}

Em complemento ao mencionado no Capítulo 8, a questão fundamental é identificar os requisitos para eventuais flexibilizações na atual especificação técnica, pois a reflexão é no sentido de levar em consideração o critério de isonomia, o que pode servir de balizamento, como por exemplo, o critério utilizado nos mercados vizinhos, mencionado no Capítulo 7, que seria flexibilizar os requisitos técnicos para os menores níveis de tensão com conseqüente menor quantidade de energia transacionada.

Nestes casos poderiam ser incluídos, nesta eventual flexibilização, os Pontos de Medição de Pequenas Centrais Hidrelétricas - $\mathrm{PCH}$, Intercâmbio entre Concessionárias (Pequenas Cargas), Centrais Geradoras Hidrelétricas - CGH's.

No caso específico de Pontos de Intercâmbio entre Concessionárias nos quais existem contratos de compra e venda de energia, os Sistemas de Medição para Faturamento não foram instalados devido às seguintes alegações dos Agentes:

a) Existência de dificuldades técnicas para a instalação dos Sistemas de Medição para Faturamento, relativas à segurança e integridade dos equipamentos devido à localização do Ponto de Medição estar em área de difícil acesso e distante dos centros de manutenção das empresas;

b) Pequeno volume de energia comercializado nestes pontos entre as empresas em seus contratos de compra e venda de energia, face ao elevado custo de implantação dos Sistemas de Medição, o que no entendimento das empresas inviabilizam a instalação;

c) Em determinadas situações os Agentes de medição solicitam a flexibilização da não instalação do Sistema de Comunicação e se comprometem a instalar os equipamentos de medição, atendendo 
assim parcialmente os requisitos técnicos previstos no Módulo 12 dos Procedimentos de Rede do ONS;

d) Alguns Agentes solicitam flexibilização total dos requisitos técnicos, ou seja, manter eventualmente os equipamentos de medição instalados (que não atendem ao Módulo 12 dos Procedimentos de Rede do ONS), bem como não dotar o Ponto de Medição de Sistema de Comunicação, sendo que os dados seriam encaminhados para a CCEE uma única vez por mês (em formato arquivo tipo "txt") a serem inseridos pelo Agente diretamente no Sistema de Contabilização e Liquidação (SCL) da CCEE. Esta prática não possibilita a realização de Inspeção Lógica dos dados armazenados na memória de massa dos medidores;

Nesta situação, sugere-se o envio de um leiturista ao local para realizar a coleta por meio de leitoras ou até mesmo notebook, visando o posterior envio dos dados de medição para a CCEE apenas uma vez por mês com todos os registros mensal do Ponto em questão.

A análise destas proposições de flexibilização deve ser realizada dentro de uma visão operacional e regulatória.

De ordem operacional não ocorre nenhum problema, pois mensalmente um leiturista pode se dirigir ao Ponto de Medição e realizar a coleta dos dados mensais diretamente nos medidores (obrigatoriamente devem ser eletrônicos e dotados de memória de massa) utilizando leitora ou notebook e posteriormente encaminhar os dados para a CCEE, embora aqui se depare com uma questão de isonomia, pois de um total de 66 Pontos de Medição nesta situação, se tem uma quantidade de 40 Pontos de Medição sem Sistema de Medição adequados aos requisitos técnicos exigidos, o que representa um total de $60 \%$.

Invariavelmente, todos os Pontos de Medição localizados no Sul, Sudeste e CentroOeste do Brasil estão com os Sistemas de Medição adequados o que pode 
representar um tratamento não isonômico entre todos os Agentes, pois muitos investiram nas adequações/instalações mesmo em locais de difícil acesso ou mesmo desprovidos inicialmente de recursos de Comunicação de Dados. Neste contexto, torna-se preocupante o critério a ser adotado também pelo órgão regulador no que diz respeito às sanções a serem aplicadas pelo não cumprimento das obrigações regulatórias.

Outra preocupação é sobre o eventual critério a ser utilizado para a desobrigação do Sistema de Comunicação, pois critérios a princípios factíveis, seria o montante de energia transacionado nestes pontos ou até mesmo o nível de tensão, embora como segunda opção. Entretanto, uma análise mais apurada apresenta-se uma questão que deve ser avaliada de forma geral, ou seja, estaria desobrigado de dotar o ponto de sistema de comunicação se comprovadamente não existir tal opção, sendo esta situação uma excepcionalidade e deveria ser tratado em solicitação específica.

Com relação aos empreendedores de geração, com certeza ocorreria grande quantidade de solicitações para que seus empreendimentos sejam contemplados em tais flexibilizações, Pontos de Medição de $\mathrm{PCH}$ - Pequenas Centrais Hidrelétricas e CGH - Central Geração Hidrelétrica.

Como proposta, a sugestão é de reavaliar os atuais requisitos técnicos previstos no Anexo I do Submódulo 12.2 dos Procedimentos de Rede do ONS, que é o documento que atualmente baliza as adequações/instalações dos Sistemas de Medição para Faturamento, embora o documento tenha sido amplamente discutido no âmbito do mercado por representantes de todas as empresas do Setor Elétrico Nacional.

A análise dos mercados em outros países, indica que para diferentes níveis de tensão ou de montante de energia, é considerada a flexibilização da especificação dos equipamentos, fato este que não ocorre no mercado brasileiro.

Para início das discussões de análise dos requisitos técnicos previstos na Especificação Técnica, seguem os tópicos: 
- Criação de um Grupo de Trabalho, coordenado pela ANEEL que deve contar com ampla participação de representantes todos os Agentes de Mercado, entidades representantes de todas as categorias (Comercializadores, Distribuidores, Geradores, Transmissores e Consumidores), Universidades, Fabricantes de Equipamentos, CCEE e ONS;

- Análise das Especificações Técnicas existentes em outros países visando balizar as discussões sendo respeitadas as especificidades do Sistema Elétrico Nacional e particularidades do mercado de energia elétrica do Brasil;

- Premissas a serem analisadas: Tipos de Ponto de Medição, Demanda Contratada, Energia Comercializada no Ponto, Nível de Tensão e Localização, Inexistência de recursos tecnológicos para transmissão de dados;

- Aspectos inicialmente passíveis de aceitação: Dispensa da instalação de Sistema de Comunicação e extensão da flexibilização de utilização de medidores classe $0,5 \%$ (2 quadrantes) para Clientes Livres, sem distinção do nível de tensão, embora para unidades onde comprovadamente não exista geração interna;

Com referência aos impactos da adoção da aceitação de não se implantar Sistemas de Comunicação, pois as coletas seriam realizadas de forma única e mensal através de leitura local e posterior envio dos dados de medição para a CCEE, em arquivo cujo formato deve ser definido por esta entidade, pois para estes casos, não seriam realizadas as coletas de Inspeção Lógica dos dados, ou seja, acesso direto pela CCEE aos medidores. Isto implicaria também a não aplicação de eventual penalidade por não realização das Inspeções; 
Com relação à extensão da flexibilização não haveria problema, pois apenas seria necessário se promover as alterações necessárias no Módulo 12 dos Procedimentos de Rede do ONS.

Este Grupo de Trabalho poderia definir também um padrão de medição para consumidores residenciais, comerciais e industriais, preparando assim a especificação técnica do Sistema de Medição para Faturamento visando a futura abertura de mercado para estes tipos de consumidores.

Toda e qualquer alteração deve ser acompanhada da constante avaliação dos possíveis impactos no Módulo 5 - Sistemas de Medição do PRODIST Procedimentos de Distribuição de Energia Elétrica no Sistema Elétrico Nacional, no Módulo 12 dos Procedimentos de Rede do ONS e nos Procedimentos de Comercialização da CCEE.

A concepção de empresas certificadas, permitindo às mesmas implantarem os Sistemas de Medição para Faturamento de acordo com os requisitos técnicos vigentes, bem como de acordo com os padrões técnicos do Agente Conectado, instituindo assim um novo ator no cenário do setor promovendo uma alternativa para escolha do responsável quanto a implantação do seu Sistema de Medição para Faturamento.

Estas empresas deveriam manter corpo técnico comprovadamente habilitado para a execução das tarefas, possuírem material e equipamentos adequados para a execução das atividades e se responsabilizarem pela correta adequação/instalação dos Sistemas de Medição de acordo com o contrato firmado com o contratante, uma vez que através da emissão do Relatório de Comissionamento (pelo Agente Conectado) poderia se verificar que os requisitos técnicos previstos foram cumpridos em sua totalidade.

Outra sugestão seria utilizar medidores específicos a serem desenvolvidos e/ou adaptados, quando da aprovação de exceção de instalação de sistema de comunicação, pois estes medidores instalados teriam que disponibilizar os dados de energia criptografados, ficando assim em poder da CCEE a 'chave' para decifrar os 
códigos/dados, evitando-se assim qualquer interferência humana nos dados de medição, bem como no processo de geração dos dados a serem contabilizados pela CCEE.

Esta proposta necessita ser debatida com os fabricantes de equipamentos, visando a viabilização da implementação de tal funcionalidade em seus equipamentos, embora não se deva esquecer que para o fabricante é importante ter mercado para os seus produtos e para os usuários o custo deve ser atrativo, não devendo ser assim criada uma situação onde se teria a viabilidade técnica, embora o custo poderia ser um fator de desestímulo para a implementação da solução.

As Universidades podem participar ativamente do desenvolvimento destes medidores em seus Projetos de P\&D.

A eventual adoção desta solução, traria alguns impactos nos processos atuais de coleta de dados realizadas pelo Sistema de Coleta de Dados de Energia - SCDE da CCEE. Os aspectos a serem avaliados neste caso são:

- Reavaliação do módulo de cadastro, necessário para adaptá-lo para reconhecimento deste tipo de medidor e respectivo(s) ponto(s) de medição que estaria(m) sujeito(s) a esta situação;

- Avaliação do módulo de coleta, pois seria necessária a criação de opção para inserção direta do arquivo por parte do agente responsável (file upload), tendo o sistema a necessidade de reconhecer tal arquivo após a realização das devidas consistências: Código do medidor, número de série e constante de integração;

- Definição da "chave de acesso" para decifrar os códigos e de que forma seria realizado o acesso aos dados de forma a manter a preservação dos registros;

- Definição da eventual desobrigação de realização de Inspeção Lógica dos dados de medição armazenados na memória de massa dos 
medidores. Tal desobrigação também impacta o processo de apuração e aplicação de eventuais Penalidades de Medição pela ocorrência do não sucesso nos acessos aos medidores;

- Face acima exposto, seria necessário se reavaliar o processo de apuração de Penalidades de Medição;

- Revisão nos Procedimentos de Comercialização da CCEE.

Outra proposta a ser considerada é o incremento do desenvolvimento de novos tipos de medidores eletrônicos, que poderiam ser instalados em unidades consumidoras ainda obrigatoriamente suprida no ACR, preparando-se assim a referida unidade para migrar para o ambiente $A C L$ quando a legislação assim o permitir. Tal sugestão vem de encontro com o disposto no PRODIST, pois passa a ser obrigatória a instalação de medidores de idênticas características técnicas tanto para os consumidores cativos (instalações novas) como para consumidores livres.

Seguem as características técnicas que são indispensáveis para este tipo de medição, ou seja, visando abranger consumidores residenciais, comerciais e industriais (pequeno porte):

- Medidor Estático (Energia Ativa, Energia Reativa, Demanda, Fator de Potência);

- Trifásico 3 elementos (4 fios)

- Classe de precisão $0,5 \%$ ou melhor;

- Dotado de LED's para aferição de energia ativa e reativa;

- Dotado de memória de massa;

- Multi-tarifa;

- Possibilidade de configuração de demanda programável em intervalos pré-definidos;

- Dotado de interfaces de comunicação;

- Saída de pulso ao usuário. 
Estes medidores podem ser projetados para atender às características próprias do mercado brasileiro, pois devem ser capaz de medir energia ativa e reativa, fator de potência e tarifa diferenciada, com possibilidade de oferecer outras funcionalidades como: saída digital de dados, pré-venda, desligamento e religamento remoto, alarme de ligação incorreta, operação programável e permitir o registro de falta de energia.

Existe também a possibilidade de introdução para os consumidores em baixa tensão, a chamada Tarifa Amarela que consiste na cobrança diferenciada ao longo do dia, aplicando valores distintos. A título de exemplo, os medidores poderiam operar com tarifas mais elevadas nos horários de pico - compreendido entre 17 e 20 horas, quando as distribuidoras normalmente registram um grande consumo - e com tarifas reduzidas nas demais horas do dia.

Como objetivo, de implantação de uma nova modalidade tarifária diferenciada para clientes ligados na baixa tensão (Tarifa Amarela), poder-se-ia incrementar o desenvolvimento de medidores para atendimento a esta aplicação específica mediante a avaliação tecnológica de medição existente, avaliar a resposta do consumidor ao sinal tarifário diferenciado, em termos de modulação de carga, avaliar a aplicação da tarifa sobre o sistema elétrico de distribuição em termos de deslocamento de demanda na ponta e os impactos econômico-financeiros da tarifa sobre a receita e a margem de comercialização de energia.

No que diz respeito aos principais benefícios pode-se destacar:

- Sinal tarifário diferenciado - Modulação de Carga;

- Comparação com as modalidades tarifárias monômia e binômia;

- Avaliação de novas tecnologias de medição de energia elétrica;

- Incremento no desenvolvimento de novos equipamentos;

- Mudança de hábitos de consumo;

- Postergação de investimentos em atendimento ao aumento de demanda por energia. 
Este tipo de equipamento pode vir a se tornar realidade no mercado, embora poderia existir Projetos de P\&D de Empresas em parcerias com Universidades, voltados a fomentar o desenvolvimento e com certeza reduzir os custos dos equipamentos.

Existem inúmeras possibilidades a serem discutidas visando a implementação da medição de energia nos vários segmentos, principalmente visando a ampliação da opção de abertura do mercado para novos consumidores poderem optar por comprar energia no ambiente livre, embora os aspectos de medição são sempre mencionados como possível fator de desestímulo para a migração dos consumidores, embora também neste ponto entende-se que o fator preponderante é o próprio custo da energia.

Toda e qualquer possível adoção de novos padrões e/ou especificações deve ser amplamente discutida com todos os envolvidos, ou seja, empresas, entidades representativas, fabricantes, órgão regulador, pois qualquer implementação teria considerável respaldo de todos os possíveis impactados.

A freqüente evolução da medição eletrônica já é realidade nos dias de hoje e de caráter irreversível, pois no Brasil existe um número considerável de consumidores, cuja medição é efetuada com medidores eletromecânicos, sendo assim os fabricantes também possuem interesse no desenvolvimento de novos produtos visando atender este segmento, o que serve sem dúvida como plataforma para a adoção de medição eletrônica para a abertura do mercado no futuro, chegando assim a atingir-se até o segmento residencial com liberdade de compra de sua energia de qualquer fornecedor que não o da distribuidora de energia da sua área de concessão, fato este que já ocorre em vários países do mundo. 


\section{CONSIDERAÇÕES FINAIS}

O tema medição de energia elétrica é freqüentemente abordado quando do atendimento às exigências para permitir a comercialização de energia no mercado, pois os dados de medição é insumo básico para permitir a efetiva contabilização e liquidação do mercado realizada pela CCEE.

As simulações realizadas no Capítulo 10 indicaram que para os Consumidores Livres e Especiais geralmente torna-se viável migrar para o Ambiente de Livre Contratação - ACL, frente aos custos de adequação dos Sistemas de Medição para Faturamento, pois os custos de aquisição de energia no mercado livre atualmente são atrativos se comparados com o mercado cativo, embora a migração é viável se a aquisição de energia for realizada de fonte alternativa, já que usufruem de redução nos valores das tarifas de uso de rede.

Para os consumidores cujo enquadramento tarifário no mercado cativo é a tarifa horo-sazonal verde, cabe ressaltar que atualmente estes consumidores optam pela implantação de gerador diesel para suprir sua unidade de energia elétrica no horário de ponta, pois neste horário as tarifas no mercado cativo possuem custos consideráveis. Nesta situação se consegue redução da ordem de $18 \%$ com relação ao custo de aquisição de energia, sendo que caso nas simulações ocorra ganho igual ou superior a este índice o consumidor possa não optar por migrar para o mercado livre, embora tem-se aqui impactos ambientais com a conseqüente carbonização da matriz energética.

Para os Consumidores potencialmente livres, de grande porte, é menos atrativo migrar para o ACL, visto que eventuais ganhos não são significativos e os custos de adequação são consideráveis no dispêndio final por parte dos responsáveis.

Outro ponto importante observado é que a avaliação final deve considerar os custos relativos à medição, o de aquisição de energia no mercado livre e as tarifas de uso de rede, que são diferenciadas em cada área de concessão. Após esta análise é 
que se torna possível se tomar a decisão e não apenas se basear em um único dispêndio, o da adequação da medição nos padrões requeridos, que invariavelmente é apontado como fator inibidor para a migração.

As simulações indicam também que as análises devem ser efetuadas de forma a considerar todos os custos, não sendo possível embasar uma decisão de forma única e simplista.

A questão principal então é o fomento da oferta de energia ao mercado, principalmente a de fonte alternativa, pois com custos de energia atrativos, os custos de adequação da medição tornam-se cada vez menos um fator eventualmente impeditivo para continuidade da abertura do mercado para um grupo maior de consumidores, principalmente os especiais e no futuro os consumidores residenciais.

A evolução dos aspectos regulatórios é outro fator que se mostra cada vez mais imprescindível e sem dúvida é de fundamental importância para permitir a implantação de todos os Sistemas de Medição para Faturamento necessários em todo o Sistema Interligado Nacional, bem como o comprometimento de todos os Agentes envolvidos no cumprimento de suas obrigações legais.

Embora, cabe reflexão sobre o disposto na Resolução Normativa ํo. 247, de 21 de dezembro de 2006, que estabelece as condições para comercialização de energia oriunda de fontes incentivadas para unidade ou conjunto de unidades consumidoras com carga maior ou igual a $500 \mathrm{KW}$, pois para este porte de consumidor o custo da adequação do Sistema de Medição para Faturamento é considerável e não temos no momento incremento na quantidade de unidades que migraram para o mercado livre enquadradas nesta situação, portanto este tema merece uma revisão.

As possíveis flexibilizações devem ser analisadas em um ambiente que permita a participação de todos os envolvidos, e de forma multidisciplinar, que consiga promover o debate necessário para analisar as questões técnicas necessárias e imprescindíveis para a promoção do atendimento aos anseios do mercado, e permitir que as implantações dos Sistemas de Medição para Faturamento sejam 
realizadas buscando a racionalização dos custos sem se perder de vista a necessária qualidade técnica exigida.

A CCEE e o ONS que tiveram a missão de estruturar todo o processo de controle da implantação dos Sistemas de Medição para Faturamento, bem como, implantar seus Sistemas de suporte a estas atividades, primando assim pelo controle dos dados de medição sem perder de vista 0 atendimento aos padrões técnicos exigidos superaram alguns desafios, tais como:

- Diversidade de medidores instalados e respectivos protocolos;

- Infra-estrutura tecnológica diversas de comunicação de dados;

- Dispersão dos sistemas instalados em todo o território nacional;

- Diversidade de soluções de sistemas de cada Agente participante do mercado;

- Mapeamento e controle de todos os Pontos de Medição.

A participação dos fabricantes de equipamentos é imprescindível, pois a procura constante de novas tecnologias de medição para atendimento aos anseios de mercado está a cargo deste grupo empresarial. Por sua vez a inserção de Universidades no âmbito das discussões de possíveis flexibilizações de Especificações Técnicas, contribuição com novos conhecimentos tecnológicos adquiridos através de pesquisas específicas e até mesmo por origem de Projetos de P\&D devem ser previstos neste processo e a participação deve ser de forma constante.

É constatação também que o Setor Elétrico Nacional carece de um fórum permanente que promova os debates necessários que resultem no encaminhamento de soluções para a medição de energia elétrica, visando a troca de experiências, padronização de sistemas, acompanhamento da evolução tecnológica, adoção de novos padrões de medição e rastreabilidade de padrões de serviço utilizados em laboratórios de medição. 
Como sugestão, neste fórum específico, poderia participar representantes das empresas do Setor Elétrico, entidades de representação de classes, fabricantes de equipamentos, órgãos governamentais, universidades e entidades estrangeiras.

Outro tópico a ser mencionado é de que não existe a formação e/ou transmissão de conhecimentos para permitir a formação de profissionais da área de medição de energia elétrica, fato este que ao longo dos anos foi gradativamente reduzido em função da aposentadoria de vários profissionais e desativação dos Grupos de Medição das empresas do setor elétrico.

Como ponto positivo, observa-se constante evolução tecnológica nos equipamentos, sistemas de medição e de comunicação de dados, tornando assim irreversível e com opção de expansão da evolução tecnológica não só para atendimento ao mercado, mas também para outros segmentos, tais como: consumidores industriais de pequeno porte, comerciais e residenciais.

Este é um marco importante no que diz respeito à medição de energia elétrica, pois durante anos não ocorreu evolução tecnológica no Brasil, ficando assim apenas centrada na utilização de medidores eletromecânicos, embora precisos e funcionais, não permitem integração com os processos de automatização de leituras, diversificação de serviços, que poderiam ser oferecidos pelas empresas, e não compatibilidade com a abertura de mercado para livre opção de compra de energia. Entretanto, já existia em países da Europa e Estados Unidos a adoção de medidores eletrônicos e sistemas integrados sendo utilizados há muito tempo.

A implantação de um Sistema de Medição para Faturamento com novas especificações que atendam o mercado e a conseqüente necessidade de se instalar uma Central de Medição - principalmente em grandes empresas do Setor Elétrico Nacional, visando a centralização dos dados de medição necessários ao atendimento ao mercado, despacho e operação do sistema elétrico, programação de manutenção e planejamento - vem trazendo, ao longo de todo o processo de implantação, inúmeros desafios aos técnicos responsáveis, fabricantes de equipamentos e soluções, bem como de empresas de telecomunicações. Tal processo encontra-se atualmente em um estágio muito interessante, pois muitos dos 
desafios encontram-se superados podendo assim se estabelecer um novo paradigma para futuras implantações.

Em contrapartida aos desafios, ocorre notável desenvolvimento tecnológico dos equipamentos de sistemas de medição, uma vez que os próprios fabricantes vislumbram a possibilidade de venda de seus produtos para atender esta nova demanda de mercado. Um dos grandes desafios é o de adaptar em alguns casos equipamentos utilizados em outros países à realidade do mercado brasileiro, realizando-se assim uma customização dos equipamentos aos padrões e normas brasileiras.

A aplicação de novos equipamentos a serem utilizados em outros segmentos, podem permitir a medição de outros tipos de grandezas, tais como: fator de potência, qualidade de energia, registro de falta de energia, dados de tensão e corrente, possibilidade de corte e religa de unidades consumidoras sendo realizadas de forma automática e a distância, bem como os aspectos de redução de perdas técnicas e comerciais.

Possivelmente ocorrerá a abertura de mercado para outros tipos de consumidores, principalmente se ocorrer o incremento da oferta de energia no país, incluindo assim até os consumidores residenciais, e neste caso, poder-se-ia ter a necessidade de utilização de outros tipos de medidores e com certeza com custos mais atrativos, pois tendo o sinal de quantidade considerável de medidores a serem aplicados, os fabricantes se interessariam em desenvolver e fabricar equipamentos e com certeza ter-se-ia também um incremento da competição no mercado neste segmento.

No que diz respeito aos aspectos regulatórios, devido à necessidade de abertura do mercado no Brasil para aumentar a concorrência e também devido a transformações políticas e econômicas que aconteceram durante as últimas décadas, mudou-se para sempre o cenário nacional de comercialização de energia elétrica, tais mudanças vieram de um estudo do governo em base de outros mercados de energia existentes no mundo, sendo que dentro deste novo cenário a questão referente à medição de energia elétrica é de fundamental importância devido à necessidade de se atingir estabilidade regulatória, existência de especificações claras e factíveis de 
serem implantadas e sinais de penalidades a serem aplicadas de forma a sinalizar aos inadimplentes a necessidade de se atender todas as exigências regulatórias para operar no âmbito do mercado.

Nos documentos regulatórios emitidos durante os anos de 2007 e 2008, o órgão regulador definiu prazos para a definitiva implantação dos Sistemas de Medição de Consumidores Livres e Especiais, bem como aprovou a aplicação de Penalidades de Medição aos Agentes inadimplentes, fato este que demonstra o interesse do órgão regulador em regularizar as inúmeras pendências existentes no momento, com relação às adequações/implantações dos Sistemas de Medição de responsabilidade dos Agentes, tornando assim as regras mais claras e tratadas de forma objetiva, visando dirimir eventuais dúvidas ou duplicidade de entendimentos dos aspectos regulatórios.

A CCEE e o ONS, precisam continuar executando suas tarefas visando garantir a continuidade da apuração dos dados de medição de todo o mercado, para realizar as contabilizações necessárias, a continuidade da garantia da transparência das operações, como também zelar pelo constante aprimoramento dos documentos que balizam as adequações/instalações dos Sistemas de Medição para Faturamento, neste caso específico o Módulo 12 dos Procedimentos de Rede do ONS.

Qualquer alteração deve ter a participação de todos os Agentes envolvidos, como também colher subsídios de forma sistemática para aprimorar os documentos no sentido de acompanhar a evolução tecnológica da medição de energia elétrica, bem como dos anseios dos Agentes.

No caso específico da CCEE, deverá ser constante a implementação de melhorias e novas funcionalidades do SCDE - Sistema de Coleta de Dados de Energia - SCDE e SCL - Sistema de Contabilização e Liquidação (SINERCOM), considerando os estágios de implementação de novas Regras de Mercado, avanços tecnológicos, aspectos de ampliação do mercado, buscando transparência e agilidade em suas operações visando inclusive a redução do prazo para término das contabilizações/liquidações do mercado. 
Sobre as proposições de possíveis flexibilizações para determinados casos, deve ser entendidas como saudáveis ao processo de aprimoramento das questões de medição, embora não se deva esquecer que existe a questão de isonomia e que qualquer decisão de possíveis flexibilizações de requisitos técnicos devem ser muito bem embasadas e criteriosas.

A questão da implantação dos Sistemas de Medição para Faturamento é de fundamental importância para a continuidade de solidificação da abertura do mercado no Brasil e não deve ser fator de desestímulo para a migração para o Ambiente Livre Contratação, mas os requisitos devem ser avaliados, pois com o passar do tempo as definições que balizaram a opção técnica devam ser revisadas mantendo o equilíbrio entre as necessidades técnicas e o custo financeiro das implementações e manutenções necessárias para manter os Sistemas em perfeito funcionamento.

Portanto, a principal reflexão é a necessidade de estabelecer um mercado sólido e competitivo de energia elétrica no Brasil, garantindo assim a expansão da oferta de energia elétrica necessária para garantir a estabilidade e o crescimento econômico do país, fator de promoção de melhor distribuição de renda e melhoria da qualidade de vida. 


\section{REFERÊNCIAS}

ABRACEEL - Associação Brasileira dos Agentes Comercializadores de Energia Elétrica - http://www.abraceel.com.br; acesso em 2008.

ABRADEE - Associação Brasileira de Distribuidores de Energia Elétrica http://www.abradee.org.br; acesso em 2008.

ABRAGE - Associação Brasileira das Empresas Geradoras de Energia Elétrica http://www.abrage.com.br; acesso em 2008.

ACTARIS Medidores eletrônicos. Medidores eletrônicos e seu valor agregado. Apresentação de slides em power point, 2008.

ANEEL - Agência Nacional de Energia Elétrica , http://www.aneel.gov.br/, acesso em 2008. energia.

. Lei $n^{\circ} 10.848$, de 15 de março de 2004. Dispõe sobre a comercialização de

Decreto $n^{\circ} 5.163$, de 30 de julho de 2004. - Regulamenta a Lei $n^{\circ} 10.848$ (comercialização).

. Decreto $n^{\circ} 5.177$, de 12 de agosto de 2004. - Dispõe sobre a Câmara de Comercialização de Energia Elétrica - CCEE

Despacho n.․ 934 SEM/ANEEL, de 07 de março de 2008 - aprova os Procedimentos de Comercialização ME. 04 - Mapeamento de Pontos de Medição no SCDE; PdC ME.05 - Manutenção do Cadastro de Medição do SCDE; PdC ME.06 Coletar Dados de Medição do SCDE e PdC ME.07 - Penalidades de Medição.

. Lei no 9074, de 07 de julho de 1995. Dispõe sobre normas para outorga e prorrogações das concessões e permissões de serviços públicos e dá outras providências.

. Lei o 9427, de 26 de dezembro de 1996. Dispõe sobre a instituição da Agência Nacional de Energia Elétrica - ANEEL, disciplina o regime das concessões de serviços públicos de energia elétrica e dá outras providências.

Nota Técnica no 0093/2007-SRD/ANEEL, "Análise dos Procedimentos de Distribuição - PRODIST, com enfoque nos pontos de destaque, nas inovações propostas e nos impactos regulatórios detectados." - ANEEL, Brasília, Novembro/2007. 
. Nota Técnica nº 288/2007- SEM/ANEEL, "Instaura a Consulta Pública, na modalidade Intercâmbio Documental, para subsidiar o processo de aprovação dos Procedimentos de Comercialização aplicáveis ao Sistema de Coleta de Dados de Energia (SCDE), em função da Resolução n 248, de 23 de janeiro de 2007."

. Nota Técnica nº 60/2007 - SEM/ANEEL, "Regras de Comercialização de Energia Elétrica aplicáveis a fontes incentivadas e consumidores especiais."

. Nota Técnica n. 105/2006-SEM/ANEEL. Análise das contribuições à Audiência Pública AP 040/2005, referente às Regras de Comercialização de Energia Elétrica relativas aos CCEARs por disponibilidade.

- Procedimentos de Distribuição de Energia Elétrica no Sistema Elétrico Nacional - PRODIST, Módulo 5 - Sistemas de Medição. 2008. Disponível no site <http://www.aneel.gov.br/arquivos/PDF/Modulo5_F.pdf> acesso em 2008.

Resolução ANEEL no 433, de 26 de agosto de 2003 - Estabelece os procedimentos e as condições para início da operação em teste e da operação comercial de empreendimentos de geração de energia elétrica.

- Resolução Autorizativa nํ 787, de 23 de janeiro de 2007 - Autoriza a utilização, em caráter provisório, da Revisão 1 do Módulo 12 dos Procedimentos de Rede do ONS.

- Resolução no 281, de 01 de outubro de 1999 - Estabelece as condições gerais de contratação do acesso, compreendendo o uso e a conexão, aos sistemas de transmissão e distribuição de energia elétrica.

Resolução Normativa no 248, de 23 de janeiro de 2007 - Alteram os dispositivos da Resolução Normativa no 67, de 08 de junho de 2004, bem como da Resolução nำ 281, de 01 de outubro de 1999.

- Resolução Normativa nํ 67, de 8 de Junho de 2004 - Estabelece os critérios para a composição da Rede Básica do Sistema Interligado Nacional.

. Resolução Normativa n. ำ 247 de 21 de Dezembro de 2006. Estabelece as condições para a comercialização de energia elétrica.

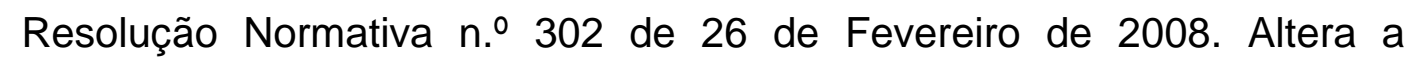
Resolução Normativa ํ․ 67 , de 8 de junho de 2004, que estabelece critérios para a composição da Rede Básica do Sistema Interligado Nacional.

BARONI NETO, Alexandre; MORETTI, Yandra Cristina. Análise dos Impactos da Implantação do Sistema Automático de Medição para a Contabilização do Mercado de Energia. Monografia apresentada ao Curso de MBA em Energia do PECE/EPUSP, 2007. 
BUTERA, Mauricio. Desregulación y fomento de la competencia en el mercado electrico Argentino. $2000 . \quad$ Artigo disponible no site $<$ http://www.aaep.org.ar/espa/anales/pdf_00/butera.pdf > acesso em 10/10/2008.

CAMMESA - Compañia Administradora del Mercado Mayorista Eléctrico - Argentina, http://www.cammesa.com.ar; acesso em 2008.

CEPEL - Centro de Pesquisas de Energia Elétrica. Avaliação de algoritmos em medidores para compensação de perdas de transformadores. 2001. Relatório técnico elaborado para CCEE.

CCEE - CÂMARA DE COMERCIALIZAÇÃO DE ENERGIA ELÉTRICA, http://www.ccee.org.br/, acesso em 2008.

CHAGAS, Eduardo Henrique Conceição - A medição de energia elétrica no ambiente competitivo do setor elétrico brasileiro, contemplando as relações geração-transmissão e transmissão-distribuição. 2004. 165 f. il. Dissertação (Mestrado em Regulação da Indústria de Energia). UNIFACS, Universidade Salvador. Disponível em

http://www.aneel.gov.br/biblioteca/trabalhos/trabalhos/Disserta\%C3\%A7\%C3\%A3o_ Eduardo\%20Chagas2004.pdf> acesso em 10/12/2008.

CREG - Comisión de Regulación de Energía y Gas - Colômbia http://www.creg.gov.co; acesso em 2008.

EPE - Empresa de Pesquisa Energética , http://www.epe.gov.br; acesso em 2008.

ITRON Sistemas e Tecnologia. htpp://www.itron.com.br; acesso em 2008;

LANDIS \& GYR Equipamentos de Medição Ltda. - http://www.landisgyr.com.br; acesso em 2008;

LAYERENZA, Guillermo O; ISSOURIBEHERE, Pedro E; GARCÍA, Jorge A. - Planes de Control de La Calidad de Medición de Energía Eléctrica a Los Usuarios en La Argentina. 1996. Artigo apresentado no II SEMETRO - Seminário de Metrologia Elétrica, Curitiba-PR, de 24 a 26/09/1996.

MEDEIROS FILHO, Sólon de. Medição de Energia Elétrica, $2^{\underline{a}}$ ed. Recife, Editora Universitária da Universidade Federal de Pernambuco, 1976. 
MELLO, João Carlos de Oliveira. Estruturas de Mercado de Energia Elétrica no Mundo, Relatório Andrade \& Canellas 042/03. Apresentação para ABRACE ABICLOR - IBS - ABAL, 2003.

MME - MINISTÉRIO DE MINAS E ENERGIA, http://www.mme.gov.br/, acesso em 2008.

ONS - OPERADOR NACIONAL DO SISTEMA, http://www.ons.org.br/, acesso em 2008.

PAIXÃO, Ernesto Lindolfo. Memórias do Projeto RE-SEB. A história da concepção da nova ordem institucional do setor elétrico brasileiro. São Paulo: Massao Ohno Editor, 2000.

PEA 5771 - Formação de Preços e Comercialização de Energia no Novo Ambiente do Setor Elétrico. Aulas de Mestrado, Escola Politécnica da Universidade de São Paulo, São Paulo, 2007.

PIRES, José Cláudio Linhares. Políticas Regulatórias no Setor de Energia Elétrica: A experiência dos Estados Unidos e da União Européia.

Rio de Janeiro, Outubro de 1999. Artigo disponível em <http://www.bndes.gov.br/conhecimento/td/Td-73.pdf> acesso em 10/12/2008.

RUIZ, Juan C. Morales; MESA, Silvia Elena Cossio. Modelo de despacho econômico do sistema elétrico colombiano.

Florianópolis, maio de 2006. X Simpósio de especialistas em planejamento da operação e expansão elétrica. Disponível em

<http://www.xm.com.co/Artculos\%20y\%20Reconocimientos/Microsoft\%20Word\%20\%20SP-013\%20-20MODELO\%20DE\%20DESPACHO\%20ECON\%20ECON\%20DO \%20SISTEMA\%20EL\%C3\%89TRICO\%20COLOMBIANO_v1.pdf> acesso em 10/12/2008.

SÁENZ, Jorge A. Sistema de Medición de Energía de Carácter Comercial - Una Experiencia Única en América. 1996. Artigo apresentado no II SEMETRO Seminário de Metrologia Elétrica, Curitiba-PR, de 24 a 26/09/1996.

SCHNEIDER Electric Brasil Ltda. - http://www.schneider-electric.com.br; acesso em 2008; 


\section{GLOSSÁRIO}

AGENTE DA CCEE ou AGENTE: Concessionário, permissionário, autorizado de serviços e instalações de energia elétrica e Consumidores Livres integrantes da CCEE;

ANEEL: Agência Nacional de Energia Elétrica, criada pela Lei n.ำ 9.427, de 26 de dezembro de 1996;

ASMAE: Administradora de Serviços do Mercado Atacadista de Energia Elétrica. Sociedade civil de direito privado, criada em 1999, braço operacional do MAE e empresa autorizada da ANEEL. Quando da crise energética vivida no ano de 2001, o Comitê de Revitalização do Modelo do Setor Elétrico Brasileiro, no Relatório de Progresso $N^{\circ} 1$, propôs a reestruturação do MAE, o que foi feito através da Lei $n^{\circ}$ 10.433, de 24 de abril de 2002, transformando a instituição ASMAE em pessoa jurídica de direito privado, com a denominação MAE, e terminando com sua autoregulamentação;

AUTOPRODUTOR: É a entidade que autorizada pela ANEEL produz, de forma individual ou consorciada, energia elétrica para uso próprio, podendo fornecer o excedente às concessionárias de energia elétrica e/ou ao mercado de curto prazo;

CCEE: Câmara de Comercialização de Energia Elétrica começou a operar em 10 de novembro de 2004 - regulamentada pelo Decreto 으 5.177, de 12 de agosto de 2004, sucedendo ao Mercado Atacadista de Energia (MAE). É uma associação civil integrada pelos agentes das categorias de Geração, de Distribuição e de Comercialização, a instituição desempenha papel estratégico para viabilizar as operações de compra e venda de energia elétrica, registrando e administrando contratos firmados entre geradores, comercializadores, distribuidores e consumidores livres; 
CCON: Comitê Coordenador de Operações do Norte/Nordeste, órgão colegiado da operação do sistema elétrico, criado pela portaria do Ministério de Minas e Energia, $N^{\circ}$. 1008, de 20 de setembro de 1974; extinto em 1997;

CEPEL: Centro de Pesquisa de Energia Elétrica. Empresa do Sistema Eletrobrás;

CLASSE DE EXATIDÃO DO MEDIDOR: A classe de exatidão de um medidor de energia elétrica é determinada, aferindo-o em todos os valores de correntes compreendidos entre $10 \%$ da corrente nominal e a corrente máxima, com fator de potência unitário, sob tensão e freqüência nominais. Se os erros se mantêm dentro da faixa $2 \%, 0,5 \%$ ou $0,2 \%$, então se diz que o medidor é de "Classe 2", "Classe 0,5 " ou "Classe 0,2" respectivamente, e estes números representam o "índice de classe" do medidor. MEDEIROS FILHO, SOLON DE, Medição de Energia Elétrica;

COEX: Comitê Executivo, formado pelos presidentes de empresas do setor elétrico (conselheiros) representando os agentes da categoria Produção (7 votos) e categoria Consumo (7 votos). Responsável pela definição das questões inerentes à implantação do SMF;

COMAE: Conselho do Mercado Atacadista de Energia Elétrica, criado em maio/2001 através das resoluções ANEEL nos 160, 161 e 162, que dentre outras medidas determinou a substituição do COEX por este conselho;

COMERCIALIZAÇÃO: Com a reestruturação do setor elétrico, surgiu a figura do comercializador de energia, responsável pela compra e venda de energia elétrica a distribuidores, geradores ou consumidores livres, com preços livremente negociados entre as partes. Esta atividade é regulada técnica e não economicamente pela ANEEL;

CONCESSIONÁRIA DE DISTRIBUIÇÃO: Pessoa jurídica com delegação do poder concedente para a exploração dos serviços públicos de distribuição de energia elétrica; 
CONCESSIONÁRIA DE TRANSMISSÃO: Pessoa jurídica com delegação do poder concedente para a exploração dos serviços públicos de transmissão de energia elétrica;

CONSUMIDOR CATIVO: Consumidor ao qual só é permitido comprar energia elétrica do concessionário, autorizado ou permissionário, a cuja rede esteja conectado;

CONSUMIDOR LIVRE: Aquele que, atendido em qualquer tensão, tenha exercido a opção de compra de energia elétrica, conforme definida nos arts. 15 e 16 da Lei no 9.074, de 7 de julho de 1995. Consumidor que adquire energia elétrica de qualquer fornecedor, conforme legislação e regulamentos específicos.

CONTRATO DE CONEXÃO AO SISTEMA DE TRANSMISSÃO - CCT: Contrato celebrado entre os usuários e as concessionárias de transmissão, que estabelece os termos e condições para conexão dos usuários à rede básica;

CONTRATO DE PRESTAÇÃO DE SERVIÇOS DE TRANSMISSÃO - CPST: Contrato

celebrado entre o ONS e as concessionárias de transmissão, que estabelece os termos e condições para prestação de serviços de transmissão de energia elétrica, por uma concessionária detentora de instalações de transmissão pertencentes à rede básica aos usuários, sob administração e coordenação do ONS , conforme modelo aprovado ANEEL;

CONTRATO DE USO DO SISTEMA DE TRANSMISSÃO - CUST: Contrato celebrado entre o ONS, as concessionárias de transmissão e os usuários, que estabelece os termos e condições para uso de rede básica por um usuário, incluindo a prestação dos serviços de transmissão pelas concessionárias de transmissão, mediante controle e supervisão do ONS e a prestação pelo ONS dos serviços de coordenação e controle da operação dos sistemas elétricos interligados, conforme modelo aprovado pela ANEEL; 
CONTRATOS BILATERAIS: São contratos de compra e venda de energia negociados livremente entre duas partes. São firmados entre os agentes sem a participação da ANEEL ou do MAE. Tais contratos são registrados no MAE sem informações de preços, apenas os montantes contratados, que serão contabilizados, registrados pelos agentes vendedores e validados pelos agentes compradores;

CONTRATOS INICIAIS: Os contratos iniciais são contratos de longo prazo, firmados entre geradores e distribuidores, com preços da energia fixados pela ANEEL. Os contratos iniciais são definidos e regidos por leis e decretos federais e estão contemplados nas Resoluções ANEEL n²67/98, n451/98, n¹41/99, n`361/00, n440/00, n447/00, n¹73/01 e n 470/01. Está estabelecida pela Lei n॰ 9648 de 27 de maio de 1998 , a redução dos contratos iniciais em $25 \%$ a cada ano, a partir de 2003, até a extinção dos mesmos, a partir de 2006;

DEMAIS INSTALAÇÕES DE TRANSMISSÃO: São instalações de transmissão que não integram a Rede Básica, conforme definido no Art. 4ํำ da Resolução Normativa ANEEL nำ 67, de 08 de junho de 2004;

DEMANDA: Montante, em MW, da potência média integralizada em intervalo de tempo de 60 minutos, podendo vir a ser alterado pela emissão de regulamentação superveniente da ANEEL;

DISTRIBUIÇÃO: A distribuição é a atividade que permanece regulada técnica e economicamente pela ANEEL. Assim como as linhas de transmissão, as redes de distribuição devem conceder liberdade de acesso a todos os agentes de mercado, através do custo do uso do sistema de distribuição, determinados pela ANEEL e administrado pelo Distribuidor;

ELETROBRÁS: Centrais Elétricas Brasileiras S.A . Empresa estatal federal;

ENCARGOS DE USO DO SISTEMA DE TRANSMISSÃO: Montantes devidos pelos usuários às concessionárias de transmissão, pela prestação dos serviços de transmissão, e ao ONS pelo pagamento dos serviços prestados, calculados em 
função da tarifa de uso da transmissão da rede básica e demandas dos usuários, conforme definidas pela ANEEL;

ENERGIA: É a potência média consumida no intervalo de 1 mês. A unidade a ser considerada é o Megawatt-médio ou seja o total do mês em Megawatt-hora dividido pelo número de horas do mês;

GCOI: Grupo Coordenador para Operação Interligada, órgão colegiado, criado pala

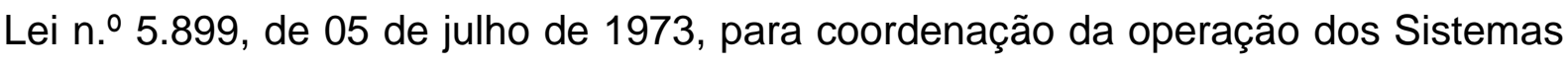
Elétricos das regiões S/SE/CO; extinto em 1997;

GERAÇÃO: Atividade aberta à competição, não regulada economicamente e todos os Geradores têm a garantia de livre acesso aos sistemas de transporte de energia elétrica (transmissão e distribuição). Os Geradores podem comercializar sua energia com preços livremente negociados. Os montantes de energia elétrica gerados são determinados pelo ONS;

INSPEÇÃO LÓGICA: Processo realizado pela CCEE - Câmara de Comercialização de Energia Elétrica, que consiste na coleta dos dados de medição dos medidores de propriedade dos Agentes, visando a comparação dos dados encaminhados pelos Agentes com os efetivamente armazenados nos medidores.

INSTALAÇÕES DA REDE BÁSICA: São as instalações e os equipamentos de transmissão e demais instalações inerentes à prestação de serviços de transmissão de energia na rede básica, tais como os sistemas de medição, operação, proteção, comando, controle e telecomunicações, definidos segundo regras e condições estabelecidas pela ANEEL;

INSTALAÇÕES DE CONEXÃO: São aquelas dedicadas ao atendimento de um ou mais usuários, com a finalidade de interligar suas instalações à rede básica;

MAE: Mercado Atacadista de Energia Elétrica. Ambiente virtual, criado pela lei $\mathrm{n}^{\circ}$ 9.648(27/05/98) e pelo Decreto $n^{\circ} 2.655$ (02/07/98), como um mercado autoregulado, instituído por um contrato de adesão multilateral (Acordo de Mercado), 
com a finalidade de viabilizar as transações de energia elétrica por meio de contratos bilaterais e do mercado de curto prazo, promovendo a livre concorrência e a ampla competição entre as empresas que executam os serviços de energia elétrica no sistema interligado nacional. O MAE iniciou suas operações em 01 de setembro de 2000, seguindo os preceitos legais da Resolução 290/2000 da ANEEL;

MEDIÇÃO DE ENERGIA ELÉTRICA: "A medição de energia elétrica é empregada, na prática, para possibilitar à entidade fornecedora o faturamento adequado da quantidade de energia elétrica consumida por cada usuário, dentro de uma tarifa estabelecida. O medidor hoje empregado é do tipo indução por sua simplicidade, robustez, exatidão e desempenho ao longo dos anos". (MEDEIROS FILHO, Sólon de, Medição de Energia Elétrica, $2^{\underline{a}}$ ed., página 167);

MEDIDOR DE ENERGIA ELÉTRICA: Instrumento destinado a medir a energia elétrica através da integração da potência em relação ao tempo;

MEDIDOR ELETROMECÂNICO: "É o medidor tipo indução, que tem o conjugado motor originado no disco em função do fenômeno da interação eletromagnética e que é empregado em corrente alternada para medir a energia elétrica absorvida por uma carga. É constituído essencialmente por bobina de tensão (Bp), bobina de corrente $(\mathrm{Bc})$, núcleo de lâminas de material ferromagnético (normalmente ferrosilício) conjugado móvel ou rotor constituído de disco de alumínio, de alta condutibilidade, com grau de liberdade de girar em torno do seu eixo de suspensão e registrar, num mostrador, a energia elétrica consumida e imã permanente para produzir o conjugado frenador ou de amortecimento sobre o disco". (MEDEIROS FILHO, Sólon de, Medição de Energia Elétrica, $2^{\text {a }}$ ed., páginas 168 e 169);

MEDIDOR ELETRÔNICO DE ENERGIA ELÉTRICA: Medidor estático no qual a corrente e a tensão agem sobre elementos de estado sólido (componentes eletrônicos) para produzir uma informação de saída proporcional à quantidade de energia elétrica produzida;

NORMAS DO GCOI e do CCON: Regras técnicas e comerciais aplicáveis às geradoras, distribuidoras e transmissoras de energia elétrica, estabelecidas pelo 
GCOI e pelo CCON. Essas normas perderam sua validade após a entrada em vigor dos Procedimentos de Rede;

ONS: Operador Nacional do Sistema Elétrico, pessoa jurídica de direito privativo, sem fim lucrativo, constituído sob a forma de Associação Civil que, conforme disposto na Lei n. 9 9.648, de 27 de maio de 1998 e sua regulamentação, autorizada da ANEEL mediante Resolução n.․ 351, de 11 de novembro de 1998, é responsável pela coordenação, supervisão e controle da operação da geração e transmissão de energia elétrica no sistema interligado, integrado por titulares de concessão, permissão ou autorização e consumidores;

PROCEDIMENTOS DE COMERCIALIZAÇÃO: Os Procedimentos de Comercialização (PdC's) são um conjunto de normas aprovadas pela ANEEL que definem condições, requisitos, eventos e prazos relativos à comercialização de energia elétrica no âmbito da CCEE e estão definidos conforme a estrutura da Cadeia de Valor da CCEE.

PROCEDIMENTOS DE DISTRIBUIÇÃO: São documentos regulatórios na forma de regulamentações, normatizações e padronizações que têm como objetivo possibilitar a conexão elétrica aos sistemas de distribuição por usuários, garantindo que os indicadores de desempenho ou de qualidade de serviço sejam atingidos de forma clara e transparente, preservando, dentre outros aspectos, a segurança, a eficiência e a confiabilidade dos sistemas elétricos.

PROCEDIMENTOS DE MERCADO: Conjuntos de normas operacionais que definem os requisitos e prazos necessários ao desenvolvimento das atribuições do MAE, incluindo as estabelecidas nas Regras de Mercado, descrevendo as relações e as responsabilidades entre os diversos agentes de mercado, para que as regras do MAE possam ser implementadas;

PROCEDIMENTOS DE REDE: Documento elaborado pelo ONS, com a participação dos agentes e aprovado pela ANEEL, que estabelece os procedimentos e os requisitos técnicos para o planejamento, a implantação, o uso e a operação do 
sistema de transmissão, as penalidades pelo descumprimento dos compromissos assumidos pelos respectivos usuários do sistema de transmissão, bem como as responsabilidades do ONS e de todas as concessionárias de transmissão;

PRODUTOR INDEPENDENTE: Pessoa jurídica ou empresas reunidas em consórcio que recebam concessão ou autorização do poder concedente para produzir energia elétrica destinada ao comércio de toda ou parte da produção, por sua conta e risco;

PROPRIETÁRIO DO SISTEMA DE MEDIÇÃO: É o Agente, ou não, proprietário legal do Sistema de Medição para faturamento de energia na CCEE, sendo responsável por todas as atividades definidas nos procedimentos de rede, associados ao Sistema de Medição de Faturamento.

REDE BÁSICA: Sistema elétrico interligado constituído pelas linhas de transmissão, barramentos, transformadores de potência e equipamentos com tensão igual ou superior a $230 \mathrm{kV}$ ou instalações em tensão inferior, quando especificamente definidas pela ANEEL;

REDE DE DISTRIBUIÇÃO: Conjunto de instalações de distribuição de energia elétrica, com tensão inferior a 230 kV, ou instalações em tensão igual ou superior, quando especificamente definidas pela ANEEL.

RE-SEB: Projeto de Reestruturação do Setor Elétrico Brasileiro, iniciado em agosto de 1996, conduzido sobre a coordenação da Secretaria de Energia do Ministério de Minas e Energia, responsável pela concepção do novo modelo, implementado no período de governo do presidente Fernando Henrique Cardoso (1995-2002), no qual foi indicada a conveniência da criação da ANEEL, ONS e MAE. Concluído em agosto de 1998, tendo definido todo o arcabouço conceitual e institucional do setor elétrico do Brasil;

SERVIÇOS ANCILARES: Serviços prestados mediante a utilização de equipamentos ou instalações do sistema interligado que possibilitam viabilizar a operação do sistema nos padrões de qualidade, segurança e confiabilidade exigida. 
São exemplos de serviços ancilares, a compensação reativa e a capacidade de recomposição do sistema;

SISCOMEX: Sistema Integrado de Comércio Exterior, é um instrumento informatizado, por meio do qual é exercido o controle governamental do comércio exterior brasileiro.

SISTEMA DE CONTABILIZAÇÃO E LIQUIDAÇÃO (SCL): Sistema de Contabilização e Liquidação, baseado nas Regras Algébricas, que suporta a comercialização de energia elétrica no âmbito da CCEE;

SISTEMA DE COLETA DE DADOS DE ENERGIA (SCDE): Sistema de Coleta de Dados de Energia da CCEE para o tratamento dos dados de medição que serão utilizados para a contabilização na CCEE, formação de preços e para o cálculo do custo de uso do sistema de transmissão;

SISTEMA DE MEDIÇÃO PARA FATURAMENTO (SMF): Conjunto de equipamentos necessários para a medição das grandezas elétricas. É o conjunto de medidores, transformadores de potencial e de corrente e equipamentos associados, necessários para medir fluxo de potência ativa e reativa, tensão, corrente e qualidade de energia, que devem ser instalados conforme requisitos técnicos previstos no Anexo I do Submódulo 12.2 dos Procedimentos de Rede do ONS;

SISTEMA DE TRANSMISSÃO: São as instalações e os equipamentos de transmissão considerados integrantes da Rede Básica, bem como as conexões e demais instalações de transmissão pertencentes a uma concessionária de transmissão;

SISTEMA INTERLIGADO NACIONAL - SIN: Instalações responsáveis pelo suprimento de energia elétrica a todas as regiões do país eletricamente interligadas. Apenas cerca de $2 \%$ da capacidade de produção de eletricidade do país encontra-se fora do SIN, em pequenos sistemas isolados localizados principalmente na região amazônica; 
TRANSFORMADOR DE POTENCIAL - TP: "É um transformador para instrumento cujo enrolamento primário é ligado em derivação com um circuito elétrico e cujo enrolamento secundário se destina a alimentar bobinas de potencial de instrumentos elétricos de medição, controle ou proteção. Na pratica é considerado um "redutor de tensão", pois a tensão no seu circuito secundário é normalmente menor que a tensão no seu enrolamento primário".(MEDEIROS FILHO, Sólon de. Medição de Energia Elétrica, página 29);

TRANSFORMADOR DE CORRENTE - TC: "É um transformador para instrumento cujo enrolamento primário é ligado em série em um circuito elétrico e cujo enrolamento secundário se destina a alimentar bobinas de correntes de instrumentos elétricos de medição, controle ou proteção. Na prática é considerado um "redutor de corrente", pois a corrente que percorre o seu circuito secundário é normalmente menor que a corrente que percorre o seu enrolamento primário". (MEDEIROS FILHO, Sólon de. Medição de Energia Elétrica, página 29);

TRANSFORMADOR PARA INSTRUMENTOS - TI: Os transformadores para instrumento são equipamentos elétricos projetados e construídos especificamente para alimentarem instrumentos elétricos de medição, controle ou proteção. Os dois tipos de transformadores para instrumentos são TP e TC;

TRANSMISSÃO: As linhas de transmissão constituem vias de uso aberto e podem ser utilizadas por qualquer agente, com a devida remuneração ao proprietário através do custo de uso do sistema de transmissão determinado pela ANEEL e administrado pelo ONS;

USUÁRIO: Todos os agentes conectados ao sistema de transmissão que venham a fazer uso da rede básica. 